\author{
UNIVERSIDADE DE SÃO PAULO \\ ESCOLA DE ENFERMAGEM \\ PROGRAMA DE PÓS-GRADUAÇÃO EM ENFERMAGEM
}

SHEYLA MARA SILVA DE OLIVEIRA

ESCORPIONISMO NO INTERIOR DA AMAZÔNIA:

GEOESPACIALIZAÇÃO E ASPECTOS CLÍNICOEPIDEMIOLÓGICOS

SÃO PAULO - SP

2018 
SHEYLA MARA SILVA DE OLIVEIRA

\title{
ESCORPIONISMO NO INTERIOR DA AMAZÔNIA: GEOESPACIALIZAÇÃO E ASPECTOS CLÍNICO- EPIDEMIOLÓGICOS
}

\author{
Versão corrigida da Tese apresentada à Escola \\ de Enfermagem da Universidade de São Paulo \\ (EEUSP), Programa de Pós-Graduação em \\ Enfermagem (PPGE), para obtenção do título \\ de Doutora em Ciências. \\ Área de Concentração: Enfermagem em Saúde \\ Coletiva \\ Orientadora: Prof. Dra. Maria Rita Bertolozzi \\ Co- orientador: Prof. Dr. Francisco Oscar de \\ Siqueira França
}

\section{VERSÃO CORRIGIDA}

A versão original encontra-se disponível na Biblioteca da Escola de Enfermagem da Universidade de São Paulo e na Biblioteca Digital de Teses e Dissertações da Universidade de São Paulo. 
AUTORIZO A REPRODUÇÃO E DIVULGAÇÃO TOTAL OU PARCIAL DESTE TRABALHO, POR QUALQUER MEIO CONVENCIONAL OU ELETRÔNICO, PARA FINS DE ESTUDO E PESQUISA, DESDE QUE CITADA A FONTE.

Assinatura:

Data:

\section{Catalogação na Publicação (CIP)}

Biblioteca "Wanda de Aguiar Horta"

Escola de Enfermagem da Universidade de São Paulo

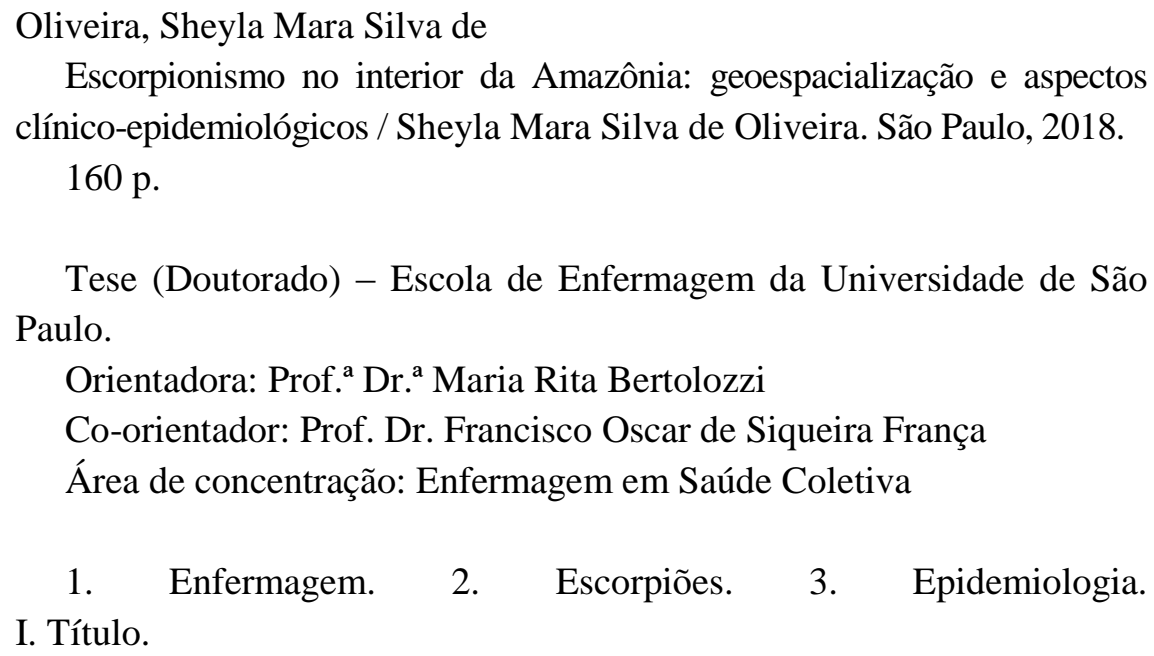

Orientadora: Prof. ${ }^{\text {a }}$ Dr. ${ }^{a}$ Maria Rita Bertolozzi

Co-orientador: Prof. Dr. Francisco Oscar de Siqueira França

Área de concentração: Enfermagem em Saúde Coletiva

1. Enfermagem. 2. Escorpiões. 3. Epidemiologia. I. Título.

Ficha catalográfica elaborada por Fabiana Gulin Longhi Palacio (CRB-8: 7257)

Nome: Sheyla Mara Silva de Oliveira 
Título: Escorpionismo no interior da Amazônia: Geoespacialização e Aspectos clínicoepidemiológicos

Tese apresentada ao Programa de Pós- Graduação da Escola de Enfermagem da Universidade de São Paulo para obtenção do título de Doutora em Ciências.

Aprovado em:

BANCA EXAMINADORA

Orientador Prof. Dr.

Instituição:

Assinatura:

Prof. Dr.

Instituição:

Julgamento:

Assinatura:

Prof. Dr.

Instituição:

Julgamento:

Assinatura:

Prof. Dr. Instituição:

Julgamento: Assinatura:

Prof. Dr. Instituição:

Julgamento: Assinatura: 


\section{DEDICATÓRIA}

Dedico este estudo aos meus queridos pais, João Ferreira de Oliveira e Maria do Socorro Silva de Oliveira, que sempre me incentivaram a estudar e conquistar meus sonhos. Ao meu querido esposo Wenderson Pereira, pelo amor e companheirismo. Ao meu amado filho Gabriel Henrique, amor incondicional. A minha querida, Santarém do meu amor... 
Nada se compara a alegria

Que é estar na minha terra

Pérola do tapajós

Que encanta todos nós

Hoje meu cantar

É pra homenagear tua beleza

Rara beleza

Todo meu bem

Entrego ao coração de Santarém

Eu digo égua, falo pai d'égua

Não nego a ninguém

Que meu orgulho é Santarém

Eu digo égua, mas olha já Mas quando que eu nego

Eu sou cabloca do Pará

(Jana Figarella) 


\section{AGRADECIMENTOS}

Este momento é muito especial, uma vez que posso compartilhar minha gratidão àqueles que fizeram parte desta conquista tão sonhada.

Agradeço primeiramente a Deus que me oportunizou trilhar o caminho da pesquisa, me fortalecendo nos momentos de dificuldade.

A minha família, meus queridos Pais João Ferreira de Oliveira e Maria do Socorro Silva de Oliveira pelo amor e educação oportunizada, para transformar nossas realidades.

Ao meu querido esposo Wenderson Pereira e amado filho Gabriel Henrique. O amor, a compreensão; foram fundamentais para a realização deste sonho.

À Escola de Enfermagem da Universidade de São Paulo por me oportunizar vasto conhecimento e riquíssimas experiências durante esta trajetória.

À minha querida orientadora Profa. Dra. Maria Rita Bertolozzi por todas as orientações, conhecimento compartilhado. Meu exemplo de profissional e pessoa incrível. Nossa parceria vai além da orientação, do profissional, segue para toda a vida. Obrigada pela confiança. Você é muito especial e importante para mim.

Ao meu querido co-orientador Prof. Dr. Francisco Oscar de Siqueira França. Meu profundo respeito e admiração pelo seu trabalho. Muito grata por todas as orientações, momentos de amizade que se fortaleceram cada vez mais ao longo desta trajetória.

À Profa. Dra.Lúcia Izumi e à Dra. Pasesa Torrez; pelas valiosas contribuições no Exame de Qualificação.

Ao Prof. Dr.Rogério Bertani pela identificação dos escorpiões e grandes contribuições no Exame de Qualificação.

À Universidade do Estado do Pará por fazer despertar mais forte a pesquisa, a busca pela qualificação para não somente minha realização pessoal, mas também profissional, contribuindo para uma melhor formação em benefício da população.

À SESPA, $9^{\circ}$ Centro Regional de Saúde e às secretarias municipais de saúde dos vinte municípios.

Às colegas Enfermeiras dos vinte municípios do $9^{\circ} \mathrm{CRS}$, que me auxiliaram na fase de coleta de dados.

Aos pacientes que participaram deste estudo. Sem a participação de cada um, nada disso seria possível. 
Às queridas amigas Fernanda Cardoso, Nádia Martins, Lívia Valentim, Tatiane Quaresma companheiras do início de jornada. Os momentos de estudos e amizade foram essenciais para segurar a saudade de casa.

À Família Seade que me acolheu em sua residência em São Paulo nas primeiras viagens. Que Deus abençoe sempre essa família linda. Minha eterna gratidão.

Ao querido amigo e Engenheiro Pablo Rodrigues Lopes de Sousa, e à geógrafa Lidiane Cristina Félix Gomes, pelo auxílio na geoespacialização e análise estatística.

Às queridas amigas, Franciane Fernandes, Erli Marta Reis, Ana Cely Coelho, e Veridiana Barreto, pelo auxílio e amizade durante o desenvolvimento da pesquisa.

À querida Kássia Lima de Souza por me auxiliar na organização e condensação dos dados.

À querida Giovanna Mariah Orlandi, por seu apoio e presteza em me auxiliar em muitos momentos junto à Escola de Enfermagem.

À todos os colegas da turma de Doutorado.

À todos os colegas, amigos e alunos que me incentivaram, torcendo por esta conquista. 
Oliveira SMS. Escorpionismo no interior da Amazônia: Geoespacialização, Aspectos Clínico-

Epidemiológicos[Tese]. São Paulo: Escola de Enfermagem, Universidade de São Paulo; 2018.

\section{RESUMO}

Introdução: No Oeste do Pará os acidentes escorpiônicos evidenciam um quadro diverso das demais regiões do país, com manifestações neurológicas singulares, que acometem indistintamente todas as idades. Objetivo: Analisar a distribuição espacial e os aspectos clínico-epidemiológicos dos acidentes escorpiônicos no $9^{\circ}$ e $10^{\circ}$ Centro Regional de Saúde do Estado do Pará. Método: Trata-se de pesquisa observacional, descritiva, retrospectiva e prospectiva, com abordagem quantitativa, realizada em duas etapas. A primeira etapa teve delineamento retrospectivo e baseou-se em fichas de notificação dos municípios pertencentes ao $9^{\circ}$ e $10^{\circ}$ Centro Regional de Saúde, no período de 2011 a 2015, e prontuários de pacientes atendidos no Hospital Municipal de Santarém (HMS), em 2016. A segunda etapa, prospectiva, foi realizada por meio de pesquisa de campo junto aos indivíduos acometidos pelo agravo, no período de março a setembro de 2017. Testes estatísticos viabilizaram a análise descritiva e inferencial, além de realizar-se análise espacial. Resultados: Entre 2011 a 2015 foram notificados 6.997 casos de escorpionismo na região, sendo o último ano o que apresentou maior incidência, com $1.470(21,0 \%)$ casos. O estudo prospectivo acompanhou 259 vítimas de escorpionismo em 18 municípios da região, uma vez que os municípios de Curuá e Faro não registraram casos. O perfil das pessoas acometidas revela maior concentração de casos na faixa etária entre 16 a 30 anos $(29,0 \%)$, sexo masculino $(69,0 \%)$, agricultores $(34,0 \%)$, com renda até um salário mínimo $(61,0 \%)$ e ensino fundamental incompleto $(58,0 \%)$. A zona rural foi a área de maior ocorrência de casos $(78 \%)$, principalmente ocorridos durante atividades laborais $(42,0 \%)$. Os dados evidenciam vulnerabilidade individual e social dos indivíduos acometidos. Também verificou-se que, para a maior parcela dos casos, o intervalo de tempo entre a picada e a assistência foi de 1 a 3 horas $(36,3 \%)$. As mãos $(52,0 \%)$ foram os locais mais acometidos. As manifestações locais mais comuns foram: dor $(99,0 \%)$, sensação de choque elétrico $(51,0 \%)$ e parestesia $(50,0 \%)$. As manifestações sistêmicas prevalentes reuniram sensação de choque elétrico $(57,1 \%)$, formigamento $(52,1 \%)$ e ataxia de marcha $(34,3 \%)$. As manifestações neuromusculares duraram em média 24 horas. Houve diferença entre o tempo de atendimento levando em consideração a gravidade do caso. As espécies T. obscurus, T. strandi, T. silvestris foram as responsáveis pelos acidentes na região. A análise espacial revelou que 12 municípios apresentaram alto risco para o agravo. A maioria dos acidentes acompanhados foram classificados como leves $(56,4 \%)$. Todos os pacientes evoluíram favoravelmente. Conclusão: O estudo apresenta importante achado, ao constatar que outras espécies de Tityus também foram responsáveis pelos acidentes que evidenciaram manifestações neuromusculares, com destaque para a sensação de choque elétrico. O estudo também contribui para que os profissionais de saúde reconheçam as características dos sinais e sintomas compatíveis com o agravo. A identificação do risco para o agravo, nos vários municípios em que ocorreu o estudo, demonstra a necessidade de que a população seja instrumentalizada a respeito de práticas de prevenção, destacando-se que o escorpionismo, na região em que ocorreu o estudo, acomete os grupos com maior vulnerabilidade individual e social.

Palavras-Chave: Enfermagem, Picadas de Escorpião, Manifestações Clínicas, Epidemiologia, Georreferenciamento 
Oliveira SMS. Scorpion envenomation in Amazon: Geospatialization and clinicalepidemiological aspects [thesis]. São Paulo: Escola de Enfermagem, Universidade de São Paulo; 2018.

\section{ABSTRACT}

Introduction: The accidents with scorpion envenomation in the West region of Pará evidence a diverse clinical picture of the other regions of Brazil with singular neurological manifestations affecting indiscriminately all ages. Objectives: Analyze the spatial distribution and clinical and epidemiological aspects of accidents with scorpions in the 9th and 10th Regional Health Center of the state of Pará, Brazil. Method: This is an observational, descriptive, retrospective and prospective research with a quantitative approach, held in two stages. The first stage had a retrospective design and was based on notification forms from the municipalities within the 9th and 10th Regionals of Health in the years 2011 to 2015 and on medical records of scorpion envenomation patients attended at Santarém City Hospital in 2016. The second stage was prospective and was a field research carried out with individuals affected by this accident from March through September 2017. In addition to a spatial analysis, statistical tests were applied making it possible to achieve a descriptive and inferential analysis. Results: During the period of 2011 and 2015, 6,997 cases of scorpion envenomation were reported in the region studied. The last year (2015) of the period presented highest incidence with 1,470 (21.0\%) cases. The prospective study followed 259 victims of scorpion envenomation in 18 of the 20 municipalities in the region studied, once the municipalities of Curuá and Faro did not report any cases. The profile of the people affected shows a higher concentration of cases in the age group between 16 and 30 years $(29,0 \%)$, males $(69.0 \%)$, farmers $(34.0 \%)$, with income up to one minimum wage $(61.0 \%)$, and incomplete elementary school (58.0\%). The rural area had the higher occurrence of cases (78\%), mainly during labor activities (42.0\%). Data demonstrate individual and social vulnerability of the affected individuals. It was also found that for the most of the cases the time between the sting accident and medical assistance was of 1 to 3 hours (36.3\%). Hands $(52.0 \%)$ were the most affected sites. The most common local symptoms were: pain $(99.0 \%)$, sensation of electric shock $(51.0 \%)$ and paresthesia $(50.0 \%)$. The prevalent systemic signs were a sensation of electric shock (57.1\%), tingling $(52.1 \%)$ and gait ataxia $(34.3 \%)$. The neuromuscular manifestations of the victims lasted on average 24 hours. Happened Difference between the time of attendance taking into account the severity of the case. It was demonstrated the relation between the time elapsed till medical assistance and the consequent aggravation of the case. The accidents were caused by the species T. obscurus, T. strandi, $T$. silvestris in the region studied. The spatial analysis revealed that twelve municipalities have a high risk for the aggravation. Most of the accidents followed were classified as light $(56.4 \%)$. All patients evolved favorably. Conclusion: The study presents an important finding, pointing that other species of Tityus were also responsible for the accidents that evidenced neuromuscular manifestations, featured the sensation of electric shock. The study also helps health professionals to recognize the signs and symptoms compatible with the aggravation. The identification of the risk to the aggravation, in the various municipalities in which the study occurred, demonstrates the need for the population to be instrumentalized regarding prevention practices, highlighting that the scorpion envenomation, in the region where the study occurred, affects the groups with greater individual and social vulnerability.

Key words: Nursing, scorpion stings, clinical manifestations, epidemiology, Georeferencing 


\section{LISTA DE ILUSTRAÇÕES}

Figura 1 - Morfologia externa dorsal e ventral de um escorpião (Tityus aba):

es) par de estigmas respiratórios do sexto segmento mesossomal;

et) esterno; ms) mesossoma; mt) metassoma; pe) perna; pd) pedipalpo; pn) pentes; ps) prossoma; ql) quelícera; tl) télson

Figura 2 - Fêmea adulta de Tityus obscurus

Figura 3 - Classificação da gravidade do acidente escorpiônico.

Figura 4 - Nota Técnica do Ministério da Saúde

Figura 5 - Distribuição Geográfica dos Municípios do $9^{\circ}$ e $10^{\circ}$ Centro Regional de Saúde do Pará.

Figura 6

- Distribuição das Mesoregiões dos Municípios do Pará.

Figura 7

Área onde ocorreu o estudo prospectivo.

Figura 8 - Municípios do Estado do Pará.

Gráfico 1 - Distribuição dos acidentes escorpiônicos notificados na mesoregião do Baixo Amazonas e Sudoeste do Pará. Período 2011 a 2015.

Gráfico 2 - Distribuição dos casos segundo local da picada. Hospital Municipal de Santarém, 2016.

Gráfico 3 - Manifestações locais apresentadas pelos pacientes. Hospital Municipal de Santarém - Pará, 2016.

Gráfico 4 - Manifestações sistêmicas apresentadas pelos pacientes. Hospital Municipal de Santarém - Pará, 2016.

Gráfico 5 - Outras manifestações sistêmicas apresentadas pelos pacientes. Hospital Municipal de Santarém - Pará, 2016.

Gráfico 6 - Distribuição dos pacientes segundo classificação do quadro clínico. Hospital Municipal de Santarém-Pará, 2016.

Quadro 1 - Caracterização do quadro clínico apresentado pelas vítimas de acidentes escorpiônicos segundo relato dos profissionais de saúde atuantes nos municípios pertencentes ao 9² CRS/SESPA, 2017.

Gráfico 7 - Manifestações locais apresentadas pelos pacientes. 
Figura 9 - Escorpiões causadores de acidentes nos municípios pertencentes ao $9^{\circ} \mathrm{CRS} / \mathrm{SESPA}, 2017$.

Figura 10 - Escorpiões capturados e encaminhados pelos profissionais de saúde dos municípios pertencentes ao 9 ${ }^{\circ} \mathrm{CRS} / \mathrm{SESPA}, 2017$.

Fotografia 1 - Ptose Palpebral em vítima de escorpionismo no HMS. 2017.

Fotografia - Escrita de vítima de escorpionismo. Caso Moderado. Santarém$2 \mathbf{a}$ PA, 2017.

Fotografia - Desenho de vítima de escorpionismo. Caso Grave. Belterra-PA,

$2 \mathbf{b}$ 2017.

Figura 11 - Distribuição do total de casos e daqueles que apresentaram características de comprometimento cerebelar e/ou muscular. $9^{\circ}$ CRS/SEPA, 2017.

Figura 12 - Risco Relativo dos casos totais e daqueles que apresentaram características de comprometimento cerebelar e/ou muscular. $9^{\circ} \mathrm{CRS} / \mathrm{SESPA}, 2017$.

Figura 13 - Método Scan Espacial aplicado ao total de casos e aos casos que apresentaram características de comprometimento cerebelar e/ou muscular. Municípios do $9^{\circ}$ CRS.2017.

Fotografia 3 - Criança vítima de escorpionismo no setor de reanimação do Hospital Municipal de Santarém- PA, 2017.

Quadro 2 - Aspectos clínicos e epidemiológicos de pacientes vítimas de escorpionismo que trouxeram o animal para o serviço de saúde nos municípios pertencentes ao $9^{\circ} \mathrm{CRS} / \mathrm{SESPA}$, ano 2017. 


\section{LISTA DE TABELAS}

Tabela 1- Acidentes escorpiônicos notificados. Região Oeste do Pará, 2011 a 2015.

Tabela 2- Distribuição dos acidentes escorpiônicos notificados no SINAN, segundo município de notificação e população correspondente. Baixo Amazonas e Sudoeste do Pará, 2011 a 2015.

Tabela 3 - Distribuição dos acidentes escorpiônicos ocorridos nos municípios que compõem o Baixo Amazonas. 2011-2015.

Tabela 4 - Distribuição dos acidentes escorpiônicos nos municípios que compõem a região Sudoeste. 2011-2015.

Tabela 5 - Distribuição dos casos de escorpionismo atendidos no Hospital Municipal de Santarém-PA, segundo variáveis sociodemográficas, 2016.

Tabela 6 - Casos de escorpionismo segundo variáveis epidemiológicas. Hospital Municipal de Santarém-Pará, 2016.

Tabela 7 - Distribuição dos casos segundo o tipo de ocupação. Hospital Municipal de Santarém, 2016.

Tabela 8 - Profissionais atuantes nos 20 municípios pertencentes ao $9^{\circ} \mathrm{CRS} / \mathrm{SESPA}$, ano 2017.

Tabela 9 - Ocorrência de acidentes segundo municípios pertencentes à $9^{\circ} \mathrm{CRS} / \mathrm{SESPA}, 2017$.

Tabela 10 - Perfil epidemiológico dos pacientes acompanhados em municípios pertencentes ao $9^{\circ} \mathrm{CRS} / \mathrm{SESPA}, 2017$.

Tabela 11 - Teste qui-quadrado para Faixa Etária, Sexo e Escolaridade.

Tabela 12 - Teste qui-quadrado para Faixa Etária e Escolaridade segundo sexo.

$9^{\circ} \mathrm{CRS} / \mathrm{SESPA}, 2017$

Tabela 13 - Características do escorpião causador dos acidentes nos municípios pertencentes ao $9^{\circ} \mathrm{CRS} / \mathrm{SESPA}, 2017$.

Tabela 14 - Distribuição dos indivíduos acometidos segundo manifestações locais referidas.

$9^{\circ} \mathrm{CRS} / \mathrm{SESPA}, 2017$.

Tabela 15 - Frequência de manifestações sistêmicas apresentadas pelos pacientes. Serviços de saúde de municípios pertencentes à 9º CRS/SESPA, 2017.

Tabela 16 - Distribuição dos pacientes acometidos segundo manifestações clínicas neurológicas e musculares. $9^{\circ} \mathrm{CRS} / \mathrm{SESPA}, 2017$.

Tabela 17 - Duração de manifestações neurológicas e musculares de pacientes atendidos nos serviços de saúde dos municípios do $9^{\circ}$ CRS/SESPA, 2017. 
Tabela 18 - Distribuição dos pacientes segundo comprometimento cerebelar e/ou muscular. $9^{\circ} \mathrm{CRS} / \mathrm{SESPA}, 2017$.

Tabela 19 - Distribuição dos pacientes segundo local do acidente e comprometimento cerebelar. $9^{\circ} \mathrm{CRS} / \mathrm{SESPA}, 2017$

Tabela 20 - Distribuição dos acidentes escorpiônicos em pacientes atendidos nos serviços de saúde pertencentes ao $9^{\circ} \mathrm{CRS/SESPA}$, segundo classificação de gravidade. 2017.

Tabela 21 - Distribuição dos pacientes segundo tempo de ocorrência da picada e classificação do caso escorpiônico. $9^{\circ} \mathrm{CRS/SESPA,} \mathrm{2017 \ldots ......................................................} 81$

Tabela 22 - Distribuição dos pacientes e condutas clínicas nos serviços de saúde dos municípios pertencentes ao $9^{\circ} \mathrm{CRS} / \mathrm{SESPA}, 2017$. 


\section{LISTA DE SIGLAS}

USP

T. obscurus

SINAN

HUJBB

ICC

FC

PA

EPA

CTI

SAEsc

EV

HMS

CRS

SESPA

CNDSS

CIR

FAPESPA

UBS

ESF

UPA

PSM

HRBA

SEMSA

RR

CNS

UEPA

NUMETROP
Universidade de São Paulo

Tityus obscurus

Sistema de Informação de Agravos de Notificação

Hospital Universitário João de Barros Barreto

Insuficiência Cardíaca Congestiva

Frequência Cardíaca

Pressão Arterial

Edema Pulmonar Agudo

Centro de Terapia Intensiva

Soro Antiescorpiônico

Endovenosa

Hospital Municipal de Santarém

Centro Regional de Saúde

Secretaria de Estado de Saúde Pública

Comissão Nacional de Determinantes Sociais da Saúde

Comissão Intergestores Regionais

Fundação Amazônia de Amparo a Estudos e Pesquisas do

Pará

Unidade Básica de Saúde

Estratégia Saúde da Família

Unidade de Pronto Atendimento

Pronto Socorro Municipal

Hospital Regional do Baixo Amazonas

Secretaria Municipal de Saúde

Risco Relativo

Conselho Nacional de Saúde

Universidade do Estado do Pará

Núcleo de Medicina Tropical 


\section{SUMÁRIO}

1 INTRODUÇÃO ............................................................................................................................... 19

1.1 CARACTERÍSTICAS GERAIS DOS ESCORPIÕES............................................ 19

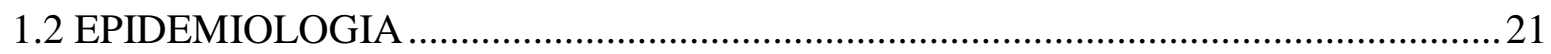

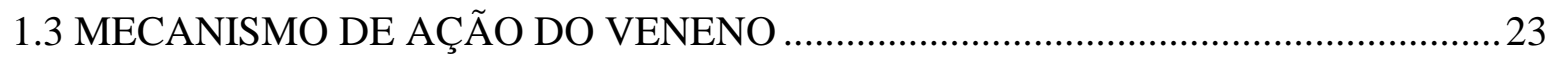

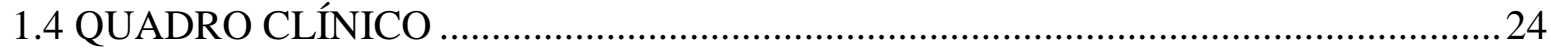

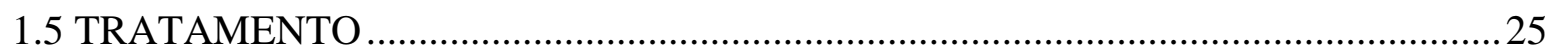

1.6 JUSTIFICATIVA/ PROBLEMATIZAÇÃO ...................................................... 27

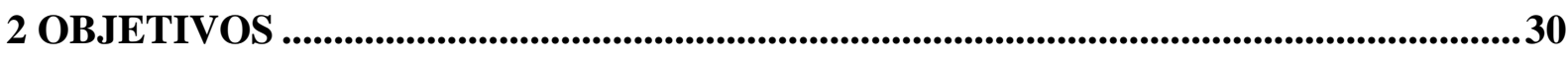

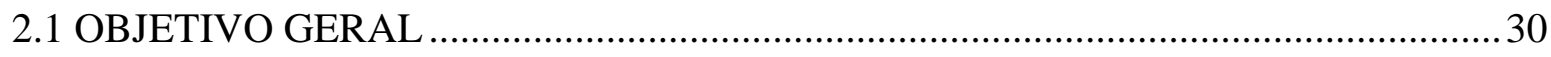

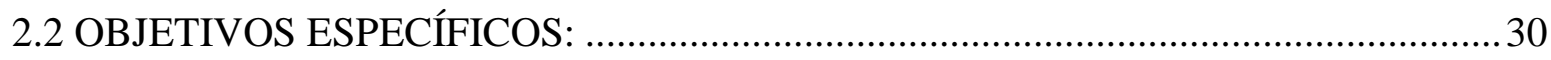

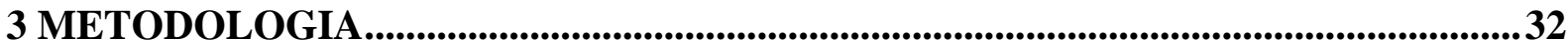

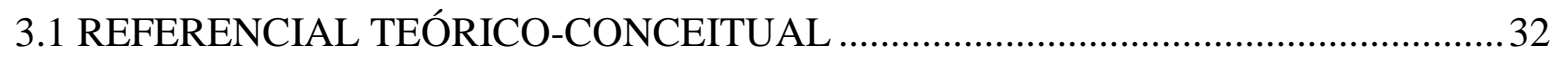

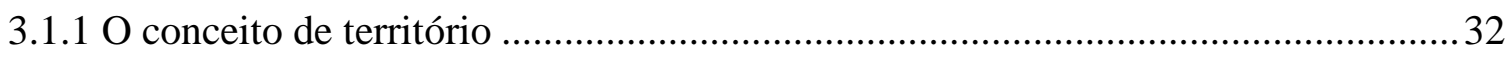

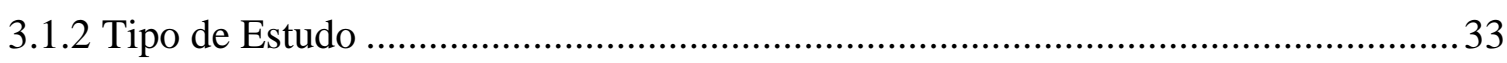

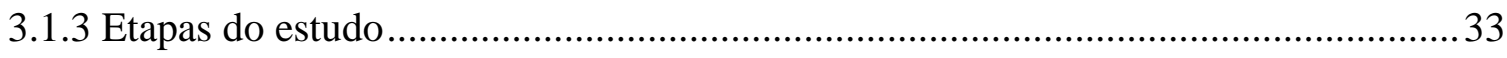

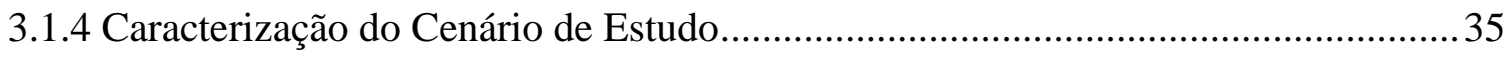

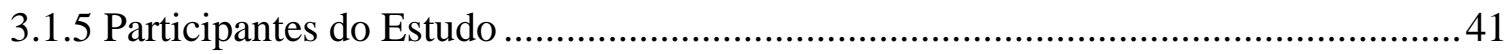

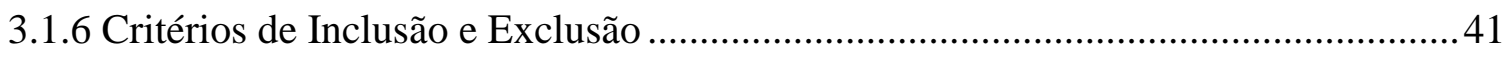

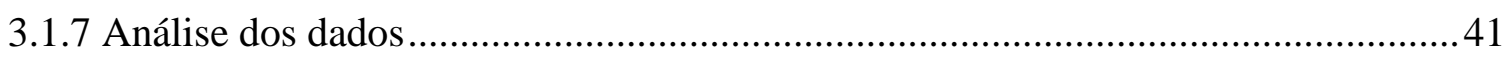

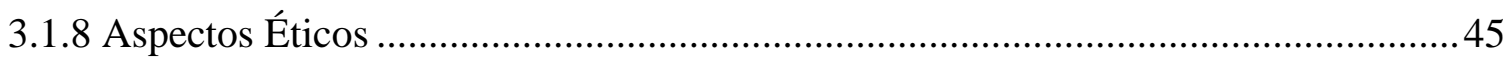

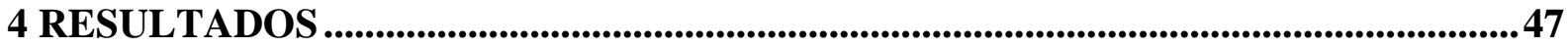

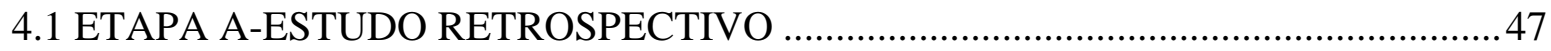

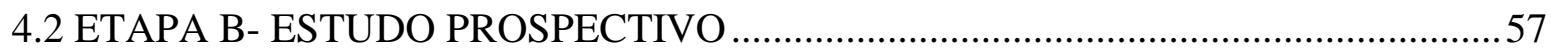

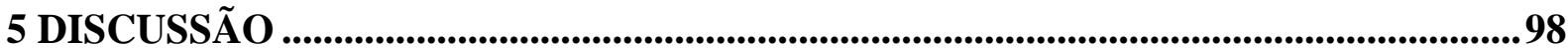

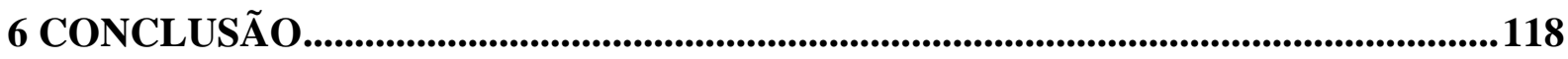

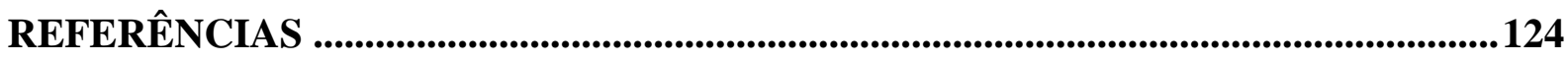

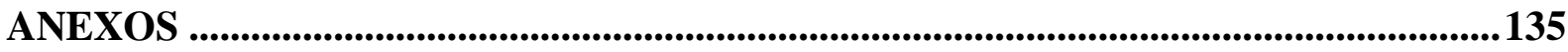

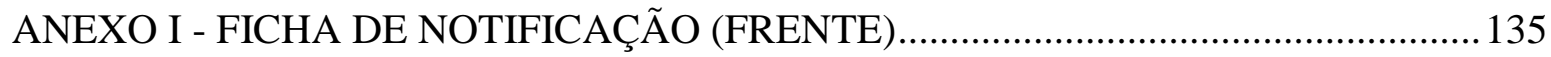

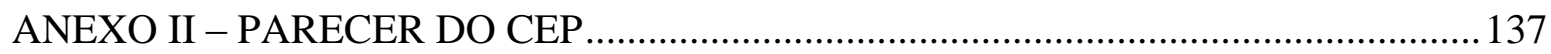

ANEXO III - CARTA DE ACEITE SESPA …........................................................... 138

ANEXO IV - CARTA DE ACEITE SEMSA .............................................................. 139 
APÊNDICES.

APÊNDICE I - TERMO DE CONSENTIMENTO DE USO DE DADOS - TCUD ........141

APÊNDICE II - TERMO DE CONSENTIMENTO LIVRE E ESCLARECIDO................143

APÊNDICE III - TERMO DE CONSENTIMENTO LIVRE E ESCLARECIDO ..............146

APÊNDICE IV - TERMO DE ASSENTIMENTO ……………………………….......... 148

APÊNDICE V - TERMO DE CONSENTIMENTO LIVRE E ESCLARECIDO-PAIS ... 150

APÊNDICE VI-QUESTIONÁRIO DE PESQUISA ……………………………............ 152

APÊNDICE VII -PROTOCOLO DE PESQUISA (ESTUDO RETROSPECTIVO E PROSPECTIVO) 


\section{APRESENTAÇÃO}

O presente estudo decorre de meu interesse na área desde o ano de 2003, por ocasião de minha formação em Biologia, na linha de pesquisa de Zoologia e, mais especificamente, em relação aos artrópodes (escorpiões), quando tive a oportunidade de conhecer o importante agravo de Saúde Pública, o escorpionismo. Ao término da Graduação apresentei o Trabalho de Conclusão sobre Aspectos Clínicos e Epidemiológicos do Escorpionismo no Município de Santarém-PA. Neste, já se destacava o expressivo número de acidentes e, mais relevante, que apresentavam manifestações clínicas diferentes, quando se tratava do escorpião Tityus obscurus, que apresenta sintomas compatíveis com quadro cerebelar.

Ao ingressar no curso de Enfermagem, acompanhei pacientes vítimas de escorpionismo durante os estágios e, posteriormente, como docente da Universidade do Estado do Pará- Campus Santarém. A participação nas atividades de extensão junto ao NUMETROP - Núcleo de Apoio às Atividades de Extensão em Medicina Tropical do Departamento de Moléstias Infecciosas e Parasitárias da Faculdade de Medicina da Universidade de São Paulo proporcionou olhar ampliado para a pesquisa, inspirando-me na investigação do escorpionismo na região oeste do Pará, um grande desafio para a Enfermagem nas ações de vigilância epidemiológica, no cuidado às pessoas acometidas e no auxílio à implementação de políticas públicas para o controle e manejo do agravo. 


\section{INTRODUÇÃO}

\subsection{CARACTERÍSTICAS GERAIS DOS ESCORPIÕES}

Os escorpiões são artrópodes pertencentes à classe dos Aracnídeos, e à ordem Scorpiones. Seus fósseis datam de cerca de 400 milhões de anos. Estes animais possuem um complexo mecanismo de adaptação, podendo sobreviver aos mais variados ambientes, nas regiões tropicais e subtropicais do mundo (BRASIL, 2009).

De hábito predominantemente noturno, os escorpiões preferem locais secos ou úmidos para se esconderem durante o dia. Vivem geralmente debaixo de folhas, pedras, madeira, tijolos, ou ainda, sob o entulho de qualquer natureza ou sob as cascas de árvores. São carnívoros e, quando na escassez de alimentos, praticam o canibalismo (RECKZIEGEL; PINTO JUNIOR, 2013). São animais peçonhentos, pois produzem toxinas que são inoculadas na vítima através de um aparelho inoculador. A toxicidade do veneno varia para cada espécie, podendo também sofrer variações em uma mesma espécie (BRASIL, 2009).

A fauna escorpiônica constitui-se de 18 famílias, 151 gêneros e 1.947 espécies (CHIPPAUX; GOYFFON, 2008). Os escorpiões considerados perigosos para o homem pertencem à Família Buthidae, com 550 espécies, das quais cerca de trinta são consideradas capazes de provocar acidentes graves ou fatais. As espécies mais perigosas pertencem aos gêneros Androctus e Leiurus (África do Norte e Oriente Médio), Centruróides (México e Estados Unidos) e Tityus (América do Sul e Trinidad) (COTTA, 2014).

No Brasil, apenas algumas espécies do gênero Tityus são consideradas clinicamente importantes: Tityus serrulatus, responsável pela maioria dos acidentes graves, é encontrado nas regiões Nordeste, Centro-Oeste, Sul e Sudeste; Tityus stigmurus, na região Nordeste; Tityus bahiensis, na região Sudeste; e o Tityus obscurus, na região Norte (BRASIL, 2009; CHIPPAUX; GOYFFON, 2008; TORREZ et al., 2014). Na Amazônia, as espécies mais encontradas são o $T$. obscurus (também denominado T.cambridgei e T. paraenses), o $T$. silvestris e o T. metuendus (PARDAL et al.,2003; PARDAL et al.,2014). A espécie T. obscurus apresenta ampla distribuição ocorrendo na Guiana Francesa e nos estados brasileiros do Pará, Amapá e Mato Grosso (BRASIL, 2009).

Por possuir aparência marcante, são animais facilmente reconhecidos, com corpo dividido em prossoma (ou cefalotórax) e opistossoma, que se subdivide em mesossoma (tronco) e metassoma (cauda) (BRAZIL; PORTO, 2010; RECKZIEGEL, 2013).

No prossoma estão dispostos dois olhos na região mediana e até cinco em cada lateral. Apresentam, ainda, um par de quelíceras (utilizadas para triturar os alimentos), quatro pares 
de pernas e um par de pedipalpos (pinças) com quelas em suas extremidades, que desempenham a função de imobilização de presas, defesa, condução do parceiro no ritual da corte e percepção sensorial (BRASIL, 2009; BRAZIL; PORTO, 2010; RECKZIEGEL, 2013).

O opistossoma é formado por 13 metâmeros. O mesossoma (tronco) é composto por sete metâmeros, e onde se encontra o opérculo genital na região ventral; os pentes sensoriaispermitem a captação de estímulos mecânicos e químicos do meio; e os espiráculos ou estigmas respiratóriospermitem a passagem do ar atmosférico aos pulmões foliáceos. $\mathrm{O}$ metassona (cauda) é composto por cinco metâmeros e, em sua extremidade distal, encontraseo télson. Este último é formado internamente por duas glândulas de veneno que desembocam em um aguilhão utilizado para a inoculação da peçonha, conforme pode ser visto na Figura 1 (BRASIL, 2009; BRAZIL; PORTO, 2010; RECKZIEGEL, 2013).

Figura 1 - Morfologia externa dorsal e ventral de um escorpião (Tityus aba): es) par de estigmas respiratórios do sexto segmento mesossomal; et) esterno; ms) mesossoma; mt) metassoma; pe) perna; pd) pedipalpo; pn) pentes; ps) prossoma; ql) quelícera; tl) télson.

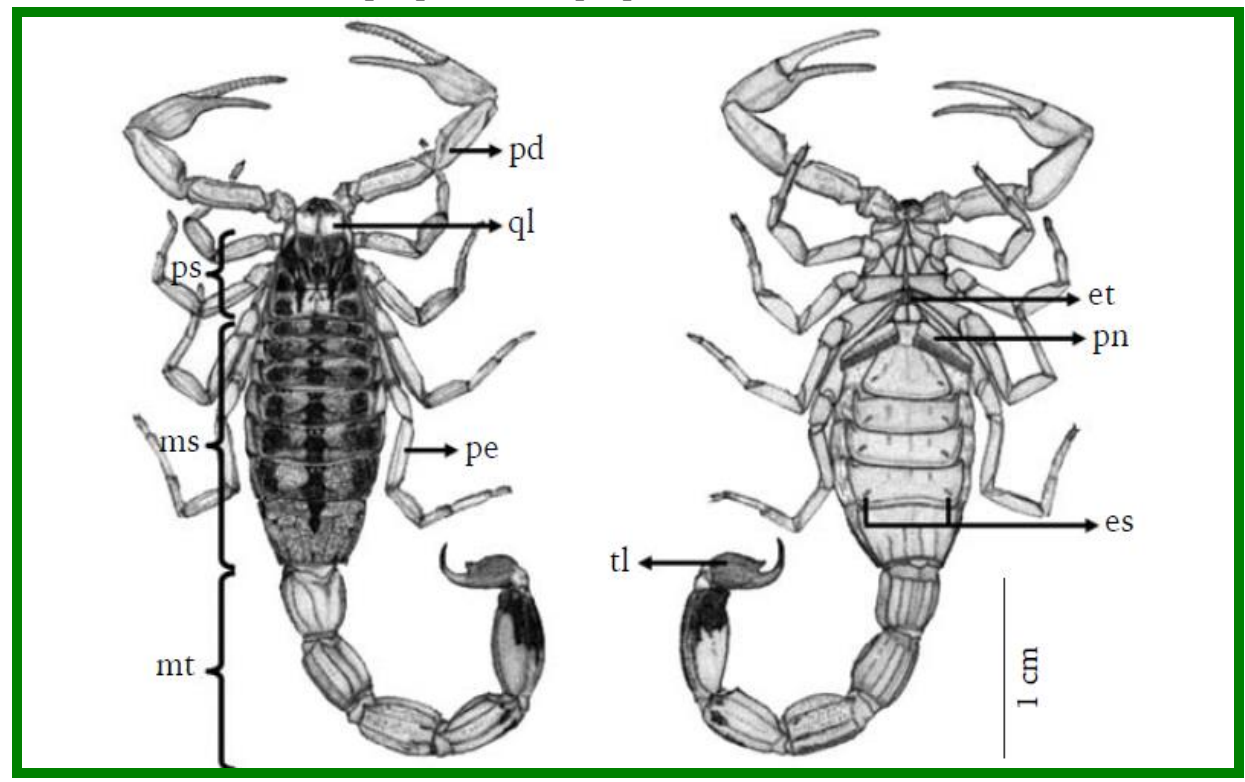

Fonte: BRAZIL T.K ; PORTO T. J. Os escorpiões. Salvador: EDUFBA, 2010.

De acordo com Pardal et al. (2003), o T. obscurus, sinônimo de T. paraensis e $T$. cambridgei, é o causador de muitos envenenamentos na Região Amazônica brasileira. Conhecido também por escorpião preto da Amazônia, possui cerca de $9 \mathrm{~cm}$ de comprimento, quando adulto é todo negro e os machos possuem pedipalpo mais fino e longo do que as fêmeas. Quando jovem, o T. obscurus apresenta coloração castanha manchada de escuro no corpo e apêndices, podendo ser confundido com outras espécies da Região Amazônica, Figura 2 (BRASIL, 2009; BRAZIL; PORTO, 2010). 
Figura 2 - Fêmea adulta de Tityus obscurus.

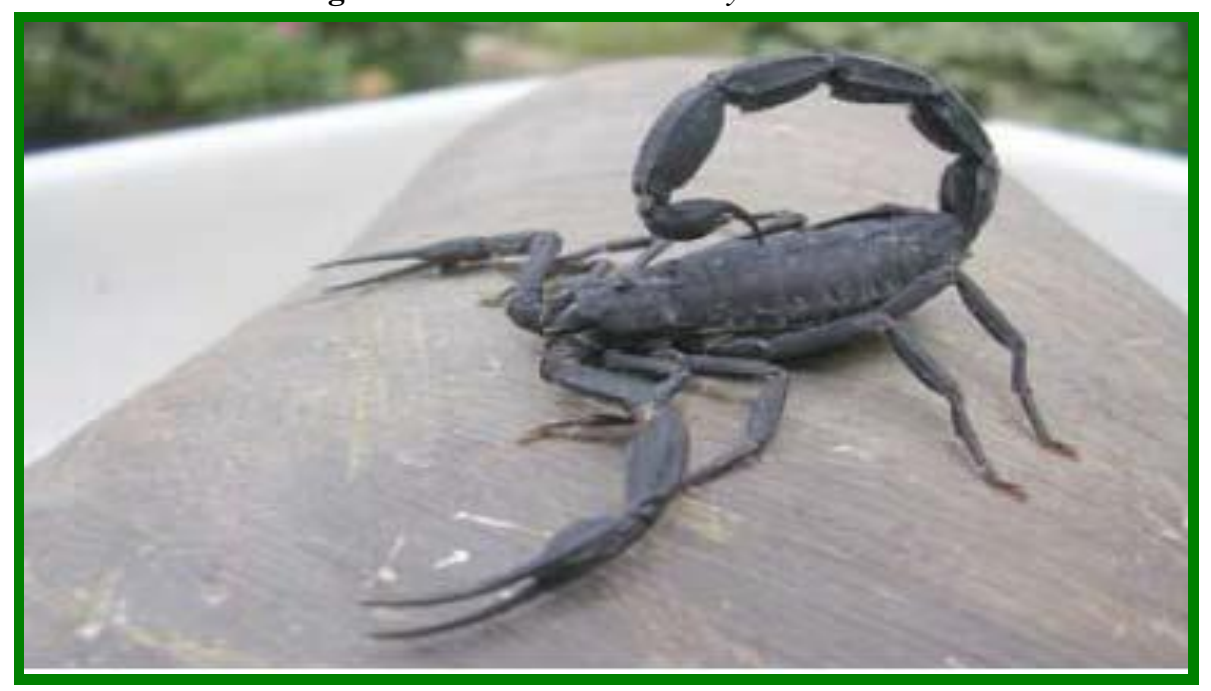

Fonte: BRASIL. Ministerio da Saúde. Secretaria de Vigilância em Saúde. Departamento de Vigilância Epidemiológica. Manual de controle de escorpiões. Brasília: Ministério da Saúde, 2009.

\subsection{EPIDEMIOLOGIA}

O escorpionismo é um problema de saúde pública em países tropicais e subtropicais, especialmente no Norte da África, Sul da Índia, América Latina e Oriente Médio (CHIPPAUX; GOYFFON, 2008).

No Norte da África, na Tunísia, a incidência anual de acidentes por escorpião é de 420 por 100.000 habitantes, porém, na província de SidiBouzid, no centro do país, a incidência é mais elevada, variando entre 1.280 e 1.500 picadas por 100.000 habitantes. No Oriente Médio, nas áreas rurais da Arábia Saudita, a incidência também pode exceder 1.000 acidentes por 100.000 habitantes. Na Ásia, o Irã tem a incidência anual de 140 acidentes por 100.000 habitantes, enquanto que, na América Latina, o México é o país com o maior número de acidentes, onde, em alguns estados do centro e do oeste, a incidência anual chega a 1.350 acidentes por 100.000 habitantes/ano (CHIPPAUX; GOYFFON, 2008).

A notificação dos acidentes escorpiônicos no Brasil começou a ocorrer a partir de 1988, passando a ser registrados no Sistema de Informação de Agravos de Notificação SINAN (BRASIL, 2009). No período de 2000 a 2010 ocorreram 359.427 acidentes escorpiônicos, dos quais, 561 evoluíram para óbito. Houve aumento nas taxas de incidência, com média de 19,6 acidentes por 100.000 habitantes. O sexo masculino (50,7\%), a raça/cor negra $(44,7 \%)$ e a faixa etária entre 20 a 49 anos (47\%) foram as mais acometidas, sendo um problema preponderantemente urbano (RECKZIEGEL; PINTO JUNIOR, 2014). 
No período de 2010 a 2012 foram registrados 172.618 acidentes, sendo a média anual de 57.539 casos. Os estados de Minas Gerais, Bahia e São Paulo foram os que mais registraram casos. A região Norte registrou 8.503 acidentes, totalizando 4,9\% dos casos do País, sendo que o Pará, com 5.056 casos, correspondeu a 59,4\% da totalidade (BRASIL, 2015). No ano de 2017 foram registrados 124.982 casos de escorpionismo no Brasil (BRASIL, 2018).

Os primeiros registros publicados de escorpionismo no Estado do Pará são provenientes de um estudo clínico e epidemiológico realizado no período de 1992-1995, com12 pacientes internados no Hospital Universitário João de Barros Barreto (HUJBB), em Belém (ASANO et al., 1996). No ano de 2002, Martins et al. (2002), em pesquisa também realizada no HUJBB, registraram 61 casos de escorpionismo, sendo que as manifestações neurológicas nas vítimas limitaram-se à tontura e sonolência.

Entretanto, no interior do Estado, nos municípios de Santarém, Belterra, Prainha, Itaituba, Altamira e Brasil-Novo foram descritas: mioclonias, referidas pelas vítimas como "sensação de choque elétrico" pelo corpo, disartria, dismetria e ataxia, entre outras manifestações neurológicas (PARDAL; CARDOSO; FAN, 1999; SPEROTTO et al., 2001 PARDAL et al., 2003).

Em artigo publicado no ano de 2003, foram registrados 72 acidentes por escorpião no município de Santarém-PA, atendidos no Hospital Municipal de Santarém, tendo como procedência Santarém $(94,4 \%)$, Belterra $(4,2 \%)$ e Prainha (1,4\%). Destes acidentes, 88,9\% das vítimas declararam sensação de choque elétrico pelo corpo, mioclonias (93\%), dismetria $(86,1 \%)$, disartria $(80,6 \%)$ e ataxia de marcha $(70,8 \%)$, reflexos profundos sincinéticos $(9,7 \%)$, disdiadocinesia $(7 \%)$, confusão mental $(4,2 \%)$, reflexos profundos policinéticos $(2,8 \%)$ e alucinações visuais $(1,4 \%)$ (PARDAL et al, 2003).

Em outro artigo publicado no ano de 2008 foram registrados 94 acidentes por escorpião no município de Santarém. O estudo epidemiológico revelou que os acidentes predominavam na zona rural, com $80,9 \%$ dos casos; no sexo masculino, com $72,3 \%$ e; na faixa etária entre 20 a 39 anos, representando 42,0\% dos casos (COSTA, 2012).

No período de 2009-2013 foram registrados pelo Sistema de Informação de Agravos de Notificação, 4.106 acidentes na região do Baixo Amazonas e Tapajós. Em relação à classificação dos casos, 2.103 (51,21\%) eram leves, 1.422 (34,63\%) moderados, 321 (7,82\%) graves, e 260 (6,34\%) não tinham classificação. Os municípios de Santarém, Alenquer, Itaituba, Jacareacanga, Trairão e Almerim registraram óbitos (OLIVEIRA et al., 2016). 
A letalidade do escorpionismo, no estado do Pará, pode ser resultado do potencial de toxicidade do veneno do T. obscurus, pois pesquisadores acreditam que é comparável ao de outras espécies do gênero, consideradas de grande interesse no Brasil, tais como do $T$. serrulatus e do T. bahiensis. Seu envenenamento, em algumas regiões da Amazônia, pode ocasionar manifestações neuromusculares, tais como mioclonia, fasciculação e sensação de choque elétrico pelo corpo, não sendo observadas em outras partes do País (BRASIL, 2009), o que coloca em relevo a necessidade de estudos desse agravo, causado por tais espécies.

\subsection{MECANISMO DE AÇÃO DO VENENO}

O veneno é uma secreção apócrina composta de proteínas e peptídeos (neurotoxinas) de baixo peso molecular, que exercem ação sobre canais iônicos dependentes das voltagens de Sódio $(\mathrm{Na}+)$, Potássio $(\mathrm{K}+)$, Cálcio $(\mathrm{Ca}++)$, e Cloro $(\mathrm{Cl}-)$ em células nervosas, músculos e células glandulares (BECERRIL et al., 1997; POSSANI et al., 1977, POSSANI et al., 1981). Estes canais são responsáveis por gerar sinais elétricos para a formação e propagação do potencial de ação, necessários para a condução do impulso nervoso, batimentos cardíacos, secreção hormonal, função renal e ativação de células do sistema imune (CATTERAL et al., 2007).

Além dos peptídeos neurotóxicos, a peçonha contém enzimas, nucleotídeos, lipídeos e aminas (RODRÍGUEZ DE LA VEJA; POSSANI, 2005). Os peptídeos com atividade biológica, presentes na peçonha dos escorpiões, podem ser classificados como peptídeos com pontes dissulfeto (DBPs, dissulfidebridged-peptides), que atuam nas membranas celulares, ligando-se a uma grande variedade de tipos e subtipos de canais iônicos ( $\mathrm{Na}+\mathrm{Ca}++, \mathrm{K}+)$, conhecidos como neurotoxinas (LORETI; HAMMOCK, 2001; POSSANI et al., 2000) e, peptídeos sem pontes dissulfeto (NDBPs, non-dissulfide-bridged-peptides), que apresentam diversas atividades biológicas, como a antimicrobiana ou hemolítica (ZENG et al., 2005).

Os canais de sódio são considerados os mais importantes na fisiopatologia dos acidentes escorpiônicos, devido à afinidade das principais neurotoxinas presentes em seus venenos (RODRÍGUEZ DE LA VEJA; POSSANI, 2005). A peçonha do Tityus obscurus é composta por aproximadamente 102 componentes peptídicos diferentes, porém apenas 18 são conhecidos. Três deles são toxinas específicas de canais de $\mathrm{K}^{+}$e 15 toxinas agem em canais de $\mathrm{Na}^{+}$. Essa diferença de composição do veneno pode estar ligada às diferenças geográficas e às particularidades do habitat de cada espécie de escorpião (GUERRERO-VARGAS et al., 2012; PARDAL et al., 2014). 
Cada espécie de escorpião apresenta diversas neurotoxinas no veneno, que compartilham entre si a característica de atuarem sobre canais iônicos de células excitáveis (GARCIA et al., 1984, RODRÍGUEZ DE LA VEJA; POSSANI, 2005). Estima-se cerca de 100.000 toxinas, do total de espécies de escorpião conhecidas pelo mundo, tendo sido isolada e caracterizada sua constituição química apenas em 1\% (GAZARIAN et al., 2005).

As neurotoxinas, sendo os compostos que mais se destacam na composição do veneno, acarretam aumento na liberação de acetilcolina, noradrenalina e adrenalina, afetando tanto o sistema simpático como o parassimpático (CUPO et al, 2009; PINTO et al., 2010; VASCONCELOS et al., 2005).

\subsection{QUADRO CLÍNICO}

Os aspectos clínicos variam conforme alguns fatores que podem influenciar na evolução clínica, determinando a gravidade do envenenamento. Entre esses fatores se incluem: local de inoculação do veneno; idade e saúde prévia do paciente; espécie do escorpião; conteúdo e constituição do veneno nas glândulas do artrópode; número de picadas e quantidade de veneno inoculado (DEHESA-DAVILA; POSSANI, 1994).

De uma forma geral, o envenenamento escorpiônico resulta em efeitos nos diversos órgãos e tecidos, sendo frequentes manifestações cardiovasculares, respiratórias e neurológicas, podendo variar desde dor local, acompanhada por parestesias (em 90\% dos casos), até alterações cardiovasculares, respiratórias, gastrintestinais, pancreáticas, neurológicas ou, até mesmo, coma e morte (FERNANDEZ-BOUZAS et al., 2000; OSNAYAROMERO et al., 2001).

As manifestações clínicas no escorpionismo podem ser locais ou sistêmicas. A dor local, de intensidade variável, é característica da maioria dos casos e pode ser acompanhada por edema, eritema, sendo difícil a visualização da marca do ferrão. Surge em minutos após a picada e evolui de forma benigna na maioria dos casos e, desta forma, sem a necessidade da soroterapia. Nos casos leves, além da sintomatologia local, agitação e vômito podem estar presentes, e se devem mais à ansiedade decorrente do acidente (BRASIL, 2009; CHIPPAUX; GOYFFON, 2008; RECKZIEGEL; PINTO JUNIOR, 2013; TORREZ et al., 2015).

As manifestações sistêmicas podem ser encontradas nos casos moderados, e apresentam-se sob a forma de náusea, vômito, dor abdominal, cólica, diarreia, febre e sudorese. Em quadros clínicos graves, o desequilíbrio entre os sistemas nervoso simpático e parassimpático se expressa inicialmente através de sudorese profusa, agitação psicomotora, 
hipertensão e insuficiência cardíaca congestiva aguda. A gravidade está relacionada também à composição do veneno, aos efeitos sintéticos da espécie e à faixa etária da vítima, pois menores de cinco anos de idade e idosos são mais gravemente afetados (BRASIL, 2009; CHIPPAUX; GOYFFON, 2008; TORREZ et al., 2015).

\subsection{TRATAMENTO}

Os acidentes escorpiônicos são classificados, em relação à gravidade, de acordo com a intensidade das manifestações clínicas apresentadas. Essa classificação tem a finalidade de subsidiar o cuidado e o tratamento realizado pelos profissionais de saúde - Figura 3 (PARDAL; GADELHA, 2010).

Figura 3 - Classificação da gravidade do acidente escorpiônico.

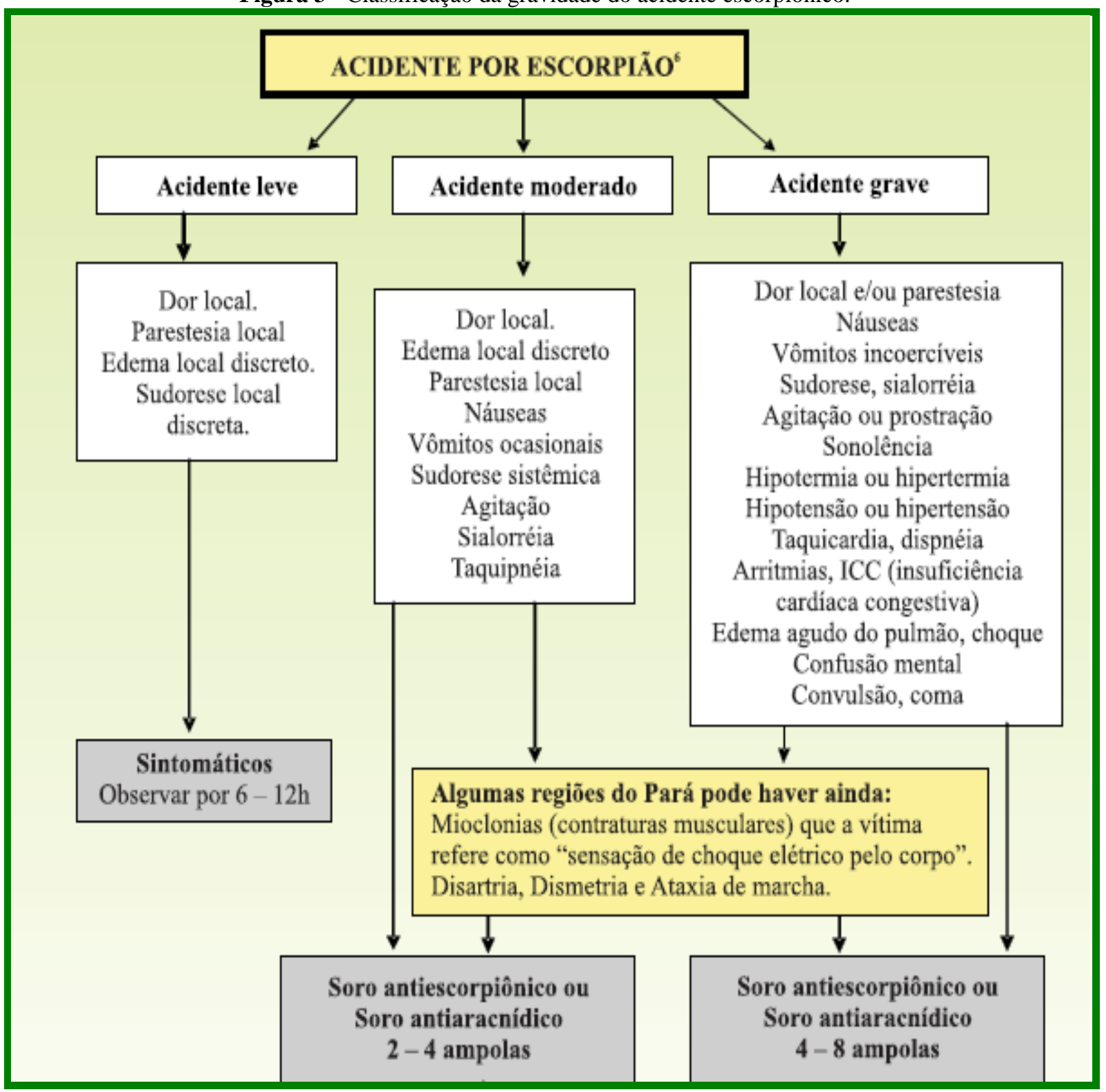

Fonte: PARDAL P.P.O; GADELHA, M. A. C. Acidentes por animais peçonhentos: manual de rotinas. Belém: SESPA -Secretaria de Estado de Saúde Pública do Pará, 2010. 
A Nota Técnica do Ministério da Saúde (2016), apresentada na Figura 4, detalha a classificação dos acidentes, além das condutas a serem tomadas, anteriormente apresentadas.

Figura 4 - Nota Técnica do Ministério da Saúde

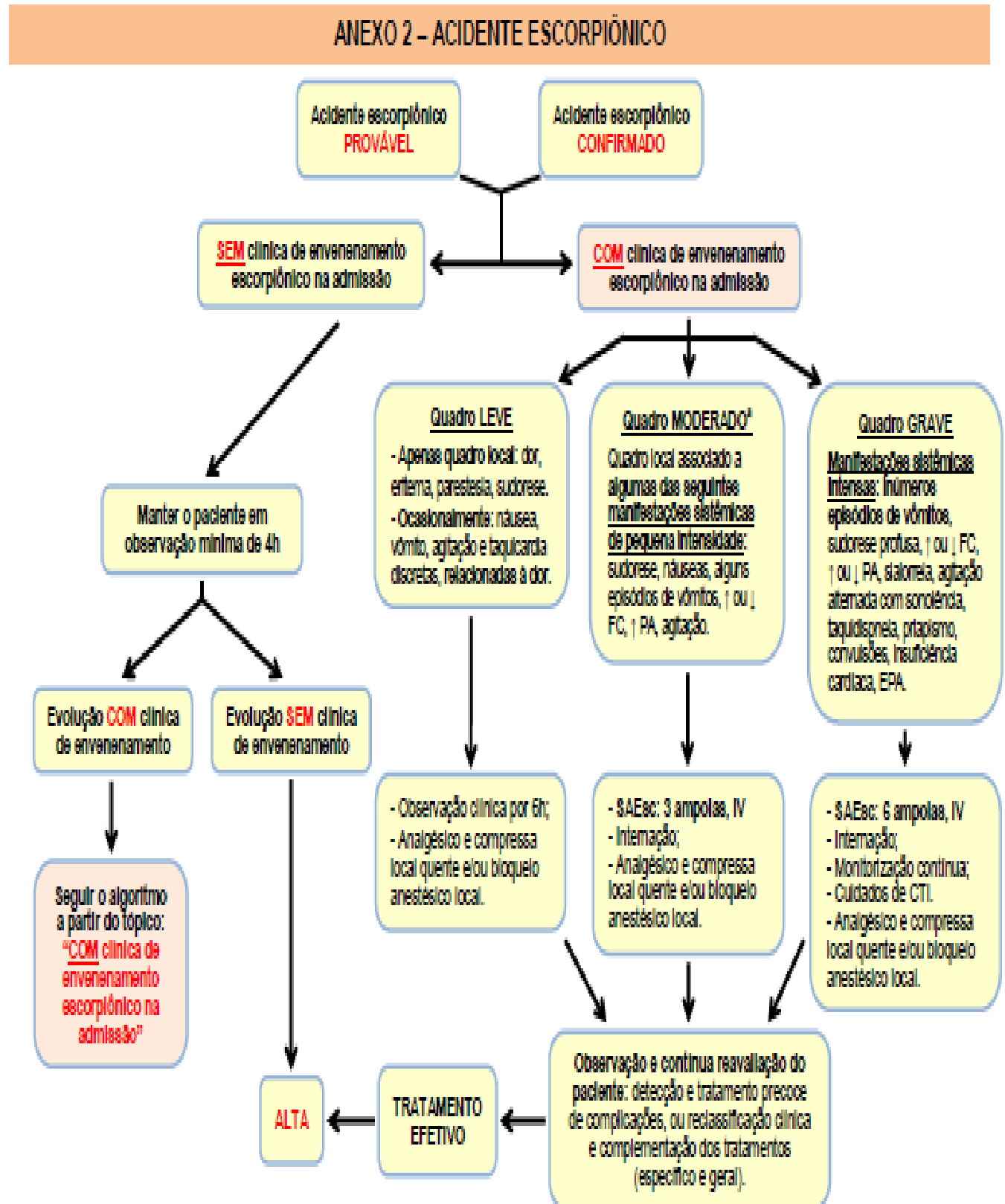

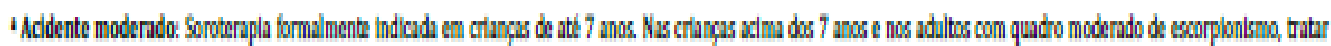

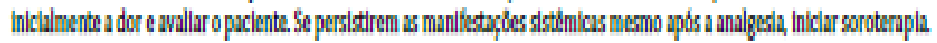

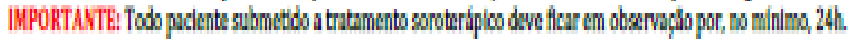

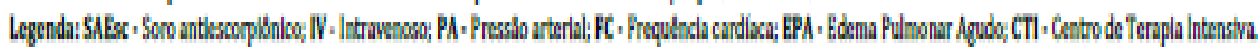

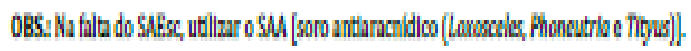

Fonte: BRASIL. Portal da Saúde [Internet]. Nota Informativa: Informações da Coordenação-Geral de Doenças Transmissíveis (CGDT) referentes à nova abordagem ao tratamento em casos de acidentes por serpentes do grupo Bothrops (“jararacas”) e por escorpiões, em situação de escassez de antivenenos. 2016. 
Os acidentes escorpiônicos no Brasil são de grande relevância, em decorrência não tão somente da incidência, mas também pela elevada potencialidade em desencadear quadros graves, muitas vezes até fatais, principalmente em crianças, reforçando a necessidade de monitorização contínua em paciente grave (CUPO et al., 1994).

O primeiro caso grave de escorpionismo, causado por Tityus obscurus, registrado na Amazônia, foi de uma criança, no município de Igarapé-Miri, região nordeste do Estado do Pará. A criança apresentava dor, eritema e edema no local da lesão. Como manifestações sistêmicas, apresentou sonolência, alucinações, taquipnéia, taquicardia, prostração, sudorese profusa, sialorréia intensa, e vômitos frequentes e incoercíveis, o que evidencia gravidade. Foi tratada com soroterapia antiescorpiônica e suporte clínico, obtendo boa evolução clínica. Os exames laboratoriais mostraram alterações das enzimas dos músculos esqueléticos e não do miocárdio (PARDAL et al., 2014).

Os aspectos apresentados, com destaque para a magnitude dos acidentes escorpiônicos na região, além da singularidade das manifestações neuromusculares determinou, portanto, o desenvolvimento do presente estudo, conforme a justificativa a seguir.

\subsection{JUSTIFICATIVA/ PROBLEMATIZAÇÃO}

Acidentes causados por animais peçonhentos são de interesse para a saúde pública em vários países tropicais e subtropicais, devido à sua elevada incidência e seu potencial em provocar quadros clínicos graves e frequentemente fatais, principalmente em crianças e idosos (HORTA et al., 2007).

Sifuentes e Wen (2007) apontavam a tendência nacional ao aumento de notificações de casos de escorpionismo no Brasil, desde o ano de 2005. No estado do Pará verifica-se o aumento da incidência, com ápice no ano de 2006, com 1.149 acidentes notificados. Na região norte, o Pará foi o Estado que mais notificou estes acidentes no período de 2000 a 2010, e ainda verifica-se tendência ao aumento dessas notificações. A letalidade é semelhante à média nacional e a gravidade muda em função da mesorregião (BRASIL, 2011; MAESTRI NETO et al., 2008).

Um estudo prospectivo, realizado no Hospital Municipal de Santarém (HMS), no ano de 2015, demonstrou que 53 (95\%) dos acidentados referiam uma "sensação de choque elétrico" pelo corpo, corroborando o estudo de Pardal e colaboradores no ano de 2003, em que foi relatada alteração dos movimentos musculares e do equilíbrio. Posteriormente, Torrez et 
al. (2015), além de demonstrarem a ocorrência de manifestações cerebelares e musculares, descreveram alterações renais com menor frequência, caracterizando estes acidentes como graves e questionaram a eficácia dos soros antiescorpiônico e /ou antiaracnídico, produzidos no Brasil, em neutralizar estas atividades. Os autores recomendam mais estudos, tanto clínicos como experimentais, para a elucidação dos mecanismos celulares e moleculares envolvidos nas manifestações observadas no cerebelo e nos músculos esqueléticos nestes acidentes.

Na região Oeste Paraense, os acidentes escorpiônicos evidenciam um quadro diverso das demais regiões, com manifestações neurológicas singulares, que não são descritas no Manual de Diagnóstico e Tratamento dos Acidentes por Animais Peçonhentos do Ministério da Saúde. Portanto, ainda não há caracterização clara que permita o aprimoramento do sistema de classificação e manejo clínico destes acidentes, o que coloca em destaque a importância do desenvolvimento de pesquisas para reforçar as ações de controle e de prevenção. Também se postula que é necessário conhecer a amplitude da ocorrência destes acidentes com estas manifestações clínicas na mesoregião do Baixo Amazonas e Sudoeste do Pará. Fundamentalmente, a análise espacial da ocorrência do escorpionismo e de suas características clínicas e epidemiológicas possibilitará melhor manejo clínico do paciente, controle e prevenção dos acidentes, assim como planejamento estratégico das ações de saúde,interferindo positivamente em indicadores epidemiológicos, sociais, ambientais e de saúde.

São, pois, perguntas que nortearam o desenvolvimento do presente estudo: Há características epidemiológicas, clínicas e espaciais específicas do escorpionismo causado por T.obscurus na região? Como é realizado o sistema de classificação e manejo clínico desses acidentes na região?

Junto à vigilância epidemiológica, o enfermeiro desenvolve ações de investigação, planejamento e implementação de medidas de prevenção, controle etratamento (BRAGA et al., 2011; BRASIL,2002). Este, portanto, é um motivo relevante que também levou à proposição do presente estudo.

Assim, este projeto teve como finalidade precípua identificar as regiões de ocorrência do escorpionismo causado pelo Tityus obscurus, no $9^{\circ}$ e $10^{\circ}$ Centro Regional de Saúde do Estado do Pará, e caracterizar as manifestações clínicas e epidemiológicas para o aperfeiçoamento da vigilância em saúde. 


\section{OBJETIVOS}

\subsection{OBJETIVO GERAL}

Analisar a distribuição espacial e aspectos clínico-epidemiológicos dos acidentes escorpiônicos no $9^{\circ}$ e $10^{\circ}$ Centro Regional de Saúde do Estado do Pará ( $\left.9^{\circ} \mathrm{CRS} / \mathrm{SESPA}\right)$.

\subsection{OBJETIVOS ESPECÍFICOS:}

Determinar a incidência dos acidentes escorpiônicos na mesoregião do Baixo Amazonas e Sudoeste do Pará;

Verificar aspectos epidemiológicos e clínicos dos acidentes escorpiônicos ocorridos nos municípios pertencentes ao $9^{\circ} \mathrm{CRS} / \mathrm{SESPA}$;

Caracterizar a distribuição espacial dos acidentes que apresentam manifestações clínicas compatíveis com comprometimento cerebelar e/ou muscular nessa região;

Propor medidas de vigilância à saúde e de informação em saúde. 


\section{METODOLOGIA}

\subsection{REFERENCIAL TEÓRICO-CONCEITUAL}

\subsubsection{O conceito de território}

Primeiramente, é necessário explicitar o entendimento de que a interpretação do agravo tem base nos determinantes sociais do processo saúde-doença. Tudo na vida em sociedade, aí incluída a vida humana, é determinado, em um último nível, pelo grau de desenvolvimento alcançado pela sociedade, que de igual maneira é determinado socialmente (ALBUQUERQUE et al.,2014). Entende-se que a saúde-doença é determinada pela forma específica de organização da sociedade, pela forma como as pessoas vivem, incluindo as possibilidades de desgaste e de fortalecimentono cotidiano. Acredita-se, portanto, que também o escorpionismo é um fenômeno socialmente determinado, uma vez que acomete principalmente pessoas que vivem em condições de maior vulnerabilidade e porque as possibilidades para enfrentá-lo também são distintas, incluindo o acesso aos serviços de saúde.

Ainda que numa perspectiva de multifatorialização da causalidade da saúde-doença, a Comissão Nacional sobre os Determinantes Sociais da Saúde - CNDSS (2006) admite que os determinantes sociais são os fatores sociais, econômicos, culturais, étnicos/raciais, psicológicos e comportamentais que influenciam a ocorrência de problemas de saúde e seus fatores de risco na população (PELLEGRINI FILHO et al., 2011).

O conceito de território converge com a racionalidade posta na premissa da determinação social do processo saúde-doença. A palavra território pode revelar diferentes significados como "terra pertencente a"-terri (terra) e torium (pertencente a)-, de origem latina; ou como "térreo-territor" (aterrorizar- aquele que aterroriza) de origem grega (HAESBAERT, 2004). O conceito tem diferentes significados nas diversas áreas: Ciências Políticas (Estado), Biologia (Etologia) e Antropologia (territorialidade), dentre outras (BARCELLOS; PEREIRA, 2006).

O Professor Milton Santos trouxe importantes contribuições para a construção do conceito de território em várias de suas obras, também relevantes para a Geografia Médica. Para o autor, na base territorial é que tudo acontece, mesmo configurações e reconfigurações mundiais influenciam o espaço territorial (SANTOS, 2002). 
$\mathrm{O}$ autor advogava que as formas podem permanecer as mesmas durante muito tempo, mas, como a sociedade está sempre em movimento, a mesma paisagem, a mesma configuração territorial oferecem, no transcurso histórico, espaços diferentes (SANTOS, 1996, p.7).

O território não pode ser visto como um mero perímetro de uma área física, nem muito menos um terreno, no sentido de uma dimensão de terra. É necessário considerar toda a dinamicidade que envolve este conceito; para além da topografia natural há a social, que decorre das relações entre os que nele vivem e suas relações com os que vivem em outros territórios (SPOSATI, 2008). Neste sentido, a crescente ocupação desenfreada de terras antes intocadas também pode mediar o recrudescimento do escorpionismo.

A análise da compreensão de conexões e relações que se dão na dinâmica dos territórios é fundamental para pensar em respostas, pelo Estado, que priorizem situações de risco, vulnerabilidades e exclusões de indivíduos e de grupossociais. Assim, a implementação de políticas públicas deve ser pensada a partir de necessidades emergentes do território (KOGA; NAKANO, 2006). Portanto, essa forma específica de compreender o território, o espaço em que se vive, é permeada pelos determinantes sociais, ou seja, o espaço ocupado pelas pessoas também é socialmente determinado.

\subsubsection{Tipo de Estudo}

Trata-se de pesquisa observacional, descritiva, retrospectiva e prospectiva, com abordagem quantitativa, que foi realizada em duas etapas.

\subsubsection{Etapas do estudo}

A primeira etapa A, tem delineamento retrospectivo e teve, como fonte de dados, Fichas de Notificação de Acidentes por Animais Peçonhentos (Base de Dados SINAN) dos municípios pertencentes ao $9^{\circ}$ e $10^{\circ}$ Centro Regional de Saúde, no período de 2011 a 2015, e prontuários dos pacientes vítimas de escorpionismo, atendidos no Hospital Municipal de Santarém, em 2016. A partir dos prontuários foram levantadas evidências de manifestações clínicas neurológicas e musculares compatíveis com aquelas causadas por Tityus obscurus, além de características demográficas, e epidemiológicas relativas ao agravo.

Nas Fichas de Notificação de Acidentes por Animais Peçonhentos foram capturadas as seguintes variáveis de importância demográfica e epidemiológica: procedência, idade, sexo, atividade laboral e escolaridade do paciente, local de ocorrência do acidente (trabalho, lazer, 
domicílio), período de tempo (horas) entre o acidente até o atendimento, e mês em que ocorreu o acidente.

Também foram capturadas variáveis de importância clínica: local da picada, sintomas e sinais locais e sistêmicos, classificação do acidente, manifestações clínicas neurológicas e/ou musculares: mioclonias, tontura, ataxia cerebelar, disdiadococinesia, nistagmo, vômito; tratamento instituído e evolução do caso.

$\mathrm{Na}$ segunda etapa B realizou-se o estudo exploratório, prospectivo, com abordagem multi-método. Esta etapa foi realizada em três momentos:

A) Aplicação de questionário (Apêndice VI) para profissionais de saúde (Técnicos de Enfermagem, Enfermeiros(as) e ou Médicos(as) lotados em Unidades de Saúde dos 20 municípios do $9^{\circ}$ Centro Regional de Saúde do Pará que realizavam assistência à vítimas de escorpionismo. Tal iniciativa ocorreu para verificar o conhecimento desses profissionais acerca do escorpionismo, assim como verificar se tais profissionais conheciam manifestações de comprometimento cerebelar e/ou muscular decorrentes do agravo. A aplicação do questionário para os profissionais dos municípios de Santarém, Rurópolis, Mojuí dos Campos e Belterra ocorreu em reunião técnica "Atualização em acidentes escorpiônicos para profissionais de saúde" da região. Para os profissionais dos demais municípios do $9^{\circ}$ CRS/SESPA que não puderam participar dessa Atualização, o questionário foi encaminhado junto com o protocolo de pesquisa ao profissional enfermeiro(a) assistente da pesquisa no município.

B) Com a finalidade de apoiar a identificação dos aspectos clínicos e epidemiológicos relacionados ao escorpionismo, assim como a identificação e reconhecimento do acidente e ações de cuidado, foi oferecida outra atualização em acidentes escorpiônicos para profissionais de saúde (médicos, enfermeiros e técnicos de enfermagem) atuantes nos 20 municípios do $9^{\circ}$ Centro Regional de Saúde e que prestavam atendimento às vítimas de escorpionismo nos serviços de saúde de seus respectivos municípios. A atualização ocorreu nas dependências da Universidade do Estado do Pará- Campus XII, durante o Simpósio de Medicina Tropical e Atenção Primária do Baixo Amazonas, no mês de junho de 2016, com a participação de cerca de 30 profissionais de saúde incluindo médicos, enfermeiros e técnicos de enfermagem.

C) Dado que nem todos os profissionais de enfermagem (Enfermeiros, Técnicos de Enfermagem) tiveram a oportunidade de participar da atualização anteriormente mencionada e em decorrência das grandes distâncias que separam os municípios da região, optou-se por utilizar um aplicativo que permitisse o contato rápido e a conexão entre o(a)s enfermeiro(a)s 
participantes e assistentes do estudo, por meio do WhatsApp, formando-se 20 grupos dos municípios pertencentes ao $9^{\circ} \mathrm{CRS} / \mathrm{SESPA}$. Por essa via foi apresentado o projeto, o protocolo de pesquisa, os termos de consentimento e vídeos acerca de sinais clínicos apresentados pelas vítimas de escorpionismo, com a finalidade de instrumentalizar os participantes para identificar o agravo. Vale ressaltar ainda que o projeto foi apresentado junto aos 20 secretários municipais de saúde em reunião da CIR (Comissão Intergestores Regionais) das regiões do Baixo Amazonas e Tapajós.

D) Trabalho de Campo: Coleta de dados de pacientes vítimas de acidentes escorpiônicos atendidos nos serviços de saúde situados no $9^{\circ}$ Centro Regional (20 municípios) de Saúde do Estado do Pará. Os profissionais Enfermeiro(a)s que participaram da atualização em acidentes escorpiônicos no momento B) acima descrito, além de outras enfermeiras queforam convidadas a atuarem como assistentes de pesquisa, auxiliaram na coletados dados demográficos, clínicos e epidemiológicos junto aos pacientes. Para a coleta de dados foi utilizado instrumento específico (Apêndice VII). Todos os pacientes que foram picados por escorpião e buscaram os serviços de saúde dos 20 municípios, foram convidados a participar do estudo. Em cada município havia um representante assistente de pesquisa Enfermeiro(a), totalizando 19 municípios. Em Santarém os pacientes foram sistematicamente acompanhados pela pesquisadora. Tendo em vista a importância de identificar a singularidade do quadro cerebelar compatível com o acidente escorpiônico, causado pelo T. obscurus, esses profissionais de saúde foram instados a documentar os sinais apresentados por meio de filmagem (média de 20 vídeos) e fotografia.

As amostras de espécies entregues pelas vítimas nos serviços de saúde foram devidamente identificadas e encaminhadas para análise taxonômica no Laboratório do Instituto Butantan-São Paulo* .

\subsubsection{Caracterização do Cenário de Estudo}

A primeira etapa do estudo, que corresponde ao estudo retrospectivo, inclui os dados das Fichas de Notificação Compulsória de pacientes de 29 municípios da região Oeste do Pará, de competência da Secretaria de Estado da Saúde do Pará (SESPA) - que constituem a $9^{\mathrm{a}}$ e a $10^{\mathrm{a}}$ Regional. A SESPA - $9^{\mathrm{a}}$ Regional tem sede em Santarém e tem por competência os seguintes municípios: Alenquer, Almerim, Aveiro, Belterra, Curuá, Faro, Itaituba, Jacareacanga, Juruti, Monte Alegre, Novo Progresso, Óbidos, Oriximiná, Placas, Prainha,

\footnotetext{
* Profissional responsável técnico pela identificação dos escorpiões: Prof. Dr. Rogério Bertani. Instituto Butantan - São Paulo.
} 
Rurópolis, Santarém, Terra Santa, Mojuí dos Campos e Trairão. A SESPA - 10ª Regional tem sede em Altamira e integra os municípios de: Altamira, Brasil Novo, Medicilândia, Porto de Moz, Senador José Porfírio, Pacajá, Anapu, Uruará e Vitoria do Xingú (Figura 5).

Figura 5 - Distribuição Geográfica dos Municípios do $9^{\circ}$ e $10^{\circ}$ Centro Regional de Saúde do Pará.

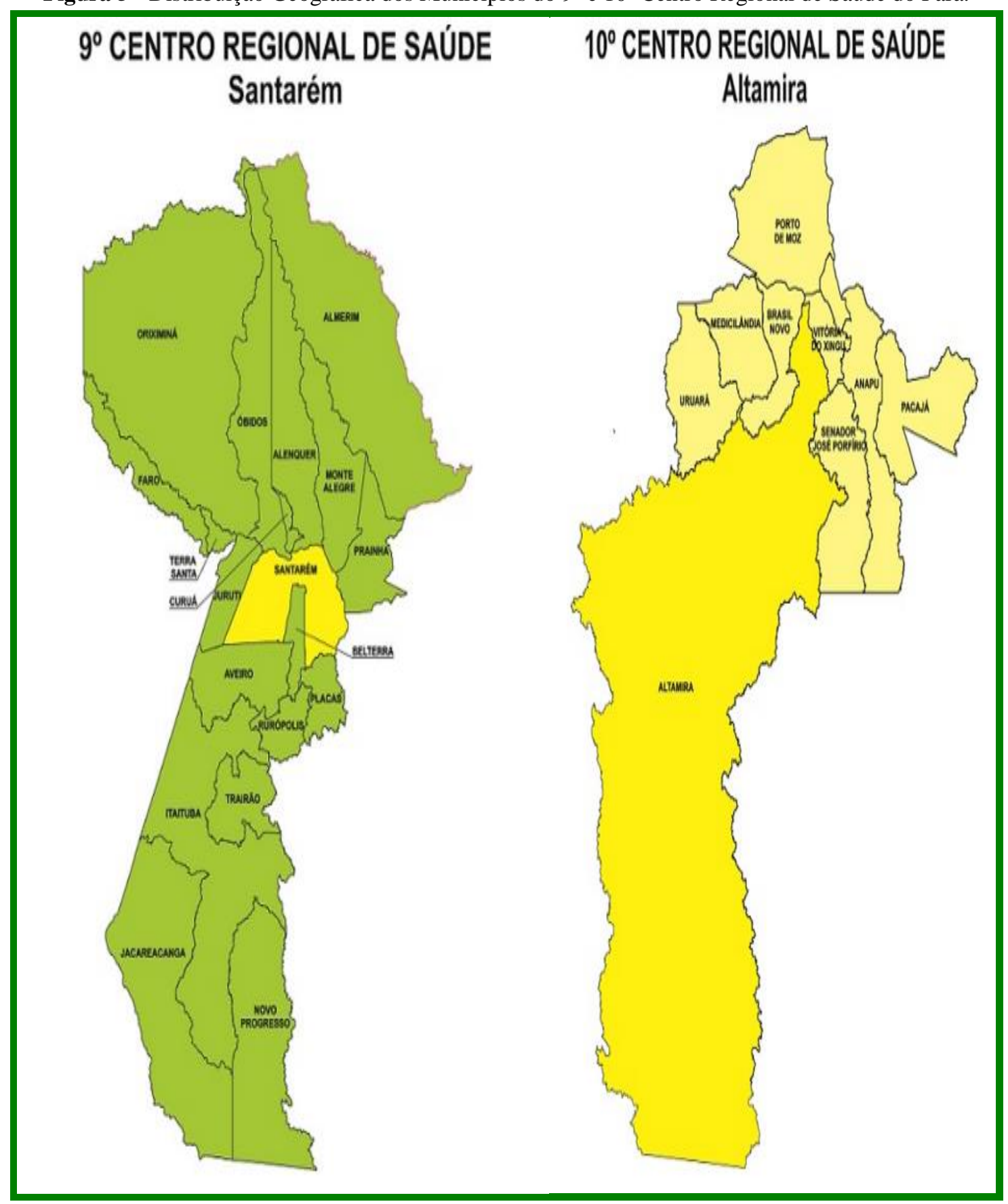

Fonte: SESPA. Secretaria de Estado de Saúde Pública. Mapas Centros Regionais de Saúde. 2015. 
A mesoregião do Baixo Amazonas tem uma área de $340.452,728 \mathrm{~km}^{2}$, com aproximadamente 770.000 habitantes. O Sudoeste, que agrega os municípios do $10^{\circ}$ CRS/SESPA, possui área de $415.788,848 \mathrm{~km}^{2}$ e população de 535.222 habitantes (Figura 6) (IBGE, 2014).

Figura 6 - Distribuição das Mesoregiões dos Municípios do Pará.
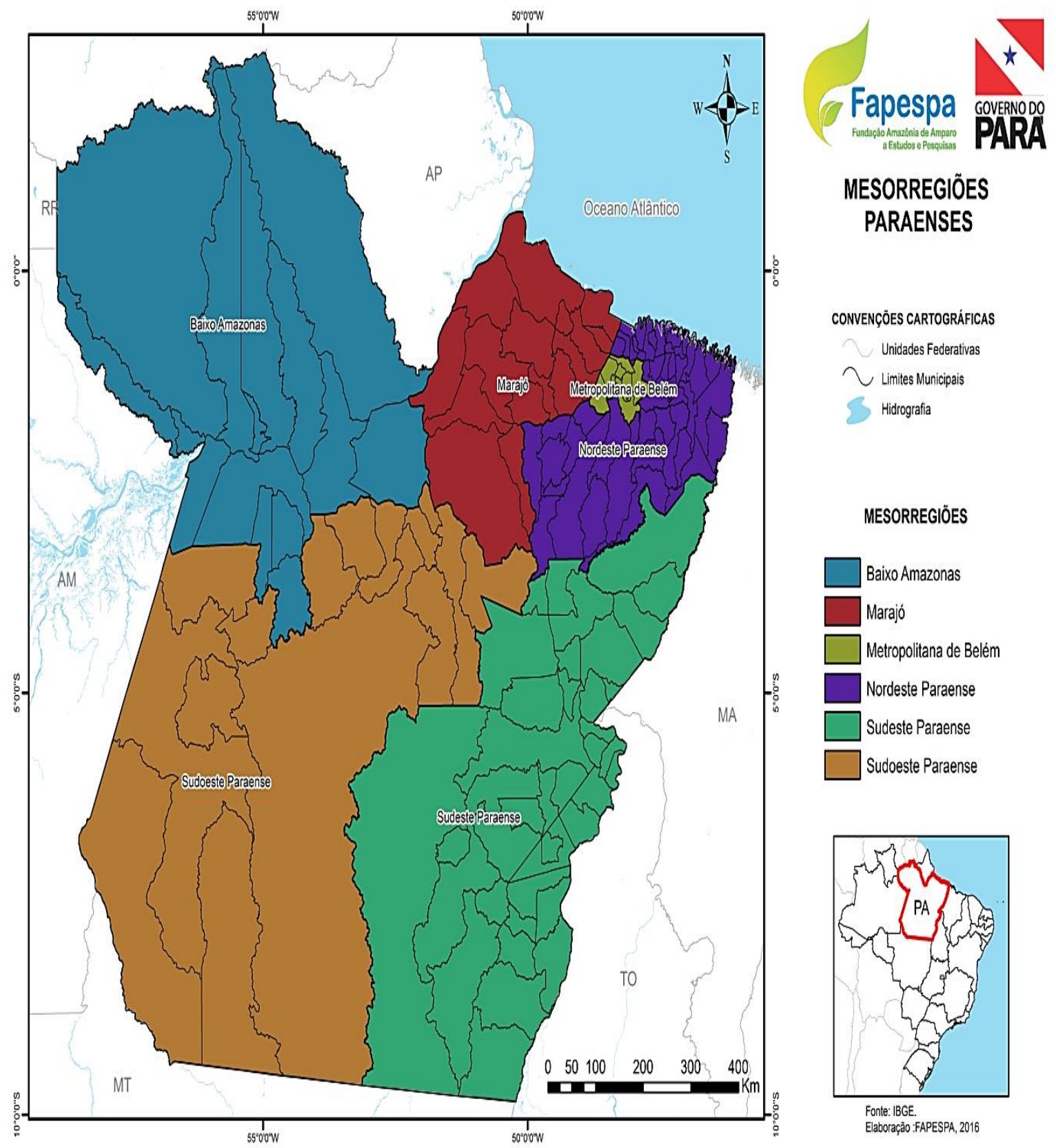

CONVENÇÖES CARTOGRÁFICAS

$$
\begin{aligned}
& \smile \text { Unidades Federativas } \\
& \curvearrowright \text { Limites Municipais } \\
& \text { Hidrografia }
\end{aligned}
$$

MESORREGIÖES

Baixo Amazonas

Marajó

Metropolitana de Belém

Nordeste Paraense

Sudeste Paraense

Sudoeste Paraense

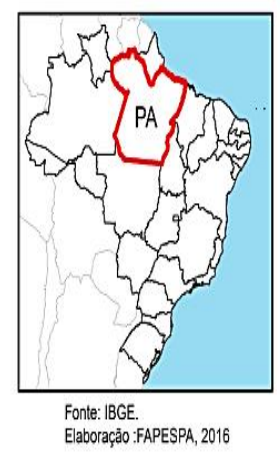

Fonte: FAPESPA. Fundação Amazônia de Amparo a Estudos e Pesquisas do Pará. Mapas de Mesoregiões. 2016 
A segunda etapa do estudo, que corresponde ao estudo prospectivo, foi realizada nos 20 municípios do $9^{\circ}$ Centro Regional de Saúde, sendo 14 municípios pertencentes à região do Baixo Amazonas e 6 à região do Tapajós (Sudoeste Paraense) (Figura 5 e Figura 6).

A área do estudo prospectivo pode ser observada em verde nas Figuras 7 e 8.

Figura 7 - Área onde ocorreu o estudo prospectivo.

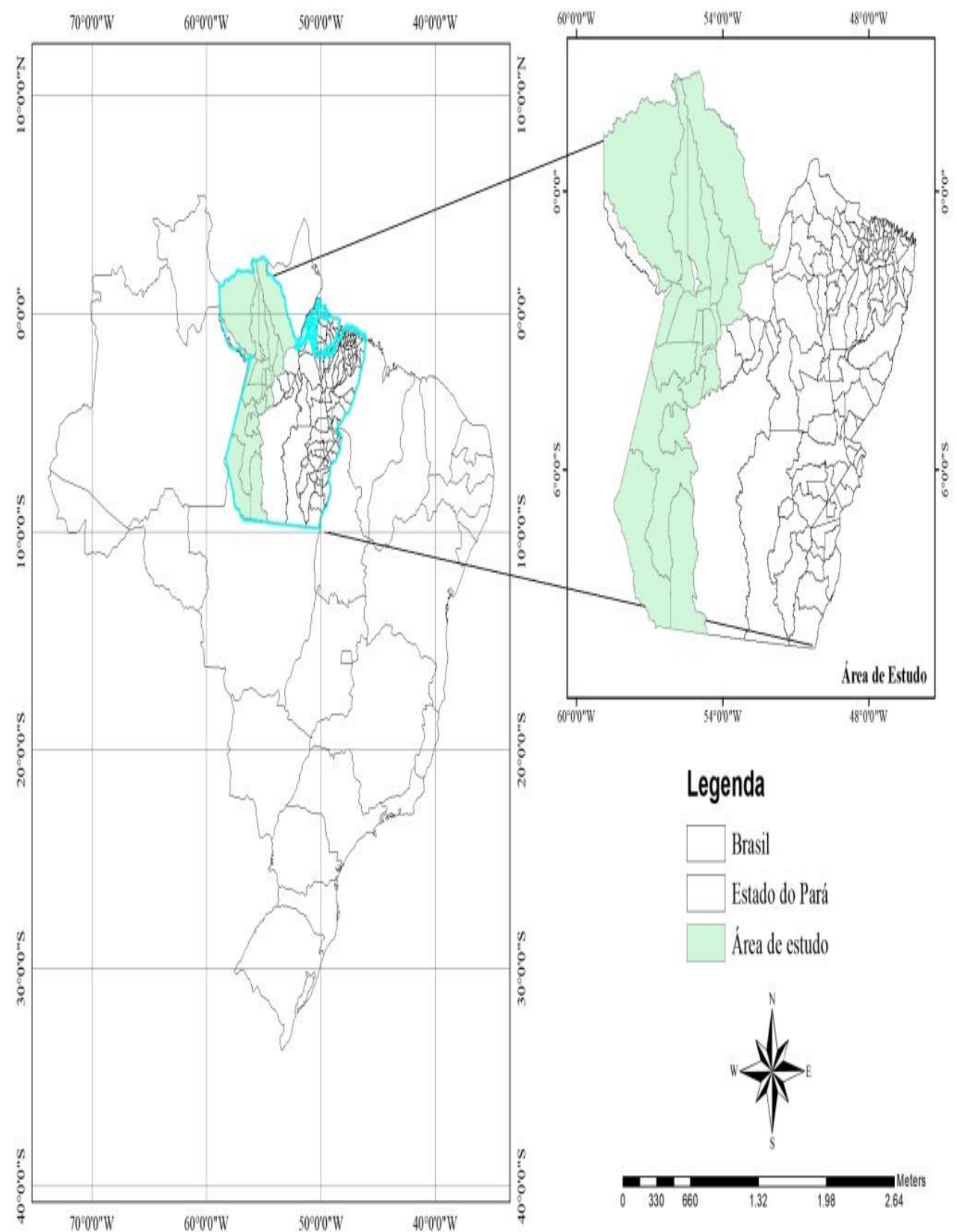

Fonte: GOMES, L. F. Mapa do Estado do Pará. Municípios que integram o 9²CRS/SESPA. 2018. 
Figura 8 - Municípios do Estado do Pará.

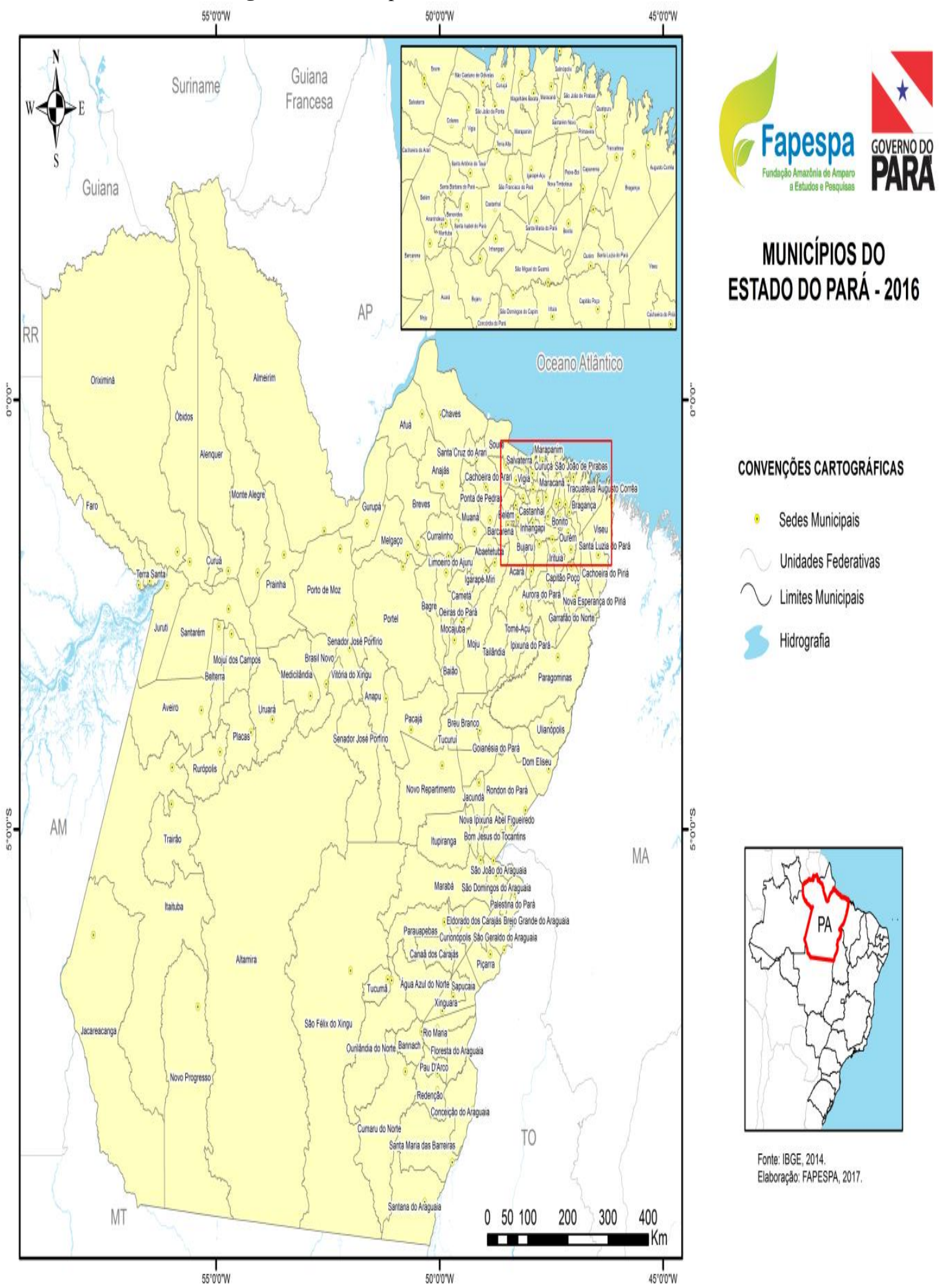

Fonte: FAPESPA.Fundação Amazônia de Amparo a Estudos e Pesquisas do Pará. Mapas de Mesoregiões.2016 
A região de integração do Baixo Amazonas destaca-se na extração de bauxita e é importante polo de pesca continental. É a região com maior produção de mandioca do Estado (30\%), de castanha do Pará (94\%) e terceira na produção de soja (17\%), na extração madeireira (19\%) e na produção de milho (18\%). Possui a segunda menor taxa de analfabetismo do Estado, em relação às pessoas com 15 anos ou mais (12\%), mas ocupa a terceira maior taxa de pobreza da Unidade Federada, com 49\%. Também apresenta a quinta maior taxa de mortalidade infantil do Pará, com 17\% (FAPESPA, 2015a).

A região de integração do Baixo Amazonas, no ano de 2014, teve 100\% de cobertura de agentes comunitários de saúde, 55\% de cobertura pela Estratégia Saúde da Família (ESF), $3,2 \%$ por postos e centros de saúde por 10 mil habitantes e $1,7 \%$ leitos por mil habitantes (FAPESPA, 2015a).

Conforme anteriormente mencionado, a sede do $9^{\circ}$ Centro Regional de Saúde situa-se no município de Santarém, na região Oeste do Pará, e está localizada na Mesoregião do Baixo Amazonas, à margem direita do Rio Tapajós, na confluência com o Rio Amazonas. Dista cerca de $807 \mathrm{Km}$ da capital Belém e tem população aproximada de 297.039 habitantes (IBGE, 2014). O Município de Santarém é o terceiro mais populoso do Pará, possuindo uma área de 22.887.080 $\mathrm{Km}^{2}$.

A rede pública de atenção à saúde de Santarém disponibiliza 93 Unidades Básicas de Saúde (UBS), seis Unidades Básicas 24h (UBS-24), uma Unidade de Pronto Atendimento 24h (UPA-24), o Pronto Socorro Municipal (PSM) e, ainda, os serviços do Hospital Municipal (HMS) e do Hospital Regional do Baixo Amazonas (HRBA) (SEMSA, 2016).

Já a região de integração do Tapajós destaca-se na extração do ouro, com Itaituba correspondendo a $60 \%$ da produção estadual e na extração do calcário, principal insumo da indústria de cimento. É a sétima região com a maior taxa de analfabetismo do Pará, considerando a faixa etária de 15 anos ou mais, com $15 \%$ e oitava no ranking da pobreza no Estado, com 39,7\%. A região apresenta, ainda, a primeira maior taxa de mortalidade infantil do Estado, com 18,6\% (FAPESPA, 2015b).

A região do Tapajós apresentou, no ano de 2014, 88,4\% de cobertura por agentes comunitários de saúde, 36,3\% de cobertura pela ESF, 2,5\% por postos e centros de saúde por 10 mil habitantes e 2,3\% leitos por mil habitantes (FAPESPA, 2015b). 


\subsubsection{Participantes do Estudo}

Para a identificação do conhecimento e das ações realizadas em relação ao escorpionismo foi realizada com a participação de Técnicos de Enfermagem, Enfermeiros e Médicos.

$\mathrm{Na}$ segunda etapa do estudo, que corresponde ao momento $\mathrm{D}$, e que ocorreu no período de março a setembro de 2017, participaram todos os pacientes vítimas de acidentes por escorpião, ocorridos nos 20 municípios do $9^{\circ}$ Centro Regional de Saúde do Estado do Pará.

\subsubsection{Critérios de Inclusão e Exclusão}

Foram incluídos na primeira etapa do estudo, todos os casos notificados de acidentes causados por escorpião, no período de 2011-2015, assim como os casos atendidos no HMS, em 2016, registrados nos prontuários. Foram excluídos dessa etapa, os casos duplicados, registrados em fichas de notificação. Nesse caso, foi sempre selecionada a primeira notificação. Também foram excluídos os casos de 2016, registrados em prontuários que apresentaram rasuras que impossibilitaram a leitura e obtenção dos dados.

$\mathrm{Na}$ segunda etapa do estudo, que corresponde ao prospectivo, foram incluídos profissionais de saúde vinculados aos municípios do $9^{\circ}$ Centro Regional de Saúde, sendo excluídos profissionais que se encontravam em licença no período da aplicação do questionário; além de serem incluídas vítimas de acidentes por escorpião que buscaram atendimento nos serviços de saúde pertencentes aos vinte municípios no período de março a setembro de 2017. Foram excluídas vítimas de acidentes por outros animais peçonhentos (cobras, arraias, aranhas).

\subsubsection{Análise dos dados}

Os dados receberam tratamento estatístico descritivo através do Programa EpiInfo versão 7.2. O tratamento estatístico inferencial foi realizado com a aplicação do teste de Quiquadrado de Pearson e Teste Exato de Fisher.

Para o cálculo das taxas de incidência de acidentes escorpiônicos, realizou-se uma estimativa de tamanho populacional, com baseno censo do IBGE 2010. Foram calculadas as taxas de incidência acumulada para o período e a médias anuais por mil habitantes referentes aos acidentes escorpiônicos para cada município. 
A análise espacial ocorreu, inicialmente, com a utilização do software Google Fusion Tables, para a realização da geocodificação. Posteriormente, foi empregado o Google Earth para marcar manualmente os casos. O software Trackmaker, utilizado a posteriori, permitiu a conversão dos dados do formato Kml para Shp, a fim de manipulá-los sequencialmente no software ArcGIS10 daEsri. Para a análise estatística espacial, foram utilizados o software ArcGIS 10 da Esri e o programa estatístico R versão 3.5.1 for Windows.

A análise espacial valeu-se, também, do risco relativo de ocorrência dos acidentes escorpiônicos na região. O Risco Relativo (RR) é aplicado para verificar a ocorrência de certo evento em uma região, dado que a chance de uma população ser similar à outra é muito pequena. Esta medida foi calculada para cada município e, se o RR do município foi menor que 1 indica que seu RR é inferior ao RR relativo do Estado. Caso contrário, é considerado alto risco, ou seja, indica que o RR do município é superior ao RR do Estado (FREITAS et al., 2011):

$$
R R_{i}=\frac{I_{l(i)}}{I_{t}}, i=1, \ldots, m
$$

Kulldorff; Nagarwalla(2005).

Para a obtenção do RR de cada cidade foi necessário o cálculo da taxa de incidência local (referente à incidência do município). $\mathrm{O}$ cálculo da incidência total refere-se à toda a área de estudo. A obtenção da taxa de incidência local dos casos de acidentes escorpiônicos ocorreu através da razão entre o número de casos registrados em cada município e a sua população. Já a incidência total foi obtida através da soma dos casos em relação ao total da população de toda área em estudo. Como é necessária a população para calcular a incidência, foi obtida através de projeção pelo método geométrico (SPIEGELMAN, 1968) para o ano de 2017, conforme preconiza Siegel (2006), e de acordo com o PNAD de 2007 e o CENSO do ano de 2010. Portanto, a projeção geométrica foi obtida da seguinte maneira:

$\mathrm{P}_{\mathrm{n}}=\mathrm{P}_{0}(1+\mathrm{r})^{\mathrm{t}}\left(\right.$ Knox, 1998), onde $\mathrm{P}_{\mathrm{n}}$ é a população desejada, $\mathrm{P}_{0}$ é a população inicial, $\mathrm{r}$ é a taxa de crescimento e o té o tempo entre o ano ou mês inicial e o desejado.

A taxa de crescimento para o método geométrico foi calculada da seguinte maneira:

$$
r=\left(\frac{P_{n}}{P_{0}}\right)^{\frac{1}{t}}-1
$$

(LUCENA; MORAES, 2009).

Com o resultado da projeção é possívelcalcular a taxa de incidência local e total, através de: $I_{l}=\frac{n^{o} \text { de casos do município }}{\text { população do município }}$ 
Com base em López A; Gómez- Rubio e Ferrádiz (2006), admitindo que $\mathrm{I}_{1}$ representa a incidência local,para calcular a incidência total, tem-se:

$$
I_{t}=\frac{\sum n^{o} \text { de casos do estado }}{\sum \text { população do estado }} \quad \text { (GENTLE, 2006). }
$$

O método de varredura Scan espacial foi desenvolvido e proposto por Kulldorff e Nagarwalla (1995). O Scan espacial utiliza uma área de estudo particionada em sub-regiões menores. O método associa um centróide a cada sub-região e, a esses centróides, círculos de raio zero e com o número de indivíduos com determinada doença e o tamanho da população da sub-região. Em seguida, o raio é aumentado continuamente, até possuir uma determinada quantidade da população, com isso, centróides vizinhos podem ser envolvidos. À medida em que os círculos são aumentados, é realizado um teste de significância para verificar se a região delimitada pela circunferência corresponde a um conglomerado espacial (KNOX, 1998).

Define-se conglomerado como um conjunto de áreas que apresentam um risco significantemente alto em relação a um determinado evento, embora não seja esperada tal observação nestas áreas (KNOX, 1998). A detecção de conglomerados espaciais tem como objetivo, a delimitação de uma região geográfica na qual a hipótese de ocorrência aleatória de um determinado evento é rejeitada, ou seja, o conglomerado não ocorre ao acaso. Assim, para cada agrupamento é testada a hipótese de ter ocorrido aleatoriamente, através do teste da razão de verossimilhança. São encontrados na literatura vários métodos que se propõem a identificar conglomerados. A Varredura Scan pertence à classe de testes genéricos de conglomerados e foi desenvolvida por Kuldorff (LUCENA; MORAES, 2009).

A Varredura Scan tem como objetivo identificar conglomerados em unidades cuja ocorrência de um evento é significantemente mais provável dentro de uma área do que fora dela (LUCENA; MORAES, 2009). Para uma área particionada em K sub-regiões menores (bairros, distritos, municípios) é associado um centróide $(\xi i) \mathrm{i}=(1,2, \ldots, \mathrm{K})$. A Varredura Scan é iniciada calculando-se a distância de um centróide em relação aos demais. Em seguida, são sobrepostos círculos z de raio arbitrário, em que seu raio é aumentado até envolver um novo centróide de cada sub-região em estudo. Para cada círculo é calculada a probabilidade de um indivíduo estar dentro (p) ou estar fora (q), conforme López et al., (2005).São testadas duas hipóteses: $\mathrm{H}_{o} p=q$ contra $\mathrm{H}_{l} p>q$. 
Neste estudo utilizou-se o modelo Poisson, pois é adequado para dados de contagem e é possível a incorporação de covariáveis. Para o modelo em estudo foi computado o raio, cujos valores de $p(z)$ e $q(z)$ maximizam a função de verossimilhança condicionada ao total de casos observados. Calcula-se $z$ como um candidato a conglomerado (LOPÉZ et al., 2006), sendo seu valor dado por: $K N=\max _{z \in Z} \frac{L(z, \hat{p}(z), q(z))}{L_{0}}$,onde zé o conjunto de todos os possíveis candidatos à conglomerados, e $\hat{p}(\mathrm{z})$ e $q(\mathrm{z})$ são as estimativas de $p(z)$ e $q(z) . L_{0}$ é definido como:

$$
L_{0}=\frac{C^{c}(M-C)^{M-C}}{M^{M}}
$$

Em que C é o total de casos observados na região considerada e $M$ a população total sob toda região de estudo. $L(z)$ é definido como:

$$
L(z)=\frac{\exp \left[-p \cdot n_{z}-q\left(M-n_{z}\right)\right]}{C !} p^{C_{z}} q^{C-C_{z}} \prod_{i} C_{i},
$$

Onde $\exp$ representa a função exponencial; $c_{z} \mathrm{e} c_{i}$ são, respectivamente o número de casos no círculo $z$ e no círculo $i$ e $\mathrm{n}_{z}$ é o número de indivíduos em risco no círculo $z$.

A Varredura Scan tem como referência o centróide da região em estudo. Para cada centróide é calculada sua distância em relação a todos os demais. Em seguida, é criado um círculo em cada centróide e o seu raio é aumentado até englobar o próximo centróide. Para cada ponto inserido no círculo $\mathrm{z}$, calculam-se o número de casos $\mathrm{c}_{z}$, e a população $\mathrm{n}_{z}$ dentro do círculo. Obtém-se o valor de $\mathrm{KN}$ para cada $\operatorname{par}\left(c_{z}, \mathrm{n}_{z}\right)$. Ao final, registra-se o maior valor de $\mathrm{KN}$ e foram calculadas as simulações de Monte Carlo para avaliar a significância do teste (GENTLE, 2002).

Na simulação de Monte Carlo são gerados vários conjuntos de dados independentes com o mesmo número de casos que o conjunto original, segundo uma distribuição de probabilidade específica ou determinada. Para cada conjunto é calculada a estatística do teste KN e ordenam-se os valores. Se a estatística gerada para o conjunto original estiver entre os $100 \alpha \%$ valores mais altos das estatísticas dos conjuntos de dados independentes, rejeita-se a hipótese nula ao nível de significância $\alpha$ (GENTLE, 2002). 


\subsubsection{Aspectos Éticos}

O estudo foi desenvolvido de acordo com a Resolução 466/2012 do Conselho Nacional de Saúde (CNS), sendo aprovado pelo Comitê de Ética em Pesquisa da Universidade de São Paulo, e pelo $9^{\circ}$ CRS/SESPA e Secretaria Municipal de Saúde de Santarém, sob o $\mathrm{n}^{\mathrm{o}}$ de parecer 2.490.681 CAAE 57934116.9.0000.5392 (ANEXO 2). 


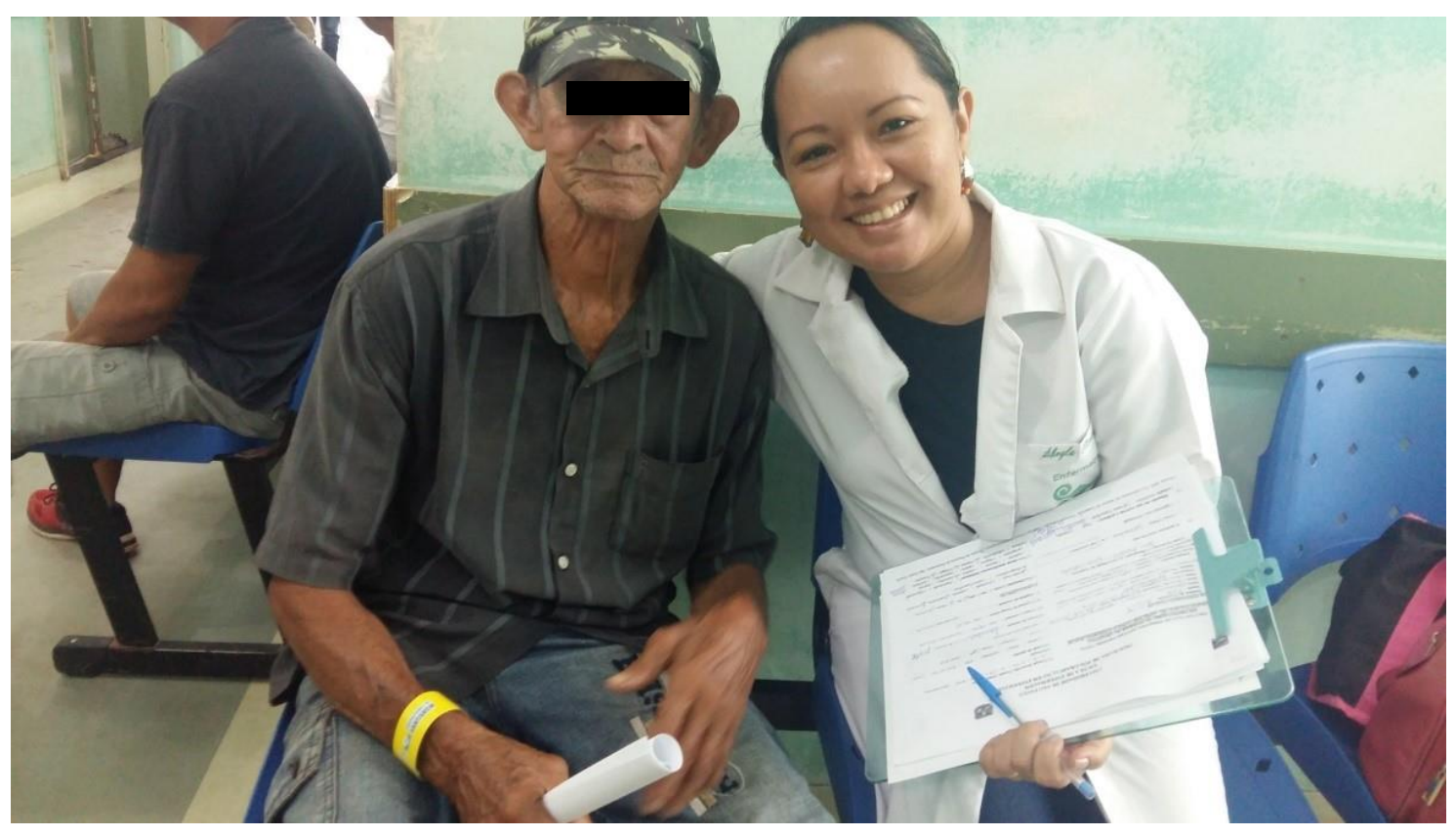

4 RESULTADOS 


\section{RESULTADOS}

\subsection{ETAPA A-ESTUDO RETROSPECTIVO}

No estado do Pará, no período de 2011 a 2015, de acordo com os dados do DATASUS (2016), ocorreram 8.694 notificações de acidentes escorpiônicos. Deste total, 6.997 eram oriundos dos 29 municípios do oeste Paraense.

Tabela 1- Acidentes escorpiônicos notificados. Região Oeste do Pará, 2011 a 2015.

\begin{tabular}{ccc}
\hline Ano da Notificação & $\begin{array}{r}\text { Casos Notificados } \\
\text { (em Números) }\end{array}$ & \% \\
\hline 2011 & 1.339 & 19,0 \\
2012 & 1.328 & 19,0 \\
2013 & 1.414 & 20,0 \\
2014 & 1.470 & 21,0 \\
& & 21,0 \\
\hline 2015 & $\mathbf{6 . 9 9 7}$ & $\mathbf{1 0 0 , 0}$ \\
\hline
\end{tabular}

Fonte: Divisão de endemias/ $9^{\circ} \mathrm{CRS}$ e Coordenação Estadual de Zoonoses - SESPA.

No período, verifica-se média de 1.399,4 casos por ano, apresentando um crescimento de mais de 9,0\% em cinco anos (Tabela 1). 
Tabela 2- Distribuição dos acidentes escorpiônicos notificados no SINAN, segundo município de notificação e população correspondente. Baixo Amazonas e Sudoeste do Pará, 2011 a 2015.

\begin{tabular}{|c|c|c|c|c|}
\hline Município da Notificação & $\begin{array}{r}\text { Casos } \\
\text { (em números) }\end{array}$ & $\%$ & População a & $\begin{array}{c}\text { Taxa de } \\
\text { Incidência por } \\
1.000 \text { habitantes } \\
\text { b }\end{array}$ \\
\hline Alenquer & 69 & 1,0 & 52.626 & 1,3 \\
\hline Almeirim & 400 & 6,0 & 33.614 & 12,0 \\
\hline Altamira & 384 & 5,0 & 99.075 & 4,0 \\
\hline Anapu & 51 & 1,0 & 20.543 & 2,0 \\
\hline Aveiro & 77 & 1,0 & 15.849 & 5,0 \\
\hline Belterra & 307 & 4,0 & 16.318 & 19,0 \\
\hline Brasil Novo & 553 & 8,0 & 15.690 & 35,0 \\
\hline Curuá & 7 & 0,1 & 12.254 & 0,5 \\
\hline Faro & 2 & 0,0 & 8.177 & 0,2 \\
\hline Itaituba & 174 & 2,0 & 97.493 & 2,0 \\
\hline Jacareacanga & 39 & 1,0 & 14.103 & 3,0 \\
\hline Juruti & 97 & 1,0 & 47.086 & 2,0 \\
\hline Medicilândia & 544 & 8,0 & 27.328 & 20,0 \\
\hline Monte Alegre & 319 & 4,0 & 55.462 & 6,0 \\
\hline Novo Progresso & 305 & 4,0 & 25.124 & 12,0 \\
\hline Óbidos & 6 & 0,1 & 49.333 & 0,1 \\
\hline Oriximiná & 14 & 0,2 & 62.794 & 0,2 \\
\hline Pacajá & 26 & 0,4 & 39.979 & 0,6 \\
\hline Placas & 261 & 4,0 & 23.934 & 11,0 \\
\hline Porto de $\mathrm{Moz}$ & 35 & 1,0 & 33.956 & 1,0 \\
\hline Prainha & 518 & 7,0 & 29.349 & 18,0 \\
\hline Rurópolis & 488 & 7,0 & 40.087 & 12,0 \\
\hline Santarém & 884 & 13,0 & 294.580 & 3,0 \\
\hline Senador José Porfírio & 40 & 1,0 & 13.045 & 3,0 \\
\hline Terra Santa & 12 & 0,1 & 16.949 & 0,7 \\
\hline Trairão & 567 & 8,0 & 16.875 & 34,0 \\
\hline Uruará & 768 & 11,0 & 44.789 & 17,0 \\
\hline Vitória do Xingu & 50 & 1,0 & 13.431 & 4,0 \\
\hline Total & 6.997 & 100,0 & 1.219 .843 & 5,7 \\
\hline
\end{tabular}

*a Dados do IBGE 2010, b correspondente a grupos populacionais de 1.000 habitantes

Fonte: Divisão de endemia/ 9 CRS e Coordenação Estadual de Zoonoses - SESPA.

Dado que região estudada possui densidade populacional muito baixa, e dado que a maioria dos municípios possui populações abaixo de 100.000 habitantes, optou-se por apresentar a incidência por 1.000 habitantes. 
A região apresenta uma incidência acumulada de 5,7 casos por 1.000 habitantes. Brasil Novo (35,0/1.000 habitantes), Trairão(34,0/1.000 habitantes) e Prainha (18,0/1.000 habitantes) apresentaram os maiores índices de incidência de casos na região.

A mesoregião do Baixo Amazonas corresponde à 42,0\% dos casos notificados na região oeste paraense. E os municípios de Almeirim, Belterra, Monte Alegre, Placas, Prainha e Santarém foram responsáveis por 92,0\% (2.689) dos acidentes. Observa-se crescimento no número de casos notificados em Alenquer de 25\%, em Curuá de 100\%, em Placas de $80 \%$, em Porto de Moz, de 15\% e em Prainha de 8,0\% (Gráfico1/Tabela 3).

Gráfico 1 - Distribuição dos acidentes escorpiônicos notificados na mesoregião do Baixo Amazonas e Sudoeste do Pará. Período 2011 a 2015.

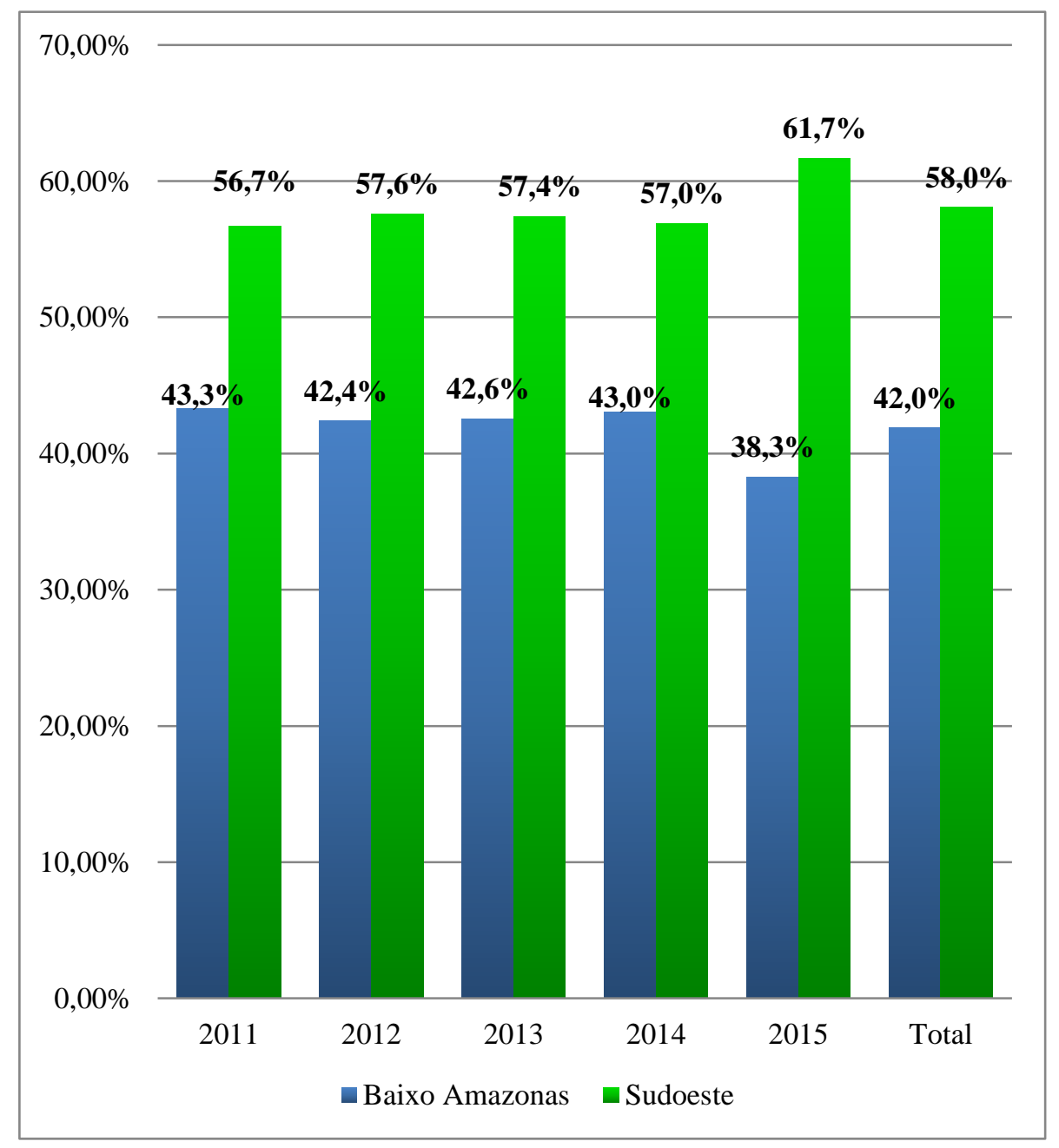

Fonte: Divisão de Endemias/ $9^{\circ}$ CRS e Coordenação Estadual de Zoonoses - SESPA. 
Tabela 3 - Distribuição dos acidentes escorpiônicos ocorridos nos municípios que compõem o Baixo Amazonas. 2011-2015.

\begin{tabular}{|c|c|c|c|c|c|c|c|c|c|c|c|c|}
\hline Município & 2011 & $\%$ & 2012 & $\%$ & 2013 & $\%$ & 2014 & $\%$ & 2015 & $\%$ & Total & $\%$ \\
\hline Alenquer & 16 & 3,0 & 17 & 3,0 & 8 & $\overline{1,0}$ & 8 & 1,3 & 20 & 4,0 & 69 & 2,4 \\
\hline Almeirim & 87 & 15,0 & 83 & 14,8 & 86 & 14,0 & 79 & 13,0 & 65 & 12,0 & 400 & 14,0 \\
\hline Belterra & 68 & 12,0 & 55 & 10,0 & 71 & 12,0 & 64 & 10,0 & 49 & 9,0 & 307 & 10,0 \\
\hline Curuá & 1 & 0,1 & 1 & 0,2 & 1 & 0,2 & 2 & 0,3 & 2 & 0,4 & 7 & 0,2 \\
\hline Faro & 0 & 0,0 & 0 & 0,0 & 0 & 0,0 & 2 & 0,3 & 0 & 0,0 & 2 & 0,1 \\
\hline Juruti & 24 & 4,0 & 17 & 3,0 & 5 & 0,8 & 27 & 4,0 & 24 & 4,0 & 97 & 3,0 \\
\hline $\begin{array}{l}\text { Monte } \\
\text { Alegre }\end{array}$ & 84 & 14,0 & 66 & 12,0 & 80 & 13,0 & 59 & 10,0 & 30 & 5,0 & 319 & 11,0 \\
\hline Óbidos & 0 & 0,0 & 0 & 0,0 & 4 & 0,7 & 0 & 0,0 & 2 & 0,4 & 6 & 0,2 \\
\hline Oriximiná & 0 & 0,0 & 3 & 0,5 & 2 & 0,3 & 5 & 0,8 & 4 & 0,7 & 14 & 0,5 \\
\hline Placas & 35 & 6,0 & 55 & 10,0 & 46 & 8,0 & 62 & 10,0 & 63 & 11,0 & 261 & 9,0 \\
\hline $\begin{array}{l}\text { Porto de } \\
\text { Moz }\end{array}$ & 4 & 0,7 & 5 & 0,9 & 9 & 2,0 & 7 & 1,00 & 10 & 2,0 & 35 & 1,2 \\
\hline Prainha & 90 & 15,5 & 86 & 15,0 & 138 & 23,0 & 107 & 17,0 & 97 & 17,0 & 518 & 18,0 \\
\hline Santarém & 167 & 29,0 & 172 & 30,0 & 152 & 25,0 & 199 & 32,0 & 194 & 34,0 & 884 & 30,0 \\
\hline $\begin{array}{l}\text { Terra } \\
\text { Santa } \\
\end{array}$ & 4 & 0,7 & 3 & 0,5 & 0 & 0,0 & 2 & 0,3 & 3 & 0,5 & 12 & 0,4 \\
\hline TOTAL & 580 & 100,0 & 563 & 100,0 & 602 & 100,0 & 623 & 100,0 & 563 & 100,0 & 2931 & $\overline{100,0}$ \\
\hline
\end{tabular}

Fonte: Divisão de Endemias/ $9^{\circ} \mathrm{CRS}$ e Coordenação Estadual de Zoonoses - SESPA.

Santarém corresponde a 30,0\% dos casos da mesoregião do Baixo Amazonas e 13,0\% da região oeste, sendo o Município com o maior número de notificações, mas também é o que apresenta o maior número de habitantes (Tabelas 2 e 3). Também é importante apontar que os registros de casos do município de Mojuí dos Campos estão incluídos no conjunto do município de Santarém, pois Mojuí era um distrito de Santarém, tendo sido elevado à categoria de Município em 2013, mas ainda não desmembrado no sistema do $9^{\circ} \mathrm{CRS} / \mathrm{SESPA}$ no período em que ocorreu o estudo.

A mesoregião do Sudoeste representa 58,1\% do total, com 4.066 casos, com um importante crescimento de 19,5\% de 2011 a 2015 (Gráfico 1). Os municípios de Uruará (19,0\%), Trairão (14,0\%), Brasil Novo (14,0\%), Medicilândia (13,0\%), Rurópolis (12,0\%), Altamira $(9,0 \%)$ e Novo Progresso $(8,0 \%)$ correspondem a $89,0 \%$ dos casos notificados entre os 14 municípios da mesorregião (Tabela 4). 
Tabela 4 - Distribuição dos acidentes escorpiônicos nos municípios que compõem a região Sudoeste. 2011 2015.

\begin{tabular}{|c|c|c|c|c|c|c|c|c|c|c|c|c|}
\hline Município & 2011 & $\%$ & 2012 & $\%$ & 2013 & $\%$ & 2014 & $\%$ & 2015 & $\%$ & Total & $\%$ \\
\hline Altamira & 69 & 9,0 & 73 & 10,0 & 80 & 10,0 & 57 & 7,0 & 105 & 12,0 & 384 & 9,0 \\
\hline Anapu & 6 & 1,0 & 14 & 2,0 & 7 & 1,0 & 10 & 1,0 & 14 & 2,0 & 51 & 1,0 \\
\hline Aveiro & 20 & 2,6 & 23 & 3,0 & 12 & 1,5 & 15 & 1,0 & 7 & 1,0 & 77 & 2,0 \\
\hline Brasil Novo & 103 & 13,5 & 101 & 13,0 & 92 & 11,0 & 101 & 12,0 & 156 & 17,0 & 553 & 14,0 \\
\hline Itaituba & 16 & 2,0 & 16 & 2,0 & 35 & 4,0 & 23 & 3,0 & 84 & 9,0 & 174 & 4,0 \\
\hline Jacareacanga & 6 & 1,0 & 4 & 0,0 & 0 & 0,0 & 12 & 1,5 & 17 & 2,0 & 39 & 1,0 \\
\hline Medicilândia & 155 & 20,0 & 64 & 8,0 & 90 & 11,0 & 137 & 17,0 & 98 & 11,0 & 544 & 13,0 \\
\hline $\begin{array}{l}\text { Novo } \\
\text { Progresso }\end{array}$ & 44 & 6,0 & 68 & 9,0 & 55 & 7,0 & 62 & 8,0 & 76 & 8,0 & 305 & 8,0 \\
\hline Pacajá & 3 & 0,0 & 8 & 1,0 & 7 & 1,0 & 5 & 1,0 & 3 & 0,0 & 26 & 1,0 \\
\hline Rurópolis & 96 & 13,0 & 112 & 15.0 & 108 & 13,0 & 84 & 10,0 & 88 & 10,0 & 488 & 12,0 \\
\hline $\begin{array}{l}\text { Sen. José } \\
\text { Porfírio }\end{array}$ & 8 & 1,0 & 12 & 2,0 & 4 & 0,5 & 7 & 1,0 & 9 & 1,0 & 40 & 1,0 \\
\hline Trairão & 94 & 12,0 & 114 & 15,0 & 114 & 14,0 & 129 & 16,0 & 116 & 13,0 & 567 & 14,0 \\
\hline Uruará & 134 & 18,0 & 154 & 20,0 & 208 & 26,0 & 169 & 20,0 & 103 & 11,0 & 768 & 19,0 \\
\hline $\begin{array}{l}\text { Vitória do } \\
\text { Xingu }\end{array}$ & 5 & 0,0 & 2 & 0,0 & 0 & 0,0 & 12 & 1,5 & 31 & 3,0 & 50 & 1,0 \\
\hline Total & 759 & 100,0 & 765 & 100,0 & 812 & 100,0 & 823 & 100,0 & 907 & 100,0 & 4066 & 100,0 \\
\hline
\end{tabular}

Fonte: Divisão de Endemia/ $9^{\circ}$ CRS e Coordenação Estadual de Zoonoses - SESPA.

Quanto aos dados coletados junto ao Hospital Municipal de Santarém, relativos ao ano de 2016, verificou-se que foram atendidas 123 pessoas vítimas de acidentes escorpiônicos. O perfil sociodemográfico revelou que, destes, 87 (70,7\%) eram do sexo masculino, e as faixas etárias de 16 a 30 anos, e de 31 a 45 anos representaram 26,8\% (33) cada. As variáveis renda e escolaridade foram registradas como "ignorada"/sem informação na maioria dos casos: (97:79,0\% e 78:63,0\%), respectivamente, seguida de renda de até um salário mínimo $(23: 18,6 \%)$ e ensino fundamental incompleto $(27: 22,0 \%)$ (Tabela 5). 
Tabela 5 - Distribuição dos casos de escorpionismo atendidos no Hospital Municipal de Santarém-PA, segundo variáveis sociodemográficas, 2016.

\begin{tabular}{|c|c|c|}
\hline VARIÁVEIS & $\mathbf{N}^{\mathbf{o}}$ & $\%$ \\
\hline \multicolumn{3}{|l|}{ Sexo } \\
\hline Masculino & 87 & 70,7 \\
\hline Feminino & 35 & 28,5 \\
\hline Ignorado/Sem Informação & 01 & 0,8 \\
\hline \multicolumn{3}{|l|}{ Faixa Etária (em anos) } \\
\hline $0-15$ & 26 & 21,0 \\
\hline $16-30$ & 33 & 27,0 \\
\hline $31-45$ & 33 & 27,0 \\
\hline $46-60$ & 21 & 17,0 \\
\hline 61 ou mais & 09 & 7,0 \\
\hline Ignorado/Sem Informação & 01 & 1,0 \\
\hline \multicolumn{3}{|l|}{ Renda (em salário mínimo) } \\
\hline Sem Renda & 01 & 0,8 \\
\hline Até 1 & 23 & 18,6 \\
\hline 2 a 3 & 01 & 0,8 \\
\hline Não se aplica & 01 & 0,8 \\
\hline Ignorado/Sem Informação & 97 & 79,0 \\
\hline \multicolumn{3}{|l|}{ Escolaridade } \\
\hline Nenhum & 06 & 5,0 \\
\hline $\begin{array}{l}\text { Nível Fundamental } \\
\text { Incompleto }\end{array}$ & 27 & 22,0 \\
\hline Nível Fundamental Completo & 03 & 2,0 \\
\hline Nível Médio Incompleto & 07 & 6,0 \\
\hline Nível Médio Completo & 01 & 1,0 \\
\hline Nível Superior Completo & 01 & 1,0 \\
\hline Ignorado/Sem Informação & 78 & 63,0 \\
\hline Total & 123 & $100 \%$ \\
\hline
\end{tabular}

Fonte: Divisão de Endemias/ $9^{\circ} \mathrm{CRS}$ e Coordenação Estadual de Zoonoses - SESPA.

Conforme pode se verificar na Tabela 6, o município de Santarém foi o local de maior ocorrência dos casos registrados (88:71,0\%), seguido de Mojuí dos Campos com 18,0\% 
(22\%) e Belterra: 5,0\% (6). A maioria dos casos era proveniente da zona rural $(98: 80,0 \%)$, a situação em que ocorreu o acidente constava como ignorada/sem informação, em sua maioria (98:80,0\%), seguida do trabalho com $(15: 12,0 \%)$. O tempo entre a picada e o atendimento também apresentou importante número de casos ignorados/sem informação $(47: 38,0 \%)$, seguido de 4-12 horas (32:26,0\%) (Tabela 6).

Tabela 6 - Casos de escorpionismo segundo variáveis epidemiológicas. Hospital Municipal de Santarém-Pará, 2016.

\begin{tabular}{|c|c|c|}
\hline VARIÁVEIS & $\mathbf{N}^{\mathbf{0}}$ & $\%$ \\
\hline \multicolumn{3}{|l|}{ Município de Ocorrência } \\
\hline Santarém & 88 & 71,0 \\
\hline Mojuí dos Campos & 22 & 18,0 \\
\hline Belterra & 06 & 5,0 \\
\hline Placas & 02 & 2,0 \\
\hline Novo Progresso & 01 & 1,0 \\
\hline Prainha & 01 & 1,0 \\
\hline Ignorado/Sem Informação & 03 & 2,0 \\
\hline \multicolumn{3}{|l|}{ Zona de Ocorrência } \\
\hline Zona Rural & 98 & 80,0 \\
\hline Zona Urbana & 14 & 11,0 \\
\hline Ignorado/Sem Informação & 11 & 9,0 \\
\hline \multicolumn{3}{|l|}{ Situação do Acidente } \\
\hline Trabalho & 15 & 12,0 \\
\hline Lazer & 03 & 2,0 \\
\hline Outra & 07 & 6,0 \\
\hline Ignorado/Sem Informação & 98 & 80,0 \\
\hline \multicolumn{3}{|c|}{$\begin{array}{l}\text { Tempo Picada/Atendimento } \\
\text { (em horas) }\end{array}$} \\
\hline $0-1$ & 09 & 7,0 \\
\hline $2-3$ & 29 & 24,0 \\
\hline $4-12$ & 32 & 26,0 \\
\hline+12 & 06 & 5,0 \\
\hline Ignorado/Sem Informação & 47 & 38,0 \\
\hline Total & 123 & 100,0 \\
\hline
\end{tabular}

Fonte: Divisão de Endemias/ $9^{\circ}$ CRS e Coordenação Estadual de Zoonoses - SESPA.

A maioria dos pacientes denominou o escorpião como lacrau, segundo dados registrados no prontuário $(73: 59,0 \%) ; 107(87,0 \%)$ não souberam informar a cor do animal 
agressor, seguidos daqueles que informaram terem sido agredidos por escorpião preto: 12 (10,0\%), amarelo: $01(1,0 \%)$ e, marrom escuro: 01 (1,0\%). Foi bastante reduzido o número daqueles que não visualizaram o animal: $02(2,0 \%)$. Apenas uma $(1,0 \%)$ vítima trouxe o animal ao serviço de saúde.

Em relação à ocupação das pessoas acometidas, para 68 (55,0\%) o registro constava como ignorada/sem informação. Por outro lado, aproximadamente um quarto $(25,2 \%)$ eram agricultores, seguidos de "outras ocupações" (22:18,0\%) como garimpeiros, motorista, pedreiro, carregador, estudantes (Tabela 7).

Tabela 7 - Distribuição dos casos segundo o tipo de ocupação. Hospital Municipal de Santarém, 2016.

\begin{tabular}{lcr}
\hline VARIÁVEL & $\mathbf{N}^{\mathbf{0}}$ & $\boldsymbol{\%}$ \\
\hline Agricultor & 31 & 25,0 \\
Outras Ocupações & 22 & 18,0 \\
Do lar & 02 & 2,0 \\
Ignorado/sem informação & 68 & 55,0 \\
Total & $\mathbf{1 2 3}$ & $\mathbf{1 0 0 , 0}$ \\
\hline
\end{tabular}

Fonte: Divisão de Endemias/ $9^{\circ} \mathrm{CRS}$ e Coordenação Estadual de Zoonoses - SESPA.

Em relação ao local da picada verificou-se maior ocorrência nos pés (incluindo dedos dos pés): 42 (34,0\%), seguida de mãos (incluindo dedos): 28 (23,0\%), e em outros 13 (cabeça, braço, antebraço, tronco, coxa, nádegas, perna), com 12,0\%. Também é bastante expressivo o número de casos cujo registro no prontuário constava como ignorado/sem informação: 40 $(32,0 \%)$ (Gráfico2).

Gráfico 2 - Distribuição dos casos segundo local da picada. Hospital Municipal de Santarém, 2016.

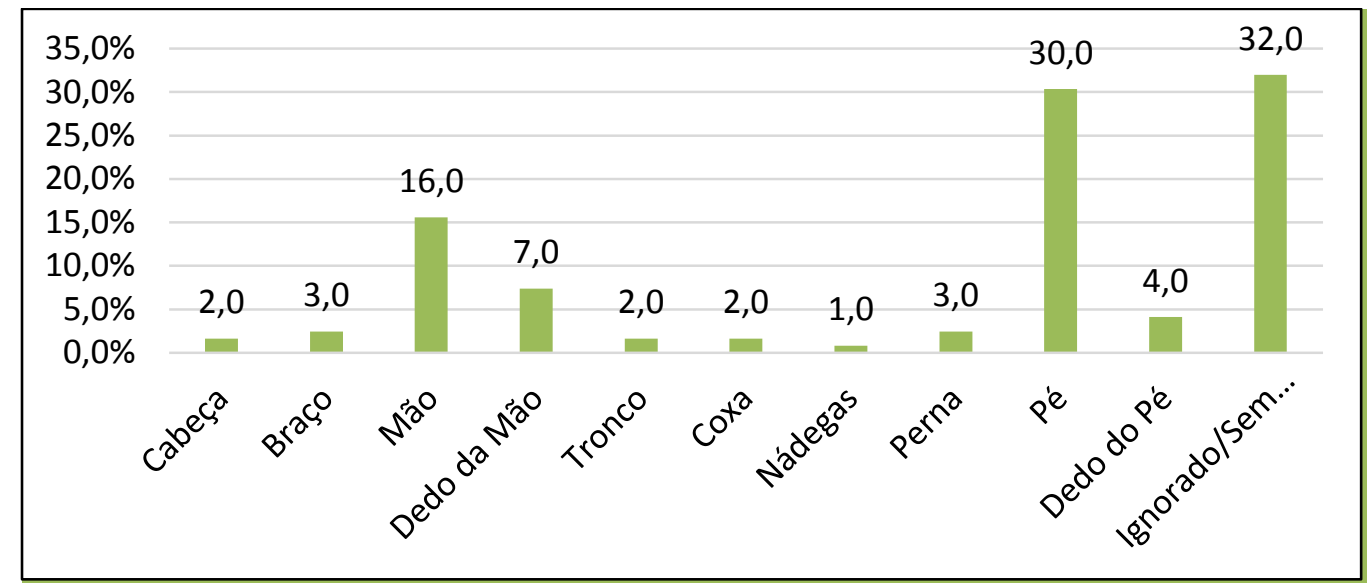

*Valores acima de 100\% configuram pacientes que sofreram mais de uma picada em locais diferentes

Fonte: Divisão de Endemias/ $9^{\circ}$ CRS e Coordenação Estadual de Zoonoses - SESPA.

As manifestações locais apresentadas pelas vítimas de escorpionismo foram: dor (107:87,0\%), parestesia (29: 22,0\%), edema (17: 14,0\%), sensação de choque elétrico (16: 
$12,0 \%)$, eritema $(2: 2,0 \%)$, calor $(2: 2,0 \%)$, sudorese $(2: 2,0 \%)$ e outros $(2: 2,0 \%)$ como o formigamento (Gráfico 3).

Gráfico 3- Manifestações locais apresentadas pelos pacientes. Hospital Municipal de Santarém - Pará, 2016.

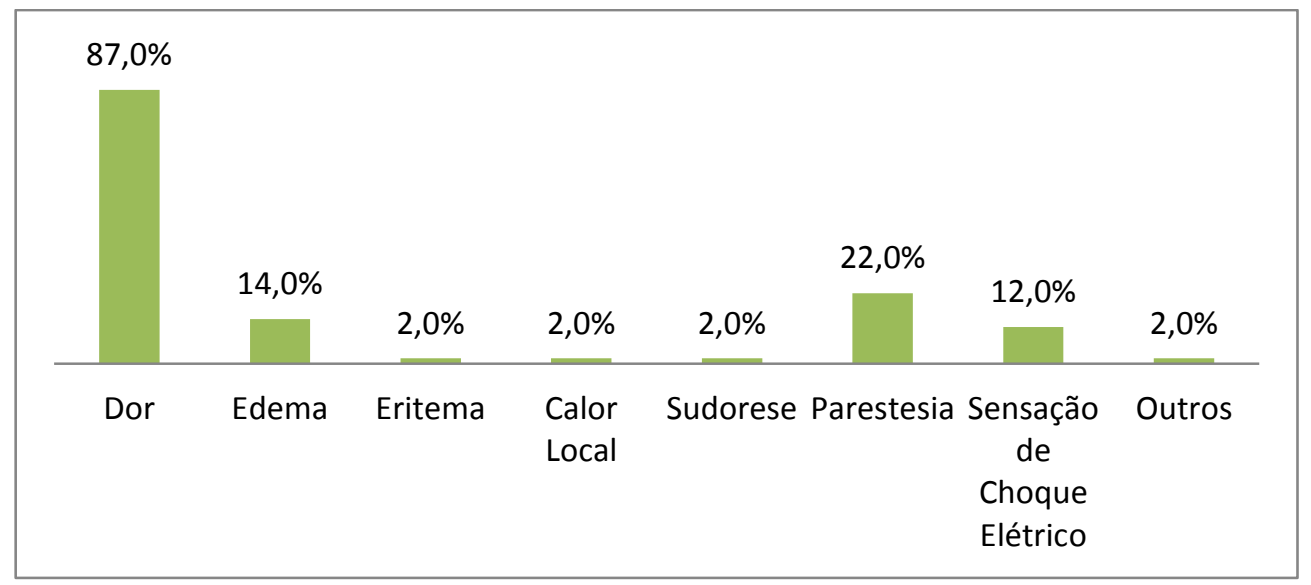

Já as manifestações sistêmicas apresentadas foram: hipertensão arterial (7:5,7\%), sudorese $(1: 0,8 \%)$, náuseas $(4: 3,3 \%)$, vômitos $(5: 4,1 \%)$, sialorréia $(2: 1,6 \%)$, oligúria $(2: 1,6 \%)$, anúria $(2: 1,6 \%)$, bradicardia $(1: 0,8 \%)$, astenia $(10: 8,1 \%)$, disfagia $(1: 0,8 \%)$, tremores (20:16,3\%) e outras (27:22,0\%) (Gráfico 4). Dentre outras manifestações sistêmicas registradas destacam-se a turvação visual, em 15 pacientes, representando 48,0\% desse conjunto (Gráfico 5).

Gráfico 4- Manifestações sistêmicas apresentadas pelos pacientes. Hospital Municipal de Santarém - Pará, 2016.

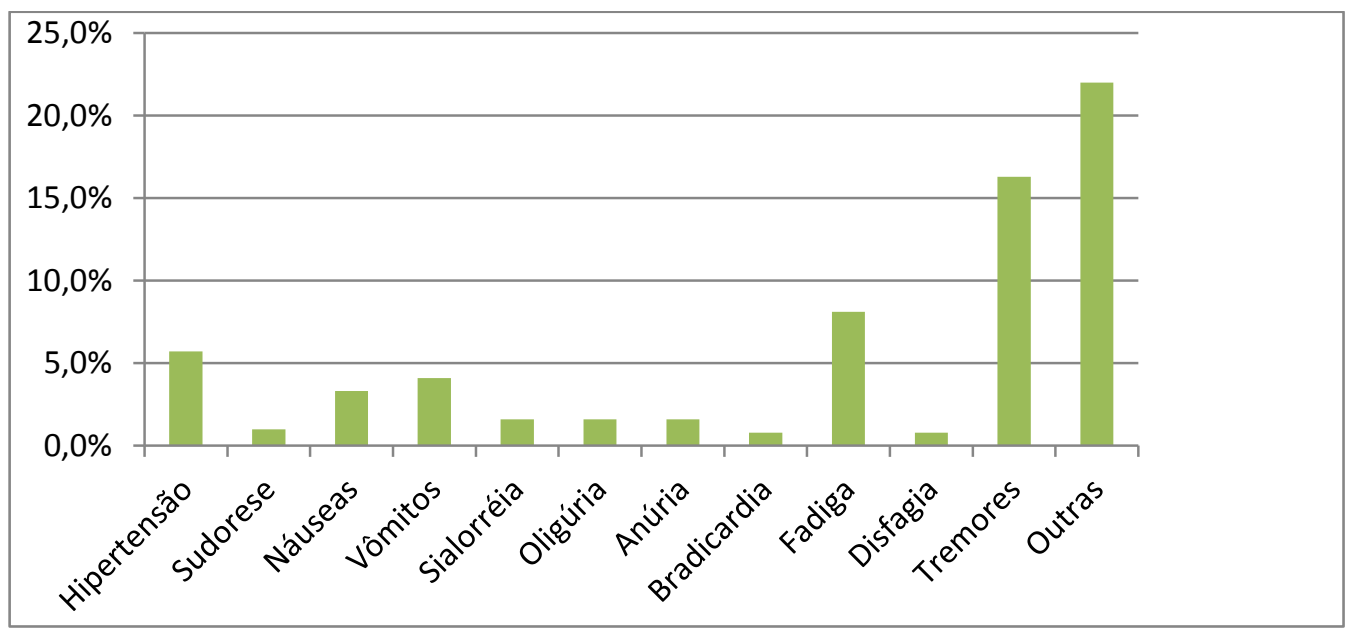


Gráfico 5- Outras manifestações sistêmicas apresentadas pelos pacientes. Hospital Municipal de Santarém Pará, 2016.

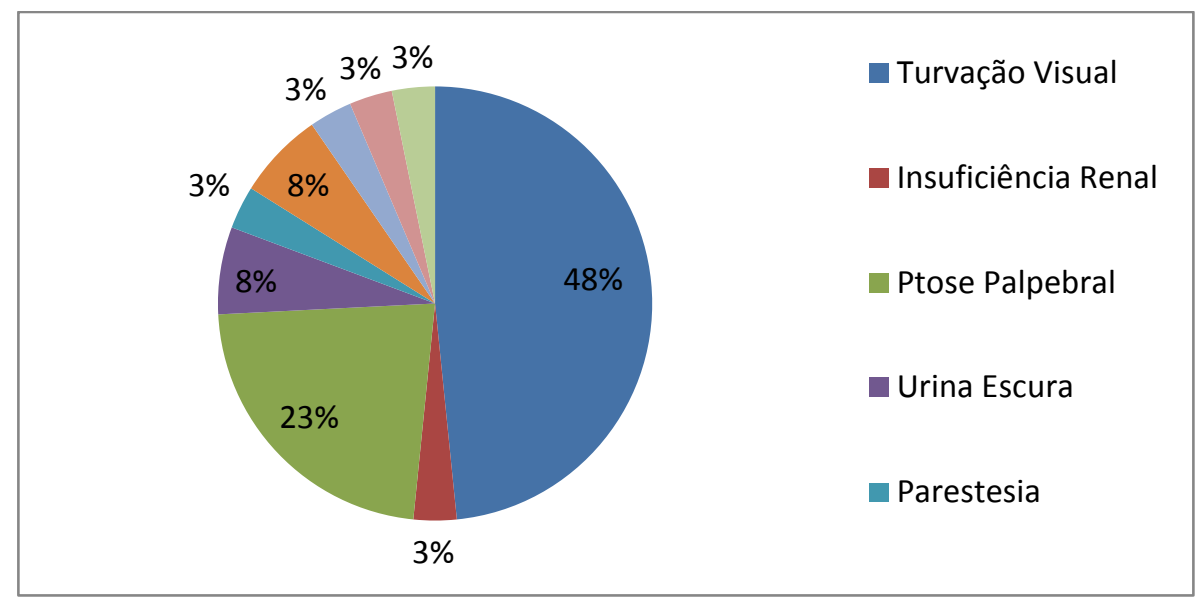

Os acidentes escorpiônicos atendidos no Hospital Municipal de Santarém no ano de 2016 foram classificados como: leves (40: 33,0\%), moderados (48: 39,0\%) e graves (15: 12,0\%), mas não é desprezível o conjunto de ignorados/sem informação: 20 (16,0\%) (Gráfico $6)$.

Gráfico 6- Distribuição dos pacientes segundo classificação do quadro clínico. Hospital Municipal de SantarémPará, 2016.

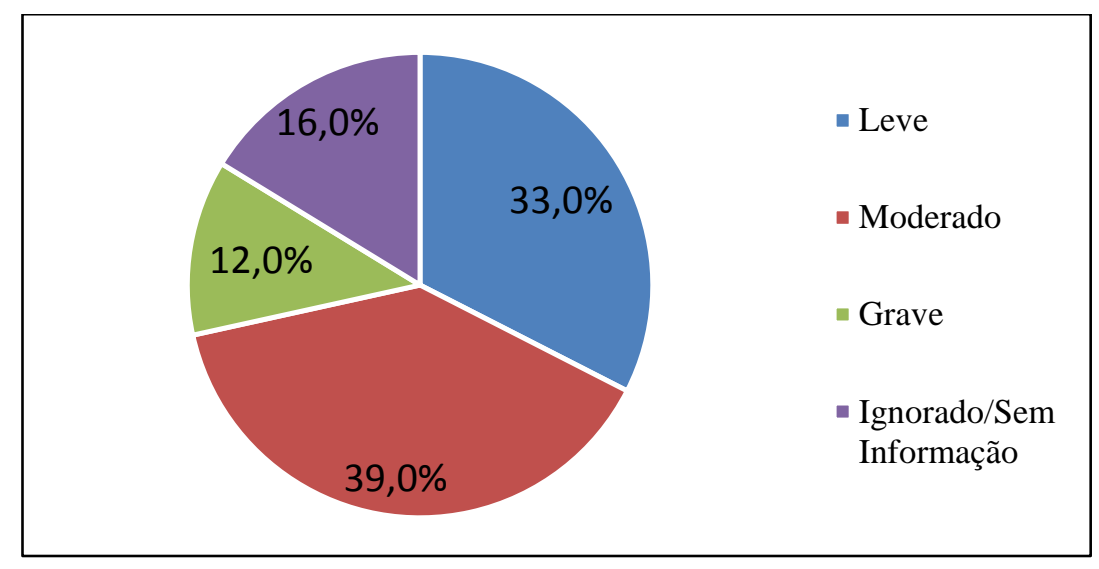

Do total de 123 pacientes, 88 (71,5\%) receberam soroterapia específica, 27 (22,0\%) não receberam e para $08(6,5 \%)$ não havia informação ou constavam como ignorados. Todos os pacientes obtiveram melhora do quadro com alta. Os prontuários não continham dados em relação ao período de tempo em que as pessoas permaneceram hospitalizadas. 


\subsection{ETAPA B- ESTUDO PROSPECTIVO}

Conforme mencionado no Método, na primeira etapa do estudo prospectivo, profissionais de saúde (médicos, enfermeiros e técnicos de enfermagem) foram entrevistados com a finalidade de verificar se conheciam casos de escorpionismo. A amostra contou, em sua maioria, com profissionais de enfermagem, representando $85,0 \%$ do total de profissionais participantes; o tempo de atuação dos profissionais de saúde, em sua maioria, era de mais de 07 anos (40,0\%), e 87,5\% reportaram ter realizado assistência a vítimas de escorpionismo (Tabela 8). É importante destacar que todos os municípios tinham enfermeiras em unidades de saúde.

Tabela 8 - Profissionais atuantes nos 20 municípios pertencentes ao $9^{\circ}$ CRS/SESPA, ano 2017.

\begin{tabular}{|c|c|c|}
\hline MUNICÍPIO & $\mathbf{N}^{\mathbf{o}}$ & $\%$ \\
\hline Alenquer & 06 & 4,0 \\
\hline Almeirim & 07 & 4,4 \\
\hline Aveiro & 07 & 4,4 \\
\hline Belterra & 03 & 2,0 \\
\hline Curuá & 02 & 1,2 \\
\hline Faro & 01 & 0,6 \\
\hline Itaituba & 24 & 15,0 \\
\hline Jacareacanga & 10 & 6.2 \\
\hline Juruti & 09 & 5,6 \\
\hline Mojuí dos Campos & 03 & 2,0 \\
\hline Monte Alegre & 11 & 7,0 \\
\hline Novo Progresso & 13 & 8,0 \\
\hline Óbidos & 10 & 6,2 \\
\hline Oriximiná & 08 & 5.0 \\
\hline Placas & 10 & 6,2 \\
\hline Prainha & 05 & 3,0 \\
\hline Rurópolis & 05 & 3,0 \\
\hline Santarém & 18 & 11,2 \\
\hline Terra Santa & 04 & 2,5 \\
\hline Trairão & 04 & 2,5 \\
\hline Total & 160 & 100,0 \\
\hline
\end{tabular}


Tabela 8 - Profissionais atuantes nos 20 municípios pertencentes ao $9^{\circ} \mathrm{CRS} / \mathrm{SESPA}$, Ano 2017

(continuação)

\begin{tabular}{|c|c|c|}
\hline PROFISSÃO & $\mathbf{N}^{\circ}$ & $\%$ \\
\hline Técnico de Enfermagem & 64 & 40,0 \\
\hline Enfermeiro(a) & 72 & 45,0 \\
\hline Médico(a) & 24 & 15,0 \\
\hline Total & 160 & 100,0 \\
\hline TEMPO DE ATUAÇÃO & $\mathbf{N}^{\circ}$ & $\%$ \\
\hline$>1$ ano & 19 & 12,0 \\
\hline 1 a 3 anos & 43 & 27,0 \\
\hline 4 a 6 anos & 34 & 21,0 \\
\hline+7 anos & 64 & 40,0 \\
\hline Total & 160 & 100,0 \\
\hline $\begin{array}{l}\text { ATENDEU CASOS DE } \\
\text { ESCORPIONISMO }\end{array}$ & $\mathbf{N}^{\mathbf{o}}$ & $\%$ \\
\hline Sim & 140 & 87,5 \\
\hline Não & 20 & 12,5 \\
\hline Total & 160 & 100,0 \\
\hline
\end{tabular}

Fonte: Divisão de Endemias/ $9^{\circ}$ CRS e Coordenação Estadual de Zoonoses - SESPA.

Os profissionais de saúde descreveram o quadro clínico apresentado pelas vítimas de escorpionismo com manifestações neurológicas e musculares, conforme discrimina o Quadro 1 a seguir:

Quadro 1 - Caracterização do quadro clínico apresentado pelas vítimas de acidentes escorpiônicos segundo relato dos profissionais de saúde atuantes nos municípios pertencentes ao $9^{\circ} \mathrm{CRS} / \mathrm{SESPA}, 2017$.

\begin{tabular}{|c|c|}
\hline MUNICÍPIO & QUADRO CLÍNICO VERBALIZADO PELOS PROFISSIONAIS \\
\hline ALENQUER & Dor e dormência no local da picada. \\
\hline ALMEIRIM & $\begin{array}{l}\text { Dor local intensa e no membro afetado, quadro de desorientação, confusão } \\
\text { mental, espasmos musculares, sialorréia, dispneia, taquicardia e } \\
\text { hiperemia/rubor no local da picada do escorpião, dificuldade para } \\
\text { deambular, fortes dores musculares, palidez, sudorese, náuseas, vômitos, } \\
\text { agitação psicomotora, disartria, visão turva, sensibilidade a ruídos, } \\
\text { claridade e ao toque, contraturas no corpo, dor no ouvido, hipertemia, } \\
\text { "*convulsão", cefaléia, frio, sensibilidade de não poder tocar, "*atrofia dos } \\
\text { dedos" das mãos, dificuldade para urinar. Alguns profissionais } \\
\text { mencionaram que alguns pacientes não apresentaram quaisquer sintomas. }\end{array}$ \\
\hline AVEIRO & $\begin{array}{l}\text { Algia local, edema local, sensação de choque elétrico, dificuldade de } \\
\text { verbalizar, dificuldade de deambular, visão turva, cefaléia, eritema local, } \\
\text { sudorese, agitação, hipertensão arterial, parestesia local, vômitos, tonturas, } \\
\text { contraturas musculares, "*quadro alérgico". }\end{array}$ \\
\hline BELTERRA & $\begin{array}{l}\text { Dor local, edema, sensação de choque elétrico, hipertensão arterial, } \\
\text { taquicardia, sudorese intensa, dispneia, disartria, ataxia de marcha, } \\
\text { confusão mental, espasmos musculares. Em caso mais grave, paciente } \\
\text { referia sede e apresentou distúrbios neurológicos. }\end{array}$ \\
\hline
\end{tabular}

\footnotetext{
* Convulsão; Quadro alérgico: Não documentados na literatura científica.

* Atrofia dos dedos: Provavelmente refere-se à ocorrência de contraturas musculares.
} 
Quadro 1 - Caracterização do quadro clínico apresentado pelas vítimas de acidentes escorpiônicos segundo informações dos profissionais de saúde atuantes nos municípios pertencentes ao 9² CRS/SESPA, ano 2017.

(continuação)

\begin{tabular}{|c|c|}
\hline CURUÁ & $\begin{array}{l}\text { Taquicardia, oscilação entre hiper e hipotensão, espasmos musculares, } \\
\text { visão turva, vômitos, frequentemente sangramentos ("*hematêmese"). } \\
\text { Paciente referindo dores intensas na musculatura, descrevendo sensação } \\
\text { de choque elétrico, gemente às contrações musculares. }\end{array}$ \\
\hline FARO & Dor, edema e eritema local. \\
\hline ITAITUBA & $\begin{array}{l}\text { Dor intensa no local da picada, parestesia, eritema local, edema, } \\
\text { náuseas, vômitos, sialorréia,agitação, espasmos musculares, mioclonias, } \\
\text { pele fria,sudorese, hipertemia,hipertensão arterial, "*confusão mental", } \\
\text { sensação de choque elétrico pelo corpo principalmente ao toque, } \\
\text { dislalia,dificuldade para deambular, nistagmo, , oligúria,anúria, } \\
\text { desorientação,empastamento de língua, voz arrastada. }\end{array}$ \\
\hline JACAREACANGA & $\begin{array}{l}\text { Algia, edema e eritema no local da picada, espasmos musculares ao toque } \\
\text { ou ruídos elevados, hipertensão arterial, hipertemia em alguns } \\
\text { casos,náuseas, vômitos, dificuldade para verbalizar e deambular, sudorese, } \\
\text { sonolência e alucinações em alguns casos; sensibilidade ao toque, } \\
\text { relatando a sensação de choque elétrico intenso pelo corpo, reação tônico- } \\
\text { clônica. }\end{array}$ \\
\hline JURUTI & $\begin{array}{l}\text { dor moderada a intensa no local da picada, hiperemia e edema locais, } \\
\text { parestesia facial e em membro afetado e, em outros casos, por todo o } \\
\text { corpo, ansiedade, agitação e mioclonias, formigamento pelo corpo e, em } \\
\text { alguns casos, apenas no membro afetado, náuseas, vômitos, sialorréia } \\
\text { intensa, espasmos musculares, hemiplegia temporária, "*edema de glote", } \\
\text { desconforto respiratório, parestesia, dislalia, "*confusão mental", } \\
\text { sensação de choque elétrico pelo corpo, sendo bastante intenso ao toque. }\end{array}$ \\
\hline MOJUÍ DOS CAMPOS & $\begin{array}{l}\text { dor e edema localizado, reação de hipersensibilidade, cefaléia, náuseas, } \\
\text { sensação de choque elétrico. }\end{array}$ \\
\hline MONTE ALEGRE & $\begin{array}{l}\text { dor intensa, dificuldade para falar, dificuldade visual, sensação de choque } \\
\text { elétrico, edema, eritema e dormência local, "*convulsão", alteração no } \\
\text { nível de consciência (*desorientado), "*confusão mental", espasmos } \\
\text { musculares, parestesia, bradicardia, dificuldade para falar e engolir, } \\
\text { alteração renal, agitação, sonolência. }\end{array}$ \\
\hline NOVO PROGRESSO & $\begin{array}{l}\text { Dor intensa, edema e eritema local, êmese, sudorese, taquicardia, náuseas, } \\
\text { agitação, dificuldade para falar e movimentar, espasmos musculares, } \\
\text { mioclonias,"*desorientação", "*confusão mental", hipertensão arterial } \\
\text { sistêmica, dislalia, disfagia, disúria, sensação de choque elétrico local e } \\
\text { sistêmico, descargas elétricas recorrentes ao se movimentar, anúria, urina } \\
\text { escura (cor de café). }\end{array}$ \\
\hline
\end{tabular}

\footnotetext{
* Hematêmese/ Convulsão/ Confusão Mental; Desorientação: Não documentado nos casos de escorpionismo na literatura científica.

* Edema de glote: Não documentado na literatura científica. A expressão verbalizada pode estar relacionada à interpretação do paciente "não poder falar".
} 
Quadro 1 - Caracterização do quadro clínico apresentado pelas vítimas de acidentes escorpiônicos segundo informações dos profissionais de saúde atuantes nos municípios pertencentes ao $9^{\circ} \mathrm{CRS} / \mathrm{SESPA}$, ano 2017.

(continuação)

\begin{tabular}{|c|c|}
\hline ÓBIDOS & $\begin{array}{l}\text { Dor local de moderada a intensa, edema e eritema no local da picada, } \\
\text { sudorese, sonolência, "*confusão mental", náuseas, vômitos, } \\
\text { formigamento, espasmos musculares, mioclonias, fasciculação, disartria, } \\
\text { dificuldade para deambular ("andando como se estivesse bêbado"), } \\
\text { aparência de embriaguez apresentando desequilíbrio, discreta taquicardia, } \\
\text { hipertensão arterial sistêmica, agitação. }\end{array}$ \\
\hline ORIXIMINÁ & $\begin{array}{l}\text { Dor local, mialgia, artralgia, calafrios, sensação de choques elétricos pelo } \\
\text { corpo e no membro afetado, vômitos, cefaléia ocasional, eritema local, } \\
\text { edema discreto, sudorese fria, espasmos, alterações no eletrocardiograma, } \\
\text { calafrios. Em alguns casos paciente referia picada seca. }\end{array}$ \\
\hline PLACAS & $\begin{array}{l}\text { Dor local, dormência, formigamento, edema e eritema no local da picada, } \\
\text { sensação de choque elétrico pelo corpo de discreto a intenso, vômitos, } \\
\text { febre, cefaléia, mioclonias, visão turva, dislalia, sensação de língua } \\
\text { pesada, dificuldade para deambular, retenção urinária, anúria, urina } \\
\text { escura, dispneia, "atrofia dos nervos", sudorese intensa. }\end{array}$ \\
\hline PRAINHA & $\begin{array}{l}\text { Dor intensa no local da picada, contraturas musculares, sensação de } \\
\text { choque elétrico pelo corpo, vômitos, turvação visual, anúria, hipertensão } \\
\text { arterial, sialorréia, palavras desconexas, inquietação e piora no quadro } \\
\text { clínico em presença de ruído. }\end{array}$ \\
\hline RURÓPOLIS & $\begin{array}{l}\text { Dor local de moderada a intensa, parestesia, mioclonias, sensação de } \\
\text { choque elétrico pelo corpo, disartria, dismetria, ataxia de marcha, } \\
\text { sintomas urinários como oligúria e até mesmo anúria, dispnéia, } \\
\text { taquicardia, "*edema de glote", hipotensão arterial. }\end{array}$ \\
\hline SANTARÉM & $\begin{array}{l}\text { Dor local de leve a intensa; edema e eritema local, sudorese, mal estar } \\
\text { geral, agitação psicomotora, náuseas, vômitos, sensação de choque } \\
\text { elétrico pelo corpo, parestesia, espasmos musculares; } \\
\text { mioclonias,mialgias,sialorréa; disfagia,disartria, confusão mental, } \\
\text { taquicardia, hipertemia, anúria. Alterações importantes como taquipnéia e } \\
\text { dispneia. Apresentam sintoma cerebelar como disdiadococinesia e } \\
\text { marcha atáxica. }\end{array}$ \\
\hline TERRA SANTA & $\begin{array}{l}\text { Dor intensa no local da picada, edema e eritema no local da picada, } \\
\text { parestesia, dificuldade em movimentar as falanges. }\end{array}$ \\
\hline TRAIRÃO & $\begin{array}{l}\text { Dor intensa, edema e eritema no local da picada, sensação de choque } \\
\text { elétrico, sudorese, náuseas, vômitos, sialorréia, agitação, taquipnéia, } \\
\text { taquicardia, espasmos musculares, visão turva, dificuldade em } \\
\text { movimentar as falanges. }\end{array}$ \\
\hline
\end{tabular}

(conclusão)

*Confusão Mental; Desorientação: Não documentado nos casos de escorpionismo na literatura científica.

* Edema de glote: Não documentado na literatura científica. A expressão verbalizada pode estar relacionada à interpretação do paciente "não poder falar".

Há que se ter precaução na interpretação desses achados, uma vez que foram extraídos de prontuários e podem não ser compatíveis ao quadro clássico do escorpionismo.

Para o estudo prospectivo, os dados foram coletados no período de março a setembro de 2017, tendo sido acompanhadas 259 vítimas de acidentes escorpiônicos em 18 municípios pertencentes ao $9^{\circ} \mathrm{CRS} / \mathrm{SESPA}$ nos diversos serviços de saúde. Na Tabela 9 podem ser 
verificados os acidentes escorpiônicos por município. O município com maior registro de picadas foi Rurópolis, com um total de 73 indivíduos (28,2\%), seguido por Santarém, com 50 pacientes $(19,3 \%)$. Esses dois municípios se destacam quando comparados aos demais, pois a terceira cidade com maior registro de picadas, Trairão, apresentou 22 ocorrências $(8,5 \%)$, ou seja, quase 2 vezes menos registros que o município de Santarém. O município com menor número de ocorrências foi Terra Santa, com apenas 1 registro $(0,4 \%)$, seguido por: Alenquer, Óbidos e Oriximiná, com 2 casos ( $0,8 \%$, respectivamente) acompanhados em cada um deles. Apenas os municípios de Curuá e Faro não registraram acidentes causados por escorpiões no período de estudo.

Tabela 9 - Ocorrência de acidentes segundo municípios pertencentes à 9CRS/SESPA, 2017.

\begin{tabular}{lcc}
\multicolumn{1}{c}{ MUNICÍPIO } & $\mathbf{N}^{\mathbf{0}}$ & $\mathbf{\%}$ \\
Alenquer & 02 & 0,8 \\
Almeirim & 04 & 1,5 \\
Aveiro & 05 & 2,0 \\
Belterra & 08 & 3,0 \\
Itaituba & 06 & 2,3 \\
Jacareacanga & 08 & 3,0 \\
Juruti & 06 & 2,3 \\
Mojuí dos Campos & 15 & 5,8 \\
Monte Alegre & 07 & 2,7 \\
Novo Progresso & 18 & 7,0 \\
Óbidos & 02 & 0,8 \\
Oriximiná & 02 & 0,8 \\
Placas & 19 & 7,3 \\
Prainha & 11 & 4,2 \\
Rurópolis & $\mathbf{7 3}$ & $\mathbf{2 8 , 2}$ \\
Santarém & $\mathbf{5 0}$ & $\mathbf{1 9 , 3}$ \\
Terra Santa & 01 & 0,4 \\
Trairão & 22 & 8,5 \\
TOTAL & $\mathbf{2 5 9}$ & $\mathbf{1 0 0 , 0}$ \\
\hline
\end{tabular}

Fonte: Divisão de Endemias/ $9^{\circ}$ CRS e Coordenação Estadual de Zoonoses - SESPA.

A maioria dos indivíduos encontrava-se na faixa etária entre 16-30 anos (76: 29,0\%), era do sexo masculino (179: 69,0\%), e agricultores (88: 34,0\%). Em “demais ocupações" (96: $37,0 \%$ ) compreendendo estudantes, motoristas, garimpeiros, pedreiros, serviços gerais, caseiro. A maior parcela tinha renda de até um salário mínimo (158: 61,0\%), e ensino fundamental incompleto (149: 58,0\%). A zona rural foi a área de maior ocorrência dos casos, com 203 (78,0\%), sendo o maior número de ocorrências no trabalho (109: 42,0\%), seguido de 
"outras situações" (73: 28,0\%), como na parte externa do domicílio, estrada, dentre outras. Prevaleceu o intervalo de tempo entre a picada e o atendimento entre 1-3 horas (94: 36,3\%), seguido de 4 a 12 horas (86: 33,2\%).

Tabela 10 - Perfil epidemiológico dos pacientes acompanhados em municípios pertencentes ao $9^{\circ} \mathrm{CRS} / \mathrm{SESPA}$, 2017.

\begin{tabular}{|c|c|c|}
\hline VARÍAVEIS & $\mathbf{N}^{\mathbf{0}}$ & $\%$ \\
\hline \multicolumn{3}{|l|}{ IDADE (em anos) } \\
\hline $0-15$ & 49 & 19,0 \\
\hline $16-30$ & 76 & 29,0 \\
\hline $31-45$ & 63 & 24,0 \\
\hline $46-60$ & 46 & 18,0 \\
\hline 61 ou mais & 25 & 10,0 \\
\hline Total & 259 & 100 \\
\hline \multicolumn{3}{|l|}{ SEXO } \\
\hline $\mathbf{M}$ & 179 & 69,0 \\
\hline $\mathrm{F}$ & 80 & 31,0 \\
\hline Total & 259 & 100 \\
\hline \multicolumn{3}{|l|}{ OCUPAÇÃO } \\
\hline Agricultor & 88 & 34,0 \\
\hline Do lar & 29 & 11,0 \\
\hline Demais ocupações & 96 & 37,0 \\
\hline Não se aplica & 35 & 14,0 \\
\hline Desempregado(a) & 11 & 4,0 \\
\hline Total & 259 & 100 \\
\hline \multicolumn{3}{|l|}{$\begin{array}{c}\text { RENDA(em salários } \\
\text { mínimos) }\end{array}$} \\
\hline Sem Renda & 32 & 12,4 \\
\hline Até 1 salário & 158 & 61,0 \\
\hline 2 a 3 salários & 14 & 5,4 \\
\hline
\end{tabular}


Tabela 10- Perfil epidemiológico dos pacientes acompanhados em municípios pertencentes ao $9^{\circ} \mathrm{CRS} / \mathrm{SESPA}$, 2017.

(continuação)

3 ou mais

Não se aplica
01

54

259

19

149

10

39

21

02

03

Superior Completo

Não se aplica

Total

Total
ZONA DE OCORRÊNCIA
DO ACIDENTE

Zona Rural

56

259

Total

SITUAÇÃO DE

OCORRÊNCIA DO

ACIDENTE

Trabalho

109

73

43

34

No domicílio (afazeres

domésticos)

Outra
Lazer
icílio (afazeres
mésticos)

0,4

$20,8 \%$

100

7,0

58,0

4,0

15,0

8,0

1,0

1,0

6,0

100

59100

100

78,0

22,0 
Tabela 10- Perfil epidemiológico dos pacientes acompanhados em municípios pertencentes ao $9^{\circ} \mathrm{CRS} / \mathrm{SESPA}$, 2017.

(continuação)

TEMPO ENTRE A PICADA-

ATENDIMENTO (em horas)

\begin{tabular}{ccc}
\hline$<1$ & 61 & 23,6 \\
$\mathbf{1 - 3 h}$ & $\mathbf{9 4}$ & $\mathbf{3 6 , 3}$ \\
$4-12 \mathrm{~h}$ & 86 & 33,2 \\
12 ou mais horas & 18 & 6,9 \\
\hline Total & $\mathbf{2 5 9}$ & $\mathbf{1 0 0}$ \\
\hline
\end{tabular}

(conclusão)

Ao observar a Tabela 11, o teste do Qui-Quadrado resultou em um valor de $\mathrm{p}$ de 0,00001038, que é significativo para a idade.

Tabela 11 - Teste qui-quadrado para Faixa Etária, Sexo e Escolaridade.

\begin{tabular}{|c|c|c|c|c|c|c|c|c|}
\hline $\begin{array}{c}\text { FAIXA } \\
\text { ETÁRIA }\end{array}$ & \multicolumn{2}{|c|}{$0 \mid--15$} & \multicolumn{2}{|c|}{$15 \mid--30$} & \multicolumn{2}{|c|}{$30 \mid--45$} & $\begin{array}{c}60 \text { ou } \\
\text { mais }\end{array}$ & $\begin{array}{c}\mathrm{X}^{2} \\
\text { (p-valor) }\end{array}$ \\
\hline $\mathrm{n}$ & & 9 & 7 & 6 & 63 & 46 & 25 & $\begin{array}{c}28.394 \\
\left(1.038 \times 10^{-}\right. \\
5)\end{array}$ \\
\hline SEXO & \multicolumn{4}{|c|}{ MASCULINO } & \multicolumn{3}{|c|}{ FEMININO } & $\begin{array}{c}\mathrm{X}^{2} \\
\text { (p-valor) }\end{array}$ \\
\hline $\mathrm{n}$ & \multicolumn{4}{|c|}{179} & \multicolumn{3}{|c|}{80} & $\begin{array}{c}37.842 \\
\left(7.672 \times 10^{-}\right.\end{array}$ \\
\hline ESCOLARIDADE & Nenhum & $\begin{array}{c}\text { Fundam. } \\
\text { Incom }\end{array}$ & $\begin{array}{l}\text { Fundam. } \\
\text { Comp. }\end{array}$ & $\begin{array}{l}\text { Medio } \\
\text { Incom. }\end{array}$ & $\begin{array}{l}\text { Medio } \\
\text { Comp. }\end{array}$ & $\begin{array}{l}\text { Superior } \\
\text { Incomp. }\end{array}$ & $\begin{array}{c}\text { Superior } \\
\text { Comp. }\end{array}$ & $\begin{array}{c}\mathrm{X}^{2} \\
\text { (p-valor) }\end{array}$ \\
\hline $\mathrm{n}$ & 19 & 149 & 10 & 39 & 21 & 2 & 3 & $\begin{array}{c}466.71 \\
\left(2.2 \times 10^{-16}\right)\end{array}$ \\
\hline
\end{tabular}


$\mathrm{Na}$ Tabela 12, é possível verificar o teste Qui-Quadrado, primeiramente em relação à faixa etária e sexo, em que o valor do qui-quadrado obtido foi de 10,461, resultando em um valor de p de 0,033, que é menor que o nível de significância adotado de 5\%, ou seja, diante dos pacientes do sexo masculino e feminino, existe diferença entre as faixas etárias por sexo. No caso da escolaridade, o valor do qui-quadrado foi de 8,7435, resultando em um valor de $\mathrm{p}$ de 0,1885 , maior que $5 \%$ do nível de significância, ou seja, neste caso, não se verificou diferença significativa.

Tabela 12 - Teste qui-quadrado para Faixa Etária e Escolaridade segundo sexo. $9^{\circ} \mathrm{CRS} / \mathrm{SESPA}, 2017$.

\begin{tabular}{|c|c|c|c|}
\hline \multirow{2}{*}{ Faixa Etária } & \multicolumn{2}{|c|}{ Sexo } & \multirow{2}{*}{$\begin{array}{c}\mathrm{X}^{2} \\
\text { (p-valor) }\end{array}$} \\
\hline & Feminino & Masculino & \\
\hline $0 \mid--15$ & 23 & 26 & \multirow{5}{*}{$\begin{array}{c}10,461 \\
(0,0333)\end{array}$} \\
\hline $15 \mid--30$ & 26 & 50 & \\
\hline $30 \mid--45$ & 13 & 50 & \\
\hline $45 \mid--60$ & 12 & 34 & \\
\hline 60 ou mais & 6 & 19 & \\
\hline \multicolumn{4}{|l|}{ Escolaridade } \\
\hline Nenhum & 3 & 16 & \multirow{7}{*}{$\begin{array}{c}8,7435 \\
(0,1885)\end{array}$} \\
\hline $\begin{array}{l}\text { Fundam. } \\
\text { Incomp. }\end{array}$ & 43 & 106 & \\
\hline $\begin{array}{l}\text { Fundam. } \\
\text { Comp. }\end{array}$ & 3 & 7 & \\
\hline $\begin{array}{l}\text { Medio } \\
\text { Incom. }\end{array}$ & 16 & 23 & \\
\hline $\begin{array}{l}\text { Médio } \\
\text { Comp. }\end{array}$ & 7 & 14 & \\
\hline $\begin{array}{l}\text { Superior } \\
\text { Incomp. }\end{array}$ & 2 & 0 & \\
\hline $\begin{array}{l}\text { Superior } \\
\text { Comp. }\end{array}$ & 1 & 2 & \\
\hline
\end{tabular}


No gráfico 7 é possível verificar os locais da picada que apresentaram maior freqüencia: mãos (134: 52,0\%), pés (69: 27,0\%), membros inferiores (9,0\%), membros superiores $(7,0 \%)$, e outros, com menor expressão: cabeça $(2,0 \%)$, tronco $(2,0 \%)$ e nádegas $(1,0 \%)$

Gráfico 7- Manifestações locais apresentadas pelos pacientes. 9² CRS/SESPA, 2017.

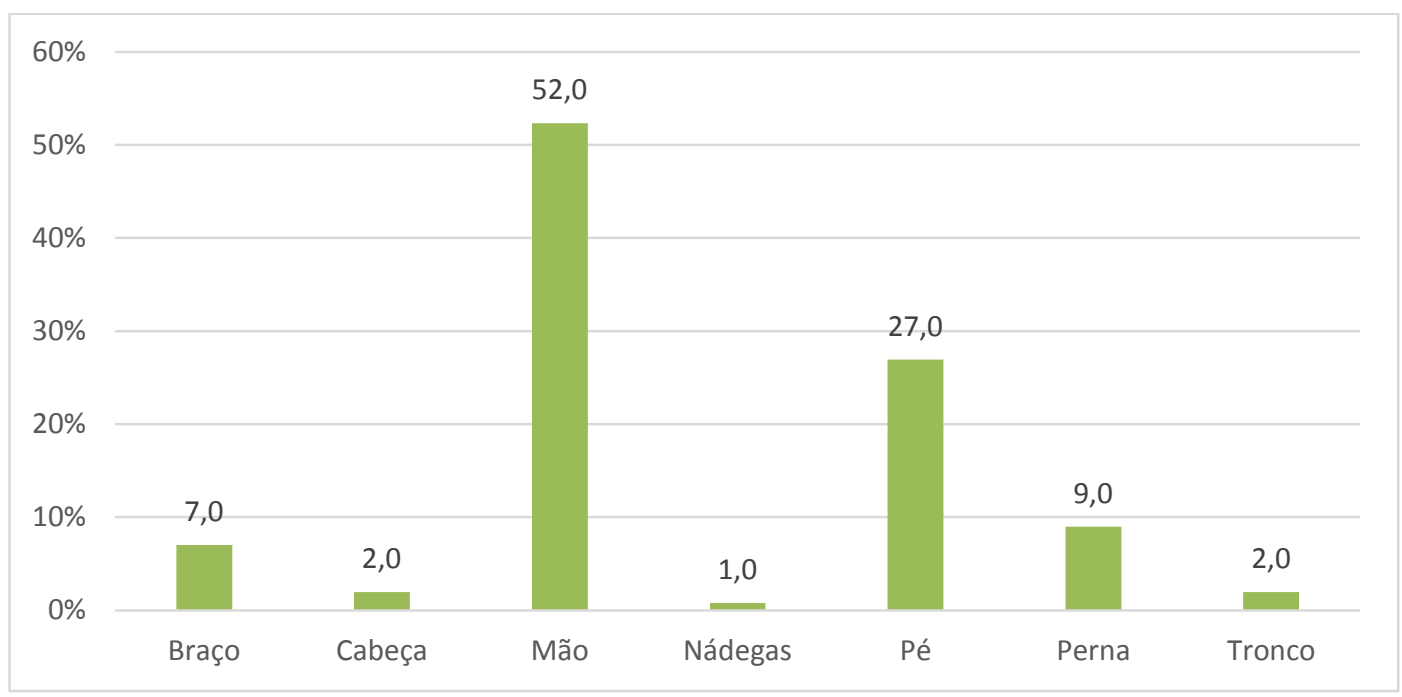

A maioria das vítimas de escorpião (143: 55,0\%), nos municípios pertencentes ao $9^{\circ}$ CRS/SESPA, reconhecem o escorpião "preto" como o animal causador da maior parte dos acidentes na região. Destaca-se que apenas $13(5,0 \%)$ trouxeram o animal ao serviço de saúde (Tabela 13). 
Tabela 13 - Características do escorpião causador dos acidentes nos municípios pertencentes ao $9^{\circ} \mathrm{CRS} / \mathrm{SESPA}$, 2017.

\begin{tabular}{ccc}
\hline VARIÁVEIS & N & \% \\
Nome do Animal & 194 & 64 \\
Escorpião & 165 & 36 \\
Lacrau & $\mathbf{2 5 9}$ & $\mathbf{1 0 0}$ \\
\hline Total & & \\
Cor & 25 & 10 \\
Amarelo & 02 & 01 \\
Amarelo e Preto & 10 & 04 \\
Marrom & 01 & 0 \\
Marrom Amarelado & 07 & 03 \\
Marrom Avermelhado & 02 & 01 \\
Marrom Escuro & 01 & 0 \\
Marrom e Preto & 66 & 25 \\
Não visualizou & 143 & 55 \\
Preto & 02 & 01 \\
Vermelho & $\mathbf{2 5 9}$ & $\mathbf{1 0 0}$ \\
\hline Total & & 95,0 \\
\hline Trouxe o Animal & 245 & 5,0 \\
\hline Não & 13 & $\mathbf{1 0 0}$ \\
Sim & $\mathbf{2 5 9}$ & \\
\hline Total & & \\
\hline
\end{tabular}

As amostras de escorpiões entregues pelos pacientes nos serviços de saúde foram devidamente identificadas por profissional especializado do Instituto Butantan ${ }^{1}$ (Figura 9).

Figura 9- Escorpiões causadores de acidentes nos municípios pertencentes ao $9^{\circ} \mathrm{CRS} / \mathrm{SESPA}, 2017$.

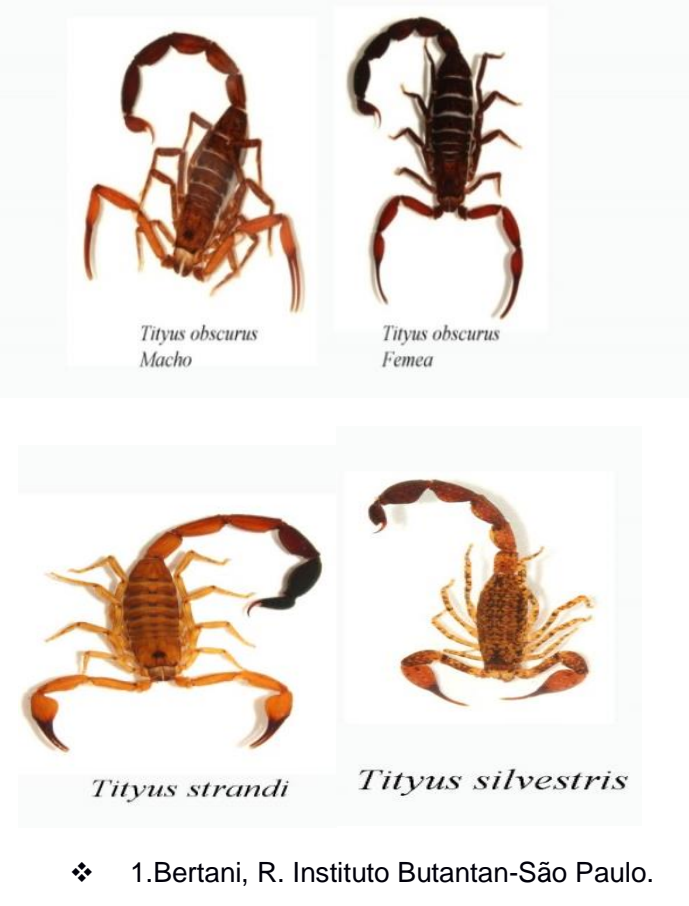


Os profissionais dos municípios de Alenquer, Almeirim, Monte Alegre, Novo Progresso, Belterra, Mojuí dos Campos e Santarém encaminharam amostras de escorpiões que foram também identificadas. Abaixo segue a identificação das espécies capturadas que podem causar acidentes na região (Figura 10).

Figura 10 - Escorpiões capturados e encaminhados pelos profissionais de saúde dos municípios pertencentes ao $9^{\circ} \mathrm{CRS} / \mathrm{SESPA}, 2017$.

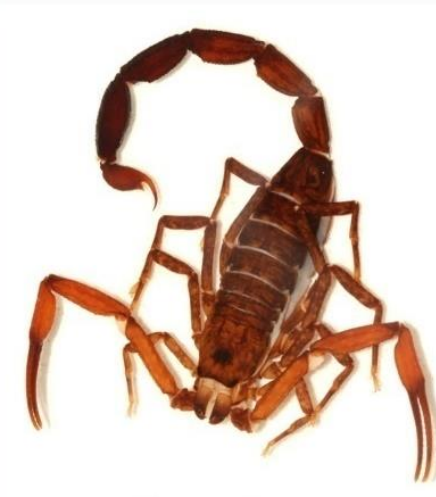

Tityus obscurus Macho

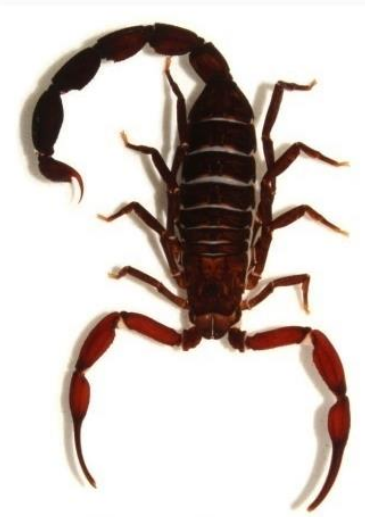

Tityus obscurus Femea

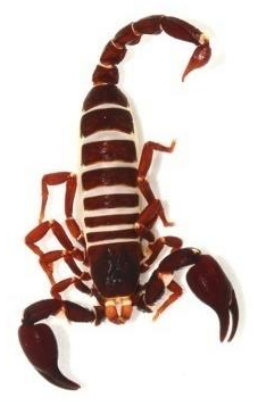

Brotheas sp.

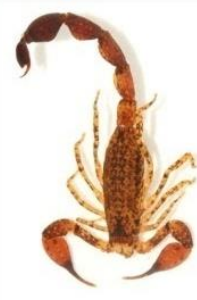

Tityus silvestris

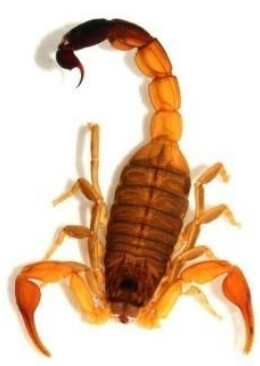

Rhopalurus laticauda

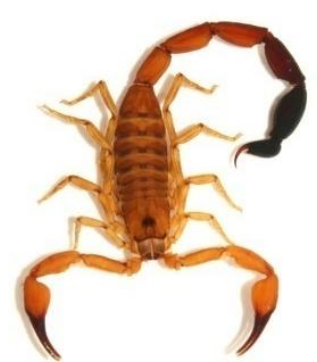

Tityus strandi

* Bertani, R. Instituto Butantan-São Paulo.

As manifestações locais mais freqüentes, mencionadas pelos indivíduos acometidos, nos municípios pertencentes ao $9^{\circ} \mathrm{CRS/SESPA}$ foram: dor (257: 99,0\%), sensação de choque elétrico (132: 51,0\%) e parestesia (130: 50,0\%) - Tabela 14. 
Tabela 14 - Distribuição dos indivíduos acometidos segundo manifestações locais referidas. $9^{\circ} \mathrm{CRS} / \mathrm{SESPA}$, 2017.

\begin{tabular}{|l|c|r|}
\hline \multicolumn{2}{|c|}{ MANIFESTAÇÕES CLÍNICAS LOCAIS } \\
\hline & $\mathbf{N}^{\mathbf{0}}$ & $\%$ \\
\hline Dor & 257 & 99,0 \\
\hline Edema & 76 & 29,0 \\
\hline Eritema & 48 & 19,0 \\
\hline Calor Local & 47 & 18,0 \\
\hline Piloereção & 8 & 3,0 \\
\hline Sudorese & 26 & 10,0 \\
\hline Parestesia & 130 & 50,0 \\
\hline Sensação de Choque & 132 & 51,0 \\
\hline Elétrico Local & & \\
\hline
\end{tabular}

Fotografia 1 -Ptose Palpebral em vítima de escorpionismo no HMS. 2017.

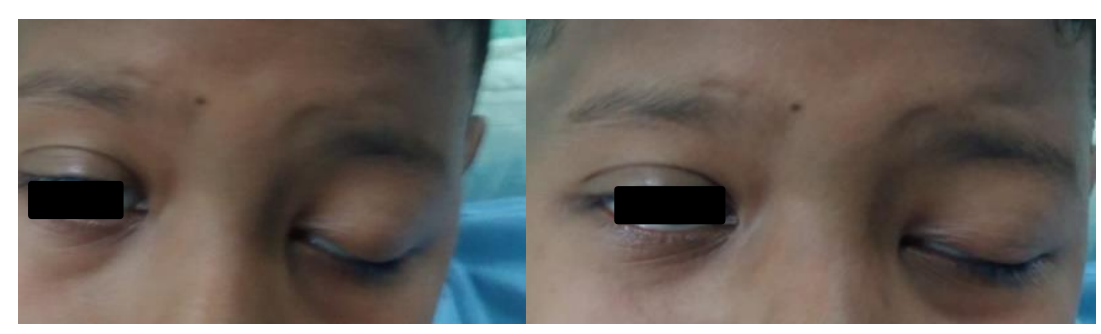

Fonte: Acervo fotográfico da pesquisadora

Conforme pode se verificar na Tabela 15, as manifestações sistêmicas mais frequentes encontradas nas vítimas de escorpionismo, atendidas nos serviços de saúde dos municípios pertencentes ao $9^{\circ} \mathrm{CRS} / \mathrm{SESPA}$ foram: outras manifestações (412: 56\%), que incluem: hipertensão arterial (30: 4,0\%); sudorese (27: 3,7\%); visão turva (25: 3,4\%) e outras alterações oftalmológicas (15: 2,0\%); tremores (81: 11,0\%); disfagia (50: 6,8\%); fadiga (47: 6,4\%); e sialorréia (37: 5,0\%). Dentre as alterações oftalmológicas verificou-se ptose palpebral (1: 7,0\%) (Fotografia 1), nistagmo (5:33,0\%), pupilas anisocóricas $(2: 13,0 \%)$, fotofobia $(2: 13,0 \%)$ e ardência nos olhos (5:33,3\%). Não foram observadas diarréia, priapismo e bradicardia. 
Tabela 15 - Frequência de manifestações sistêmicas apresentadas pelos pacientes. Serviços de saúde de municípios pertencentes à $9^{\circ} \mathrm{CRS} / \mathrm{SESPA}, 2017$.

\begin{tabular}{|c|c|c|}
\hline \multicolumn{3}{|c|}{ MANIFESTAÇÕES SISTÊMICAS } \\
\hline & $\mathbf{N}^{\mathbf{0}}$ & $\%$ \\
\hline Hipertensão & 30 & 4,0 \\
\hline Hipotensão & 02 & 0,3 \\
\hline Sudorese & 27 & 3,7 \\
\hline Náuseas & 19 & 2,6 \\
\hline Vômitos & 07 & 0,9 \\
\hline Sialorréia & 37 & 5,0 \\
\hline Oligúria & 09 & 1,2 \\
\hline Anúria & 06 & 0,8 \\
\hline Taquicardia & 07 & 0,9 \\
\hline Arritmia Cardíaca & 04 & 0,5 \\
\hline Fadiga & 47 & 6,4 \\
\hline Disfagia & 50 & 6,8 \\
\hline Tremores & 81 & 11,0 \\
\hline Hipertermia & 01 & 0,1 \\
\hline $\begin{array}{l}\text { Outras Manifestações } \\
\text { Sistêmicas }\end{array}$ & 412 & 56,0 \\
\hline
\end{tabular}

* Valores acima de 259 correspondem a manifestações sistêmicas associadas, apresentadas pelos pacientes.

A Tabela 16 mostra as manifestações clínicas neurológicas e musculares mais frequentes encontradas nas vítimas dos acidentes: dor em 257 (99,2\%), sensação de choque elétrico em 148 (57,1\%), formigamento em 135 (52,1\%), ataxia de marcha em 89 (34,3\%), disartria em $86(33,2 \%)$ e espasmos musculares em 80 (31,0\%). 
Tabela 16 - Distribuição dos pacientes acometidos segundo manifestações clínicas neurológicas e musculares. $9^{\circ}$ CRS/SESPA, 2017.

\begin{tabular}{|l|c|c|}
\hline $\begin{array}{l}\text { MANIFESTAÇÕES CLÍNICAS } \\
\text { NEUROLÓGICAS E } \\
\text { MUSCULARES }\end{array}$ & $\mathbf{N}^{\mathbf{0}}$ & $\%$ \\
\hline DOR & 257 & 31,0 \\
\hline ESPASMOS MUSCULARES & 80 & 52,1 \\
\hline FORMIGAMENTO & 135 & 14,3 \\
\hline HIPERTONIA MUSCULAR & 37 & 24,7 \\
\hline MIOCLONIAS/ & & \\
\hline FASCICULAÇÃO & 64 & 57,1 \\
\hline SENSAÇÃO DE CHOQUE & 148 & 8,1 \\
\hline ELÉTRICO & 21 & 34,3 \\
\hline ALTERAÇÕES URINÁRIAS & 89 & 33,2 \\
\hline ATAXIA DE MARCHA & 86 & 22,4 \\
\hline DISARTRIA & 57 & \\
\hline DISMETRIA & & \\
\hline
\end{tabular}

A duração das manifestações neurológicas e musculares foi monitorada desde a admissão do paciente no serviço de saúde até a alta. Na Tabela 17 é possível constatar que a dor no acidente escorpiônico teve uma duração média de 11 horas, iniciando imediatamente após a picada, ou ainda não ocorrendo em alguns casos (picada seca). O formigamento pode iniciar imediatamente após a picada ou em até 30 minutos, e pode estender-se em até 76 horas após a picada. A sensação de choque elétrico pode iniciar também imediatamente após a picada, como também em até 30 minutos ou 84 horas após, perdurando em até 24 horas em grande parte dos casos, podendo se estender em até 100 horas após a picada. A mioclonia/fasciculação teve média de duração de 20 horas. Já a disartria teve seu início entre 10 a 30 minutos e perdurou em média 18 horas. 
Tabela 17 - Duração de manifestações neurológicas e musculares de pacientes atendidos nos serviços de saúde dos municípios do $9^{\circ} \mathrm{CRS} / \mathrm{SESPA}, 2017$.

\begin{tabular}{|c|c|c|c|c|}
\hline $\begin{array}{l}\text { DOR } \\
\text { Tempo Inicial } \\
\text { (minutos) }\end{array}$ & $\begin{array}{l}\text { Observações } \\
173\end{array}$ & $\begin{array}{l}\text { Média } \\
9,6919\end{array}$ & $\begin{array}{l}\text { Mediana } \\
0\end{array}$ & $\begin{array}{l}\text { Moda } \\
0\end{array}$ \\
\hline $\begin{array}{l}\text { DOR } \\
\text { Tempo Final } \\
\text { (horas) }\end{array}$ & $\begin{array}{l}\text { Observações } \\
170\end{array}$ & $\begin{array}{l}\text { Média } \\
11,2347\end{array}$ & $\begin{array}{l}\text { Mediana } \\
10\end{array}$ & $\begin{array}{l}\text { Moda } \\
12\end{array}$ \\
\hline $\begin{array}{l}\text { FORMIGAMENTO } \\
\text { Tempo } \\
\text { Inicial (minutos) }\end{array}$ & $\begin{array}{l}\text { Observações } \\
91\end{array}$ & $\begin{array}{l}\text { Média } \\
57,1444\end{array}$ & $\begin{array}{l}\text { Mediana } \\
30\end{array}$ & $\begin{array}{l}\text { Moda } \\
30\end{array}$ \\
\hline $\begin{array}{l}\text { FORMIGAMENTO } \\
\text { Tempo } \\
\text { Final (horas) }\end{array}$ & $\begin{array}{l}\text { Observações } \\
90\end{array}$ & $\begin{array}{l}\text { Média } \\
23,2472\end{array}$ & $\begin{array}{l}\text { Mediana } \\
17,5\end{array}$ & $\begin{array}{l}\text { Moda } \\
12\end{array}$ \\
\hline $\begin{array}{l}\text { SENSAÇÃO DE } \\
\text { CHOQUE } \\
\text { ELÉTRICO } \\
\text { Tempo Inicial } \\
\text { (minutos) }\end{array}$ & $\begin{array}{l}\text { Observações } \\
112\end{array}$ & $\begin{array}{l}\text { Média } \\
100,2072\end{array}$ & $\begin{array}{l}\text { Mediana } \\
30\end{array}$ & $\begin{array}{l}\text { Moda } \\
30\end{array}$ \\
\hline $\begin{array}{l}\text { SENSAÇÃO DE } \\
\text { CHOQUE } \\
\text { ELÉTRICO } \\
\text { Tempo Final } \\
\text { (horas) }\end{array}$ & $\begin{array}{l}\text { Observações } \\
109\end{array}$ & $\begin{array}{l}\text { Média } \\
20,9259\end{array}$ & $\begin{array}{l}\text { Mediana } \\
21\end{array}$ & $\begin{array}{l}\text { Moda } \\
24\end{array}$ \\
\hline $\begin{array}{l}\text { MIOCLONIAS } \\
\text { FASCICULAÇÃO } \\
\text { Tempo } \\
\text { Inicial (minutos) } \\
\end{array}$ & $\begin{array}{l}\text { Observações } \\
45\end{array}$ & $\begin{array}{l}\text { Média } \\
153,6364\end{array}$ & $\begin{array}{l}\text { Mediana } \\
30\end{array}$ & $\begin{array}{l}\text { Moda } \\
30\end{array}$ \\
\hline $\begin{array}{l}\text { MIOCLONIAS } \\
\text { FASCICULAÇÃO } \\
\text { Tempo } \\
\text { Final(horas) } \\
\end{array}$ & $\begin{array}{l}\text { Observações } \\
45\end{array}$ & $\begin{array}{l}\text { Média } \\
23,6477\end{array}$ & $\begin{array}{l}\text { Mediana } \\
20\end{array}$ & $\begin{array}{l}\text { Moda } \\
6\end{array}$ \\
\hline $\begin{array}{l}\text { DISARTRIA } \\
\text { Tempo } \\
\text { Inicial(minutos) }\end{array}$ & $\begin{array}{l}\text { Observações } \\
60\end{array}$ & $\begin{array}{l}\text { Média } \\
97,4576\end{array}$ & $\begin{array}{l}\text { Mediana } \\
60\end{array}$ & $\begin{array}{l}\text { Moda } \\
30\end{array}$ \\
\hline $\begin{array}{l}\text { DISARTRIA } \\
\text { Tempo Final(horas) }\end{array}$ & $\begin{array}{l}\text { Observações } \\
66\end{array}$ & $\begin{array}{l}\text { Média } \\
20,2308\end{array}$ & $\begin{array}{l}\text { Mediana } \\
18\end{array}$ & $\begin{array}{l}\text { Moda } \\
24\end{array}$ \\
\hline
\end{tabular}

* Valores de Observações diferentes em tempo inicial e tempo finalocorrerampois alguns pacientes não foram acompanhados, quer seja por evasão ou quando no ato da admissão não ter sido registrado pelo profissional de saúde. 
Tabela 17 - Duração de manifestações neurológicas e musculares de pacientes atendidos nos serviços de saúde dos municípios do $9^{\circ} \mathrm{CRS} / \mathrm{SESPA}, 2017$.

(continuação)

\begin{tabular}{|c|c|c|c|c|}
\hline $\begin{array}{l}\text { ATAXIA DE } \\
\text { MARCHA } \\
\text { Tempo Inicial } \\
\text { (horas) }\end{array}$ & $\begin{array}{l}\text { Observações } \\
70\end{array}$ & $\begin{array}{l}\text { Média } \\
3,7474\end{array}$ & $\begin{array}{l}\text { Mediana } \\
1,5\end{array}$ & $\begin{array}{l}\text { Moda } \\
1\end{array}$ \\
\hline $\begin{array}{l}\text { ATAXIA DE } \\
\text { MARCHA } \\
\text { Tempo Final(horas) }\end{array}$ & $\begin{array}{l}\text { Observações } \\
71\end{array}$ & $\begin{array}{l}\text { Média } \\
25,6429\end{array}$ & $\begin{array}{l}\text { Mediana } \\
24\end{array}$ & $\begin{array}{l}\text { Moda } \\
24\end{array}$ \\
\hline $\begin{array}{l}\text { ESPASMOS } \\
\text { MUSCULARES } \\
\text { Tempo } \\
\text { Inicial (minutos) }\end{array}$ & $\begin{array}{l}\text { Observações } \\
59\end{array}$ & $\begin{array}{l}\text { Média } \\
132,4138\end{array}$ & $\begin{array}{l}\text { Mediana } \\
30\end{array}$ & $\begin{array}{l}\text { Moda } \\
30\end{array}$ \\
\hline $\begin{array}{l}\text { ESPASMOS } \\
\text { MUSCULARES } \\
\text { Tempo } \\
\text { Final (horas) } \\
\end{array}$ & $\begin{array}{l}\text { Observações } \\
58\end{array}$ & $\begin{array}{l}\text { Média } \\
15,8947\end{array}$ & $\begin{array}{l}\text { Mediana } \\
12\end{array}$ & $\begin{array}{l}\text { Moda } \\
12\end{array}$ \\
\hline $\begin{array}{l}\text { HIPERTONIA } \\
\text { MUSCULAR } \\
\text { Tempo Inicial } \\
\text { (minutos) }\end{array}$ & $\begin{array}{l}\text { Observações } \\
21\end{array}$ & $\begin{array}{l}\text { Média } \\
292,5\end{array}$ & $\begin{array}{l}\text { Mediana } \\
30\end{array}$ & $\begin{array}{l}\text { Moda } \\
30\end{array}$ \\
\hline $\begin{array}{l}\text { HIPERTONIA } \\
\text { MUSCULAR } \\
\text { Tempo final } \\
\text { (horas) }\end{array}$ & $\begin{array}{l}\text { Observações } \\
21\end{array}$ & $\begin{array}{l}\text { Média } \\
13,5\end{array}$ & $\begin{array}{l}\text { Mediana } \\
8\end{array}$ & $\begin{array}{l}\text { Moda } \\
6\end{array}$ \\
\hline
\end{tabular}

(conclusão)

A ataxia de marcha iniciou imediatamente ou em até 3 horas após a picada, permanecendo em até 25 horas. Os espasmos musculares, em alguns casos, também iniciaram imediatamente após a picada ou em até 30 minutos, perdurando em média por 15 horas. A hipertonia muscular teve tempo de início semelhante ao apresentado em relação aos espasmos musculares, porém com duração em até 13 horas.

Na Tabela 18 pode-se observar a ocorrência de comprometimento cerebelar e/ou muscular nas 148 vítimas de escorpionismo, nos 20 municípios doestudo. Destaca-se que apenas os municípios de Óbidos e Terra Santa não tiveram vítimas com tal comprometimento. 
Tabela 18 - Distribuição dos pacientes segundo comprometimento cerebelar e/ou muscular. $9^{\circ}$ CRS/SESPA, 2017.

\begin{tabular}{|c|c|c|}
\hline MUNICÍPIO & $\mathbf{N}^{\mathbf{0}}$ & $\%$ \\
\hline ALENQUER & 2 & 100,0 \\
\hline ALMEIRIM & 4 & 100,0 \\
\hline AVEIRO & 5 & 100,0 \\
\hline BELTERRA & 6 & 75,0 \\
\hline ITAITUBA & 2 & 33,3 \\
\hline JACAREACANGA & 7 & 87,5 \\
\hline JURUTI & 2 & 33,3 \\
\hline MOJUÍ DOS CAMPOS & 9 & 60,0 \\
\hline MONTE ALEGRE & 4 & 57,1 \\
\hline NOVO PROGRESSO & 6 & 33,3 \\
\hline ÓBIDOS & 0 & 0,0 \\
\hline ORIXIMINÁ & 2 & 100,0 \\
\hline PLACAS & 9 & 47,3 \\
\hline PRAINHA & 10 & 91,0 \\
\hline RURÓPOLIS & 54 & 74,0 \\
\hline SANTARÉM & 21 & 42,0 \\
\hline TERRA SANTA & 0 & 0,0 \\
\hline TRAIRÃO & 5 & 23,0 \\
\hline TOTAL & 148 & 57,1 \\
\hline
\end{tabular}

A fotografia $2 \mathrm{a}$ e $2 \mathrm{~b}$ revela a escrita e desenhos de vítimas de escorpionismo atendidas no Hospital Municipal de Santarém-PA, cujas vítimas apresentaram sinais de comprometimento cerebelar e/ou muscular, e acidentes classificados como moderado e grave, respectivamente. 
Fotografia 2a - Escrita de vítima de escorpionismo. Caso Moderado. Santarém-PA, 2017.

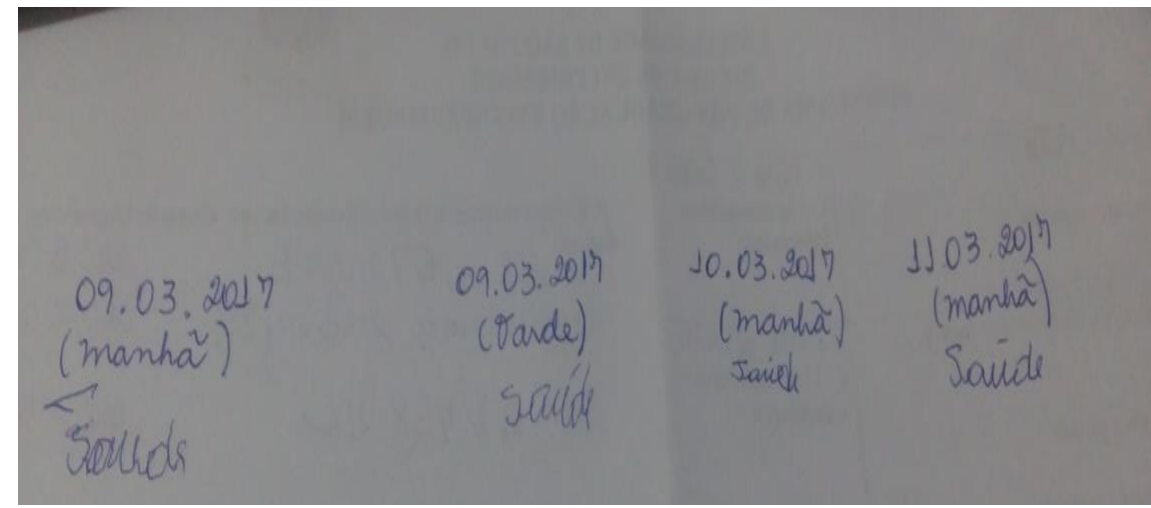

Fotografia 2b - Desenho de vítima de escorpionismo. Caso Grave.Belterra-PA, 2017.

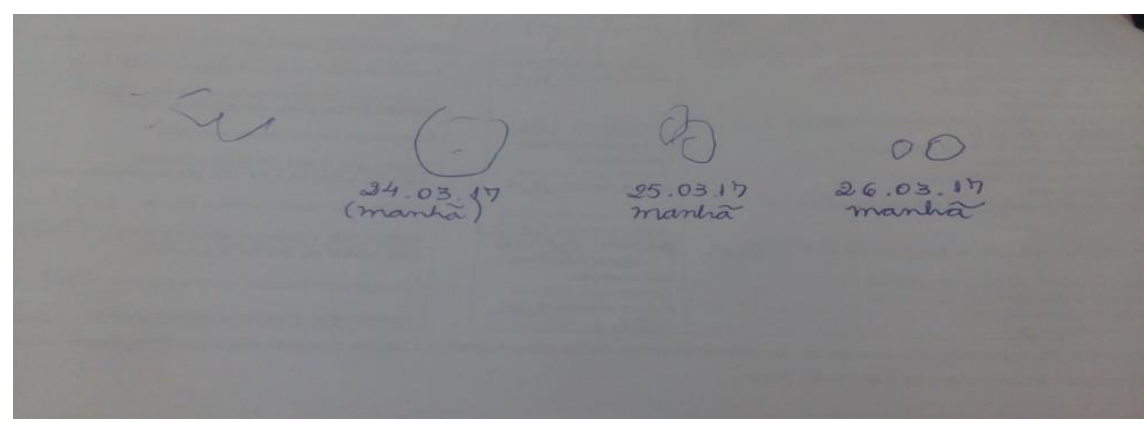

Fonte: Arquivo fotográfico da pesquisadora.

A tabela 19 mostra os casos que apresentaram comprometimento cerebelar e zona de ocorrência do acidente. A zona rural dos 18 municípios investigados corresponde a 84,5\%, com 125 indivíduos que apresentaram comprometimento cerebelar e/ou muscular.

Tabela 19 - Distribuição dos pacientes segundo local do acidente e comprometimento cerebelar. $9^{\circ}$ CRS/SESPA, 2017

\begin{tabular}{c|c|r}
\hline Zona do Acidente & $\mathbf{N}^{\mathbf{0}}$ & \% \\
\hline Rural & 125 & 84,5 \\
\hline Urbana & 23 & 15,5 \\
\hline Total & 148 & 100,0 \\
\hline
\end{tabular}

Na Figura 11 verifica-se a distribuição espacial dos acidentes (Figura 11-a) e a distribuição espacial dos casos que apresentaram sinais e sintomas que podem ser indicativos de comprometimento cerebelar e/ou muscular (Figura 11-b). Na Figura 11-a é possível identificar dois municípios com número de casos acima de 40: Santarém e Rurópolis. Já em relação aos casos com comprometimento cerebelar e/ou muscular (Figura 11-b), Rurópolis manteve o número de casos acima de 40. Por outro lado, Santarém apresentou 20 a 30 casos. 
Figura 11 - Distribuição do total de casos e daqueles que apresentaram características de comprometimento cerebelar e/ou muscular. $9^{\circ} \mathrm{CRS} / \mathrm{SEPA}, 2017$.

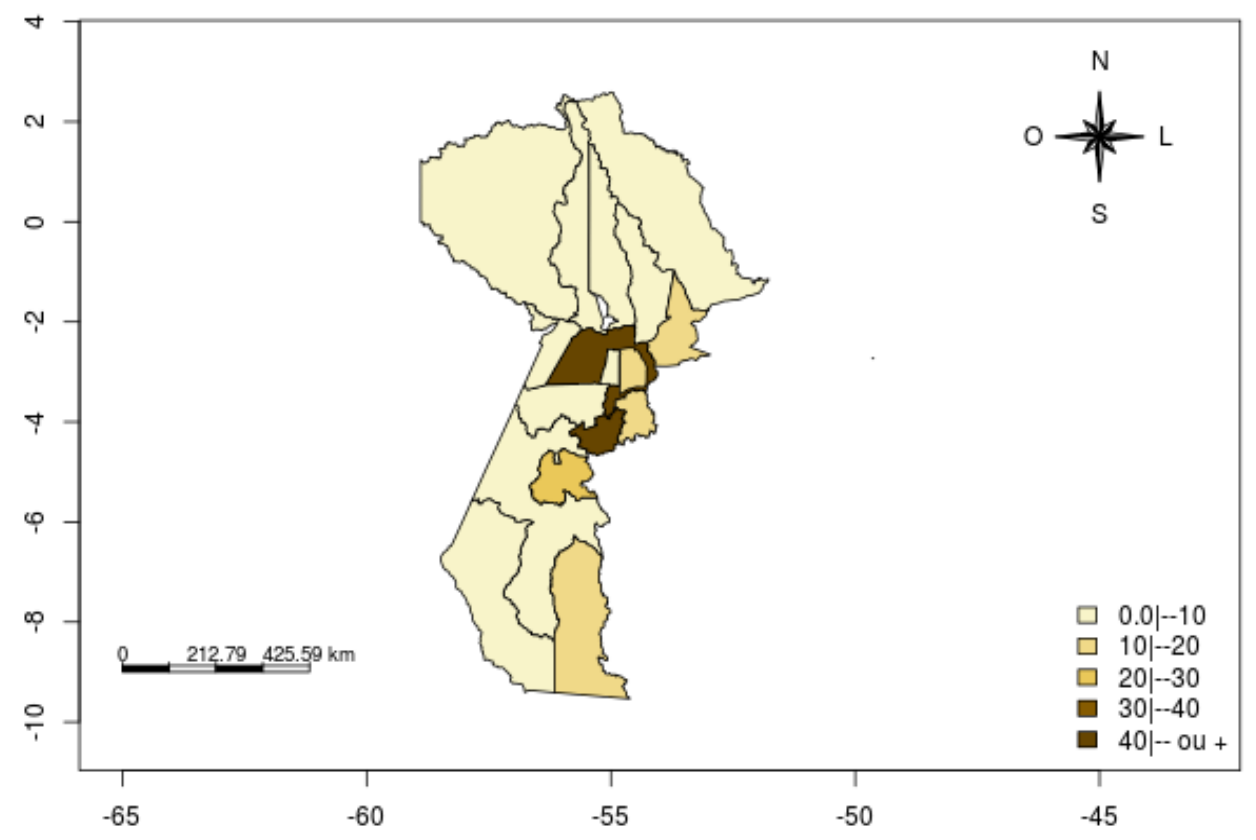

(a) Total de Casos

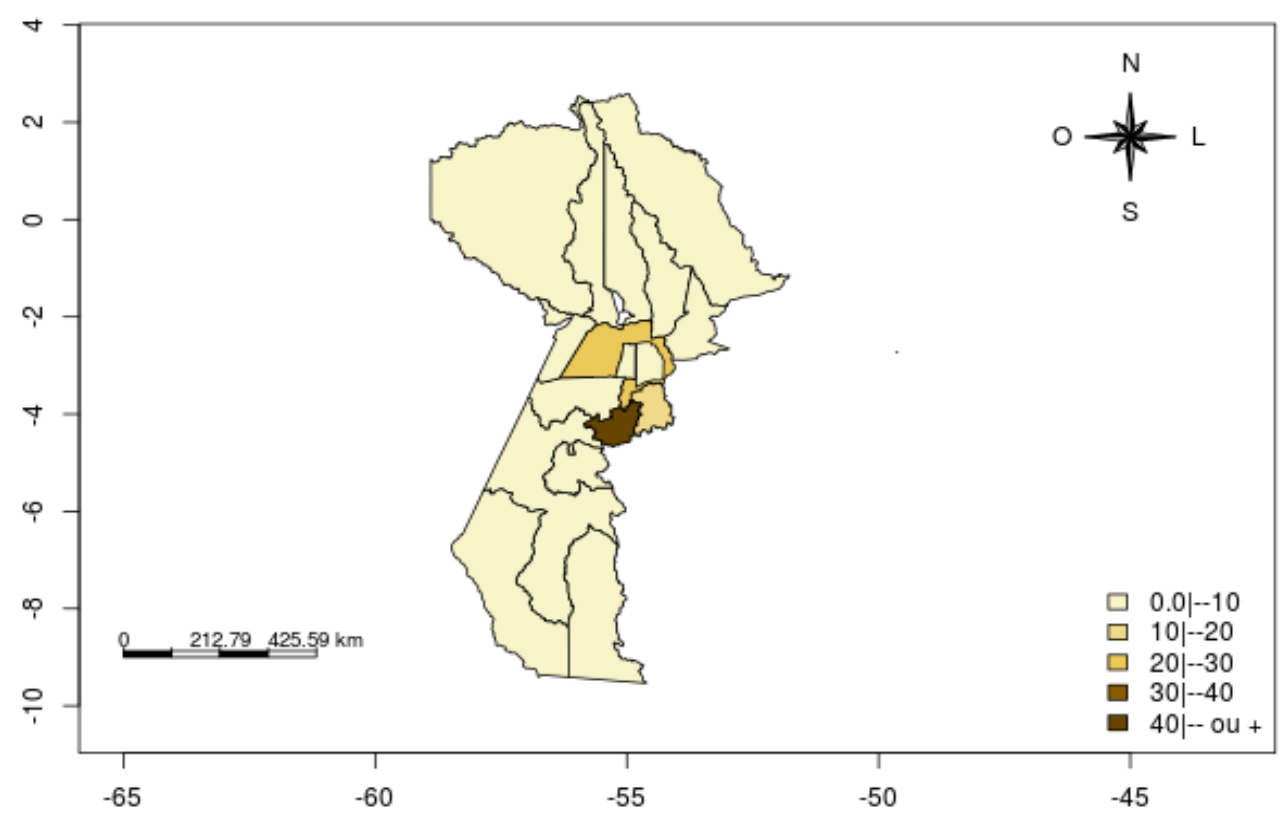

(b) Casos que apresentaram comprometimento cerebelar e/ou muscular 
Figura 12 - Risco Relativo dos casos totais e daqueles que apresentaram características de comprometimento cerebelar e/ou muscular. $9^{\circ} \mathrm{CRS} / \mathrm{SESPA}, 2017$.

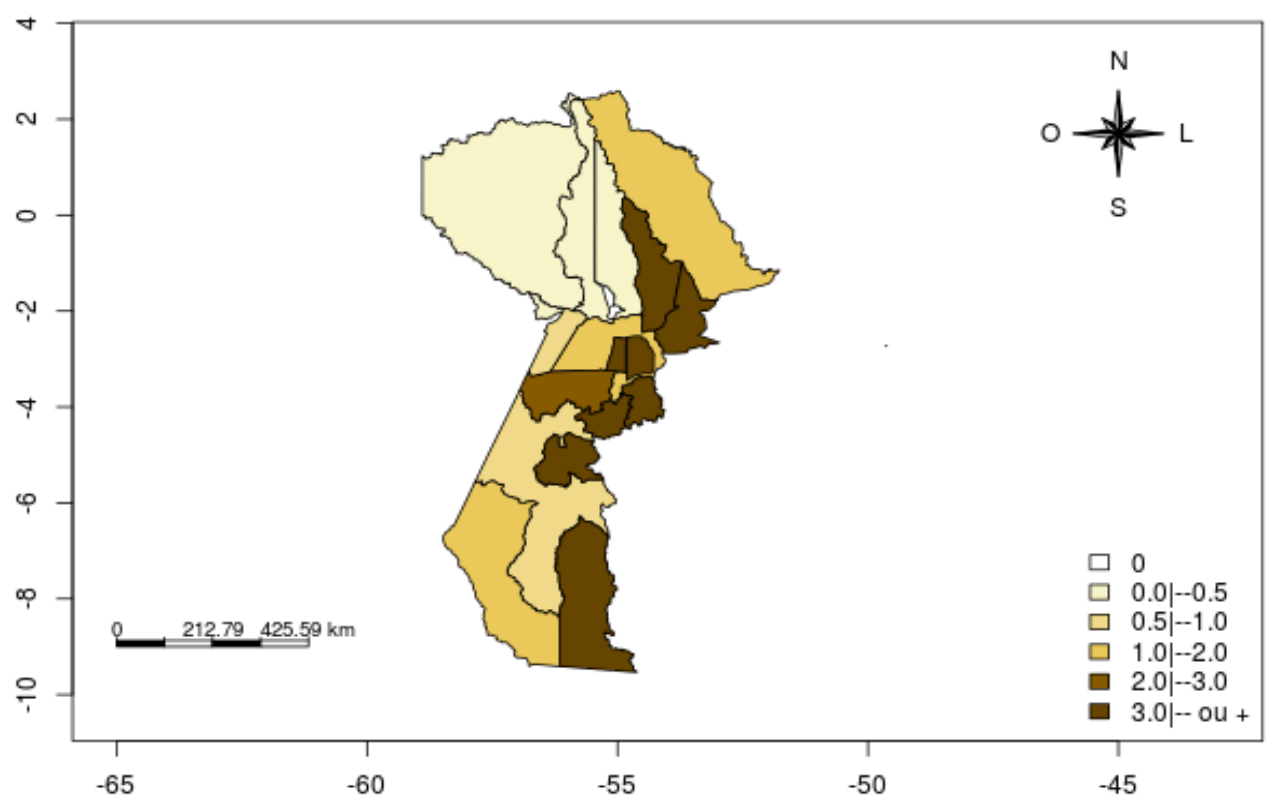

(a) Risco Relativo do total de casos

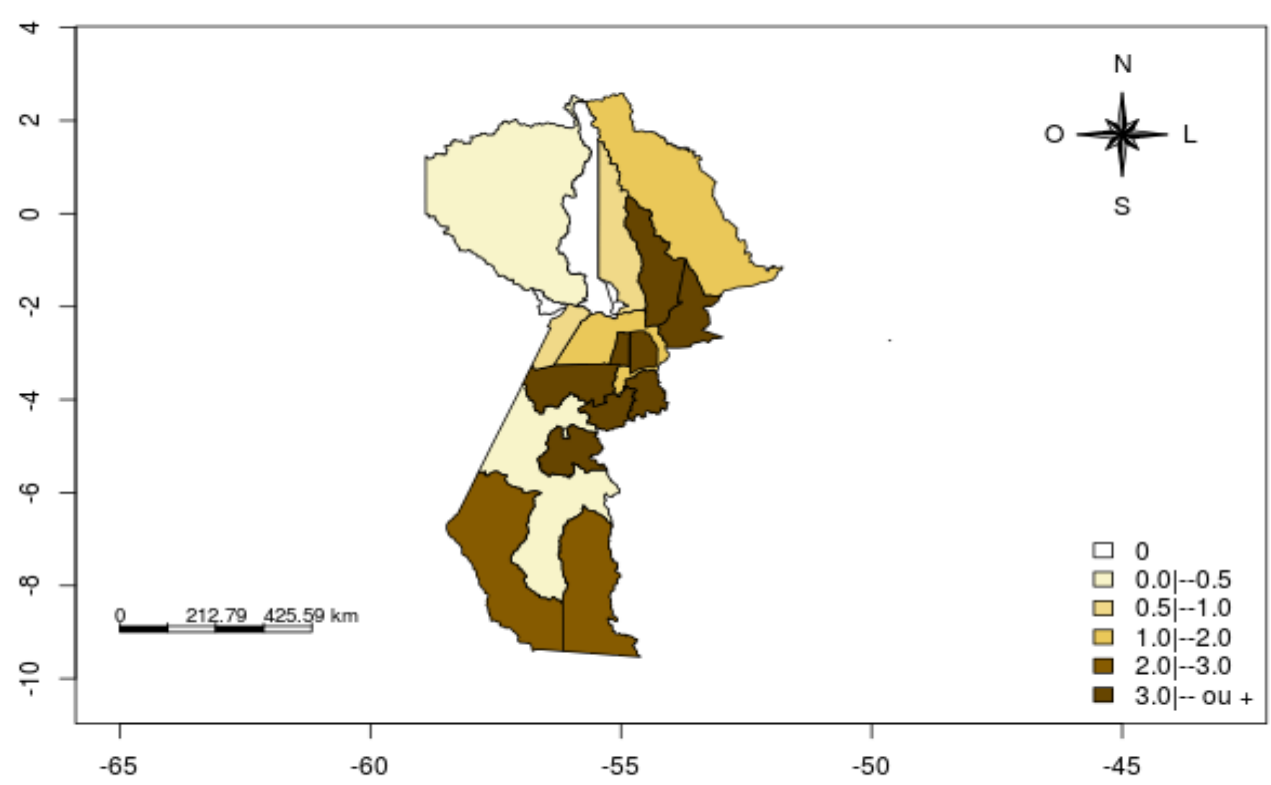

(b) Risco Relativo dos casos que apresentaram características de comprometimento cerebelar e/ou muscular 
Quanto ao risco relativo (RR) dos acidentes nos municípios, pode ser encontrado na Figura 12. A Figura 12-a representa o Risco Relativo para o número total de casos. É possível perceber que a maioria dos municípios em estudo apresenta Risco Relativo acima de 1. Seis (6) municípios apresentam RR 3 vezes maior (Monte Alegre, Prainha, Belterra, Placas, Rurópolis e Novo Progresso) que o RR da área. A Figura 12-b representa o RR referente aos casos que apresentaram sintomatologia compatível com comprometimento cerebelar e/ou muscular. Neste caso, 6 municípios possuem RR 3 vezes maior (Monte Alegre, Prainha, Trairão, Placas, Rurópolis e Aveiro) que o RR da área em estudo, e 2 municípios possuem RR 2 vezes maior (Jacareacanga e Novo Progresso).

Na Figura 13 verifica-se o resultado da aplicação do método Scan Espacial para o total de casos (Figura 13-a) e para os casos que apresentaram comprometimento cerebelar e/ou muscular (Figura 13-b). Verificam-se conglomerados significativos de áreas de risco. A Figura 10-a mostra que 12 municípios (Monte Alegre, Mojuí dos Campos, Placas, Rurópolis, Trairão, Novo Progresso, Prainha, Belterra, Alenquer, Almeirim, Juruti e Aveiro) foram considerados como áreas de risco, e ao comparar com o mapa de Risco (Figura 12-a), é possível perceber que todos esses municípios possuem um alto Risco, ou seja, Risco Relativo maior que 1. O mesmo padrão é encontrado na Figura 13-b. O método Scan detectou um conglomerado espacial, uma área significativa, composta pelos municípios de Monte Alegre, Prainha, Mojuí dos Campos, Belterra, Aveiro, Rurópolis e Placas. Ao comparar esse achado com a Figura 12-b, conclui-se que todas as áreas significativas representam áreas de alto risco. 
Figura 13 - Método Scan Espacial aplicado ao total de casos e aos casos que apresentaram características de comprometimento cerebelar e/ou muscular. Municípios do $9^{\circ}$ CRS.2017.

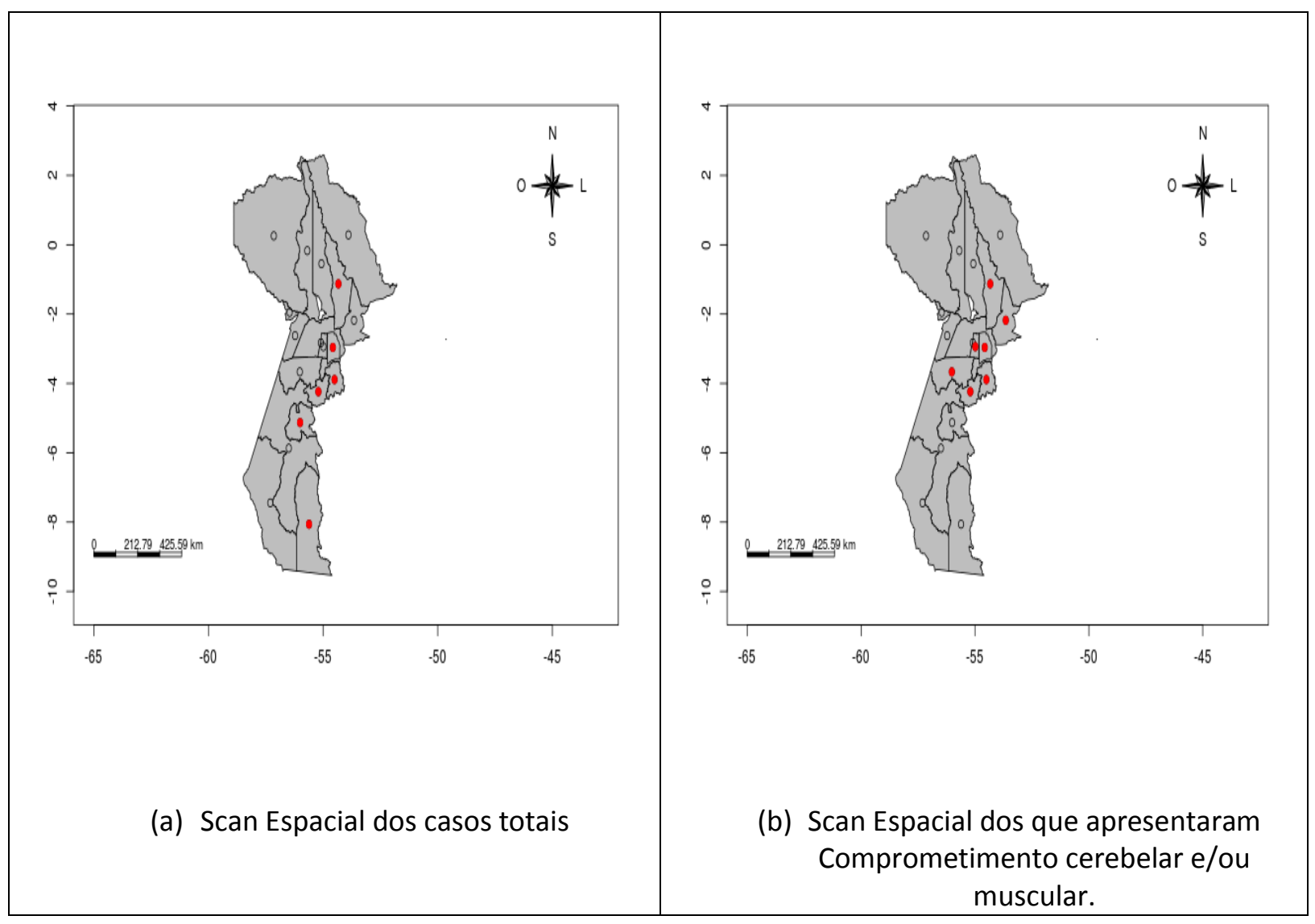

A Tabela 20 mostra a classificação dos acidentes escorpiônicos acompanhados neste estudo. A maioria dos acidentes foi classificada como leve (146: 56,4\%), seguidos dos moderados (99: 38,2\%) e dos graves (14: 5,4\%). Todos os pacientes acompanhados neste estudo tiveram evolução favorável.

Tabela 20 - Distribuição dos acidentes escorpiônicos em pacientes atendidos nos serviços de saúde pertencentes ao $9^{\circ} \mathrm{CRS} / \mathrm{SESPA}$, segundo classificação de gravidade. 2017.

\begin{tabular}{|l|c|r|}
\hline $\begin{array}{l}\text { CLASSIFICAÇÃO } \\
\text { DOS ACIDENTES }\end{array}$ & No & \multicolumn{1}{|c|}{$\%$} \\
\hline Leve & 146 & 56,4 \\
\hline Moderado & 99 & 38,2 \\
\hline Grave & 14 & 5,4 \\
\hline & & \\
\hline TOTAL & 259 & 100,0 \\
\hline
\end{tabular}


A Tabela 21 mostra a distribuição dos casos segundo o tempo da picada até o atendimento e a classificação dos casos. Verifica-se que 103 casos (70,0\%) que foram classificados como leves foram atendidos em menos de 3 horas do acidente, 35 (24,0\%) foram atendidos entre 3 e até 12 horas e 8 casos $(6,0 \%)$ foram atendidos de 12 a mais horas após o acidente. Em relação aos casos moderados, em sua maioria (43: 50,0\%) foram atendidos entre 3 até 12 horas. Já em relação aos casos classificados como graves, 8 (9,0\%) pacientes foram atendidos entre 3 até 12 horas do acidente, $3(3,2 \%)$ entre 1 e até 3 horas do momento em que ocorreu o acidente e $3(17,0 \%)$ de 12 a mais horas após o acidente.

$\mathrm{Na}$ Tabela 21 encontra-se o teste Exato de Fisher, que se constitui como uma alternativa, quando não é possível utilizar o teste Qui-Quadrado. A restrição de utilizar o teste qui-quadrado nestas variáveis se coloca quando menos de $25 \%$ das categorias possuem frequência abaixo de 5, ou possuir algum valor 0 (zero) na tabela cruzada, neste caso, temos o valor zero, em atendimento abaixo de 1 hora, levando em consideração que a classificação do caso é grave. De acordo com o valor de p obtido de $4.34 \times 10^{-4}$, é menor que o nível de significância adotado de 5\%, ou seja, pode-se concluir que existe diferença entre o tempo de atendimento levando em consideração a gravidade do caso. 
Tabela 21 - Distribuição dos pacientes segundo tempo de ocorrência da picada e classificação do caso escorpiônico. $9^{\circ} \mathrm{CRS} / \mathrm{SESPA}, 2017$.

\begin{tabular}{c|c|c|c|c}
\hline \multirow{2}{*}{$\begin{array}{c}\text { Tempo } \\
\text { decorrido até }\end{array}$} & \multicolumn{2}{|c|}{ Classificação do caso } & \multirow{2}{*}{ Teste Exato } \\
\cline { 2 - 4 } o atendimento & Leve & Moderado & Grave & $\begin{array}{c}\text { de Fisher } \\
\text { (p-valor) }\end{array}$ \\
\cline { 1 - 4 }$<1 \mathrm{hr}$ & 43 & 18 & 0 & \\
\hline $1+-3 \mathrm{hr} \mathrm{s}$ & 60 & 30 & 3 & \multirow{2}{*}{$4.34 \times 10^{-4}$} \\
\hline $4 \mid--12 \mathrm{hrs}$ & 35 & 43 & 8 & \\
\hline$>12 \mathrm{hrs}$ & 8 & 7 & 3 & \\
\hline
\end{tabular}

A Tabela 22 mostra a conduta clínica tomada para as vítimas dos acidentes escorpiônicos. Todos os pacientes foram observados no serviço de saúde, 256 (99,0\%) receberam hidratação; e 249 (96,1\%) receberam analgésicos. A soroterapia foi utilizada em $128(49,4 \%)$ casos e a medicação pré-soro em 131 (50,5\%). A internação ocorreu em 133 casos $(51,3 \%)$ e $134(52,0 \%)$ receberam benzodiazepínicos.

Tabela 22 - Distribuição dos pacientes e condutas clínicas nos serviços de saúde dos municípios pertencentes ao $9^{\circ} \mathrm{CRS} / \mathrm{SESPA}, 2017$.

\begin{tabular}{|c|c|c|}
\hline CONDUTA CLÍNICA & $\begin{array}{l}\text { PACIENTES } \\
\mathbf{N}^{\circ}\end{array}$ & $\%$ \\
\hline OBSERVAÇÃO & 259 & 100,0 \\
\hline HIDRATAÇÃO & 256 & 99,0 \\
\hline ANALGÉSICOS & 249 & 96,1 \\
\hline BENZODIAZEPÍNICOS & 134 & 52,0 \\
\hline INTERNAÇÃO & 133 & 51,3 \\
\hline MEDICAÇÃO PRÉ-SORO & 131 & 50,5 \\
\hline SOROTERAPIA & 128 & 49,4 \\
\hline $\begin{array}{l}\text { SOLICITAÇÃO DE } \\
\text { EXAMES }\end{array}$ & 86 & 33,2 \\
\hline
\end{tabular}


Tabela 22 - Distribuição dos pacientes e condutas clínicas nos serviços de saúde dos municípios pertencentes ao $9^{\circ} \mathrm{CRS} / \mathrm{SESPA}, 2017$.

(continuação)

\begin{tabular}{|c|}
\hline ANTI-INFLAMATÓRIOS \\
\hline BLOQUEIO ANESTÉSICO \\
\hline ANTI-HIPERTENSIVO \\
\hline DIURÉTICO \\
\hline SONDAGEM VESICAL \\
\hline
\end{tabular}

59

15

04

01

01
23,0

6,0

1,5

0,4

0,4

A título de demonstração de caso grave, a Fotografia 3 mostra uma criança de 01 ano de idade, vítima de escorpionismo, ocorrido no município de Prainha. Por tratar-se de acidente grave, foi transferida para o Hospital Municipal de Santarém.

Fotografia 3- Criança vítima de escorpionismo no setor de reanimação do Hospital Municipal de Santarém- PA, 2017.

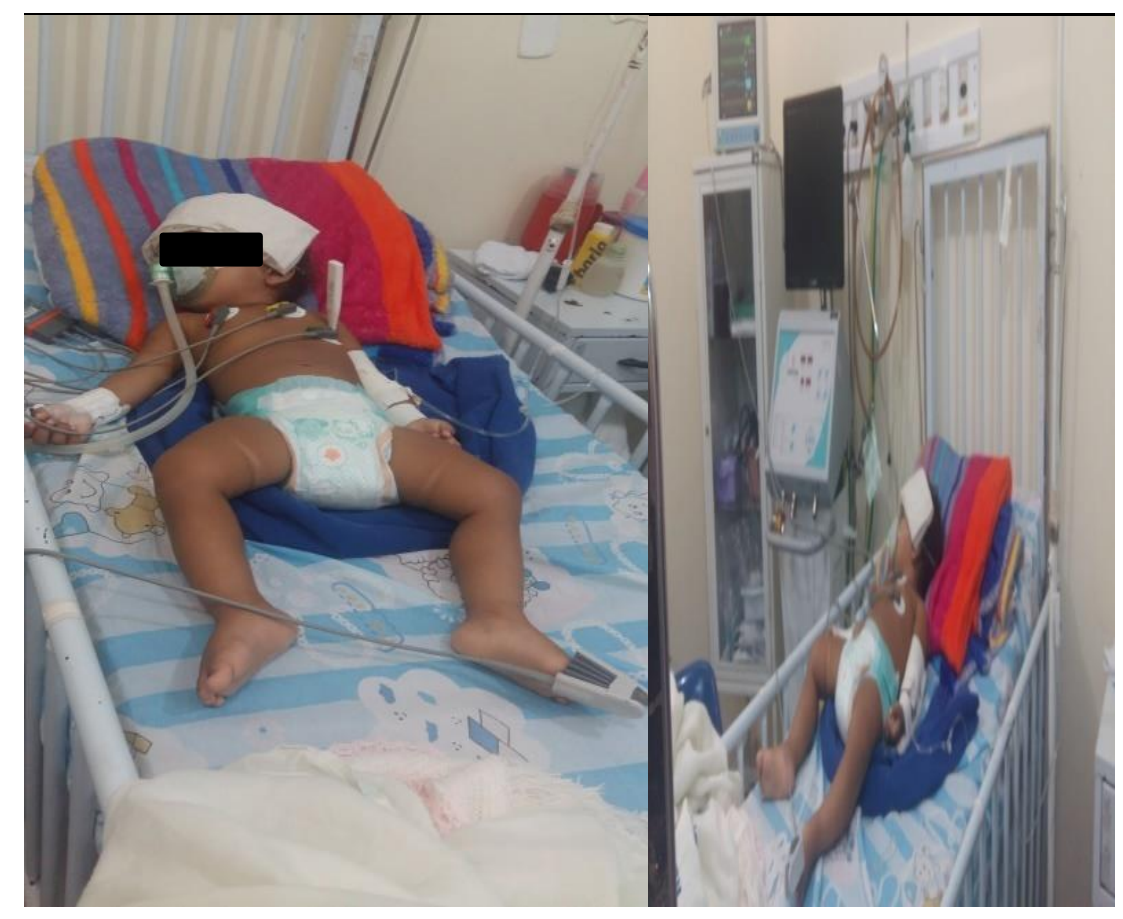

Fonte: Arquivo fotográfico da pesquisadora. 
No Quadro 2 é possível constatar aspectos clínicos e epidemiológicos dos casos cujos pacientes efetuaram a entrega do animal para a identificação. A espécie T. strandi foi responsável por dois acidentes no município de Santarém, ambos provenientes da zona rural, nas comunidades de Cipoal (Santarém-Cuiabá) (Cojuba) e Miritituba (Santarém Curuá-Una) (Aracú), e um caso ocorrido no município de Monte Alegre (Tucunaré), assinalando-se que as vítimas apresentaram sinais de comprometimento cerebelar e/ou muscular. A espécie $T$. obscurus foi responsável por acidentes nos municípios de Santarém (Acari, Curimatã, Dourado, Jaraqui, Tambaqui), Rurópolis (Mapará, Pacú, Pescada) e Placas (Pirarucu), tendo uma variação de classificação de acidente leve a moderado, também com sinais compatíveis com a síndrome cerebelar aguda. A espécie $T$. silvestris foi responsável por acidentes no município de Santarém.

Quadro 2 - Aspectos clínicos e epidemiológicos de pacientes vítimas de escorpionismo que trouxeram o animal para o serviço de saúde nos municípios pertencentes ao $9^{\circ} \mathrm{CRS} / \mathrm{SESPA}$, ano 2017.

\begin{tabular}{|c|c|c|c|c|c|c|}
\hline $\begin{array}{c}\text { Amostra } \\
\text { Identificação }\end{array}$ & $\begin{array}{c}\text { Paciente/ } \\
\text { Data e } \\
\text { Local do } \\
\text { Acidente } \\
\text { Escorpiô } \\
\text { nico }\end{array}$ & $\begin{array}{c}\text { Aspectos } \\
\text { Epidemiológicos }\end{array}$ & $\begin{array}{l}\text { Aspectos } \\
\text { Clínicos }\end{array}$ & $\begin{array}{l}\text { Classificação } \\
\text { do Acidente }\end{array}$ & Conduta & Exames \\
\hline $\begin{array}{l}01 \\
T . \\
\text { obscurus } \\
\text { (Macho) }\end{array}$ & $\begin{array}{c}\text { Acari } \\
16.06 .2017\end{array}$ & $\begin{array}{l}\text { Sexo feminino, } 63 \\
\text { anos, aposentada, } \\
\text { renda de até } 1 \\
\text { salário mínimo. } \\
\text { Local do acidente: } \\
\text { Comunidade } \\
\text { Santa Rosa } \\
\text { Santarém Curuá- } \\
\text { Una. } \\
\text { Situação em que } \\
\text { ocorreu } \\
\text { acidente: } \\
\text { domicílio, } \\
\text { retirando verduras } \\
\text { da horta. } \\
\text { Tempo } \\
\text { picada/atendimen- } \\
\text { to 1-3 horas. } \\
\text { Local da picada: } \\
\text { Mão. }\end{array}$ & $\begin{array}{l}\text { Manifestações } \\
\text { locais: dor, } \\
\text { edema, calor } \\
\text { local, parestesia } \\
\text { e sensação de } \\
\text { choque elétrico. } \\
\text { Manifestações } \\
\text { sistêmicas: } \\
\text { Hipertensão } \\
\text { arterial, } \\
\text { sialorréia, } \\
\text { taquicardia, } \\
\text { parestesia em } \\
\text { face e em } \\
\text { MMII, } \\
\text { espasmos, } \\
\text { disfagia, astenia }\end{array}$ & Moderado & $\begin{array}{l}\text { Observação, } \\
\text { Hidratação, } \\
\text { Analgésico, } \\
\text { Benzodiaze- } \\
\text { pínico, } \\
\text { Diurético, } \\
\text { Anti- } \\
\text { hipertensivo, } \\
\text { Medicação } \\
\text { pré- } \\
\text { soroterapia, } \\
\text { SAESC (02 } \\
\text { amp). }\end{array}$ & - \\
\hline
\end{tabular}


Quadro 2 - Aspectos clínicos e epidemiológicos de pacientes vítimas de escorpionismo que trouxeram o animal para o serviço de saúde nos municípios pertencentes ao 9²RS/SESPA, ano 2017

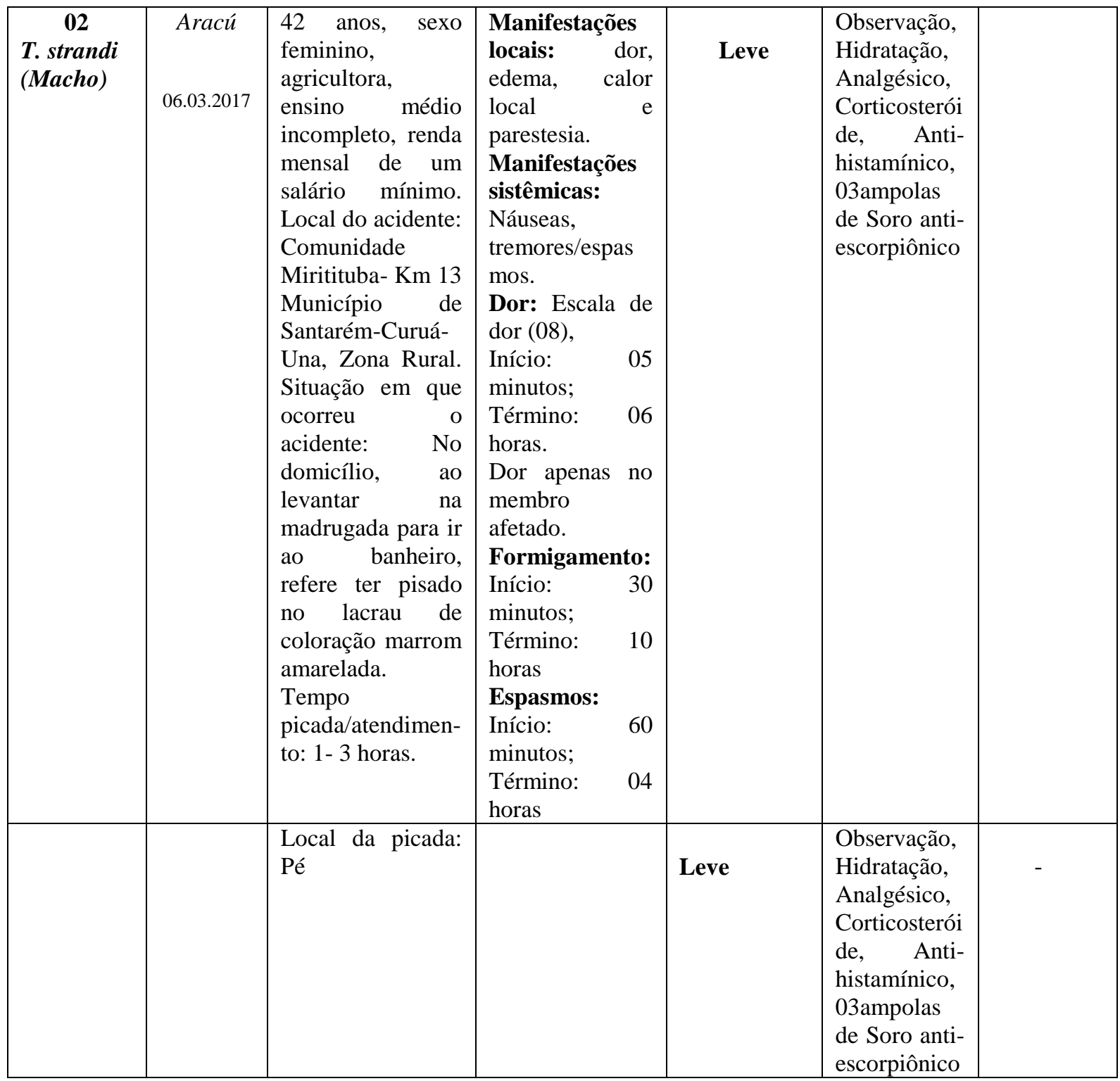


Quadro 2 - Aspectos clínicos e epidemiológicos de pacientes vítimas de escorpionismo que trouxeram o animal para o serviço de saúde nos municípios pertencentes ao $9^{\circ} \mathrm{CRS} / \mathrm{SESPA}$, ano 2017

\begin{tabular}{|c|c|c|c|c|c|c|}
\hline $\begin{array}{l}03 \\
T . \text { strandi } \\
\text { (Macho) }\end{array}$ & $\begin{array}{c}\text { Cojuba } \\
\text { 27.03.2017 }\end{array}$ & $\begin{array}{l}39 \text { anos, sexo } \\
\text { feminino, do lar } \\
\text { ensino médio } \\
\text { completo, renda } \\
\text { mensal de um } \\
\text { salário mínimo } \\
\text { Local do acidente } \\
\text { Km-15- Cipoal, } \\
\text { Zona Rural- } \\
\text { Município } \\
\text { Santarém. } \\
\text { Situação em que } \\
\text { ocorreu } \\
\text { acidente: lazer } \\
\text { Informa ter sido } \\
\text { picada por lacrau } \\
\text { marrom } \\
\text { amarelado. } \\
\text { Tempo/Picada } \\
\text { atendimento: 1-3 } \\
\text { horas. } \\
\text { Local da Picada } \\
\text { Dedo da Mão } \\
\text { direita. }\end{array}$ & $\begin{array}{l}\text { Manifestações } \\
\text { locais: dor, } \\
\text { edema, eritema, } \\
\text { calor local, } \\
\text { parestesia e } \\
\text { sensação de } \\
\text { choque elétrico. } \\
\text { Manifestações } \\
\text { Sistêmicas: } \\
\text { Hipertensão } \\
\text { Arterial (150 x } \\
\text { 100 mm Hg), } \\
\text { Náuseas, } \\
\text { Vômitos, } \\
\text { Taquicardia, } \\
\text { Arritmia } \\
\text { Cardíaca, } \\
\text { Astenia, } \\
\text { Tremores, } \\
\text { Vertigem, } \\
\text { Sensação de } \\
\text { Choque elétrico, } \\
\text { dificuldade para } \\
\text { deambular. } \\
\text { Dor: Escala de } \\
\text { dor (08), } \\
\text { Início: } \\
\text { minutos; } \\
\text { Término: } \\
\text { horas. } \\
\text { Dor de evolução } \\
\text { imediata tanto } \\
\text { no membro } \\
\text { afetado como no } \\
\text { local da picada. } \\
\text { Formigamento: } \\
\text { Início: } \\
\text { minutos; } \\
\text { Término: } \\
\text { horas. } \\
\text { Formigamento } \\
\text { de evolução }\end{array}$ & Moderado & $\begin{array}{l}\text { Observação, } \\
\text { Hidratação, } \\
\text { Prometazina } \\
\text { (01 ampola), } \\
\text { Dipirona (01 } \\
\text { ampola), } 02 \\
\text { ampolas de } \\
\text { Soro anti- } \\
\text { escorpiônico } \\
\text { (SAESC). }\end{array}$ & - \\
\hline
\end{tabular}


Quadro 2 - Aspectos clínicos e epidemiológicos de pacientes vítimas de escorpionismo que trouxeram o animal para o serviço de saúde nos municípios pertencentes ao 9² CRS/SESPA, ano 2017.

\begin{tabular}{|c|c|c|c|c|c|}
\hline & & & 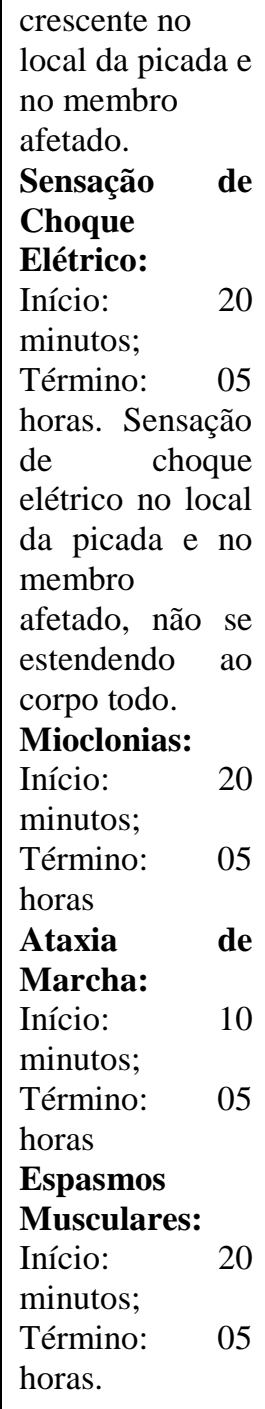 & & \\
\hline $\begin{array}{l}04 \\
\text { T. obscurus } \\
\text { (Macho) }\end{array}$ & $\begin{array}{l}\text { Curimatã } \\
\text { 29.03.2017 }\end{array}$ & $\begin{array}{l}36 \text { anos, sexo } \\
\text { masculino, } \\
\text { eletricista, ensino } \\
\text { fundamental } \\
\text { incompleto, renda } \\
\text { de um salário } \\
\text { mínimo. } \\
\text { Local do acidente: } \\
\text { Alter-do-Chão- } \\
\text { Município de de } \\
\text { Santarém. } \\
\text { Situação em que } \\
\text { ocorreu }\end{array}$ & \begin{tabular}{l}
\multicolumn{2}{l}{ Manifestações } \\
locais: dor, \\
edema, eritema, \\
parestesia e \\
sensação de \\
choque elétrico. \\
Manifestações \\
Sistêmicas: \\
Astenia, \\
Tremores/Espas \\
mos, Nistagmo, \\
Disdiadococcine-
\end{tabular} & Moderado & - \\
\hline
\end{tabular}


Quadro 2 - Aspectos clínicos e epidemiológicos de pacientes vítimas de escorpionismo que trouxeram o animal para o serviço de saúde nos municípios pertencentes ao $9^{\circ} \mathrm{CRS} / \mathrm{SESPA}$, ano 2017.

(continuação)

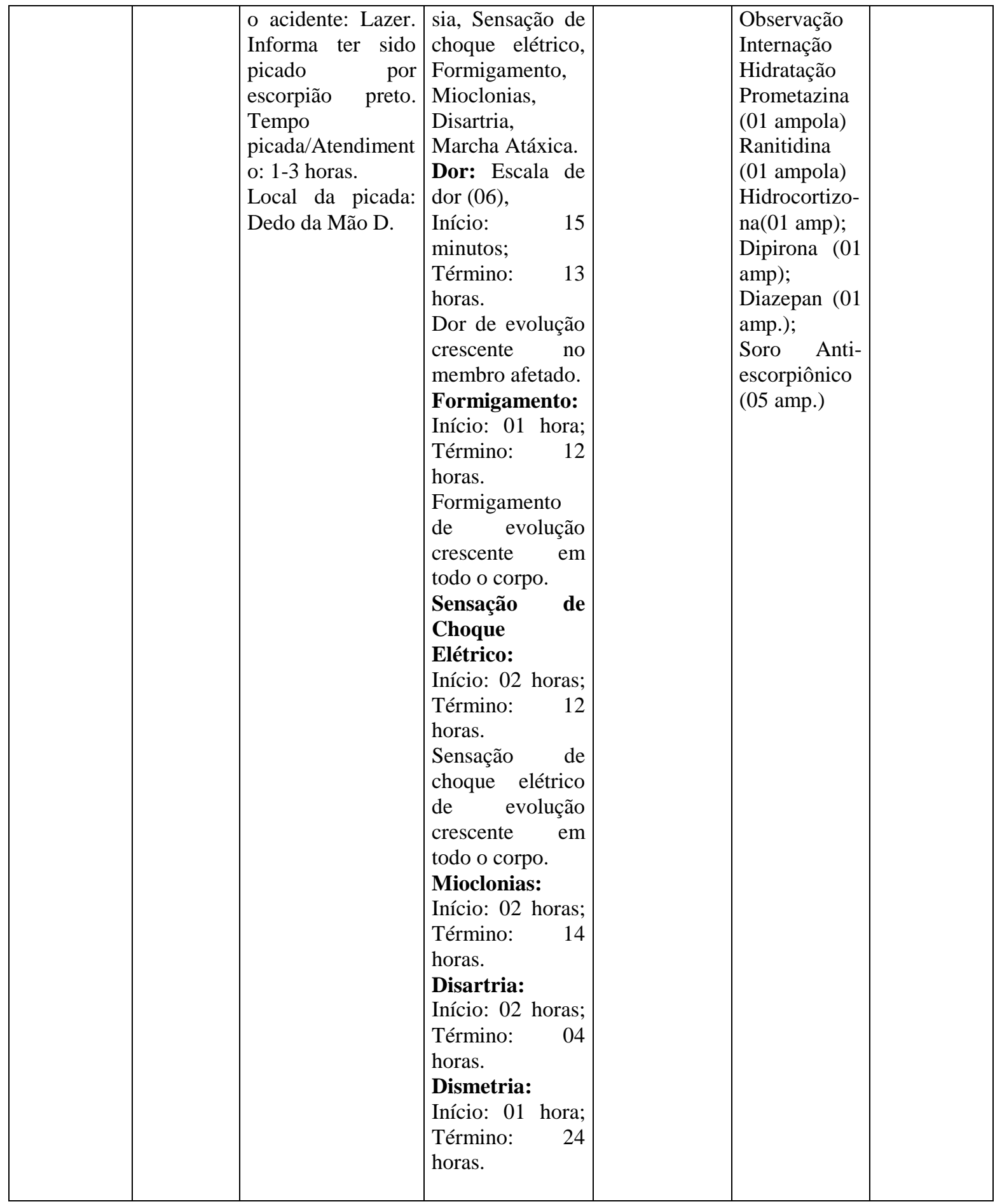


Quadro 2 - Aspectos clínicos e epidemiológicos de pacientes vítimas de escorpionismo que trouxeram o animal para o serviço de saúde nos municípios pertencentes ao $9^{\circ} \mathrm{CRS} / \mathrm{SESPA}$, ano 2017.

(continuação)

\begin{tabular}{|c|c|c|c|c|c|c|}
\hline & & & 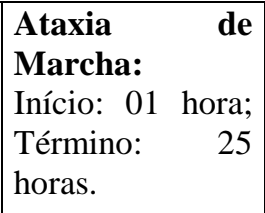 & & & \\
\hline \begin{tabular}{|l|}
05 \\
$T$. \\
obscurus \\
(Macho)
\end{tabular} & $\begin{array}{l}\text { Dourado } \\
18.03 .2017\end{array}$ & $\begin{array}{l}33 \text { anos, sexo } \\
\text { masculino, } \\
\text { vigilante, ensino } \\
\text { médio completo, } \\
\text { renda entre } 2 \text { a } 3 \\
\text { salários mínimos. } \\
\text { Local do acidente: } \\
\text { Bairro Matinha, } \\
\text { Zona Urbana- } \\
\text { Município de } \\
\text { Santarém. } \\
\text { Situação em que } \\
\text { ocorreu rar o } \\
\text { acidente: No } \\
\text { banho (ao pegar a } \\
\text { toalha para se } \\
\text { enxugar). Informa } \\
\text { ter sido picado por } \\
\text { lacrau pequeno } \\
\text { marrom escuro. } \\
\text { Tempo/Picada } \\
\text { atendimento: 1-3 } \\
\text { horas. Local da } \\
\text { picada: Região } \\
\text { Escapular E. }\end{array}$ & 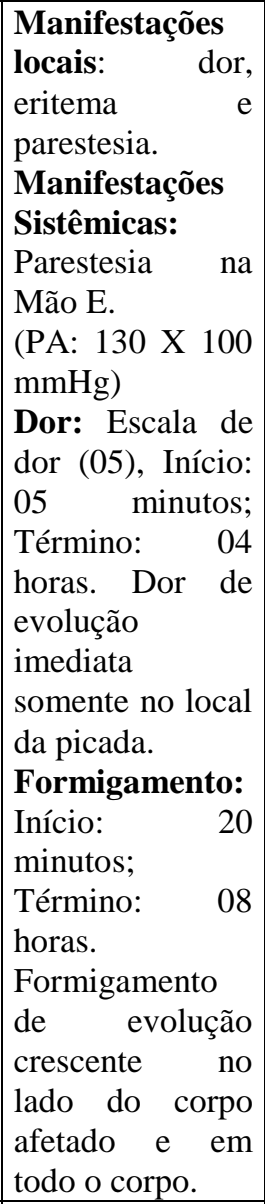 & Leve & 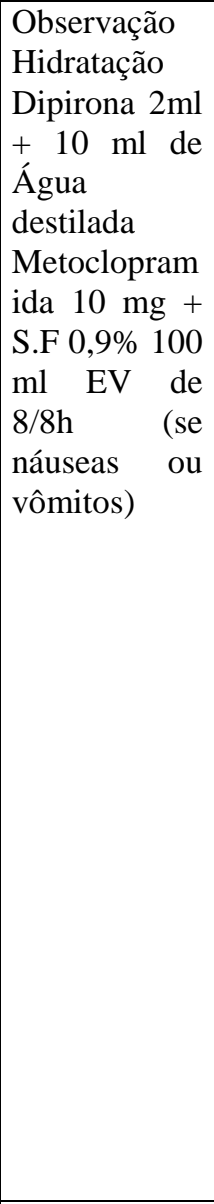 & \\
\hline \begin{tabular}{|l|}
06 \\
$T$. \\
obscurus \\
(Macho)
\end{tabular} & $\begin{array}{l}\text { Jaraqui } \\
\text { 08.06.2017 }\end{array}$ & $\begin{array}{l}19 \text { anos, sexo } \\
\text { masculino, } \\
\text { soldado, ensino } \\
\text { médio incompleto, } \\
\text { renda de um } \\
\text { salário mínimo. } \\
\text { Local do } \\
\text { Acidente: Bairro } \\
\text { Cambuquira, Zona } \\
\text { Urbana-Município } \\
\text { de Santarém. }\end{array}$ & $\begin{array}{l}\text { Manifestações } \\
\text { locais: dor } \\
\text { intensa, edema, } \\
\text { eritema, calor } \\
\text { local, sudorese, } \\
\text { parestesia, } \\
\text { sensação de } \\
\text { choque elétrico. }\end{array}$ & Moderado & & $\begin{array}{l}\text { Observação } \\
\text { Hidratação } \\
\text { Pré- } \\
\text { anestésico } \\
02 \text { amp. } \\
\text { SAESC } \\
\text { Benzodiaze } \\
\text { pínicos }\end{array}$ \\
\hline
\end{tabular}


Quadro 2 - Aspectos clínicos e epidemiológicos de pacientes vítimas de escorpionismo que trouxeram o animal para o serviço de saúde nos municípios pertencentes ao $9^{\circ}$ CRS/SESPA, ano 2017.

(continuação)

\begin{tabular}{|c|c|c|c|c|c|c|}
\hline & & $\begin{array}{l}\text { Situação em que } \\
\text { ocorreu o acidente: } \\
\text { Ambiente de } \\
\text { trabalho. } \\
\text { Informa ter sido } \\
\text { picado por lacrau } \\
\text { preto. Tempo } \\
\text { picada/atendiment } \\
\text { o: 1-3 horas. } \\
\text { Local da picada: } \\
\text { Mão direita. }\end{array}$ & 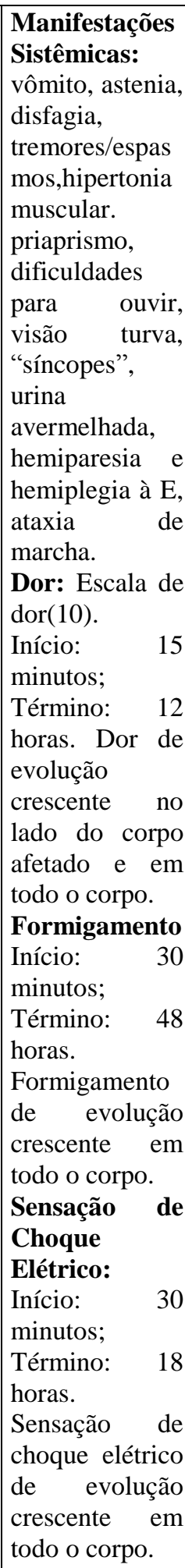 & Moderado & $\begin{array}{l}\text { Observação } \\
\text { Hidratação } \\
\text { Internação } \\
\text { Pré- } \\
\text { soroterapia: } \\
\text { Ranitidina } \\
(01 \text { ampola) } \\
\text { EV; } \\
\text { Prometazina } \\
(01 \text { ampola) } \\
\text { IM } \\
\text { Hidrocortizon } \\
\text { a 500 mg- EV } \\
\text { Diazepam 5 } \\
\text { mg- EV }\end{array}$ & $\begin{array}{l}\text { Uréia: } \\
\text { mg/dl } \\
\text { Creatinina: } \\
0,96 \text { mg/dl } \\
\text { CKMB: } \\
\text { 28,7 U/L } \\
\text { Sódio: } \\
\text { 132,50 } \\
\text { mmol/L } \\
\text { Potássio: } \\
\text { 4,32 mmol }\end{array}$ \\
\hline
\end{tabular}


Quadro 2 - Aspectos clínicos e epidemiológicos de pacientes vítimas de escorpionismo que trouxeram o animal para o serviço de saúde nos municípios pertencentes ao $9^{\circ}$ CRS/SESPA, ano 2017.

(continuação)

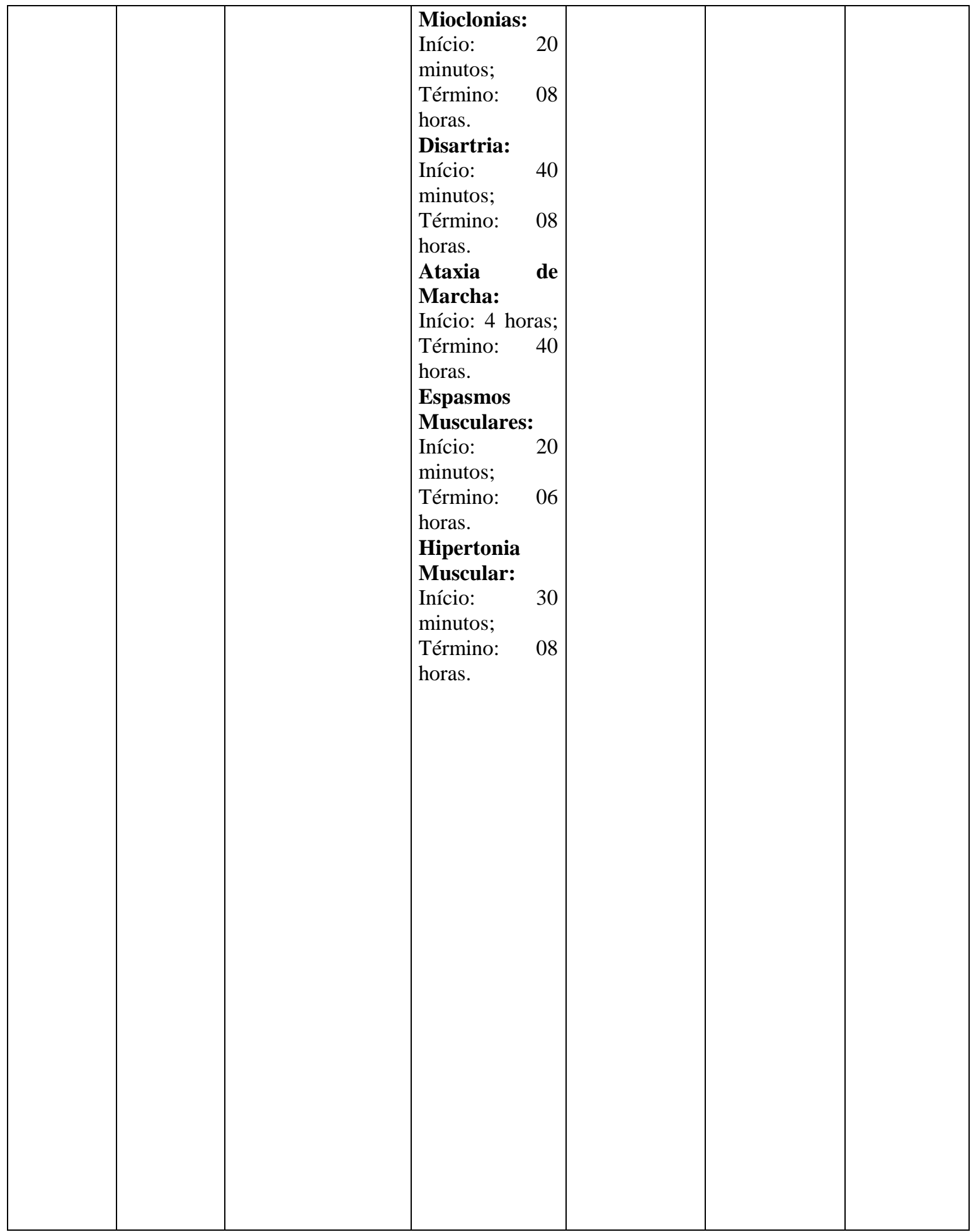


Quadro 2 - Aspectos clínicos e epidemiológicos de pacientes vítimas de escorpionismo que trouxeram o animal para o serviço de saúde nos municípios pertencentes ao $9^{\circ} \mathrm{CRS} / \mathrm{SESPA}$, ano 2017.

\begin{tabular}{|c|c|c|c|c|c|c|}
\hline \begin{tabular}{|l|}
07. \\
$T$. \\
obscurus \\
(Macho)
\end{tabular} & $\begin{array}{c}\text { Mapará } \\
19.06 .2017\end{array}$ & 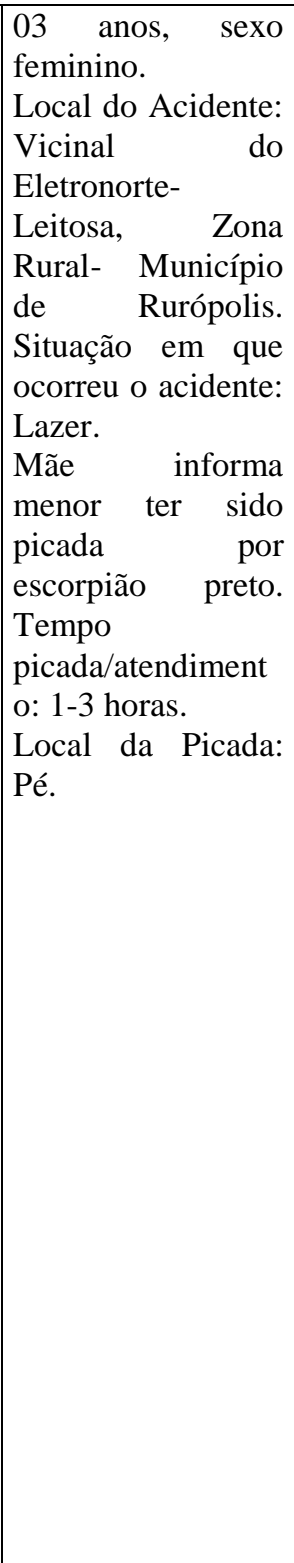 & 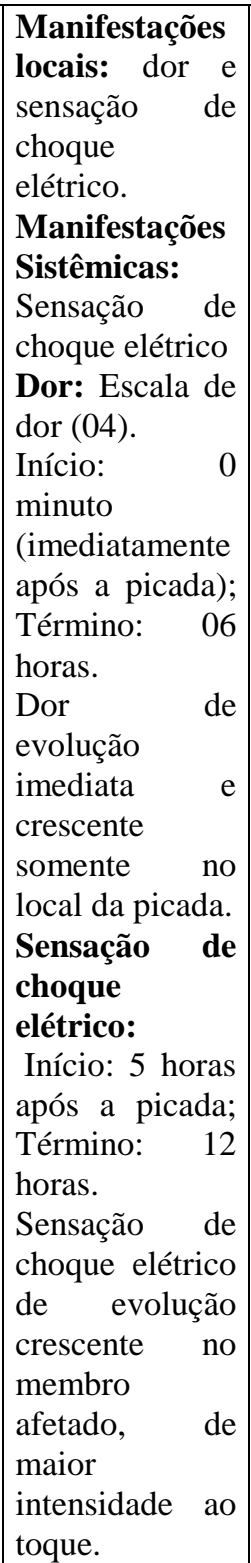 & Moderado & \begin{tabular}{|l|} 
Observação \\
Hidratação \\
Analgésico \\
Benzodiazepí \\
nico \\
Pré- \\
soroterapia, \\
Soro Anti- \\
escorpiônico \\
(02 ampolas)
\end{tabular} & \\
\hline \begin{tabular}{|l|}
08 \\
T. \\
obscurus \\
(Fêmea)
\end{tabular} & $\begin{array}{c}\text { Pacú } \\
\text { 19.05.2017 }\end{array}$ & 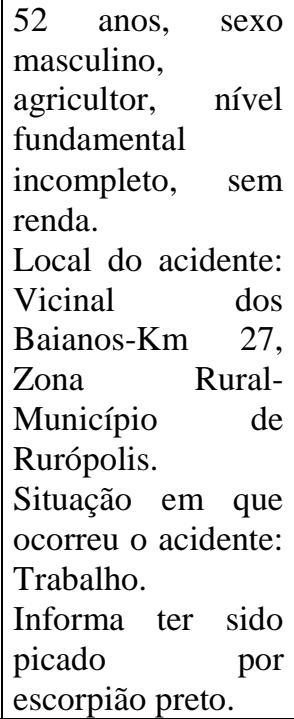 & \begin{tabular}{|lr|}
\multicolumn{2}{|l|}{ Manifestações } \\
locais: dor \\
intensa, \\
parestesia \\
sensação de \\
choque \\
elétrico. \\
Manifestações \\
Sistêmicas: \\
Sensação de \\
choque elétrico \\
em todo o \\
lorpo. \\
Dor: Escala de \\
dor (10).
\end{tabular} & Moderado & & \\
\hline
\end{tabular}


Quadro 2 - Aspectos clínicos e epidemiológicos de pacientes vítimas de escorpionismo que trouxeram o animal para o serviço de saúde nos municípios pertencentes ao $9^{\circ} \mathrm{CRS} / \mathrm{SESPA}$, ano 2017.

(continuação)

\begin{tabular}{|c|c|c|c|c|c|c|}
\hline & & $\begin{array}{l}\text { Tempo } \\
\text { picada/atendimento: } \\
\text { 1- } 3 \text { horas. } \\
\text { Local da picada: } \\
\text { Mão. }\end{array}$ & 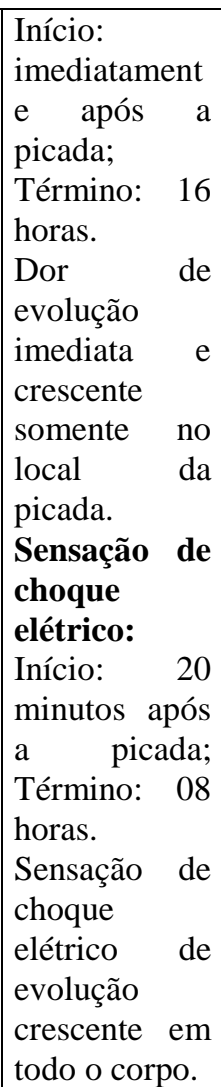 & Moderado & \begin{tabular}{|l|} 
Observação; \\
Hidratação; \\
Benzodiazepí \\
nico; \\
Analgésicos; \\
Anti- \\
Inflamatório \\
03 ampolas \\
de Soro Anti- \\
escorpiônico.
\end{tabular} & $\begin{array}{l}\text { Amilase: } \\
100 \\
\text { Creatinina: } \\
1,5 \\
\text { TGO: } 42 \\
\text { TGP:29 } \\
\text { Uréia:35 }\end{array}$ \\
\hline $\begin{array}{l}9 . T . \\
\text { obscurus } \\
\text { (Fêmea) }\end{array}$ & $\begin{array}{l}\text { Pescada } \\
21.08 .2017\end{array}$ & 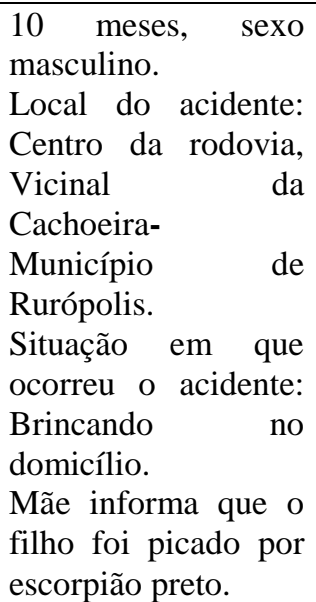 & $\begin{array}{l}\text { Manifestaçõe } \\
\text { s locais: dor e } \\
\text { edema. } \\
\text { Manifestaçõe } \\
\text { s Sistêmicas: } \\
\text { Sensação de } \\
\text { choque } \\
\text { elétrico em } \\
\text { todo o corpo. }\end{array}$ & Leve & $\begin{array}{l}\text { Observação; } \\
\text { Hidratação; } \\
\text { Analgésico; } \\
\text { Benzodiazepí } \\
\text { nico(0,5 cc de } \\
\text { Diazepan). } \\
\text { Não recebeu } \\
\text { soroterapia. }\end{array}$ & $\begin{array}{l}\text { TGO: } 46 \\
\text { TGP: } 18 \\
\text { Uréia: } 33 \\
\text { Creatinina: } \\
1,0 \\
\text { Amilase: } 45\end{array}$ \\
\hline $\begin{array}{l}\text { 10.T. } \\
\text { obscurus } \\
\text { (Fêmea) }\end{array}$ & $\begin{array}{l}\text { Pirarucu } \\
\text { 03.03.2017 }\end{array}$ & $\begin{array}{lrr}\text { sexo } & \text { feminino, } & 55 \\
\text { anos- } & \text { Comunidade } \\
\text { São } & \text { Mateus/ Vicinal } \\
\text { do } & \mathrm{Km} & 57 . \\
\text { Município de Placas }\end{array}$ & $\begin{array}{l}\text { Manifestaçõe } \\
\text { s locais: dor, } \\
\text { edema, } \\
\text { eritema, calor } \\
\text { local, } \\
\text { sudorese e } \\
\text { parestesia. } \\
\text { Manifestaçõe } \\
\text { s sistêmicas: } \\
\text { Hipotensão } \\
\text { arterial, } \\
\text { disfagia, } \\
\text { sensação de } \\
\text { choque }\end{array}$ & Moderado & $\begin{array}{l}\text { Observação; } \\
\text { Hidratação; } \\
\text { Analgésico; } \\
\text { Benzodiazepí } \\
\text { nico. } \\
\text { Soroterapia: } \\
04 \text { ampolas }\end{array}$ & - \\
\hline
\end{tabular}


Quadro 2 - Aspectos clínicos e epidemiológicos de pacientes vítimas de escorpionismo que trouxeram o animal para o serviço de saúde nos municípios pertencentes ao $9^{\circ}$ CRS/SESPA, ano 2017.

(continuação)

\begin{tabular}{|c|c|c|c|c|c|c|}
\hline & & & $\begin{array}{l}\text { elétrico, visão } \\
\text { turva, agitação } \\
\text { psicomotora, } \\
\text { formigamento, } \\
\text { disartria e } \\
\text { ataxia de } \\
\text { marcha. }\end{array}$ & Moderado & & - \\
\hline $\begin{array}{l}11 . T . \\
\text { silvestris } \\
\text { (fêmea } \\
\text { pequena) }\end{array}$ & $\begin{array}{l}\text { Surumbi } \\
29.07 .2017\end{array}$ & $\begin{array}{l}17 \text { anos, estudante, } \\
\text { ensino médio } \\
\text { incompleto. } \\
\text { Local do acidente: } \\
\text { Bairro Jacundá- } \\
\text { Distrito de Alter- } \\
\text { do -Chão- } \\
\text { Município de } \\
\text { Santarém. Situação } \\
\text { em que ocorreu o } \\
\text { acidente: } \\
\text { Domicílio. } \\
\text { Informa ter sido } \\
\text { picada } \\
\text { escorpião amarelo. } \\
\text { Tempo } \\
\text { picada/atendiment } \\
\text { o: 0-1 hora. } \\
\text { Local da Picada: } \\
\text { Pé. }\end{array}$ & 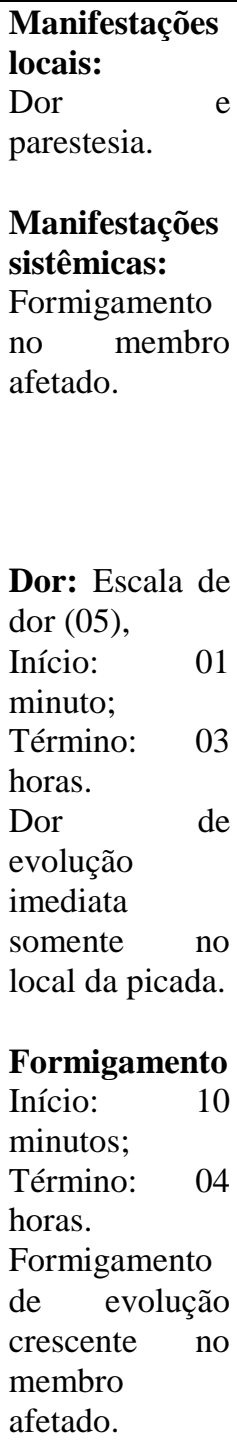 & Leve & $\begin{array}{l}\text { Observação, } \\
\text { Hidratação, } \\
\text { Analgésico. }\end{array}$ & - \\
\hline
\end{tabular}


Quadro 2 - Aspectos clínicos e epidemiológicos de pacientes vítimas de escorpionismo que trouxeram o animal para o serviço de saúde nos municípios pertencentes ao $9^{\circ}$ CRS/SESPA, ano 2017.

(continuação)

\begin{tabular}{|c|c|c|c|c|c|c|}
\hline $\begin{array}{l}12 \\
T . \\
\text { obscurus } \\
\text { (Macho) }\end{array}$ & $\begin{array}{c}\text { Tambaqui } \\
14.07 .2017\end{array}$ & $\begin{array}{l}10 \text { anos, sexo } \\
\text { masculino, } \\
\text { estudante, nível } \\
\text { fundamental } \\
\text { incompleto. } \\
\text { Local do acidente: } \\
\text { Bairro Mararú, } \\
\text { Zona Urbana do } \\
\text { município de } \\
\text { Santarém. Situação } \\
\text { em que ocorreu o } \\
\text { acidente: } \\
\text { Domicílio. } \\
\text { Pai informa que o } \\
\text { menor foi picado } \\
\text { por lacrau marrom } \\
\text { avermelhado } \\
\text { enquanto dormia } \\
\text { durante a } \\
\text { madrugada. Tempo } \\
\text { picada/atendiment } \\
\text { o: 1- 3 horas. } \\
\text { Local da Picada: } \\
\text { Dedo da Mão E. }\end{array}$ & \begin{tabular}{|l|} 
Manifestações \\
locais: \\
Dor, eritema, \\
calor local e \\
parestesia. \\
Manifestações \\
sistêmicas: \\
Formigamento. \\
Dor: Escala de \\
dor (4); \\
Início: \\
Imediatamente \\
após a picada; \\
Término: 20 \\
horas. \\
Dor \\
evolução \\
imediata \\
somente no \\
local da picada. \\
Formigamento \\
Início: 20 \\
minutos após a \\
picada; \\
Término: 24 \\
horas. \\
Formigamento \\
de evolução \\
crescente no \\
membro \\
afetado. \\
\end{tabular} & Leve & $\begin{array}{l}\text { Observação } \\
\text { SF 0,9\% } 500 \\
\text { ml- EV } \\
\text { Hidrocortizon } \\
\text { a } 100 \text { mg- EV } \\
\text { Ranitidina } 1 \\
\text { ml EV }\end{array}$ & \\
\hline $\begin{array}{c}13 \\
\text { T. strandi } \\
\text { (macho) }\end{array}$ & $\begin{array}{l}\text { Tucunaré } \\
13.07 .2017\end{array}$ & 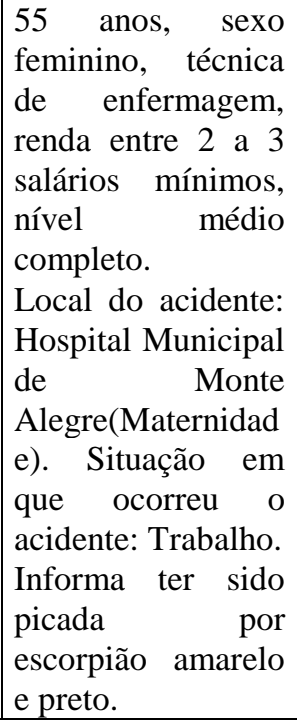 & \begin{tabular}{|l|} 
Manifestações \\
locais: \\
Dor, edema, \\
eritema, r re \\
parestesia de \\
sensação \\
choque \\
elétrico. \\
Manifestações \\
sistêmicas: \\
Taquicardia, \\
Formigamento
\end{tabular} & Leve & $\begin{array}{l}\text { Dipirona } 01 \\
\text { amp (EV) } \\
\text { Fernergan } 01 \\
\text { amp. IM } \\
\text { Hidrocortiso- } \\
\text { na } 500 \mathrm{mg}\end{array}$ & - \\
\hline
\end{tabular}


Quadro 2 - Aspectos clínicos e epidemiológicos de pacientes vítimas de escorpionismo que trouxeram o animal para o serviço de saúde nos municípios pertencentes ao 9² CRS/SESPA, ano 2017.

(conclusão)

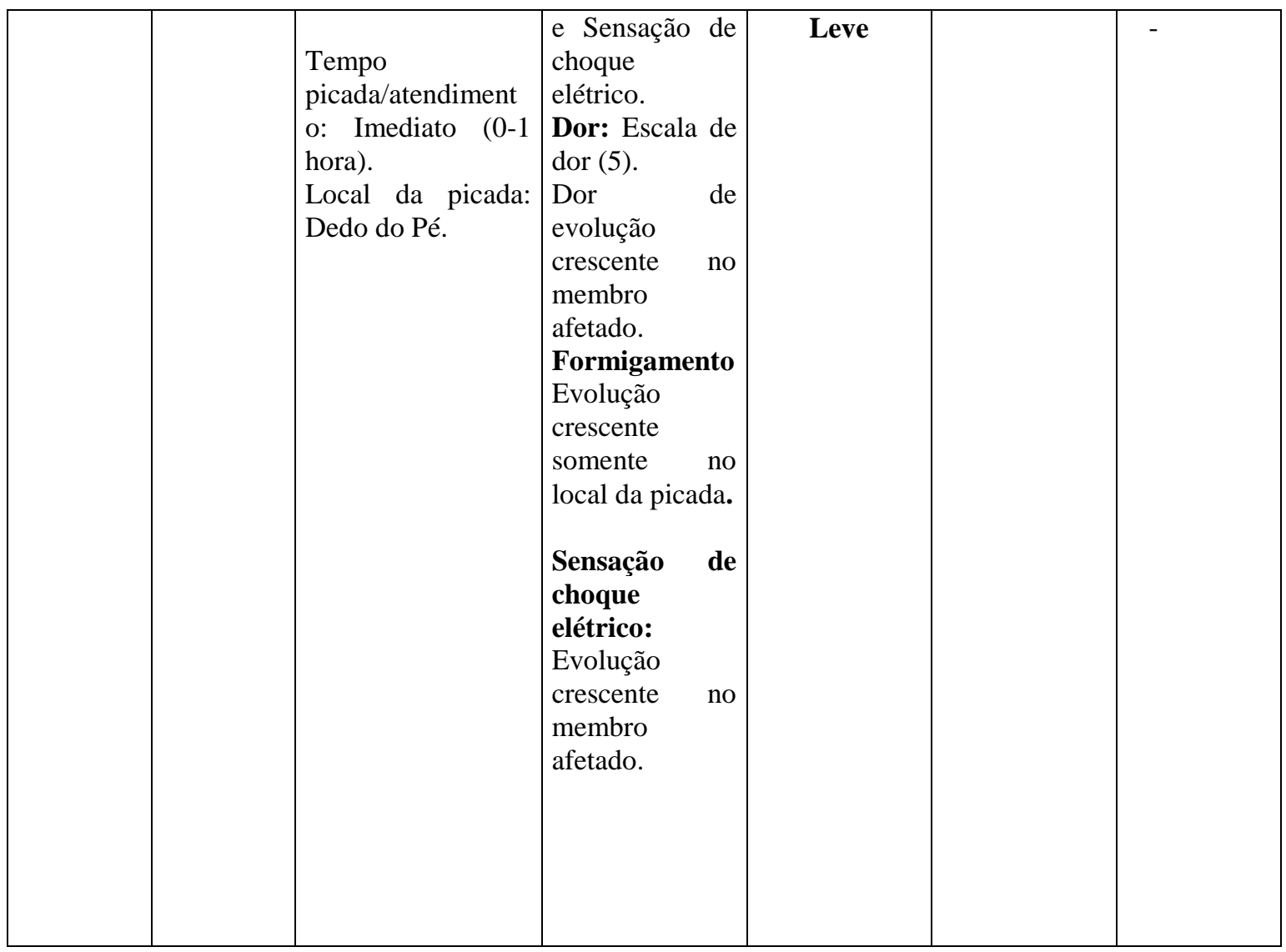

(conclusão) 


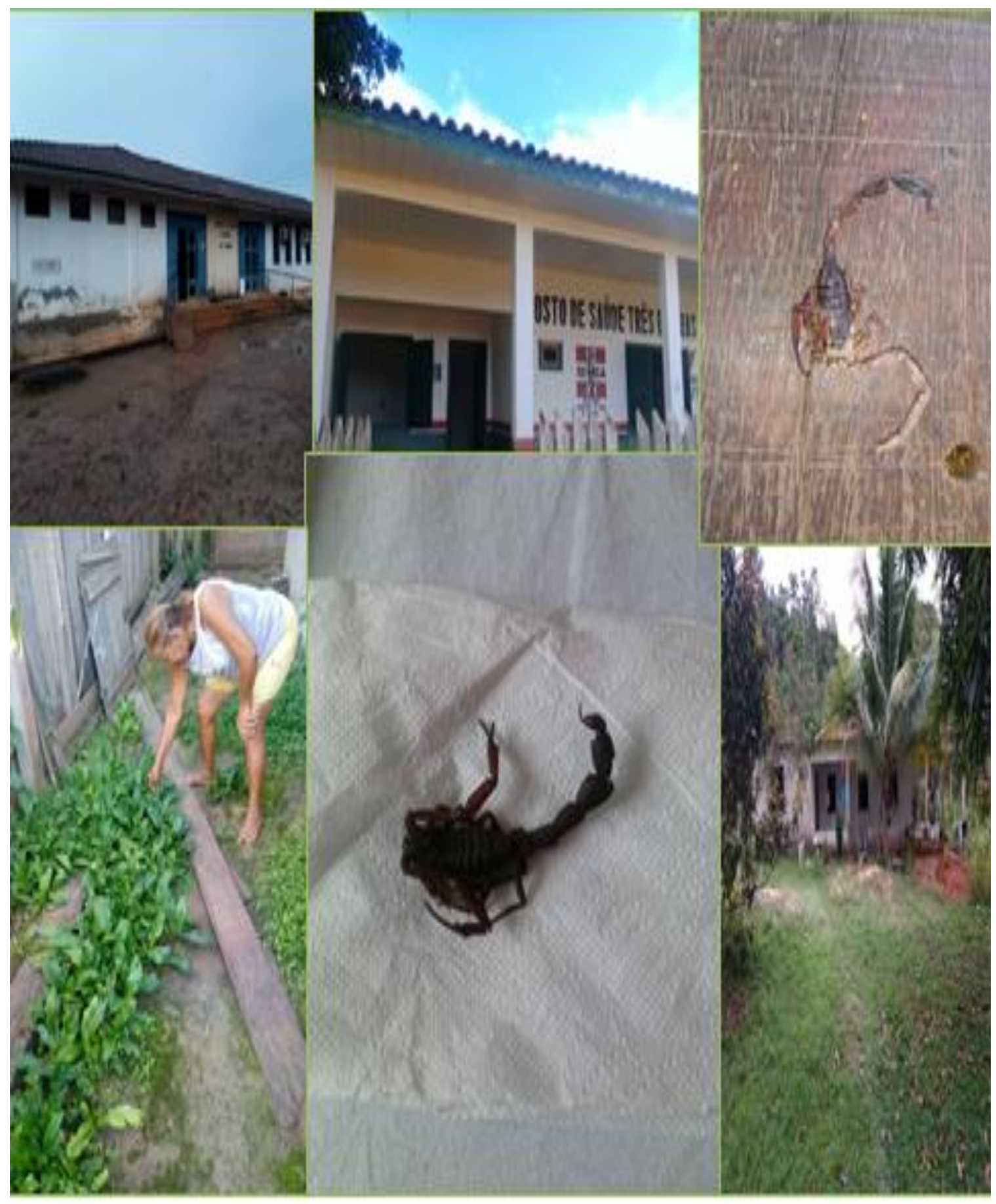

5 DISCUSSÃO 


\section{DISCUSSÃO}

Os acidentes por escorpião no oeste do Pará correspondem a 80,5\% dos casos do Estado; o que confirma a importância do escorpionismo na região, como um relevante problema de saúde pública.

Segundo Reckziegel (2013), o Pará foi o estado da região Norte que mais notificou casos de escorpionismo no período de 2000 a 2010. Sifuentes (2007) já apontava um aumento dessas notificações para a região, seguindo a tendência nacional desde 2005, o que também pode ser constatado no presente estudo, no período de 2011 a 2015, como mostra a Tabela 1.

No estudo de Quadros et al. (2014), realizado em 12 municípios da região de Amures, no estado de Santa Catarina, no período de 2000 a 2010, foram registrados 316 acidentes escorpiônicos humanos ocasionados por escorpiões de interesse em saúde pública. Já o estudo de Barbosa et al. (2014), que considera o período de 2005 a 2009, mostrou que foram notificados 2.769 casos de acidentes por escorpião apenas no município de Belo Horizonte, capital do estado de Minas Gerais.

A incidência de escorpionismo na região (Tabela 2) revelou 5,7 casos por 1.000 habitantes. A baixa densidade populacional da região pode ser explicada porque a maioria dos municípios tem menos de 30 anos de criação, pois devido à abertura das rodovias SantarémCuiabá e Transamazônica, vários povoados e distritos se emanciparam, como é o caso de Novo Progresso, que foi desmembrado de Itaituba, Mojuí dos Campos, Belterra e Placas de Santarém (ANDRADE, 2014).

Ao se calcular a incidência dos casos da região por 100.000 habitantes, obtém-se uma incidência acumulada de 574,5 acidentes de escorpionismo por 100.000 habitantes. No nordeste do Mali, país do continente africano, a pesquisa de Dabo et al. (2011) mostrou que a incidência de picadas de escorpião foi de 276 casos/100.000 habitantes/ ano. Na Argélia, Laïd et al. (2012) observaram incidência média anual de $152 \pm 3,6$ picadas de escorpião por 100.000 habitantes. No Brasil, Reckziegel (2013) aponta uma média de 17,7 acidentes para cada 100.000 habitantes. Em Minas Gerais, na cidade de Belo Horizonte, o estudo de Barbosa et al. (2014) apresenta uma incidência acumulada de 114,7 casos por 100.000 habitantes.

De acordo com documento do Ministério da Saúde (2015), a incidência de casos de escorpionismo, no ano de 2015, ano que finda o período correspondente ao estudo retrospectivo, foi de 43,2 acidentes por 100.000 habitantes, sendo que a maioria dos acidentes escorpiônicos foram classificados como leves. 
No período de estudo da presente investigação, o município de Santarém registrou o maior número de acidentes escorpiônicos na região do Baixo Amazonas (Tabela 3), e elevada incidência (884/1.000 habitantes: 30\%). Vale ressaltar que o município de Santarém é referência em relação à assistência à saúde para os demais municípios na região.

O presente estudo apontou um elevado aumento no número de acidentes escorpiônicos na região sudoeste do Pará. Esse crescimento pode estar associado ao acelerado desenvolvimento da região. Exemplo disso, de acordo com Andrade (2014), era a previsão de construção de onze usinas hidrelétricas, oito portos no rio Tapajós, a pavimentação das rodovias Transamazônica (BR-230) e Cuiabá-Santarém (BR-163) e a duplicação da linha de transmissão Tramoeste. Tal aceleração do desenvolvimento pode aumentar os impactos ambientais já observados na atualidade. É importante ressaltar que a região apresenta baixa densidade demográfica e, apesar do considerado "desenvolvimento", anteriormente mencionado, possui grande parte de sua cobertura florestal preservada.

O maior projeto de usina hidrelétrica na região é o de Belo Monte, que teve o início de suas obras no ano de 2012, porém, todo o seu processo de construção está previsto para durar dez anos e, ao todo, serão 11 municípios afetados, incluindo os afetados diretamente que são: Altamira (área urbana e rural), Vitória do Xingu (rural) e Brasil Novo (rural), além daqueles cujas influências serão indiretas: Anapu, Senador José Porfírio, Pacajá, Gurupá, Medicilândia, Placas, Porto de Moz, Uruará (LEME, 2009). Tal reflexão é importante, pois o impacto ambiental é evidenciado no comportamento dos escorpiões, contribuindo para o consequente aumento dos acidentes por esses artrópodes.

De fato, os registros de acidentes escorpiônicos, no período estudado, são extremamente relevantes e podem ser associados às modificações espaciais e sociais ocorridas na região Oeste do Estado na última década. Coincidentemente ou não, os municípios com maior incidência estão localizados às margens das rodovias federais, enquanto que aqueles com menor incidência localizam-se às margens de rios. Além das grandes obras do Governo Federal no sudoeste do Estado, como as usinas hidrelétricas de Belo Monte e Tapajós e a pavimentação das rodovias Transamazônica e Santarém-Cuiabá, destaca-se a intensificação da atividade agrícola de grãos para exportação, tendo como porta de escoamento os portos de Santarém e Itaituba, o que também contribui para o impacto ambiental negativo.

Além dessas transformações espaciais e ambientais, verifica-se a alta plasticidade ecológica de algumas espécies de escorpião, o que pode relacionar-se ao aumento do número de acidentes registrados no SINAN nos últimos anos. Ademais, com o desmatamento florestal, os escorpiões passam a se dispersar no ambiente, tendendo a estar mais próximos 
das moradias, principalmente na zona rural, oportunizando um maior número de acidentes (COSTA, 2012).

Em relação ao perfil sociodemográfico das vítimas de escorpionismo atendidas no Hospital Municipal de Santarém, no ano de 2016, conforme descrito na Tabela 5, evidencia a predominância do sexo masculino, assim como em estudo realizado em Belo Horizonte, no período entre 1990 a 1997, por Soares (2002), com 55,2\% e, em estudo também realizado em Santarém, no período de 2000 a 2001, com incidência de 83,3\% dos casos no sexo masculino (PARDAL et al., 2003) e, ainda, em estudo realizado na Bahia, por Santos et al. (2012), no período de 2007 a 2010, com predominância do sexo masculino de 52,4\%.

Ainda em relação aos achados encontrados na primeira etapa do estudo, a faixa etária preponderante esteve entre 16 a 30 anos de idade, corroborando os resultados de outros estudos epidemiológicos (Amorim et al.,2003; Lira da Silva et al., 2009). A faixa de 31 a 45 anos de idade também foi relevante. Segundo Reckziegel (2013), 46,9\% dos acidentes no Brasil, no período de 2000 a 2010, concentraram-se na faixa etária de 20 a 49 anos, e os homens foram os mais acometidos.

Continuando a discussão em relação ao perfil das pessoas acometidas pelo escorpionismo, a Tabela 5, que mostra dados relativos à primeira etapa do estudo, o retrospectivo, no Hospital Municipal de Santarém, revela importante lacuna em relação a algumas variáveis, uma vez que não estavam preenchidas corretamente ou simplesmente não registradas em sua maioria, como renda e escolaridade. Os registros efetuados para esta variável mostraram, em maior parcela, pacientes que tinham renda de até um salário mínimo (23:19,0\%) e nível fundamental incompleto $(27: 22,0 \%)$.

Araújo e Silva (2008) ressaltam a importância do SINAN para a Vigilância Epidemiológica, na efetividade e sustentabilidade de um programa de controle de doença. Os autores afirmam que a tomada de decisões, a alocação de recursos e as análises relativas ao perfil de morbimortalidade dependem de informações detalhadas, acuradas, além do conhecimento do fluxo de informações.

No que diz respeito à situação geradora do acidente, como pode ser observado nos dados da Tabela 6, em sua grande maioria, também apresentava informações inadequadas (ignorada ou sem informação, com 98 registros: 80,0\%). Entretanto, quando presentes, os registros referentes a esta variável apresentam o indivíduo acometido em situação de trabalho (15:12,0\%) corroborando com outros estudos (GALVÃO; RODRIGUES, 2012; QUEIROZ et al., 2015). A maior taxa de crescimento de acidentes pode estar relacionada às diferenças ocupacionais e comportamentais no ambiente domiciliar, a exemplo da execução de 
atividades domésticas de maior risco, como a limpeza de locais que normalmente servem de abrigo para escorpiões (OLIVEIRA et al., 2012).

Conforme apontado na Introdução, os escorpiões possuem hábitos noturnos, preferencialmente costumam permanecer em locais tranquilos e escuros, se escondendo em troncos de árvores, e debaixo de pedras. Já os que se adaptam à vida urbana são encontrados, geralmente, em entulhos (JUNKES; MAZON, 2013).

Em relação ao tempo entre a picada e o atendimento no pronto socorro de Santarém, os dados relativos à primeira etapa do estudo (Tabela 6) mostram que prevaleceu o período entre 4 a 12 horas (32: 26,0\%), seguido de 2 a 3 horas (29: 24,0\%). O primeiro resultado é semelhante ao encontrado por Campolina (2006), em Belo Horizonte, que o atribuiu ao atraso no atendimento, além de dificuldades no transporte do paciente. Pardal et al. (2003), no Hospital Municipal de Santarém, também verificaram que o tempo médio entre a picada e atendimento foi de 4,6 horas. O município de Santarém carece de transportes públicos em quantidade, ressaltando-se que as comunidades localizadas à beira do rio dependem do transporte fluvial. Da mesma forma, muitas comunidades da zona rural, na área de planalto, são muito longínquas das unidades de saúde, o que contribui para complexificar o itinerário terapêutico.

Documento do Ministério da Saúde (2001) ressalta a importância da urgência dos atendimentos, uma vez que um quadro clínico sistêmico com evolução desfavorável pode se estabelecer de alguns minutos a poucas horas.

Voltando à análise do perfil sociodemográfico, a Tabela 7 apresenta os dados em relação à ocupação, verificando-se que mais uma vez prevaleceram as informações inadequadas ou faltantes (68: 55,0\%). Dos dados registrados, verificou-se que agricultores foram os mais acometidos pelo agravo escorpiônico no ano de 2016 no Hospital Municipal de Santarém, com 31 pacientes $(25,0 \%)$. A situação geradora do acidente, no trabalho (para 15 pacientes: 12,0\%), conforme já mencionado em relação aos dados da Tabela 6, pode contribuir para o detalhamento da maior frequência do agravo entre os agricultores. Tal situação pode ser corroborada por estudo realizado no estado do Amazonas, no período de 2007 a 2014, que constatou que cerca de 38,7\% das picadas foi classificada como acidentes de trabalho (QUEIROZ et al., 2015).

Em relação ao local do corpo em que ocorreu a picada, conforme pode ser verificado no Gráfico 2, ainda que na maioria das vezes seja ignorado/sem informação (40:32,0\%), tanto em registros nos prontuários, quanto nas fichas de notificação, verifica-se a preponderância dos pés $(42: 34,0 \%)$ e mãos $(28: 23,0 \%)$, o que coloca em evidência o risco da manipulação de 
objetos e de pisar no solo ou calçar sapatos sem prévia observação. Na literatura assinala-se o acometimento dos membros superiores, com maior frequência, em decorrência do manuseio de materiais de construção ou entulho em residências ou em outros ambientes, assim como em situações de limpeza doméstica (PARDAL et al., 2003). Por outro lado, Pipelzadeh et al. (2007), em estudo realizado no Irã mostraram ser os membros inferiores os mais atingidos.

A análise do escorpionismo de pacientes atendidos no Hospital Municipal de Santarém, em 2016, revela que os pacientes apresentaram tanto manifestações locais quanto sistêmicas. A dor local foi o sintoma mais referido $(87,0 \%)$; é praticamente imediata, variando de intensidade leve a muito intensa ou insuportável, dependendo principalmente da sensibilidade individual e, às vezes, da irradiação para a raiz dos membros (CUPO, 2015). A dor decorre, provavelmente, da ação direta do veneno, devido às proteínas neurotóxicas.

No presente estudo, conforme pode ser verificado no Gráfico 3, a parestesia foi a segunda ocorrência mais registrada nos prontuários/fichas de notificação (29:22,0\%).

Além da dor local, outras manifestações clínicas encontradas, locais ou sistêmicas, são semelhantes aos achados de outros estudos realizados na Paraíba (ALBUQUERQUE et al., 2004), no Pará (PARDAL et al., 2003) e na Bahia (LIRA-DA-SILVA, 2009).

Já entre as manifestações sistêmicas (Gráfico 4), verificou-se preponderância da hipertensão arterial (7:5,7\%). Entretanto, é importante destacar que esses pacientes poderiam apresentar esse achado pregressamente ao evento em estudo. Vale ressaltar, também, que não foram encontrados registros dos valores pressóricos para se determinar a gravidade da hipertensão e a necessidade de uso de anti-hipertensivos.

Em relação a "outras manifestações sistêmicas” destaca-se a turvação visual (Gráfico 5), encontrada em $48,0 \%$ dos achados do estudo retrospectivo.

Os resultados sobre as manifestações locais e sistêmicas corroboram BUCARETCHI et al. (1995) e HORTA (2007), que afirmam que o envenenamento local causa dor, eritema e inchaço. Já o envenenamento sistêmico causa vômito, priapismo, transpiração, hipersalivação, hipotensão arterial ou hipertensão arterial, bradicardia ou taquicardia, e insuficiência cardíaca. No entanto, as manifestações neuromusculares descritas nos acidentes deste estudo não estão contempladas em sua magnitude e frequência na descrição dos autores supra-citados.

A duração das manifestações clínicas não está apresentada neste estudo retrospectivo, em decorrência da ausência de registros em prontuários de pacientes e nos boletins de emergência, o que evidencia fragilidade das informações de profissionais da equipe de saúde, o que pode comprometer a conduta clínica e dificultar a interpretação do agravo. 
Em relação à gravidade dos casos, o Gráfico 6 mostra que, em 2016, 48 (39,0\%) dos acidentes foram moderados, mas $15(12,0 \%)$ foram considerados graves. Destaca-se que as manifestações sistêmicas são características clínicas dos acidentes classificados como moderados e graves (BRASIL, 2009).

De acordo com Goyffon et al. (1982), há quatro estágios de evolução do acidente em relação à gravidade. No Estágio 1: presença de dor no local da picada, que varia de acordo com a intensidade e duração. Quando intensa pode persistir por várias horas, acompanhada por parestesia e hipertermia local. No Estágio 2: persistem sintomas locais acompanhados pelos sistêmicos, tipo sudorese, tremores, sialorréia, rinorréia, náuseas, por vezes diarreia, podendo se observar hipertensão e taquicardia. No Estágio 3: além dos sinais e sintomas anteriores, hipertermia, alterações de consciência como sonolência e torpor. Podem coexistir alterações no ECG, como elevação, achatamento ou depressão da onda $T$, e elevação ou depressão do segmento ST, sem dor torácica. Também podem estar presentes manifestações respiratórias como dispneia e cianose, o que pode indicar necessidade de ventilação mecânica. O Estágio 4: é considerado estágio neurotóxico, que se desenvolve após horas de evolução, e é marcado pela falência circulatória, edema pulmonar, insuficiência respiratória severa, e coma. O ECG sempre é anormal. Essa classificação contempla 4 estágios, sendo que no último destaca-se a manifestação neurotóxica, o que permite pressupor a possibilidade de que acidentes de outras regiões do mundo também possam apresentar manifestações compatíveis com alterações funcionais no sistema nervoso central e periférico. Há relatos de acidentes, em outras regiões do mundo, (fora do Brasil) que apresentam manifestações sugestivas desse comprometimento (CHIPPAUX; GOYFFON, 2008; WARD et al., 2018).

De acordo com Rezende et al. (1998), a gravidade do acidente escorpiônico tem relação com a concentração do veneno no plasma. Também é importante destacar que os casos de maior gravidade devem ser acompanhados em unidade de terapia intensiva (CARDOSO et al., 2009).

Sabe-se que, para a melhor efetividade do soro, ele deve ser espécie-específico, ser mantido em boas condições de conservação, deve ser aplicado o mais precocemente possível, e a dose deve ser suficiente para neutralizar todo o veneno circulante. Geralmente, para garantir a rapidez da neutralização do veneno, o soro deve ser feito por via endovenosa, rapidamente, e sem medicação prévia para combater suposta reação a ele (GUERRA, 2007).

A ação do veneno se inicia poucos minutos após a picada (CAMPOLINA, 2006). Guerra et al. (2008) demonstraram que o atraso de cada hora, na aplicação do soro 
antiescorpiônico, representou aumento de $9 \%$ na razão de chance de morte das crianças picadas em Minas Gerais, entre 2001 a 2005.

A soroterapia específica deve ser aplicada conforme a gravidade do caso. Guerra (2007), em estudo realizado com crianças e adolescentes em Minas Gerais, constatou que, em vários casos leves, foi indicada a soroterapia, fazendo supor o uso abusivo da soroterapia específica. Isso pode representar riscos e gastos desnecessários para pacientes e instituições. Ademais, assinala-se que pode estar havendo equívoco na classificação dos casos quanto à gravidade, fato também observado neste presente estudo.

O soro antiescorpiônico é heterólogo (origem equina), sendo assim, poderá induzir a reações anafiláticas, que são raras, quando administrado em pacientes com quadro moderado ou grave. Este pequeno percentual de reação, pela própria fisiopatologia do envenenamento que leva à liberação maciça de catecolaminas, de certa forma protege o paciente de reações de hipersensibilidade tipo I (ISMAIL, 1994). No presente estudo não foram verificados registros de reação ao soro nos prontuários dos pacientes.

Vale ressaltar que a peculiaridade regional da clínica, com manifestações neuromusculares, leva à internação da vítima para cuidados específicos, conforme os registros em prontuários. Sensação de choque elétrico, dismetria, disartria, ataxia de marcha, e alterações urinárias verificadas nos prontuários/fichas de notificação, promovem um alerta à equipe que assiste vítimas deste agravo. Por outro lado, destaca-se que a evolução favorável, em todos os casos de escorpionismo atendidos no Hospital Municipal de Santarém, no ano de 2016, também pode decorrer da assistência prestada pela equipe de saúde.

O perfil epidemiológico, no estudo prospectivo, revelou que a faixa etária de maior acometimento foi entre 16 a 30 anos de idade (76: 29,0\%), sexo masculino (170:69,0\%), agricultores (88: 34,0\%), seguidos de pacientes classificados em "demais ocupações" (96: $37,0 \%$ ), reunindo estudantes, do lar, pedreiro, garimpeiro, carregador, motorista), com renda de até um salário mínimo (158:61,0\%), ensino fundamental incompleto (149:58,0\%), provenientes da zona rural $(203: 78,0 \%)$, com o acidente tendo ocorrido durante o trabalho (109:42,0\%), com prevalência de tempo entre a picada e o atendimento entre 1 a 3 horas (94:36,3\%), seguida de 4 a 12 horas $(86: 33,2 \%)$. Vale destacar que apenas a variável tempo entre a picada e o atendimento que se diversificou dos achados epidemiológicos na etapa retrospectiva (Tabela 10).

Houve diferença significativa entre sexo e faixa etária no estudo prospectivo, o valor de $\mathrm{p}$ foi de 0,033 , portanto, houve diferença entre as faixas etárias por sexo; porém não entre sexo e escolaridade (p: 0,1885). 
O perfil epidemiológico encontrado neste estudo corrobora outros estudos no Brasil e, especificamente na região (EVANGELISTA; AZEVEDO, 2016; PARDAL et al., 2003; SILVA et al., 2017; TORREZ et al., 2015). Adultos jovens e agricultores em situação de trabalho na zona rural têm sido os mais acometidos pelo agravo na região, uma vez que estão mais expostos e mais vulneráveis ao ambiente do animal.

Enfatiza-se a importância da prevenção de acidentes escorpiônicos durante o trabalho, lazer ou outra atividade, em localidades em que potencialmente se encontra o animal agressor. Vale ressaltar que, em "outros locais" de ocorrência do acidente (73: 28\%), foi citado com frequência o intra-domicílio, tendo o acidente ocorrido por ocasião da troca de roupas, por exemplo; e no peridomicílio (quintal, debaixo de entulho, hortas e folhas de árvores).

Para Andrade (2014), em algumas regiões paraenses, além do crescimento da população urbana, há também uma tendência de aumento da população rural. Esse fenômeno, verificado pelo Censo do IBGE, de 2010, decorre do avanço da fronteira agrícola para a região, dos assentamentos da reforma agrária ao longo da BR-163 e da produção para exportação. De fato, a zona rural teve destaque neste estudo prospectivo e corrobora outros estudos (COSTA et al., 2016; GALVÃO; RODRIGUES, 2012; PARDAL et al., 2014). Queiroz et al. (2015) enfatizam que incidentes com picadas de escorpião mostram uma extensa distribuição na Amazônia brasileira e representam um potencial problema de saúde para as comunidades rurais.

O escorpião preto foi relatado pela maioria das vítimas de escorpionismo na região como o causador dos acidentes, o que possivelmente induz a tratar da espécie $T$. obscurus, também indicada nos estudos de Pardal et al. (2003, 2014) e Torrez et al. ( 2015). Não é comum o paciente levar o animal ao serviço de saúde, quer seja pela falta de informação, quer seja por não tê-lo visualizado, ou por ter exterminado o animal no ambiente de exposição, o que compromete a análise do material empírico.

No presente estudo, algumas vítimas, durante a admissão nos serviços, entregaram o animal agressor e, em outras situações, foram orientadas a entregá-lo durante o período de internação, em caso de sua captura, o que foi feito com frequência em relação aos atendidos no Hospital Municipal de Santarém, em Monte Alegre e em Rurópolis. Em outras situações, como no caso do município de Placas e em alguns casos do município de Rurópolis, as vítimas entregaram fotografias de espécimes.

No Brasil, as principais espécies responsáveis por acidentes graves e consideradas de maior importância clínica são: T. serrulatus, T. bahiensis, T. stigmurus e T. obscurus (MONACO et al. 2017). A espécie T.obscurus é a responsável pelos acidentes graves na 
Amazônia (BRASIL et al., 2009; PARDAL et al., 2003; PARDAL et al., 2014; TORREZ et al.; 2015). Nessa região, as espécies T. metuendus, T. silvestris e Rhopalurus são consideradas de menor importância clínica (BRASIL, 2009).

As espécies causadoras de acidentes nos municípios pertencentes ao $9^{\circ} \mathrm{CRS} / \mathrm{SESPA}$ e entregues pelas pessoas acometidas aos serviços de sáude foram: T. obscurus, T. silvestris e T. strandi. Estas espécies comprovadamente causaram acidentes nos municípios de Santarém, Rurópolis, Placas e Monte Alegre, no período de realização do estudo.

Destaca-se que este projeto é o primeiro a descrever acidente causado por T.strandi (Figura 9) na Amazônia, de acordo com a taxonomia de Lourenço (2002). Foram identificados três acidentes causados por esta espécie, sendo dois ocorridos no município de Santarém e um no município de Monte Alegre.

No que diz respeito aos locais do corpo mais atingidos, em primeiro lugar foram as mãos $(52,0 \%)$ no estudo prospectivo (Gráfico 7), assim como em estudos semelhantes: Kassiri et al. (2013) no Irã; Pardal et al., (2014), no município de Igarapé-Miri, Pará. Tal achado pode ser explicado pela manipulação de objetos, entulho, no ambiente de exposição do animal.

As manifestações locais mais frequentes nos municípios pertencentes ao $9^{\circ}$ CRS/SESPA estão apresentadas na Tabela 16. Dentre estas, a dor foi a mais freqüente e ocorreu em $257(99,0 \%)$ dos casos. De fato, esse sintoma ocorre na maioria dos casos de escorpionismo no Brasil e em estudos realizados no estado do Pará (GUERRA, 2007; Pardal et al., 2014; QUEIROZ et al., 2015; SANTOS et al., 2012; TORREZ et al., 2015). Segundo CUPO (2015), apresenta-se de intensidade variável, aumenta com a palpação, podendo irradiar-se para a raiz do membro acometido e deve-se à toxina do escorpião, que age no canal de sódio, estimulando as terminações nervosas sensitivas.

Assim como no estudo de Pardal et al. (2014), este estudo revelou "picada seca" em 02 pacientes (1\%) acompanhados nos serviços de saúde. Não foi possível a identificação da espécie, pois as vítimas não entregaram o animal agressor ao serviço de saúde. $\mathrm{Na}$ classificação de gravidade proposta por grupo de especialistas em escorpiões no consenso mundial, a picada seca ou a ausência de sintomatologia são elementos que apóiam a classificação do acidente no nível 0 (Khattabi et al., 2011).

A sensação de choque elétrico, como manifestação local, esteve presente em 132 $(51,0 \%)$ vitimas de escorpionismo, conforme destacado na Tabela 14 . O presente estudo é o primeiro a revelar a sensação de choque elétrico como manifestação local do escorpionismo na região. Pacientes revelaram, mesmo por ocasião da alta, que esse sintoma ainda perdurava, 
que sentiam "choque" de leve intensidade ao efetuar o toque no local da picada. Estudos de Pardal et al. (2003); Pardal et al.(2014); e Torrez et al. (2015), realizados em municípios da região, corroboram os achados do presente estudo, revelando dor, parestesia, edema, eritema, calor local, sudorese, piloereção. Também destaca-se que, em outras manifestações locais $(10: 4.0 \%)$, as pessoas acometidas, acompanhadas neste estudo, mencionaram a sensação de queimação e formigamento.

Em estudo realizado por Lira-da-Silva et al. (2000), no estado da Bahia, também havia referência a parestesia no local da picada, de intensidade variável, discreta ou até insuportável. A sensação de dormência e eritema são características do envenenamento por $T$. stigmurus, sendo o quadro clínico local semelhante ao reportado para outras espécies de Tityus (T. serrulatus e T. bahiensis). A parestesia foi encontrada em 130 casos $(50,0 \%)$ do presente estudo (Tabela 14).

A hipertensão arterial foi verificada em 30 pacientes (4,0\%), de acordo com a Tabela 15. Entretanto, esse achado deve ser analisado com o devido cuidado, pois não havia registro pregresso dessa informação. Ainda assim, é necessário destacar que, como consequiência da liberação de catecolaminas, pode haver midríase, arritmia respiratória e cardíaca, taquicardia, hipertensão arterial, podendo haver evolução para falência cardiocirculatória e edema agudo (CUPO et al., 2003).

Em estudo realizado por Pardal et al. (2014), no Oeste do Pará, foram constatadas alterações oftalmológicas como: visão turva (5); hiperemia conjuntival (4) e fotofobia (1) em 14 pacientes. O presente estudo revelou, além de visão turva e fotofobia, a presença de nistagmo, pupilas anisocóricas, sensação de ardência nos olhos e ptose palpebral (Fotografia 1). A presença de nistagmo também foi evidenciada no estudo de Torrez et al. (2015), em dois pacientes $(3,4 \%)$ e ptose palpebral em um paciente $(1,8 \%)$. Destaca-se que a irregularidade na atividade neuromuscular pode desencadear movimentos oculares anormais, em decorrência da estimulação do sistema nervoso periférico (BOYER et al., 2009).

Em relação às manifestações sistêmicas neurológicas e musculares, correspondem à sensação de choque elétrico (148: 57,1\%), formigamento (135: 52,1\%) e ataxia de marcha (89: 34,3\%), conforme evidenciam os dados da Tabela 16. Estes achados corroboram os resultados de Pardal et al. (2003), no município de Santarém; de Galvão e Rodrigues (2012), no município de Rurópolis; de Pardal et al. (2014), nos municípios de Santarém e Rurópolis; e de Torrez et al., (2015), no município de Santarém. Manifestações sistêmicas semelhantes 
foram encontradas também em estudo no México (Chowell et al., 2006) e na Guiana Francesa (Benmosbah et al., 2013).

No desenvolvimento do presente estudo, foi possível acompanhar os pacientes, nos diversos municípios, com os sintomas neuromusculares em todo o corpo, parte do corpo afetado, membro afetado ou ainda somente no local da picada.

Pardal e Gadelha (2010) propõem uma classificação para os casos da região Oeste, incluindo as manifestações neurológicas apresentadas, que estudo recente denomina de disfunção cerebelar aguda (Torrez et al., 2015). Esses autores comprovaram que, além dessas manifestações neurológicas, verificou-se também comprometimento renal nos casos graves, voltando a deixar uma lacuna quanto à classificação mais adequada dos casos de escorpionismo nessa localidade. No presente estudo também foram verificadas alterações urinárias como urina escura, anúria, oligúria e disúria em 21 pacientes $(8,1 \%)$ (Tabela 16). Todos esses foram classificados como acidentes moderados ou graves.

Apesar de todas as evidências que comprovam a peculiaridade e a gravidade dos casos na região, o MS ainda não elaborou diretrizes assistenciais para o manejo clínico desses casos, estando em vigência o Manual de Acidentes por Animais Peçonhentos, publicado há 17 anos e, mais recentemente, a Nota Informativa publicada em 2016, o que se configura como fragilidade da gestão em saúde pública, no que diz respeito a esse acidente em particular (BRASIL, 2001; BRASIL, 2016; TORREZ et al., 2015). Os achados do presente estudo permitem propor mudanças na ficha de notificação de animais peçonhentos para a região, uma vez que apresenta peculiaridades no comportamento clínico. Assim, além da classificação já existente, para essa região do Pará, pode ser proposto que os acidentes com quadro exclusivamente local continuem sendo considerados leves. Os pacientes que apresentam sensação de choque regional ou sistêmico poderiam ser considerados moderados e os pacientes que apresentam quadro de disfunção cerebelar aguda, com ou sem manifestações musculares e renais seriam considerados graves. Pode se propor, também, que esses acidentes, classificados como moderados e graves necessitam ser tratados com soroterapia específica.

É sabido que, por se tratar de um importante instrumento de vigilância, a ficha de notificação requer atenção ao ser preenchida e digitalizada. Principalmente no estudo retrospectivo observaram-se diversos erros, informações incompletas, ignoradas ou preenchidas em campos não correspondentes. Tal situação, além da descoberta de achados específicos do escorpionismo (Pardal et al., 2003; Pardal et al.,2014; Torrez et al., 2015), 
confirma a necessidade de atualizar a ficha de notificação compulsória, pautada na dinâmica do quadro clínico do escorpionismo na região.

Em relação à duração de manifestações neurológicas nos pacientes acompanhados, assim como no estudo de Silva et al. (2017), a dor, na maioria das vítimas, iniciou imediatamente, ou em até 30 minutos, bem como o formigamento. A dor, acompanhada em 173 pacientes, perdurou em média 11 horas.

A sensação de choque elétrico, neste estudo prospectivo, teve início imediato ou em até 30 minutos, com duração de até 24 horas. Os dados corroboram o estudo realizado por Silva et al. (2017), no Amazonas, com a espécie T. apiacas. Enfatiza-se que, no presente estudo, um paciente de 31 anos de idade, do município de Santarém, picado por escorpião na coxa e nádegas, apresentou sensação de choque elétrico que se manteve intensa até o $4^{\circ}$ dia após a picada do animal, acompanhada de hipertemia. Tendo sido o paciente admitido no Hospital Municipal de Santarém, o animal foi identificado como "escorpião preto e grande", sugestivo de T. obscurus. Porém, não foi efetuada entrega do animal ao serviço de saúde, não sendo possível sua identificação.

O acompanhamento das vítimas, que apresentaram sensação de choque elétrico nos 18 municípios neste estudo prospectivo, revela que tal manifestação teve duração de até 100 horas após a picada.

Em relação às disfunções cerebelares, são basicamente caraterizadas pelos transtornos da coordenação de movimentos. Também conhecidas como ataxia, englobam a dismetria, a disdiadococcinesia, distúrbios de marcha e fala; hipotonia, com traços de astenia, nistagmo, reflexos profundos do tipo "pendular" e fenômeno de rebote (SAADI, 2004). Ressalta-se que, no presente estudo, em um acidente grave acompanhado no município de Prainha e posteriormente transferido para o município de Santarém, a criança de 01 ano de idade apresentou hipotonia muscular. O acidente supostamente foi causado por T.obscurus, uma vez que a mãe informou tratar-se de "escorpião preto e grande".

Este estudo comprovadamente acompanhou vítimas de escorpionismo que apresentaram comprometimento cerebelar em 18 municípios pertencentes ao $9^{\circ} \mathrm{CRS} / \mathrm{SESPA}$ (Tabela 18). Estudos anteriores já haviam acompanhado vítimas no oeste do Pará, nos municípios de Santarém, Rurópolis, além de encontrar-se relatos de vítimas em Belterra, Prainha e Itaituba (PARDAL et al, 2003; PARDAL et al. 2014; TORREZ et al, 2015). No presente estudo, os pacientes provenientes desses municípios apresentaram sensação de 
choque elétrico, dismetria, disdiadococcinesia, nistagmo, ataxia de marcha, disartria, mioclonias/fasciculação, hiper e hipotonia muscular, conforme apresentado anteriormente.

A maior incidência de manifestações neurológicas neste estudo pode estar relacionada com a ação neurotóxica causada pela rápida liberação de catecolaminas e acetilcolina após o envenenamento, as quais atuam em diferentes receptores nos diversos tecidos das vítimas, sublinhando-se que há liberação em grande quantidade destes tipos de neurotransmissores (DIAS, 2016). Nas fotografias 2a e 2b, pode-se observar escrita e desenhos de pacientes vítimas de escorpionismo, evidenciando falta de coordenação motora após a picada.

No que diz respeito à espacialização desses acidentes, a metodologia utilizada permitiu revelar que todos os municípios pertencentes ao $9^{\circ} \mathrm{CRS} / \mathrm{SESPA}$ apresentaram risco para a ocorrência do escorpionismo (Figuras 11 e 12). Rurópolis e Santarém apresentaram risco elevado e merecem atenção para a tomada de medidas de prevenção dos acidentes.

A análise espacial de eventos de envenenamento escorpiônico pode ajudar a definir áreas preferenciais de intervenção na prevenção de acidentes, corroborando com a redução de custos, tempo e profissionais envolvidos e, ainda, contribuindo para o controle e manejo do agravo (Almeida et al., 2016). Destaca-se que os achados relativos à espacialização devem ser analisados com base no conceito mais amplo de território, conforme descrito na Metodologia deste estudo. Portanto, entende-se que o risco ao agravo também é socialmente mediado, pelos processos de produção e de reprodução social.

É possível constatar, na Figura 12, que seis municípios apresentaram risco relativo três vezes maior que o risco relativo de toda a área pertencente ao $9^{\circ} \mathrm{CRS} / \mathrm{SESPA}$ : Monte Alegre, Prainha, Uruará, Placas, Rurópolis e Novo Progresso. Com exceção do município de Prainha, todos os municípios situam-se à margem de rodovias. A agricultura faz parte do cotidiano de grande parte da população que reside nestes municípios. A abertura de ramais, ou seja, o desmatamento para o loteamento de terra, nas comunidades rurais, é uma realidade da população amazônica e tal contexto pode ajudar a determinar a ocorrência dos acidentes na região.

Apesar de algumas características geográficas estarem potencialmente associadas à distribuição dos escorpiões, a forma de ocupação dos espaços urbanos exerce grande influência na manutenção de populações de escorpiões em sinantropia (BRASIL, 2009; CRUZ et al., 1995; LOURENÇO et al., 1996).

O método Scan (Figura 13) revelou conglomerados significativos de risco nos municípios de: Mojuí dos Campos, Monte Alegre, Rurópolis, Placas, Trairão e Novo 
Progresso. Os municípios de Monte Alegre, Prainha, Mojuí dos Campos, Belterra, Aveiro, Rurópolis e Placas, apresentam conglomerados de risco para a ocorrência de escorpionismo com comprometimento cerebelar e/ou muscular. Apesar de Santarém ter apresentado número significativo de casos, inclusive com comprometimento cerebelar, não apresenta conglomerados significativos que possibilitem confirmar o Município como área de risco.

Conforme anteriormente mencionado, é importante salientar que, para além da dimensão político-operativa do sistema de saúde, o território, na condição de cotidiano vivido, no qual se dá a interação entre as pessoas e os serviços de saúde, no nível local do SUS, caracteriza-se por uma população específica, vivendo em tempo e espaço determinados, com problemas de saúde definidos, mas com condicionantes e determinantes que emergem de um plano mais geral e que se refere à dimensão estrutural do espaço social, configurado pela especificidade da produção e da reprodução social. Esse espaço apresenta, portanto, além de uma delimitação espacial, um perfil histórico, demográfico, epidemiológico, administrativo, tecnológico, político, social e cultural, que o caracteriza como um território em permanente construção (Miranda et al., 2008). Além destes, é pertinente incluir a dimensão relacional que também apresenta especificidade no micro-espaço social.

Entre os fatores que favorecem a adaptação e a sobrevivência de escorpiões no domicílio, estão os diretamente relacionados ao crescimento não planejado da população urbana, que traz consigo problemas de infraestrutura, falta de saneamento básico e condições precárias de moradia (Nodari et al., 2006), além de outros. A Organização Mundial da Saúde classificou o escorpionismo como doença negligenciada, uma vez que as pessoas mais frequentemente afetadas por este agravo vivem em comunidades pobres (WHO, 2007).

Voltando aos achados do presente estudo, sintomatologia compatível com comprometimento cerebelar e/ou muscular, ocorreu em 23 pacientes $(15,5 \%)$ da zona urbana (Tabela 19), em alguns casos no trabalho: 13 (um dos pacientes era carregador, quatro eram agricultores; três referiram ser autônomos (vendas de mercadorias); um trabalhava em serviços gerais, um era pedreiro, um era madeireiro, uma era do lar e uma era técnica de enfermagem). Um dos acidentes ocorreu em área de mata, seis no domicílio e três em atividades de lazer (no caso de uma criança, uma mulher e um idoso).

No que diz respeito à classificação dos acidentes, foi obtida dos registros dos profissionais de saúde, por ocasião da admissão da vítima e pautada na Nota Informativa do Ministério da Saúde de 2016, conforme informações dos próprios profissionais de saúde e da SESPA (BRASIL, 2016). O tempo entre a picada e o atendimento exerce influência nesta 
classificação, principalmente em relação ao surgimento de manifestações sistêmicas. É necessário, portanto, que os profissionais de saúde conheçam os sinais e sintomas, mas também é fator protetor o acesso à informações a respeito da sintomatologia e primeiros socorros pela comunidade.

O presente estudo corrobora outros estudos realizados em outras partes do Brasil e na região (PARDAL et al., 2014; SILVA et al., 2017; SOUZA et al., 2017; TORREZ et al., 2015) em relação à classificação dos acidentes, pois foram, em sua maioria, leves (146:56,4\%). Entretanto, destaca-se a magnitude dos moderados (99: 38,2\%) e dos graves (14: 5,4\%) (Tabela 20). Quanto a esses últimos, as vítimas foram admitidas nos serviços de saúde, em sua maior parte, entre 4 a 12 horas da ocorrência da picada e todas apresentaram comprometimento cerebelar tendo manifestações neurológicas e musculares já descritas anteriormente. Ressalta-se que duas vítimas, uma criança de 01 ano de idade e um homem de 42 anos de idade, foram monitorados no setor de reanimação do Hospital Municipal de Santarém (Fotografia 3). Assim como em outros estudos realizados na região (Pardal et al.; 2014; Torrez et al., 2015), todos os pacientes apresentaram evolução favorável.

Os fatores de pior prognóstico no acidente escorpiônico envolvem a idade do paciente, o atraso no diagnóstico, o tempo maior do que três horas decorrido entre a picada e a admissão hospitalar, o atraso na administração de soroterapia específica, na identificação e no tratamento das complicações clínicas (CAMPOLINA, 2006). Vale ressaltar que um caso considerado leve na admissão, pode evoluir desfavoravelmente, o que exige monitoramento adequado por parte da equipe de saúde.

O Ministério da Saúde normatiza o uso da soroterapia, de acordo com a classificação do acidente escorpiônico: em casos moderados recomenda-se 2 a 3 ampolas, em graves 4 a 6 ampolas e, casos leves em adultos podem ser tratados apenas com analgesia e bloqueadores (BRASIL, 2001; BRASIL, 2009).

Apesar dessas evidências acerca da soroterapia e da classificação dos casos, o estudo de Torrez et al. (2015) constatou manifestações cerebelares-musculares que não estão incluídas na classificação preconizada pelo Ministério da Saúde e que foram citadas no campo “outras manifestações” por Pardal e Gadelha (2010). A partir disso, Torrez et al. (2015) consideram qualquer sinal cerebelar como pelo menos caso moderado e, portanto, deve ser tratado com soroterapia. Entretanto, os autores constataram que, nesses casos, o antiveneno não reduziu significativamente a gravidade das manifestações cerebelares-musculares após a administração da soroterapia. O presente estudo corrobora os achados de Torrez et al. (2015), 
pois parece não haver redução do quadro de comprometimento cerebelar após o uso da soroterapia específica, conforme apresentado na duração de manifestações clínicas das vítimas acompanhadas neste estudo. A título de destaque, criança de 01 ano de idade, picada por escorpião preto e "grande", na região dos glúteos, no município de Prainha, apresentou sensação de choque elétrico com duração de 30 horas, e espasmos musculares, com duração de 24 horas. Fez uso de soroterapia (3 ampolas) e o tempo decorrido entre a picada e o atendimento foi de 4 a 12 horas. Também apresentou hipotonia muscular. Também vale destacar o caso de um soldado, de 19 anos, picado por escorpião no trabalho, que apresentou sensação de choque elétrico que perdurou por 18 horas após a picada, além de ataxia de marcha por 40 horas. O tempo decorrido entre a picada e o atendimento, nesse caso, encontrase no intervalo de 1 a 3 horas.

De acordo com Freire-Maia et al. (1994), o objetivo do soro anti-veneno é a neutralização do veneno circulante e o veneno que está sendo absorvido no local da picada, reduzindo ou interrompendo a liberação de mediadores.

A tabela 22 mostra as condutas clínicas tomadas pelos profissionais que prestaram assistência às vítimas de escorpionismo nos 18 municípios. Pardal (2014), em sua tese de Doutorado, descreveu que pacientes que apresentavam manifestações sistêmicas receberam medicação sintomática, como analgésicos para combater a dor, benzodiazepínico para o controle das mioclonias e soroterapia específica antiescorpiônica na dosagem de $15 \mathrm{ml}$, administrados por via intravenosa, durante um período de 20 minutos. No presente estudo, ressalta-se a prescrição de benzodiazepínicos para aliviar mioclonias e sensação de choque elétrico descrito pelas vítimas.

Gibly et al. (1999) sugerem o uso de infusão contínua de midazolam para o envenenamento grave por escorpião Centruroides exilicauda no Arizona, visando suprimir movimentos musculares involuntários sem comprometer a função respiratória.

No presente estudo, os pacientes que apresentaram manifestações locais foram tratados com analgésicos e receberam alta hospitalar no mesmo dia após a admissão. Por outro lado, os que apresentaram manifestações sistêmicas foram internados e receberam medicação sintomática e soroterapia escorpiônica específica. Ressalta-se que 10 (7,0\%) casos receberam soroterapia, mesmo tendo sido classificados como leves, o que não é recomendável. A esse respeito, assinala-se que, no ano de 2016, o Ministério da Saúde divulgou Nota Técnica sobre a necessidade de adequações nas doses de antivenenos para o 
tratamento de acidentes por jararacas e escorpiões, na tentativa de redução de desperdício, sem prejuízo para as vítimas (BRASIL, 2016).

O Quadro 2 apresenta aspectos clínicos e epidemiológicos, bem como a identificação dos espécimes de escorpião responsáveis pelos acidentes na região em estudo. A espécie $T$. obscurus, assim como em outros estudos já realizados na região (Pardal et al., 2003; Pardal et al., 2014; Torrez et al., 2015), foi comprovadamente a causadora da maioria dos acidentes cujas vítimas entregaram o animal ao serviço de saúde onde foram atendidos. Destes, 07 $(78,0 \%)$ apresentaram comprometimento cerebelar e/ou muscular.

Entretanto, assinala-se que este estudo é o primeiro a revelar outro espécime, além de T. obscurus, responsável por acidentes leves e moderados, cujas vítimas apresentaram manifestações compatíveis com a síndrome cerebelar aguda na região, tratando-se do $T$. strandi, de acordo com a chave taxonômica de Lourenço (2002). Até o momento não se tem registros de acidentes com esta espécie na região amazônica e que ocasionem manifestações locais e sistêmicas como as descritas neste estudo. Em um estudo realizado no Amazonas (Silva et al., 2017), as vítimas apresentaram sensação de choque elétrico, mas o acidente foi provocado pela espécie $T$. apiacas.

A diversidade da toxicidade da escorpiofauna na Amazônia é pouco explorada. Necessário se faz, portanto, a realização de estudos a esse respeito, assim como em relação à ecologia animal das espécies causadoras de acidentes na região, para melhor compreensão do agravo escorpiônico. É possível que a espécie $T$. strandi, que causou acidente que foi classificado como moderado, e acompanhado no município de Santarém, seja responsável por acidentes graves na região. Esse relato evidencia a importância da inclusão da espécie $T$. strandi entre aquelas consideradas de importância clínica na região amazônica.

Lourenço (2012) enfatiza que a primeira espécie de Tityus de coloração clara descrita na Amazônia, foi Tityus (Tityus) strandi, por Werner, em 1939. Os acidentes ocorridos no município de Santarém, ambos na zona rural, ocorreram por escorpião macho. Uma identificação mais objetiva, em 1980, foi realizada em macho de T. strandi, contribuindo com a situação taxonômica da espécie (LOURENÇO, 1981a).

Ainda destaca-se que este estudo constatou acidente causado por T. silvestris e que causou manifestações sistêmicas (Quadro 2), corroborando os achados de Coelho et al. (2016). O T. silvestris está entre os pequenos escorpiões da família Buthidae no Brasil. São escorpiões de cor amarelada com manchas escuras, medindo entre 25 a $45 \mathrm{~mm}$ e que apresentam dismorfismo sexual, sendo encontrados amplamente na Guiana Francesa e na Amazônia Brasileira (LOURENÇO, 2006). 
O Quadro 2 ainda apresenta alguns resultados de exames laboratoriais de vítimas de escorpionismo na região. A realização de exames complementares é feita nos casos moderados e graves, sendo que as alterações são reversíveis na primeira semana (CUPO et al., 2003; GUERON et al., 1992).

No escorpionismo, os achados laboratoriais de hiperglicemia, leucocitose e hipopotassemia ocorrem precocemente; e também se observa aumento nos níveis de amilase sanguínea em grande quantidade (CUPO, 2015). No mesmo Quadro 2 verificam-se níveis aumentados de TGO (42 U/L e 46 U/L) e de CK-MB (28,7 U/L). De acordo com Cupo (2015), há aumento nas enzimas fosfocreatina quinase (CK-MB), transaminase glutâmica oxoloacética (TGO), desidrogenase láctica ( $\mathrm{LDH})$, troponina I e peptídeo natriurético prócérebro aminoterminal (NT-proBNP), na determinação seriada, semelhantemente ao encontrado nos casos de infarto do miocárdio.

Por fim, com o intuito de contextualizar a segunda parte do estudo, que se refere ao estudo prospectivo, foi feito levantamento com 160 profissionais de saúde, alocados em unidades de saúde que compõem o $9^{\circ} \mathrm{CRS} / \mathrm{SESPA}$ (Tabela 8). A maioria era composta por profissionais de enfermagem: 136 (enfermeiros e técnicos de enfermagem), totalizando 85,0\% dos entrevistados. A importante participação desses profissionais deve-se à presença da pesquisadora nos municípios de Santarém, Mojuí dos Campos, Belterra, Aveiro e Itaituba. Também deve-se à articulação com enfermeiros das secretarias municipais de saúde, por meio da parceria com o $9^{\circ} \mathrm{CRS} / \mathrm{SESPA}$.

A atuação da enfermagem, frente à emergência em escorpionismo, muito embora não seja encontrada especificamente na literatura, merece destaque no trabalho junto à equipe de saúde. Conhecer sinais e sintomas locais e sistêmicos, assim como a fisiopatologia do agravo é indispensável e contribui para o prognóstico do paciente (MELO et al., 2017). Em muitas unidades de saúde na região, o atendimento inicial é realizado pelo profissional de enfermagem. Enfatiza-se, portanto, a educação permanente para os profissionais de saúde, em particular para enfermeiro(a)s, acerca da prevenção, detecção e tratamento do agravo escorpiônicos. A esse respeito, assinala-se que uma das motivações para o desenvolvimento do presente estudo decorre das atividades do NUMETROP, Núcleo de Apoio às Atividades de Extensão do Departamento de Moléstias Infecciosas e Parasitárias da Faculdade de Medicina da Universidade de São Paulo (USP), do qual a Escola de Enfermagem da USP integra o Conselho Deliberativo. Nessa mesma linha, também sublinha-se a necessidade de que esse conteúdo integre o currículo de formação das enfermeiras, dada a relevância epidemiológica e a condição de agravo negligenciado. 
Enfatiza-se a importância da entrega da espécie de escorpião agressor no serviço de saúde para que um dos fatores que promovem o silêncio epidemiológico na região deixe de ocorrer, o que favorecerá a conduta profissional, permitindo melhor suporte no enfrentamento do agravo. Estudos voltados às atividades biológicas e à toxicidade dos venenos de escorpiões que causam acidentes moderados e graves na Amazônia são essenciais no tratamento adequado às vítimas, uma vez que há clínica peculiar em muitos casos, levando à extensão da internação hospitalar, dos custos, além do sofrimento e impedimento da vítima em exercer suas atividades. 


\section{CONCLUSÃo}

Este estudo buscou analisar a distribuição espacial e os aspectos clínicoepidemiológicos dos acidentes escorpiônicos no $9^{\circ}$ e $10^{\circ}$ Centro Regional de Saúde do Estado do Pará. O estado do Pará é um dos maiores estados em extensão territorial do Brasil, rico pela diversidade, alvo de expansão da economia agrícola e possui um ambiente propício para acidentes causados por animais peçonhentos, especialmente por escorpião.

A magnitude de casos no Oeste do Pará, constatada no estudo retrospectivo, é muito importante, uma vez que equivaleu a $80 \%$ dos casos de todo o Estado. A incidência na mesorregião do Baixo Amazonas e Sudoeste do Pará foi de 5,7 casos por 1.000 habitantes, portanto, enfatiza-se a necessidade de mobilização para a realização de ações em saúde, com destaque para a evidenciação da relação desse problema de saúde pública com os impactos socioambientais, novos fluxos migratórios e a construção de hidrelétricas na Amazônia, todos decorrentes de um processo marginal de desenvolvimento do neoliberalismo com todas as suas consequiências deletérias.

Na etapa relativa ao estudo retrospectivo, no Hospital Municipal de Santarém, no ano de 2016, verificou-se que foram atendidas 123 pessoas vítimas de acidentes escorpiônicos. O perfil sociodemográfico revelou que, destes, a maioria era do sexo masculino, nas faixas etárias de 16 a 30 anos, e de 31 a 45 anos. Ainda que se tenha verificado falta de informações nos prontuários/fichas de notificação, a renda de até um salário mínimo apresentou maior parcela, assim como o ensino fundamental incompleto e o trabalho na agricultura. A maioria dos casos era proveniente da zona rural e, nos casos informados, o acidente ocorreu em sua maior parte durante atividades laborais. O tempo decorrido entre a picada e o atendimento, quando informado, foi mais expressivo entre 4 a 12 horas. Todos esses achados revelam elementos de vulnerabilidade individual, social e relativa ao acesso aos serviços de saúde.

Quanto aos aspectos clínicos verificou-se maior ocorrência nos pés. Manifestações locais como dor, parestesia e sensação de choque elétrico foram as que mais se destacaram. Manifestações sistêmicas como tremores, hipertensão arterial e "outras", como turvação visual também figuraram nos registros.

Os acidentes escorpiônicos atendidos no Hospital Municipal de Santarém no ano de 2016 foram classificados como: leves, moderados e graves, sendo mais frequentes os classificados como moderados, mas não é desprezível o conjunto de ignorados ou sem informação. 
Algumas variáveis deste estudo, em sua etapa retrospectiva, não foram identificadas nos prontuários, por isso coloca-se como fundamental aprimorar a coleta de informações, realizada pelos órgãos de saúde local, gerando fontes confiáveis de informação. Assim, destaca-se também a necessidade da educação continuada dos profissionais de saúde envolvidos nos atendimentos aos acidentes escorpiônicos, com a finalidade de aprimorar os cuidados às vítimas, assim como proporcionar o preenchimento adequado do prontuário e das fichas de notificação.

$\mathrm{Na}$ etapa relativa ao estudo prospectivo foram acompanhadas 259 pessoas acometidas por acidentes escorpiônicos em 18 municípios pertencentes ao $9^{\circ} \mathrm{CRS} / \mathrm{SESPA}$ nos diversos serviços de saúde. A maioria encontrava-se na faixa etária entre 16 a 30 anos, era do sexo masculino, exercendo ocupações variadas, como motoristas, garimpeiros, pedreiros, serviços gerais, caseiro, e agricultores, com renda de até um salário mínimo e ensino fundamental incompleto. A zona rural foi a área de maior ocorrência dos casos, sendo o maior número de ocorrências no trabalho. Prevaleceu o intervalo de tempo entre a picada e o atendimento entre 1 a 3 horas, seguido de 4 a 12 horas.

Verificou-se que o perfil epidemiológico no estudo prospectivo se manteve semelhante ao encontrado no estudo retrospectivo com exceção para o tempo decorrido entre a picada e o atendimento que, no prospectivo teve menor duração, o que é relevante, já que possibilita diminuir a gravidade deste agravo. Vale ressaltar que os municípios não possuem o soro antiescorpiônico nas unidades básicas de saúde da zona rural, sendo a referência para o atendimento, o Hospital Municipal de Santarém. Em algumas localidades da região, os usuários dos serviços de saúde dependem de transporte fluvial, o que pode implicar em evolução desfavorável dos casos.

No estudo prospectivo as mãos foram os locais da picada mais frequentes, diversamente do que se verificou no retrospectivo. Ressalta-se o acometimento de membros inferiores e superiores para os acidentes escorpiônicos na região.

No estudo prospectivo, as manifestações locais mais freqüentes, mencionadas pelos indivíduos acometidos, nos municípios pertencentes ao $9^{\circ} \mathrm{CRS} / \mathrm{SESPA}$ foram: dor, sensação de choque elétrico e parestesia. Já as manifestações sistêmicas mais frequentes foram as categorizadas como "outras manifestações": hipertensão arterial, sudorese, visão turva e outras alterações: oftalmológicas; tremores, disfagia, fadiga e sialorréia. Dentre as alterações oftalmológicas verificou-se ptose palpebral, nistagmo, pupilas anisocóricas, fotofobia e ardência nos olhos. 
As manifestações clínicas neurológicas e musculares mais frequentes foram dor, sensação de choque elétrico, formigamento, ataxia de marcha, disartria e espasmos musculares. A dor teve uma duração média de 11 horas, tendo início imediatamente após a picada, ou não ocorrendo em alguns casos (picada seca). A sensação de choque elétrico pode ter início imediatamente após a picada, ou mais tardiamente: desde em 30 minutos e pode permanecer até 100 horas após o acidente, mas perdurando, em geral, até 24 horas em grande parte dos casos.

Manifestações neurológicas e musculares foram evidenciadas no estudo prospectivo e analisadas por espacialização. Este estudo constatou que em grande parte dos municípios pertencentes ao $9^{\circ} \mathrm{CRS} / \mathrm{SESPA}$, as pessoas acometidas apresentaram, frequentemente, quadro compatível com síndrome cerebelar aguda. Foi possível ainda destacar que outra espécie de Tityus presente na região (Tityus strandi) também pode evoluir com algumas manifestações observadas nos acidentes por T. obscurus. Os acidentes causados por esta espécie ocorridos nos municípios de Santarém e Monte Alegre apresentaram sinais de comprometimento neuromuscular.

Apenas os municípios de Curuá e Faro não apresentaram registros durante o acompanhamento do estudo.

A análise espacial revelou que doze municípios: Monte Alegre, Mojuí dos Campos, Placas, Rurópolis, Trairão, Novo Progresso, Prainha, Belterra, Alenquer, Almeirim, Juruti e Aveiro foram considerados como áreas de risco. Também se verificou que, dos 20 municípios que integraram o estudo, 6 apresentaram Risco Relativo 3 vezes maior (Monte Alegre, Prainha, Uruará, Placas, Rurópolis e Aveiro) que o Risco Relativo da área em estudo, e 2 municípios apresentaram Risco Relativo 2 vezes maior (Jacareacanga e Novo Progresso).

Entende-se que a análise do agravo escorpiônico na região depende de uma série de questões que envolvem o território, como as pessoas nele estão inseridas, bem como nas medidas de vigilância frente a este agravo. A forma como a comunidade local interpreta o agravo também chama a atenção, uma vez que muitos usuários já tinham vivenciado este acidente, mas nem sempre buscaram o serviço de saúde ou não tiveram acesso por uma série de motivos, questão que não era foco do presente estudo.

Em relação à classificação do escorpionismo, baseou-se no registro dos profissionais que prestaram atendimento às vítimas no ato da admissão hospitalar. Constata-se que há necessidade de capacitação dos profissionais da região quanto ao manejo clínico das vítimas 
de escorpionismo, mesmo que a maior parcela dos acidentes não tenha se configurado como grave e não havendo desfecho letal.

O acidente escorpiônico apresenta um comportamento único na região Amazônica. Porém, a pesquisa científica é limitada em função de registros inapropriados nos prontuários e fichas de notificação, o que compromete uma das principais ferramentas de vigilância epidemiológica, o SINAN. O desenvolvimento deste estudo colocou em evidência a necessidade de revisão da ficha de notificação, uma vez que o agravo escorpiônico, nessa região, apresenta especificidades próprias. Assim, além da classificação já existente, para essa região do Pará, propõe-se que os acidentes com quadro exclusivamente local continuem sendo considerados leves. Os pacientes que apresentam sensação de choque regional ou sistêmico podem ser considerados moderados e os pacientes que apresentam quadro de disfunção cerebelar aguda, com ou sem manifestações musculares e renais podem ser considerados graves. Propõe-se, ainda, que os acidentes classificados como moderados e graves sejam tratados com soroterapia específica.

Tais propostas podem melhorar o manejo adequado e fortalecer políticas públicas de enfrentamento do agravo, ao permitir fonte de informação com dados mais fidedignos.

Constatou-se, neste estudo, a importante participação de profissionais de enfermagem no atendimento às vítimas do agravo escorpiônico. Em muitas localidades da região, é o (a) Enfermeiro(a) que presta o primeiro atendimento a estas vítimas. Assim, o tema relativo aos acidentes por animais peçonhentos, agravo negligenciado segundo a Organização Mundial da Saúde, deve integrar a formação dos profissionais de saúde, dentre eles, o(as) Enfermeiros(as). Vale ressaltar que o enfrentamento desse agravo requer trabalhar a identificação das necessidades de saúde da população da região, buscando a prevenção do agravo e o cuidado precoce, por meio da instrumentalização das pessoas, famílias e comunidades, reduzindo as situações de vulnerabilidade. A esse respeito, foi perceptível que as vítimas de escorpionismo não consideram importante a entrega do animal no serviço de saúde e, ainda, em muitos casos, desconheciam a importância desta informação. Com a identificação da espécie é possível conhecer a diversidade da fauna escorpiônica na região, o que também contribui para a conduta a ser tomada, ao se reconhecer espécies responsáveis por acidentes moderados e graves, classificadas como de maior importância clínica.

Em função do exposto, é necessário constatar as peculiaridades clínicas dos escorpiões e do escorpionismo nesta região da Amazônia, e a necessidade da realização de mais estudos, particularmente por pesquisadores da própria região. Há necessidade de ensaios clínicos 
randomizados com o objetivo de se comparar e consequentemente aprimorar o tratamento destes envenenamentos, pois permanecem dúvidas quanto à eficácia da sorologia específica para casos de acidentes ocasionados pelo T. obscurus.

Este estudo contribui para o conhecimento dos aspectos epidemiológicos, clínicos e espaciais do agravo escorpiônico na região. Os resultados contribuem para a - implantação de políticas públicas, principalmente as que envolvem à notificação com informações detalhadas, ao reconhecimento precoce do agravo e ao seu tratamento adequado, às áreas de risco, à necessidade de descentralizar o suprimento de soro, de capacitar profissionais no manejo destes acidentes. Destaca-se a necessidade de melhorar o acesso da população aos serviços de saúde, na medida em que o tempo decorrido entre o acidente e a assistência adequada é fundamental na evolução.

Enfatiza-se a necessidade de investimentos em recursos materiais e humanos e, fundamentalmente, o estabelecimento de políticas de gestão e disseminação de informações fidedignas de saúde.

Enfatiza-se, portanto, a necessidade de vigilância à saúde no território, principalmente para a população mais vulnerável. Este estudo mostra a importância do conhecimento do território, pois esse espaço expressa as vulnerabilidades e possibilidades de seu enfrentamento, determinadas pela produção e reprodução social. 


\section{REFERÊNCIAS}

ALBUQUERQUE, G.S.C.; SILVA M.J.S. Sobre a saúde, os determinantes da saúde e a determinação social da saúde. Saúde Debate. Rio de Janeiro, v. 38, n. 103, p. 953-965, OutDez 2014.

ALBUQUERQUE, I. C. S. et al. Escorpionismo em Campina Grande - PB. Revista de Biologia e Ciências da Terra, v. 4, n. 1. 2004.

ALMEIDA, S.S.O et al. Distribuição espacial de escorpiões de acordo com as condições socioeconômicas em Campina Grande, Estado da Paraíba, Brasil. Rev. Soc. Bras. Med. Trop, v.49 n.4 Uberaba julho / ago. 2016.http://dx.doi.org/10.1590/00378682-0128-2016

AMORIM, AM et al. Acidentes por escorpião em uma área do Nordeste de Amaralina, Salvador, Bahia, Brasil.Rev.Soc.Bras.Med.Trop, v. 36,n.1, p.51-56, 2003.

ANDRADE, P.S. A Ocupação do Sudoeste Paraense - Desafios Sociais e Riscos Ambientais. 2014. Dissertação (Mestrado em Desenvolvimento Sustentável) Programa de Pós-Graduação em Políticas Públicas, Governança e Conflitos Socioambientais, Universidade de Brasília. Disponível em http://repositorio.unb.br/bitstream/10482/18667/1/2014_PaulaSimasdeAndrade.pdf. Acesso em 02.02.2015

ARAÚJO, M.P; SILVA, C.G. A importância do sistema de informação de agravos de notificação - SINAN para a vigilância epidemiológica do Piauí. Revista Interdisciplinar Ciências e Saúde. Programa de Pós-Graduação em Ciências e Saúde, Universidade Federal do Piauí. ISSN: 2358-6966. 2008.

ASANO, M.E et al. Estudo clínico e epidemiológico de 12 acidentes por escorpiões atendidos no Hospital Universitário João de Barros Barreto, Belém-Pará, no período de 1992-1995. Rev.Soc.Bras.Med.Trop, v. 29 (Supl. 1), p. 243, 1996.

BARBOSA, A.D. et al. Distribuição espacial de acidentes escorpiônicos em Belo Horizonte, Minas Gerais, 2005 a 2009. Rev Arq. Bras. Med. Vet. Zootec., v.66, n.3, p.721-730, 2014.

BARCELLOS, C; PEREIRA M.P.B. O território no Programa Saúde da Família. HYGEIA Rev.Bras. de Geog. Med.Saud.,Uberlândia, v. 2, n. 2, p. 47-55, 2006. Disponível em: http:/www.ygeia.ig.ufu.br. Acesso em: 17/05/2016

BECERRIL, B; MARANGONI S; POSSANI, L.D. Toxins and genes isolated from scorpions of the genus Tityus. Toxicon. v.35, p.821-835.1997.

BENMOSBAH, $\mathrm{M}$ et al. Estudo epidemiológico e clínico sobre o escorpionismo na Guiana Francesa. Toxicon.v.73, p. 56-62.2013 doi: 10.1016/ j.toxicon.2013.05.025.

BOYER, L.V et al. Antiveneno para crianças gravemente doentes com neurotoxicidade de picadas de escorpiões. N Engl J Med2009; v.360, p. 2090-2098. 
BUCARETCHI, F. et al. A comparative study of severe scorpion envenomation in children caused by Tityus bahiensis and Tityus serrulatus. Ver Inst Med Trop. v.37, n.4, p.331-336. 1995.

BRAGA, A.L.S. et al. Atuação do enfermeiro no controle de endemias. Rev Enfermería Global. n23, p 320-329, 2011.

BRASIL. Ministério da Saúde (Org). Acidente por animais peçonhentos: Notificações registradas no Sistema de Informação de Agravos de Notificação - Sinan Net. 2018. Disponível em:< http://dtr2004.saude.gov.br/sinanweb/>. Acesso em: 18/11/2018.

BRASIL. Portal da Saúde [Internet]. NOTA INFORMATIVA: Informações da Coordenação-Geral de Doenças Transmissíveis (CGDT) referentes à nova abordagem ao tratamento em casos de acidentes por serpentes do grupo Bothrops ("jararacas") e por escorpiões, em situação de escassez de antivenenos. 2016. Disponível em: http://portalsaude.saude.gov.br/index.php/o-ministerio/principal/leia-mais-o-ministerio/197secretaria-svs/24972-nova-abordagem-ao-tratamento-em-situacao-de-escassez-deantivenenos. Acesso em 05.01.2017.

BRASIL. Ministério da Saúde (Org). Acidente por animais peçonhentos: Notificações registradas no Sistema de Informação de Agravos de Notificação - Sinan Net. 2015. Disponível em:< http://dtr2004.saude.gov.br/sinanweb/>. Acesso em: 18/12/2015.

BRASIL. Ministério da Saúde. Escorpionismo, 2011. Disponível em: <http://portal.saude.gov.br/portal/arquivos/pdf/tabela02_casos_escorpiao2000_2011_1_04_20 11.pdf> Acesso em 25/02/2016

BRASIL. Ministerio da Saúde. Secretaria de Vigilância em Saúde. Departamento de Vigilância Epidemiológica. Manual de controle de escorpiões. Brasília: Ministério da Saúde, 2009. 72p. (Série B. Textos Básicos de Saúde).

BRASIL. Ministério da Saúde. Ações de controle de endemias/Manual de agente comunitário de saúde e agente de controle de endemias. Manual do Ministério da Saúde, 2002.

BRASIL. Ministério da Saúde. Fundação Nacional de Saúde. Manual de diagnóstico e tratamento de acidentes por animais peçonhentos. Brasília: Ministério da Saúde, 2001.

BRAZIL, T. K; PORTO T.J. Os escorpiões. Salvador: EDUFBA, 2010. 84 p.

CAMPOLINA, D. Georreferenciamento e estudo clínico epidemiológico dos acidentes escorpiônicos atendidos em Belo Horizonte, no Serviço de Toxicologia de Minas Gerais. (Dissertação de Mestrado). Belo Horizonte: Universidade Federal de Minas Gerais, 2006. Disponível em:http://www.bibliotecadigital.ufmg.br/dspace/bitstream/handle/1843/ECJS6XWN79/d_lio_campolina.pdf?sequence=1. Acesso em 10.07.2015

CARDOSO, J.L.C. et al. Animais peçonhentos no Brasil: Biologia, clínica e terapêutica dos acidentes. 2 th ed. São Paulo: Savier/Fapesp. 2009. P.198-224

CATTERAL, W.A. et al. Voltage - gated ion channels and gating modifier toxins. Toxicon, v. 49, p.124 -141, 2007. 
CHIPPAUX, J. P.; GOYFFON, M. Epidemiology of scorpionism: a global appraisal. RevActa Tropica,v. 107, p. 71-79, 2008. https://doi.org/10.1016/j.actatropica.2008.05.021

CHOWELL G. et al. Características epidemiológicas e clínicas do escorpionismo em Colima, México (2000-2001).Toxicon, v.47, n.7. p.753-758. 2006.doi: 10.1016 / j.toxicon.2006.02.004.

COSTA, C.L.S.O. et al. Um perfil de escorpionismo, incluindo as espécies de escorpiões envolvidos, no estado do Amazonas, Brasil. Rev Soc Bras Med Trop, v.49, n.3, p. 376-379.

COSTA, L.S.O.C. Aspectos Epidemiológicos do Escorpionismo na região de Santarém, Estado do Pará, Brasil.Rev. Colombiana cienc. Anim, v. 4,n.1, p.59-68,2012.

COELHO, J.S. et al. Scorpionism by Tityus silvestris in eastern Brazilian Amazon. The Journal of Venomous Animals and Toxins Including Tropical Diseases (Online), v.22, p.1-6, 2016.

CRUZ, E.F.S. et al. Programa de controle de surto escorpião Tityus serrulatus, Lutz e Mello 1922, no município de Aparecida, SP (Scorpiones, Buthidae). Rev.Soc.Bras.Med.Trop, v.28, n.2, p. 123-128, 1995.

COTTA, G. A. Animais peçonhentos. Belo Horizonte: Fundação Ezequiel Dias, 2014. 24p (serie cartilha)

CUPO, P. Clinical update on scorpion envenoming. Rev Soc Bras Med Trop, v.48, n.6, p.642-649.2015.

CUPO, P. et al. Severe scorpion envenomation in Brazil. Clinical, laboratory and anatomopathological aspects. Rev. Inst. Med.Trop. São Paulo, v. 36, p.67-76, 1994.

CUPO, P; AZEVEDO-MARQUES, M.M; HERING, S.E. Escorpionismo. In: Cardoso, J.L.C., França, F.O.S., Wen, F.H., Málaque, C.M.S., Haddad, V. (Eds.), Animais Peçonhentos no Brasil: Biologia, Clínica e Terapêuticados Acidentes. Sarvier, São Paulo. 2009.

CUPO, P; AZEVEDO-MARQUES, M.M; HERING, S.E. Acidentes por animais peçonhentos: Escorpiões e aranhas. Medicina, Ribeirão Preto, v.36, p. 490-497, abr./dez. 2003.

DABO, A. et al.Scorpion envenoming in the North of Mali (West Africa): Epidemiological, clinical and therapeutic aspects. Toxicon,v. 58.2011.Disponível em Journal homepage: www.elsevier.com/locate/toxicon.

DATASUS. Acidente por animais peçonhentos - Notificações registradas no Sistema de Informação de Agravos de Notificação - Sinan Net (2016), s/d. Disponível em: http://dtr2004.saude.gov.br/sinanweb/ Acesso em 02 de fevereiro de 2017.

DEHESA-DAVILLA, M.; POSSANI, L.D. Scorpionism and serotherapy in Mexico. Toxicon, v. 32, p.1015-1018. 1994.

DIAS, N. B. de. Estudo peptídico e determinação do perfil de metabolites de escorpiões da família Buthidae: Tityus serrulatus, Tityus bahiensis e Tityus obscurus - (Tese de 
Doutorado) Universidade Estadual Paulista, Instituto de Biociências de Rio Claro. Rio Claro, 2016.

EVANGELISTA, G.F; AZEVEDO, C. S. Arachnidism, scorpionism and ophidism in Ouro Preto Municipality, Minas Gerais State, Brazil. Rev Soc Bras Med Trop, v. 49, n.6, p.786789, November-December, 2016. doi: 10.1590/0037-8682-0047-2016

FAPESPA. Fundação Amazônia de Amparo a Estudos e Pesquisas do Pará. Mapas de Mesoregiões.2016. Disponível em:http://www.fapespa.pa.gov.br Acesso em: 20.11.2018.

FAPESPA. Fundação Amazônia de Amparo a Estudos e Pesquisas do Pará. Diagnóstico Socioeconômico e Ambiental da região de integração do Baixo Amazonas. 2015a. Disponível em:http://www.fapespa.pa.gov.br Acesso em: 20.06.2016.

FAPESPA. Fundação Amazônia de Amparo a Estudos e Pesquisas do Pará. Diagnóstico Socioeconômico e Ambiental da região de integração do Tapajós. 2015b Dsiponível em:http://www.fapespa.pa.gov.br Acesso em: 20.06.2016.

FERNANDEZ-BOUZAS, A. et al. Brain infarcts due to scorpion stings in children: MRI.Neuroradiology, v. 42, p.118-120. 2000.

FREIRE-MAIA, L; CAMPOS, J.A; AMARAL, C.F. Abordagens do tratamento do envenenamento escorpiônico. Toxicon, v.32, p. 1009-1014.1994.

FREITAS, W.W.L.; SILVA, V.F.; MORAES, R.M. Análise espacial de uma década de mortes violentas por homicídios em João Pessoa-PB. Safety, Health and Environment World Congress (SHEWC'2011).24-27 Julho, Santos, Brasil, p. 73-77.2011.

GAlvãO, A. P.; RODRIGUES, D. Aspectos Clínicos e Epidemiológicos dos Acidentes Escorpiônicos no Município de Rurópolis, Pará. 2012.

GARCIA, M.L. et al. Characterization of verapamil binding sites in cardiac membrane vesicles. J. Biol. Chem., v. 259, p. 15013-15016, 1984.

GAZARIAN, K.G. et al. Imunnology of scorpion toxins and perspectives for generation of anti venoms vaccines. Vaccine, v.26, p. 3357- 3368, 2005.

GENTLE, J. E., “Elements of computational Statistics”, Springer, 2002.

GIBLY, R. et al. Continuous Intravenous Midazolam infusion for Centruroides axilicauda scorpion envenomation. Annals of Emergency Medicine, v.34, p. 620-625, 1999.

GOMES, L.F. Mapa do Estado do Pará. Municípios que integram o 9CRS/SESPA (Área do estudo Prospectivo). 2018

GOYFFON, M; VACHON, M; BROGLIO, N. Epidemiological and clinical characterists of the scorpion envenomation in Tunisia.Toxicon, v.20, n.1, p.337-344, 1982.

GUERON,M; ILIA, R; SOFER, S. The cardiovascular system after scorpion envenomation.A review. J. Toxicol. Clin.Toxicol., v.30,p. 245-258. 1992. 
GUERRA, C.M. et al. Analysis of variables related to fatal outcomes of scorpion envenomation in children and adolescents. in the state of Minas Gerais, Brazil, from 2001 to 2005. J Pediatr, v.84, n.6, p.509-515. 2008.

GUERRA, C.M.N. Estudo clínico-epidemiológico do acidente escorpiônico em crianças e adolescentes no Estado de Minas Gerais no período de 2001 a 2005. (Dissertação de Mestrado).Belo Horizonte: Universidade Federal de Minas Gerais.2007. Disponível em http://www.bibliotecadigital.ufmg.br/dspace/bitstream/handle/1843/ECJS-

7MJVQ/cl_udia_moura_nunes_guerra.pdf?sequence=1. Acesso em 02.08.2016

GUERRERO - VARGAS. et al. Identification and phylogenetic analysis of tityus pachyurus and tityus obscurus novel putative Nat-channel scorpion toxins. Plos One, v. 7, n. 2, Article e30478, 15 fev. 2012. Disponível em: $<$ http://journals.plos.org/plosone/article?id=10.1371/journal.pone.0030478>. Acesso em: 27 dez 2017. doi: https://doi.org/10.1371/journal.pone.0030478.

HAESBAERT, R. O Mito da Desterritorialização: do fim dos territórios à multiterritorialidade. Rio de Janeiro: Bertrand Brasil, 2004.

HORTA, F.M.B; CALDEIRA, A.P; SARES, J.A. Escorpionismo em crianças e adolescentes: aspectos clínicos e epidemiológicos de pacientes hospitalizados. Rev. Soc. Bras.de Med. Trop, v.40, n.3, 2007.

IBGE. Instituto Brasileiro de Geografia e Estatística. Estimativas da população residente no Brasil e unidades da federação com data de referência em $1^{\circ}$ de julho de 2014. Disponível em:ftp://ftp.ibge.gov.br/Estimativas_de_Populacao/Estimativas_2014/estimativa_dou_2014.p df./ Acesso em 28 de fevereiro de 2016.

IBGE. Instituto Brasileiro de Geografia e Estatística. Estimativas da população residente no Brasil e unidades da federação com data de referência em $1^{\circ}$ de julho de 2010 . Disponível em:ftp://ftp.ibge.gov.br/Estimativas_de_Populacao/Estimativas_2010/estimativa_dou_2010.p df./ Acesso em 01 de Maio de 2018.

ISMAIL, M. The treatment of the scorpion envenoming syndrome: the Saudi experience with serotherapy. Toxicon, v.32, p.1019-1026,1994.

JUNKES, C. H. G.; MAZON, L. M. Prevalência de acidentes por Tityus costatus e Loxosceles sp no município de Rio Negrinho/SC e ações profiláticas adotadas pelapopulação. Saúde e Meio Ambiente, v. 2, n. 1, p. 33-43, 2013.

KASSIRI, H. et al. Fatores epidemiológicos e climatológicos que influenciam no envenenamento escorpiônico no condado de Baghmalek, Irã. Acad J Entomol., v.6, n.2, p.47-54.2013. doi: 10.1016 / S2222-1808 (14) 60632-0

KHATTABI, A. et al. Grupo de especialistas em consenso de escorpiões. Classificação das consequências clínicas das picadas de escorpião: desenvolvimento de consenso. Trans R Soc Trop Med Hyg., v.105, n.7, p.364-369. doi: 10.1016 / j.trstmh.2011.03.007

KNOX, E. G., "Detection of Clusters. In: Methodology of enquiries into disease clustering", P. Elliott. London: Small Area Health Statistics Unit, ano 1998. 
KOGA, D; NAKANO, K. Perspectivas territoriais e regionais para políticas públicas brasileiras. Revista Serviço Social e Sociedade, n. 85, Cortez, 2006.

KULLDORFF, M.; NAGARWALLA, N. Spatial disease clusters: detection and inference. Statistics in Medicine, v. 14, p. 799-810, 1995.

LAÏD, Y. et al. Incidence and severity of scorpion stings in Algeria. The Journal Ven Anim and Toxi includ Trop Dis.,v.18, p. 399-400, 2012.

LEME ENGENHARIA. Relatório de Impacto Ambiental (Rima): Aproveitamento hidrelétrico Belo Monte. Elaborado por Leme Engenharia para a Eletrobrás e Ministério de Minas e Energia. Maio de 2009.

LIRA-DA-SILVA, R.M. et al. Acidentes por escorpião na cidade do Salvador, Bahia, Brasil (1982 - 2000). Gaz Méd Bahia, v.79, n.1, p.43-49, 2009.

LIRA-DA-SILVA, R.M; AMORIM, A.M; BRAZIL, T.K. Envenenamento por Tityus stigmurus (Scorpiones; Buthidae) no Estado da Bahia, Brasil. Rev Soc Bras Med Trop,v.33, n.3,p.239-245, 2000.

LÓPEZ, A; GÓMEZ-RUBIO; FERRÁDIZ_FERRAGUD, J.V. "Detecting clusters of disease with R”. Journal of Geographical Systems, v. 7, n.2, , p. 189-2006, 2005.

LOURENÇO, W R. DESCRIÇÃO DO MACHO DE TITYUS (TITYUS) RAQUELAE LOURENÇO, 1988 (SCORPIONES, BUTHIDAE), ESPÉCIE DA AMAZÔNIA BRASILEIRA. Revista Ibérica de Aracnología, no 21 (31/12/2012): 65-68. Disponível em http://sea-entomologia.org/PDF/RIA21/066068RIA21TityusraquelaeWL.pdf Acessado em 10.09.2018

LOURENÇO, W. R. Descrição do macho de Tityus strandi Werner, 1939 (Scorpiones, Buthidae). Rev bras de Bio, v.41, n.4, p. 797-801. 1981a

LOURENÇO, W.R, CLOUDSLEY-THOMPSON J.L, CUELLAR O et al. The evolution of scorpionism in Brazil in recent years. Journ VenAnim and Tox includ Trop Disea, v.1, n.1, p.71-79, 1996.

LOURENÇO, W.R. Nova proposta de découpage sous-générique do gênero Tityus CL Koch, 1836 (Scorpiones, Buthidae) .Bol SEA, v.39, p.55-67, 2006.

LOURENÇO, W.R. Escorpiões do Brasil.Paris: Les Éditions de I'lf; 2002.

LORET, E; HAMMOCK, B. Structure and neurotoxicity of venoms. In: Brownell, P.; Polis, G. Ed. Scorpion Biology and Research. Oxford. New York Oxford University Press. 204-233. 2001.

LUCENA, S. E. F.; MORAES, R. M., “Análise do desempenho dos métodos scan e besag e newell para identificação de conglomerados espaciais do dengue no munícipio de João Pessoa entre os meses de janeiro de 2004 e dezembro de 2005", Boletim de Ciências Geodésicas, v.15, p,544-561, 2009.

MAESTRI NETO A. et al. Aspectos do escorpionismo no Estado do Pará-Brasil. Rev Para de Med, v.22,n.1,p.49-55, 2008. 
MELO, M.A et al. ESCORPIONISMO: COMPLICAÇÕES, CUIDADOS E PREVENÇÃO.Rev Acad Fac Fernão Dias, v.4, n.14, 2017. Disponível em http://www.fafe.edu.br/rafe/. Acesso em 15 de julho de 2018.

MIRANDA, A.C; BARCELLOS C; MOREIRA, J.C. Território, ambiente e saúde. Rio de Janeiro: Editora Fiocruz, 2008. $272 \mathrm{p}$

MONACO, L.M; MEIRELES, F.C.; ABDULLATIF, M.T.G.V. Animais venenosos: serpentes, anfíbios, aranhas, escorpiões, insetos e lacraias. 2. ed. rev. ampl. - São Paulo: Instituto Butantan, p. 18- 21, 2017.

NODARI, F.R; LEITE, M.L; NASCIMENTO, E. Aspectos demográficos, espaciais e temporais dos acidentes escorpiônicos ocorridos na área de abrangência da $3 \mathrm{a}$ Regional de Saúde - Ponta Grossa,PR, no período de 2001 a 2004. Ciênc Biol Saúde, v.12, n.1, p.1526.2006.

OLIVEIRA, S.M.S.et al. Aspectos Clínicos dos Acidentes Escorpiônicos notificados na Região do Baixo Amazonas e Tapajós.Caderno de Resumos. GEPENF. $1^{\text {a }}$ ed.2016.

OLIVEIRA, H.F.A et al. Epidemiologia dos acidentes escorpiônicos ocorridos na Paraíba Nordeste do Brasil.RevBiolFarm, v.9, n.2, p.86-96.2012.

OSNAYA-ROMERO, N. et al. Clinical symptoms observed in children envenomated by scorpion stings, at the children's hospital from the State of Morelos, Mexico. Toxicon, v. 39, p.781-785. 2001.

PARDAL, P.P.O. de. Contribuição ao conhecimento do Escorpionismo e do Escorpião Tityus obscurus GERVAIS, 1843 (SCORPIONES: BUTHIDAE) de duas regiões distintas no Estado do Pará na Amazônia Brasileira. Tese (Doutorado) - Universidade Federal do Pará. Núcleo de Medicina Tropical. Programa de Pós-Graduação em Doenças Tropicais. Belém, 2014.

PARDAL, P.P.O et al.Envenenamento Grave pelo Escorpião Tityus obscurus Gevais, 1843. Rev. Pan AmazSaude; v. 5, n. 3, p. 65 - 70, 2014.

PARDAL, P.P.O; GADELHA, M.A.C. Acidentes por animais peçonhentos: manual de rotinas. Belém: SESPA -Secretaria de Estado de Saúde Pública do Pará, 2010.

PARDAL, P.P.O et al. Aspectos epidemiológicos e clínicos do escorpionismo na região de Santarém, Estado do Pará, Brasil. Rev. da Soc Bras de Med Trop, v.36, n.3, p.349-353, 2003.

PARDAL, P.P.O; CARDOSO B.S; FAN H.W. Escorpionismo na região do rio Tapajós, Itaituba Pará. Rev da Soc Bras de Med Trop, v.32, n.1, 1999.

PELLEGRINI FILHO, A. et al. Conferência mundial sobre determinantes sociais da saúde. Cad de Saúd Púb, v. 27, n. 11, p. 2080-2081, 2011.

PIPELZADEH, M.H. et al. An epidemiological and a clinical study on scorpionism by the Iranian scorpion Hemiscorpius lepturus.Toxicon, v. 50, p.984-992, 2007. 
PINTO, L.R. et al. Tityus fasciolatus envenomation induced cardio-respiratory alterations in rats. Toxicon, v. 55,p. 1132-1137, 2010.

POSSANI, L.D, ALAGÓN, A.C, FLETCHER, J.R, ERICKSON, B.W. Purification and properties of mammalian toxins from the venom of the Brazilian scorpions Tityus serrulatus Lutz and Mello. Arch Biochem Biophys, v.180, p.394-403.1977.

POSSANI, L.D. et al. Purification and chemical characterization of the major toxins from the venom of the Brazilian scorpions Tityus serrulatus, Lutz and Mello. Carlsberg Res Commun, v.46, p.195-205, 1981.

POSSANI, L. et al. Peptides and genes coding for scorpion toxins that affect ion-channels. Biochemistry, v. 82, n.9-10, p. 861-868.2000.

QUADROS, R. M. et al. Acidentes escorpiônicos notificados pelo sinan na região serrana de Santa Catarina, Brasil, 2000-2010. REB., v. 7, n.1, p. 96-108, 2014.

QUEIROZ, A.M et al. Gravidade de picadas de escorpião na Amazônia Ocidental Brasileira: um estudo de caso-controle. PLoS One., v. 10, 2015.

RECKZIEGEL, G. C.; PINTO JUNIOR V.L. O escorpionismo no Brasil nos anos de 2000 a 2010: uma análise descritiva. Revista de Saúde Pública, 2013.

RECKZIEGEL, G.C. Análise do escorpionismo no Brasil no período de 2000 a 2010 . 2013. 103f. Dissertação (Mestrado em Saúde Coletiva) Programa de Pós-Graduação em Saúde Coletiva, Universidade de Brasília. Brasília, 2013.

REZENDE, N.A; AMARAL C.F.S; FREIRE-MAIA L. Immunotherapy for scorpion envenoming in Brazil.Toxicon, v.36,p.1507-1513.1998.

RECKZIEGEL, G.C; PINTO JUNIOR V.L. Análise do escorpionismo no Brasil no período de 2000 a 2010. Rev Pan-Amaz Saude, v. 5, n.1, p.67-68, 2014.

RODRÍGUEZ DE LA VEGA R, POSSANI L. Overview of scorpion toxins specific for Na+ channels and related peptides: biodiversity, structure-function relationships and evolution. Toxicon, v.46, n. 831-844, 2005.

SAADI, A.V.S. Síndrome Cerebelar: alterações no controle motor decorrente de lesões cerebelares.Monografia (Pós-Graduação em Psicomotricidade) Projeto Vez do Mestre, Universidade Candido Mendes, Rio de Janeiro, 2004

SANTOS, J.M.; CROESY, G.S.; MARINHO, L.F.B. Perfil epidemiológico dos acidentes escorpiônicos em crianças, no estado da Bahia, de 2007 a 2010. Rev Enf Cont, Salvador, dez. 2012; v. 1, n.1, p.118-129.

SANTOS, M. A natureza do espaço: técnica e tempo. Razão e emoção. São Paulo: Edusp, 2002.

SANTOS, M. Metamorfoses do espaço habitado: fundamentos teóricos e metodológicos da Geografia. São Paulo: Hucitec, 1996. 
SEMSA.Secretaria Municipal de Saúde de Santarém.Dados da rede de atenção a saúde no município. 2016.Disponível em www.santarém.pa.gov.br, acesso em 15/06/2016.

SESPA. Secretaria de Estado de Saúde Pública. Mapas Centros Regionais de Saúde.2015. Disponível em: http://www.saude.pa.gov.br/?page_id=4592015 Acesso em:10.12.2015.

SIEGEL, S. Estatística não-paramétrica para ciências do comportamento / Sidney Siegel, N. John Castellan Jr.; tradução Sara Ianda Correa Carmona. - 2. ed. - Porto Alegre : Artmed, 2006

SIFUENTES, D.N; WEN F.H. Grande aumento nos casos de escorpionismo no país em 2005. Rev da Soc Bras de Med Trop, v.6, n.40, 2007.

SILVA, B.A.J. et al. Implicação de Tityus apiacas (Lourenco, 2002) em envenenamentos escorpiônicos na fronteira sul da Amazônia, Brasil. Rev. Soc. Bras. Med. Trop., v.50, n.3, 2017.http://dx.doi.org/10.1590/0037-8682-0490-2016

SPIEGELMAN, M. Introduction to demography: Editora Harvard University Press, 1968.

SOARES, M.R.M; AZEVEDO, C.S; MARIA, M. Escorpionismo em Belo Horizonte, MG: um estudo retrospectivo. Rev da Soc Bras de Med Trop, v.35, n.4, p.395-363, 2002.

SOUZA, L.M; PINTO, R.N.L.; FEITOSA, D.T.; JUNIOR, N.J.S. Estudo retrospectivo do escopionismo no estado de Goiás (2003-2012). EVS. PUC.GO, v. 44, p. 100-114, 2017.

SPOSATI, A. Territorialização e desafios à gestão pública inclusiva: o caso da assistência social no Brasil .XIII Congreso Internacional del CLAD sobre la Reforma del Estado y de la Administración Pública, Buenos Aires, Argentina, 4 - 7 nov. 2008.

SPEROTTO, L.S et al. Estudo clínico e epidemiológico de 27 casos de escorpionismo em Brasil Novo/Altamira-PA. Período de fevereiro a setembro de 2000. Rev da Soc Bras de Med Trop, v. 34(Supl. 1), p. 381, 2001.

TORREZ, P. P. Q. et al. Acute cerebelar dysfunction with neuromuscular manifestations after scorpionism presumably caused by Tityus obscurus in Santarem, Pará/ Brazil. Toxicon. v 96, p. 68-73, 2015.

VASCONCELOS, F. et al. Effects of voltage-gated Nav channel toxins from Tityus serrulatus venom on rat arterial blood pressure and plasma catecholamines. Comp. Biochem. Physiol. C Toxicol. Pharmacol., v. 141, p.85-92, 2005.

WHARD, M.J.; ELLSWORTH, S.A.; NYSTROM, G.S. A global accounting of medically significant scorpions: Epidemiology, major toxins, and comparative resources in harmless counterparts.Toxicon, v.151, p.137-155,2018.

WHO. World Health Organization. Rabies and envenomings: a neglected public health issue. Report of a Consultative Meeting. Geneva: WHO, p. 32, 2007

ZENG X, COEZO G, HAHIN R. Scorpion venom peptides without disulfide bridges. IUBMB, v.57,n. 1, p.13-21, 2005. 


\section{ANEXOS}

\section{ANEXO I - FICHA DE NOTIFICAÇÃO (FRENTE)}

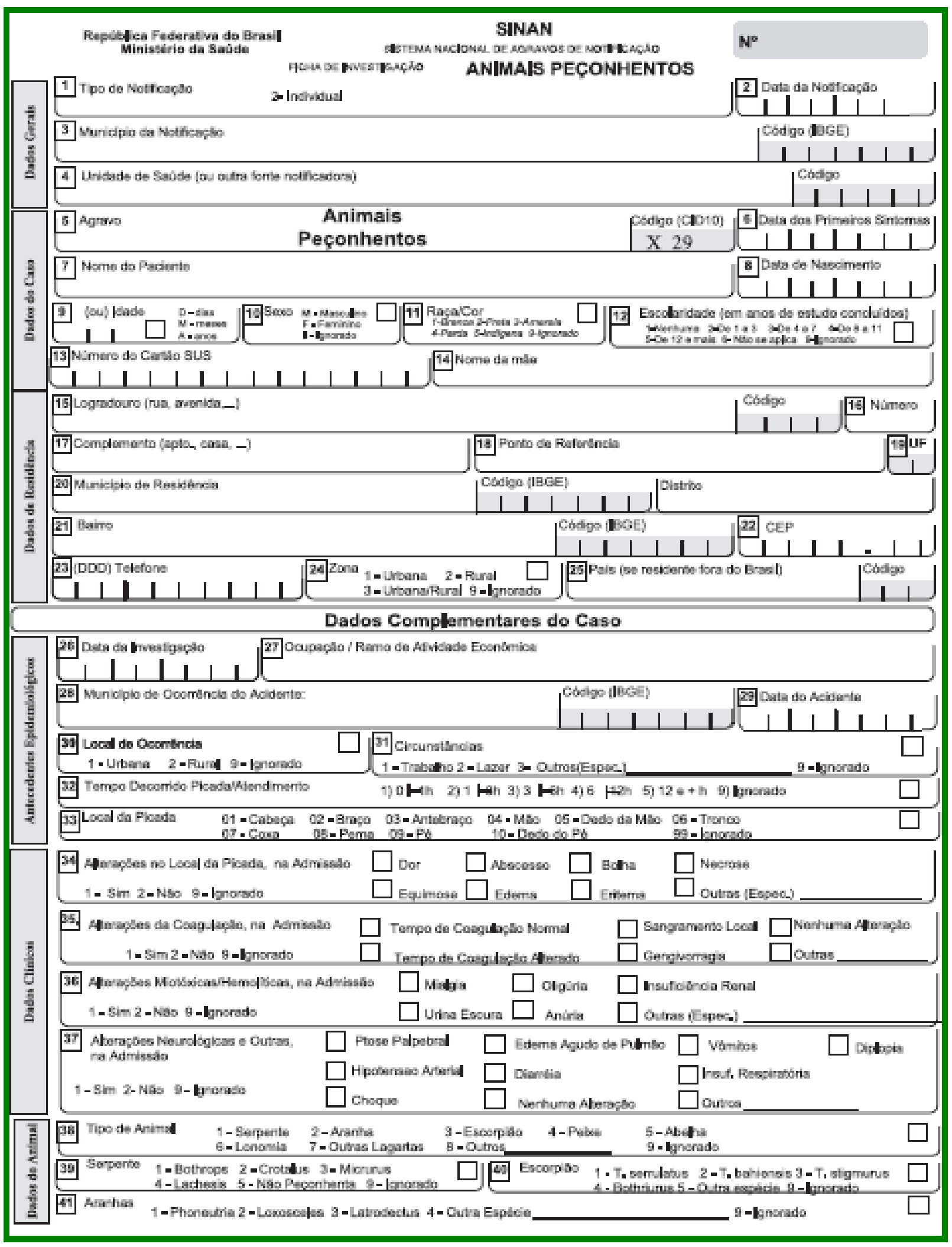


Ficha de notificação (verso)

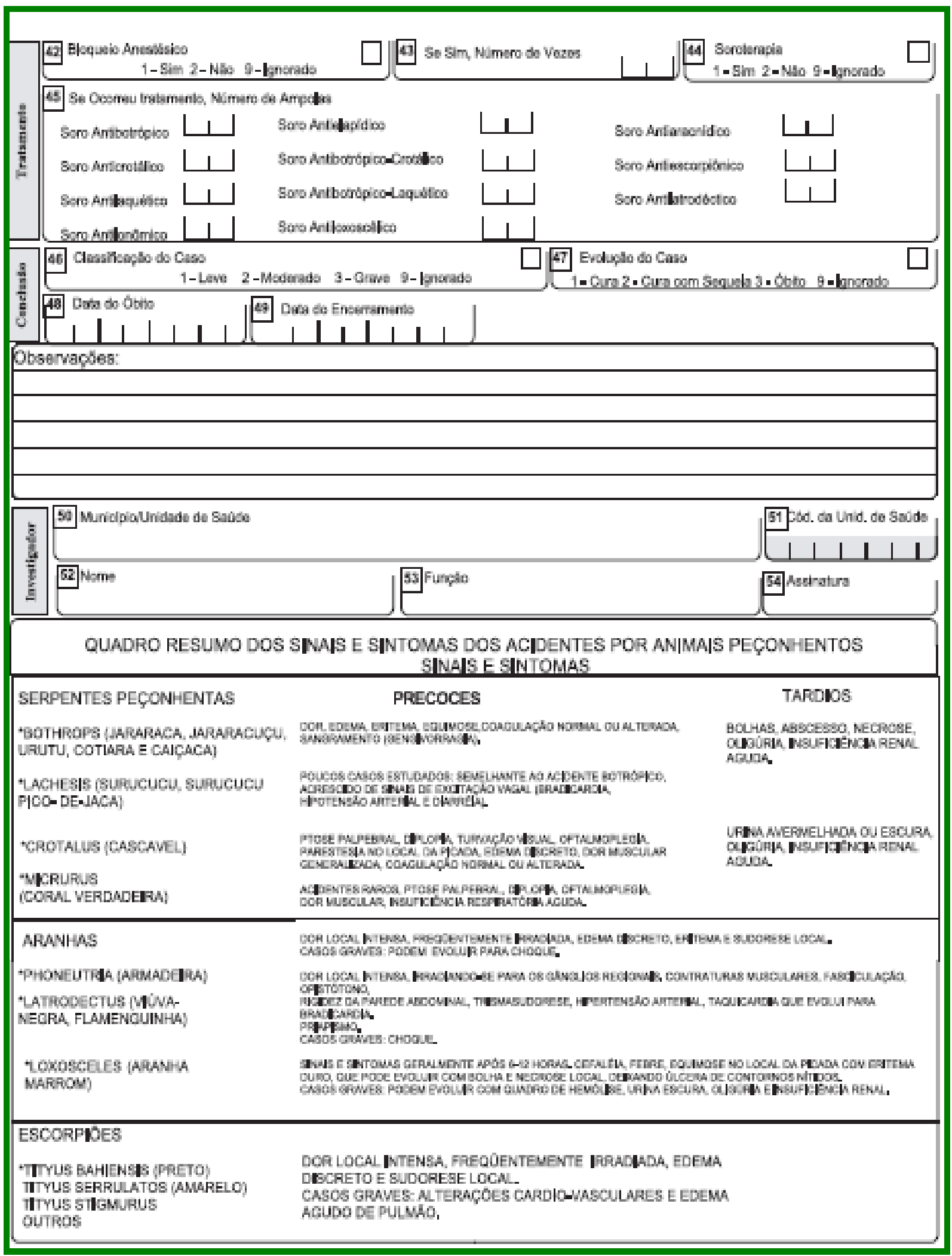


ANEXO II - PARECER DO CEP

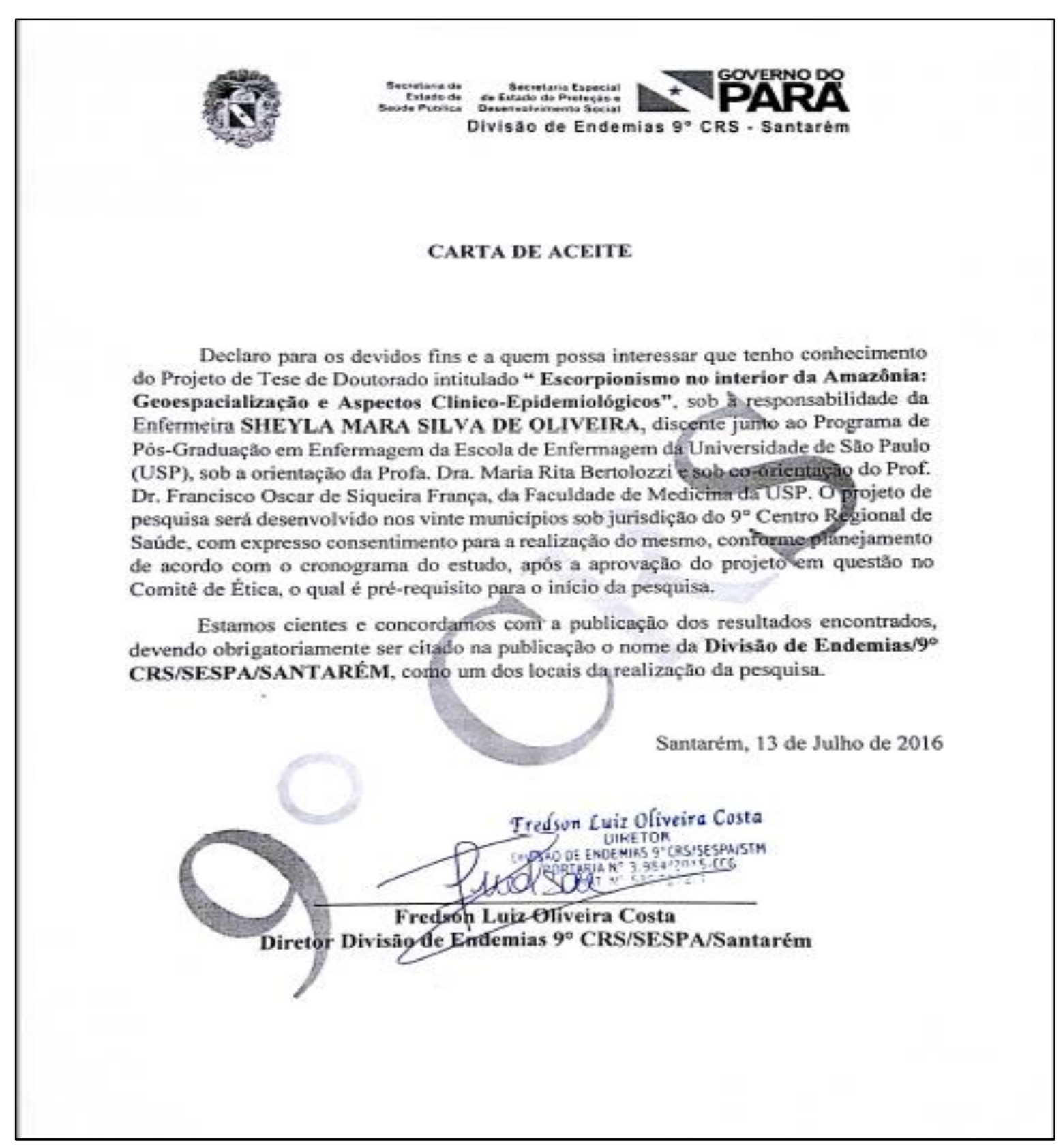




\section{ANEXO III - CARTA DE ACEITE SESPA}

Em nome do Hospital Municipal de Santarém (HMS), declaro ter conhecimento do projeto de pesquisa intitulado "ESCORPIONISMO NO INTERIOR DA AMAZÔNIA: Geoespacializaçăo, aspectos clinicoepidemiológicos". de astoria da pesquisadora Sheyla Mara Silva de Oliveira, pós-graduanda do curso de Doutorado da Escola de Enfermagem da Universidade de São Parklo, dando-lhe consentimento para execuçáo do projeto de pesquisa para fins de produçâo da Tese de Doutorado, a coleta de dados consiste em entrevista corn pacientes vitimas de acidentes escorpiônicos e dados de aspectos clín ico-epidemiológicos em prontuàrios de pacientes que aceitarem participar da pesquisa de livre vontade e assinarem o Termo de Consentimento livre e Esclarecido (TCLE), as entrevistas e coleta de dados, poderão ser reslizadas no herário de 7:00 as 22:00 horas, desde que acordadas previamente com as participantes da pesquisa, no tempo máxime de $\mathbf{3 0}$ min para que não se tornem exaustivas.

Necessàrio, porćm se faz, que antes da apresentaçầ e ou publiçaçẩo dos jesultados, o trabalho final seja apresentado a esta Instituiçio Hospritalar com o escopo de analisar e discutir os resultados obtidos, ficando em carater obrigatónio a ckaçio da Universidade de Sào Paulo e do Hospital Municipal de Santarém, como locais de realizacâo da pesquisa. 
ANEXO IV - CARTA DE ACEITE SEMSA

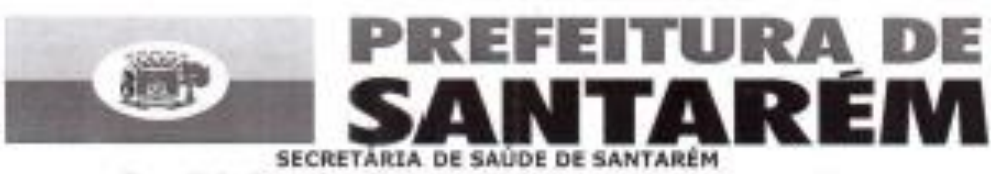

Trav, 7 de Setembro 611 - CEP 6B005-590 - BAIRRO Santa Clara

FONE: 2101-0100 - Santarem/PA

\section{CART A DE ACEITE}

Em nome da Secretaria Municipal de Saúde dedaro ter conhecimento do projeto de Tese de Doutorado intitulado "ESCORPIONISMO NO INTERIOR DA AMAZÔNIA: GEOESPACIALIZAÇÃo, ASPECTOS CLÍNICOEPIDEMIOLóGICOS", de autorla da doutoranda Sheyla Mara Sllva de Oiveira, dando-the consentimento para realizar o trabalho nesta instituiçāo e coletar dados em nosso serviço, Hospitai Municipai de Santarém/HMS, após a aprovaçăo бo projeto en questâo pelo Comitê de Ética de IES, o qual é pré-requisito para o inicio da pesquisa.

Necessario, porém, se faz que antes da publicação dos resultados o trabalho seja apresentado a esta Secretaria Municipal do Saúde com o escopo de analisar e discutir os resultados obtidos, sendo obrigatório citar na publicaçăo o nome da Instituiçăo Universidade do Estado do Para/UEPA; Universidade de SB̃o Paulo/USP e da Secretaria Municipal de Saúde/SEMSA, como locais de realizaçáo da pesquisa.

Santarém, QQ de Julho de 2016.

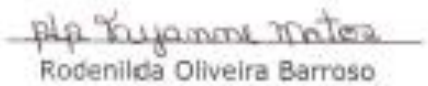

Rodenilda Oliveira Barroso Divisăo Técnica 


\section{APÊNDICES}

\section{APÊNDICE I - TERMO DE CONSENTIMENTO DE USO DE DADOS - TCUD}

Estamos desenvolvendo o estudo: "ESCORPIONISMO NO INTERIOR DA AMAZÔNIA: GEOESPACIALIZAÇÃO E ASPECTOS CLÍNICOEPIDEMIOLÓGICOS", que tem como objetivo, analisar a distribuição espacial e os aspectos clínico-epidemiológicos dos acidentes escorpiônicos no $9^{\circ}$ e $10^{\circ}$ Centro Regional de Saúde do Estado do Pará.

Este estudo integra o Curso de Doutorado que venho desenvolvendo junto ao Programa de Pós-graduação em Enfermagem da Escola de Enfermagem da Universidade de São Paulo, e tem a orientação da Profa. Dra. Maria Rita Bertolozzi e a co-orientação do Prof. Dr. Francisco Oscar França, docente da Faculdade de Medicina da USP.

Tendo em vista os objetivos do estudo, será necessário analisar os dados das Fichas de Notificação de Acidentes por Animais Peçonhentos e prontuários de pacientes que foram atendidos no período de 2016 no Hospital Municipal de Santarém. Tais dados referem-se à localidade de residência do paciente, alguns dados epidemiológicos, como sexo, idade, ocupação; dados clínicos para caracterizar as manifestações que os pacientes apresentaram, assim como tratamento e evolução do caso.

Assim, com base nos itens III.3.i e III.3.t das Diretrizes e Normas Regulamentadoras de Pesquisas Envolvendo Seres Humanos (Res CNS 466/12) e na Diretriz 12 das Diretrizes Éticas Internacionais para Pesquisas Biomédicas Envolvendo Seres Humanos (CIOMS/93), declaramos que:

a) $\mathrm{O}$ acesso aos dados registrados nas fichas de notificação e/ou prontuários será para fins da pesquisa e será feito somente após aprovação do projeto de pesquisa pelo CEP-EEUSP;

b) $\mathrm{O}$ acesso aos dados será supervisionado por uma pessoa que esteja plenamente informada sobre as exigências de confidencialidade;

c) Asseguramos o compromisso com a privacidade e a confidencialidade dos dados utilizados, preservando integralmente o anonimato e a imagem dos participantes do estudo;

d) Asseguramos a não-utilização das informações em prejuízo das pessoas incluídas nas Fichas de Notificação Individual, assim como nos prontuários do Hospital Municipal de Santarém;

e) Os dados obtidos na pesquisa serão usados exclusivamente para a finalidade prevista no estudo. 
Este termo encontra-se impresso em duas vias, sendo que uma cópia será arquivada pelo pesquisador responsável, e a outra será fornecida ao responsável pelas Fichas de Notificação da SESPA e pela gerência do Hospital Municipal de Santarém.

Caso haja danos decorrentes dos riscos previstos, o pesquisador assumirá a responsabilidade pelos mesmos.

$\mathrm{Eu}$, , fui informado dos objetivos do estudo "Escorpionismo no interior da Amazônia: Geoespacialização e Aspectos clínico-epidemiológicos". Sei que a qualquer momento poderei solicitar novas informações e modificar minha decisão de fornecer o acesso aos dados do Sistema de Notificação e/ ou prontuários de pacientes, referentes aos acidentes escopiônicos.

Santarém- Pará, 26 de Fevereiro de 2018.

Assinatura do responsável pelo setor junto à SESPA/ SEMSA

Assinatura da pesquisadora

Sheyla Mara Silva de Oliveira 


\section{APÊNDICE II - TERMO DE CONSENTIMENTO LIVRE E ESCLARECIDO}

Convidamos o(a) Sr.(a). para participar de uma das etapas do estudo sobre "Escorpionismo no interior da Amazônia: Geoespacialização e Aspectos ClínicoEpidemiológicos, sob a responsabilidade da Enfermeira Sheyla Mara Silva de Oliveira, que vem realizando o Curso de Doutorado junto ao Programa de Pós-Graduação em Enfermagem da Escola de Enfermagem da USP, sob a orientação da Profa. Dra. Maria Rita Bertolozzi e sob a co-orientação do Prof. Dr. Francisco Oscar de Siqueira França, da Faculdade de Medicina da Universidade de São Paulo.

Sua participação é muito importante, pois poderemos atingir o objetivo do estudo que é analisar onde e como ocorrem os acidentes por escorpião e conhecer algumas características das vítimas desses acidentes, que ocorrem na região do Baixo Amazonas e no Sudoeste do Pará. Sua participação consiste em responder algumas perguntas relacionadas ao local onde atua, e conhecimentos e ações realizadas no caso de acidentes por escorpião na região.

As respostas não deverão demorar mais do que 15 minutos e serão devidamente guardadas sob a responsabilidade da pesquisadora, por um período de cinco anos. Após o término desse período todos os dados serão incinerados e em nenhum momento outras pessoas, que não as envolvidas neste projeto, terão acesso a esse material. O (A) Sr.(a). poderá deixar de responder ao questionário à qualquer momento, caso sinta algum desconforto, sem que ocorra quaisquer prejuízos em relação ao seu trabalho.

Também informo que o Sr.(a) poderá participar de uma capacitação sobre Escorpionismo, que ocorrerá nas dependências da Universidade do Estado do Pará-Campus Santarém, mediante agendamento prévio da pesquisadora, com carga horária de 10 horas, correspondente a dois encontros. Nesta capacitação, será apresentado como proceder em caso desse tipo de acidente. Também poderá contribuir para o estudo, auxiliando na coleta de dados dos pacientes que forem atendidos na unidade de saúde onde o Sr.(a) atua. Caso o paciente apresente alguma alteração visível no corpo, o $\operatorname{Sr}(a)$. poderá registrar o ocorrido, por meio de filmagem, utilizando seu próprio aparelho celular. A coleta de dados com os pacientes e a filmagem só ocorrerão após consentimento e autorização dos pacientes e/ou de seus responsáveis (caso sejam menores de idade). As imagens serão de uso exclusivo da pesquisa.

Sua participação nesta pesquisa é voluntária. O Sr.(a) não terá nenhum gasto, assim como não terá nenhum ganho financeiro em participar. 
O estudo poderia oferecer risco, se sua identidade fosse revelada, mas para que isso não ocorra vamos utilizar números e não seu nome, e nos comprometemos a não revelar e preservar sua identidade.

O principal benefício da pesquisa é possibilitar verificar o que os profissionais de saúde conhecem sobre a ocorrência dos acidentes por escorpião, incluindo aspectos espaciais, epidemiológicos e clínicos dos acidentes escorpiônicos ocorridos na região.

Durante o desenvolvimento da pesquisa será garantido o livre acesso a todas as informações e esclarecimentos sobre as etapas da pesquisa, sobre tudo o que o (a) Sr.(a) queira saber antes, durante e depois da sua participação.

$\mathrm{O}(\mathrm{A})$ Sr.(a), após a leitura deste Termo deverá rubricar todas as páginas e assinar as duas vias: uma delas lhe será entregue e a outra ficará com a pesquisadora.

Como foi explicado antes, o(a) Sr.(a) não terá lucros e nem gastos financeiros com sua participação no estudo. Caso ocorra algum dano decorrente da sua participação no estudo, o(a)Sr. será devidamente indenizado(a), conforme determina a lei.

Qualquer dúvida a respeito da pesquisa, o(a)Sr.(a) poderá entrar em contato com: Sheyla Mara Silva de Oliveira, (93) 99123-9556, ou no endereço situado na avenida: Bartolomeu de Gusmão, 1745, bairro Jardim - Santarém, CEP: 68030-350, cidade de Santarém, Pará, Brasil, email: enfsheylauepastm@ @otmail.com

Caso o(a)Sr.(a) tenha alguma consideração ou dúvida sobre a ética da pesquisa, pode entrar em contato com o Comitê de Ética em Pesquisa da Escola de Enfermagem da Universidade de São Paulo, localizado na Avenida Dr. Enéas de Carvalho Aguiar, 419 - $2^{\circ}$ andar, sala 201, CEP: 05403-000 - Cerqueira César - São Paulo - SP, Telefone: (11) 30618858 - E-mail: cepee@usp.br

Esta pesquisa atende todas as especificações da Resolução 466, de 12 de Dezembro de 2012, que aprova a diretrizes e normas regulamentadoras de pesquisa envolvendo seres humanos.

Assinatura do Pesquisador

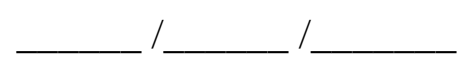




\section{APÊNDICE III - TERMO DE CONSENTIMENTO LIVRE E ESCLARECIDO}

Convidamos o(a) Sr.(a). para participar de uma das etapas do estudo intitulada "Escorpionismo no interior da Amazônia: Geoespacialização e Aspectos ClínicoEpidemiológicos, sob a responsabilidade da Enfermeira Sheyla Mara Silva de Oliveira, que vem realizando o Curso de Doutorado junto ao Programa de Pós-Graduação em Enfermagem da Escola de Enfermagem da USP, sob a orientação da Profa. Dra. Maria Rita Bertolozzi e sob a co-orientação do Prof. Dr. Francisco Oscar de Siqueira França, da Faculdade de Medicina da USP.

Sua participação é muito importante, pois poderemos atingir o objetivo do estudo que é analisar onde e como ocorrem os acidentes por escorpião, e ainda conhecer algumas características das pessoas que foram vítimas do acidente. Sua participação consiste em responder algumas perguntas sobre sua idade, onde mora, onde ocorreu o acidente, assim como queixas que está apresentando.

As respostas não deverão demorar mais do que 30 minutos e serão devidamente guardadas sob a responsabilidade da pesquisadora, por um período de cinco anos. Após o término desse período todos os dados serão incinerados e em nenhum momento outras pessoas, que não as envolvidas com este projeto, terão acesso a esse material. O (A) Sr.(a). poderá deixar de responder ao questionário caso sinta algum desconforto, sem que ocorra prejuízo em seu atendimento neste serviço de saúde.

Como temos muitos casos parecidos com o do Sr.(a), pedimos sua autorização para filmá-lo, em caso que apresente alguma alteração no corpo, que possa ser vista. Informamos que as imagens serão de uso exclusivo da pesquisa. Também pedimos sua autorização para fotografar o escorpião, caso tenha trazido para o serviço de saúde.

Sua participação nesta pesquisa é voluntária. O Sr.(a) não terá nenhum gasto, assim como não terá nenhum ganho financeiro em participar do estudo.

O estudo poderia oferecer risco, se sua identidade fosse revelada, mas para que isso não ocorra vamos utilizar números e não seu nome, e nos comprometemos a não revelar e preservar sua identidade.

O principal benefício da pesquisa é possibilitar conhecer onde ocorrem os acidentes por escorpião, e o que as pessoas apresentam, com a finalidade de apoiar o tratamento adequado. 
Durante o desenvolvimento da pesquisa será garantido o livre acesso a todas as informações e esclarecimentos sobre as etapas da pesquisa, e sobre tudo o que o (a) Sr.(a) queira saber antes, durante e depois da sua participação.

O (A) Sr.(a), após a leitura deste Termo, deverá rubricar todas as páginas e assinar as duas vias: uma vai ser entregue ao $\mathrm{Sr}$.(a) e a outra ficará com a pesquisadora.

Como foi explicado antes, o(a) Sr.(a) não terá lucros e nem gastos financeiros com sua participação no estudo. Caso ocorra algum dano decorrente da sua participação no estudo, o(a)Sr. será devidamente indenizado(a), conforme determina a lei.

Qualquer dúvida a respeito da pesquisa, o(a)Sr.(a) poderá entrar em contato com: Sheyla Mara Silva de Oliveira, (93) 99123-9556, ou no endereço situado na avenida: Bartolomeu de Gusmão, 1745, bairro Jardim - Santarém, CEP: 68030-350, cidade de Santarém, Pará, Brasil, email: enfsheylauepastm@ @otmail.com

Caso o(a)Sr.(a) tenha alguma consideração ou dúvida sobre a ética da pesquisa, pode entrar em contato com o Comitê de Ética em Pesquisa da Escola de Enfermagem da Universidade de São Paulo, localizado na Avenida Dr. Enéas de Carvalho Aguiar, 419 - $2^{\circ}$ andar, sala 201, CEP: 05403-000 - Cerqueira César - São Paulo - SP, Telefone: (11) 30618858 - E-mail: cepee@usp.br

Esta pesquisa atende todas as especificações da Resolução 466, de 12 de Dezembro de 2012, que aprova a diretrizes e normas regulamentadoras de pesquisa envolvendo seres humanos.

Assinatura do Pesquisador

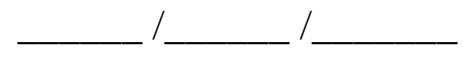

Assinatura do(a)participante 


\section{APÊNDICE IV - TERMO DE ASSENTIMENTO}

$\mathrm{Eu}$, fui convidado(a) para participar da pesquisa sobre: "Escorpionismo no interior da Amazônia: Geoespacialização, Aspectos ClínicoEpidemiológicos”, desenvolvida pela pesquisadora Sheyla Mara Silva de Oliveira.

Tomei conhecimento de que o objetivo do estudo é analisar onde e como ocorrem os acidentes por escorpião nesta região e conhecer características das pessoas que foram vítimas do acidente.

Fui informado(a) de que a pesquisadora se compromete a manter segredo do meu nome durante a pesquisa e serei identificado(a) por um número. Minha participação nessa pesquisa consiste em responder a perguntas sobre minha idade, onde moro, onde ocorreu o acidente, o que estou sentindo e apresentando após a picada do escorpião.

Também fui informado(a) de que serei entrevistado(a) enquanto estiver sendo atendido(a) no hospital e que a entrevista terá a duração de, no máximo, 30 minutos. Também tomei conhecimento e também o responsável por mim, de que posso ser filmado(a), caso haja necessidade. Sei que as imagens serão de uso exclusivo para a pesquisa. Compreendi que não sou obrigado(a) a participar desta pesquisa e minha escolha em participar ou não, será respeitada. Mesmo depois de aceitar participar, posso sair do estudo a qualquer momento e minha saída não implicará em qualquer dificuldade ou problema para mim ou minha família em relação ao atendimento neste serviço de saúde.

Confirmo que recebi as informações necessárias para entender porque e como este estudo será realizado.

Informo também, que fui esclarecido(a) que os questionários preenchidos serão armazenados pela pesquisadora por um período de 5 anos e, após esse período, serão queimados e destruídos. Estou ciente de que não terei nenhum custo ou receberei qualquer valor financeiro ou de outra natureza. Em caso de dano pessoal ou material devido à minha participação, poderei solicitar da pesquisadora meus direitos, conforme as leis vigentes no país.

Fui informado(a) de que minha participação será de grande valia e o principal benefício é possibilitar conhecer onde ocorrem os acidentes por escorpião, e como se apresentam os sinais e sintomas das pessoas que sofreram o acidente, o que pode contribuir para o tratamento adequado.

Fui informado(a) de que o estudo poderia oferecer risco, se minha identidade fosse revelada, mas para que isso não ocorra, serão utilizados números e não meu nome, para que minha identidade seja preservada e não revelada.

Qualquer dúvida a respeito da pesquisa, você ou seu responsável poderá entrar em contato com: Sheyla Mara Silva de Oliveira, (93) 99123-9556, ou no endereço situado na avenida: Bartolomeu de Gusmão, 1745, bairro Jardim - Santarém, CEP: 68030-350, cidade de Santarém, Pará, Brasil, email: enfsheylauepastm@ @otmail.com 
Se eu ou minha família tivermos dúvidas sobre a ética da pesquisa, poderemos entrar em contato com o Comitê de Ética em Pesquisa da Escola de Enfermagem da Universidade de São Paulo, localizado na Avenida Dr. Enéas de Carvalho Aguiar, 419 - $2^{\text {o }}$ andar, sala 201, CEP: 05403-000 - Cerqueira César - São Paulo - SP, Telefone: (11) 3061-8858 - E-mail: cepee@usp.br

Esta pesquisa atende a todas as especificações da Resolução 466, de 12 de Dezembro de 2012, que aprova a diretrizes e normas regulamentadoras de pesquisa envolvendo seres humanos.

Assinatura do Pesquisador

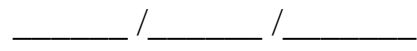




\section{APÊNDICE V - TERMO DE CONSENTIMENTO LIVRE E ESCLARECIDO- PAIS}

$\mathrm{O}$ (A) seu(sua) filho(a)___ está sendo convidado(a) a participar da pesquisa "Escorpionismo no interior da Amazônia: Geoespacialização, Aspectos Clínico- Epidemiológicos", sob a responsabilidade da pesquisadora Sheyla Mara Silva de Oliveira, que vem realizando o Curso de Doutorado junto ao Programa de Pós-Graduação em Enfermagem da Escola de Enfermagem da USP, sob a orientação da Profa. Dra. Maria Rita Bertolozzi e sob a co-orientação do Prof. Dr. Francisco Oscar de Siqueira França, da Faculdade de Medicina da Universidade de São Paulo.

Gostaria de contar com participação de (da) seu (sua) filho (a), que é voluntário (a), ou seja, o $\operatorname{Sr}($ a) decide se deseja participar. Este documento contém todas as informações necessárias sobre a pesquisa que pretendo realizar. A colaboração de(da) seu(sua) filho(a) é muito importante, pois com isso poderemos atingir o objetivo da pesquisa que é analisar onde e como ocorrem os acidentes por escorpião nesta região.

Caso o(a) seu(sua) filho(a) desista de participar do estudo ou de responder alguma pergunta, isso não causará nenhum prejuízo no atendimento dele(a) no serviço de saúde, nem para o(a) $\operatorname{Sr}(a)$.

A participação dele(a) consiste em responder algumas perguntas sobre a idade, o que faz, onde mora, onde ocorreu o acidente, assim como queixas que está apresentando. Isso não deverá demorar mais do que 30 minutos e as respostas serão devidamente guardadas sob a responsabilidade da pesquisadora, por um período de cinco anos. Após o término desse período todos os dados serão queimados e destruídos e em nenhum momento outras pessoas, que não as envolvidas neste projeto, terão acesso a esse material.

Como temos muitos casos parecidos com o do(a) seu(sua) filho(a), pedimos sua autorização para filmá-lo(a), se apresentar alguma alteração visível no corpo. Informamos que as imagens serão de uso exclusivo da pesquisa. Também pedimos sua autorização para fotografar o escorpião, caso tenha trazido para o serviço de saúde.

A participação de (da) seu (sua) filho (a) nesta pesquisa é voluntária. O (A) seu (sua) filho(a) não terá nenhum gasto, assim como não terá nenhum ganho financeiro em participar.

O estudo poderia oferecer risco, se sua identidade fosse revelada, mas para que isso não ocorra vamos utilizar números e não seu nome, e nos comprometemos a não revelar e preservar sua identidade. 
O principal benefício da pesquisa é possibilitar conhecer onde ocorrem os acidentes por escorpião, e o que as pessoas apresentam, com a finalidade de apoiar o tratamento adequado.

Durante o desenvolvimento da pesquisa será garantido o livre acesso a todas as informações e esclarecimentos sobre as etapas da pesquisa, e sobre tudo o que o(a) Sr.(a) quiser saber antes, durante e depois da participação de(da) seu(sua) filho(a).

$\mathrm{O}(\mathrm{A})$ Sr.(a), após a leitura deste Termo deverá rubricar todas as páginas e assinar as duas vias: uma delas lhe será entregue e a outra ficará com a pesquisadora.

Como foi explicado antes, seu(sua) filho(a) não terá lucros e nem gastos financeiros com a participação no estudo. Caso ocorra algum dano decorrente da sua participação no estudo, o(a) seu(sua) filho(a) será devidamente indenizado(a), conforme determina a lei.

Qualquer dúvida a respeito da pesquisa, o(a) Sr.(a) poderá entrar em contato com: Sheyla Mara Silva de Oliveira, (93) 99123-9556, ou no endereço situado na avenida: Bartolomeu de Gusmão, 1745, bairro Jardim - Santarém, CEP: 68030-350, cidade de Santarém, Pará, Brasil, email: enfsheylauepastm@ @otmail.com

Caso o(a) Sr.(a) tenha alguma consideração ou dúvida sobre a ética da pesquisa, pode entrar em contato com o Comitê de Ética em Pesquisa da Escola de Enfermagem da Universidade de São Paulo, localizado na Avenida Dr. Enéas de Carvalho Aguiar, 419 - $2^{\circ}$ andar, sala 201, CEP: 05403-000 - Cerqueira César - São Paulo - SP, Telefone: (11) 30618858 - E-mail: cepee@usp.br

Esta pesquisa atende todas as especificações da Resolução 466, de 12 de Dezembro de 2012, que aprova a diretrizes e normas regulamentadoras de pesquisa envolvendo seres humanos.

Assinatura do Pesquisador

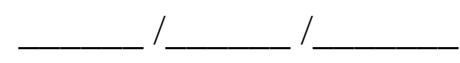

Assinatura do responsável do(a) Menor 


\section{APÊNDICE VI-QUESTIONÁRIO DE PESQUISA}

PROJETO DE PESQUISA: ESCORPIONISMO NO INTERIOR DA AMAZÔNIA: GEOESPACIALIZAÇÃO E ASPECTOS CLÍNICO-EPIDEMIOLÓGICOS

Profissão: Município que atua:

Há quanto tempo:

Atua em:

UBS / ESF. Qual?

Hospital. Qual?

Você já atendeu pessoas picadas por escorpião no Estado do Pará?

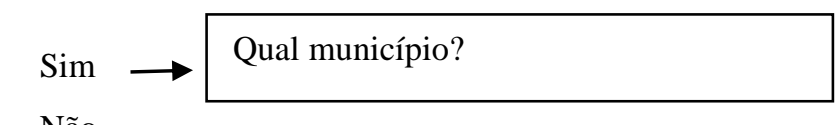

Não

Descreva o quadro clínico desses pacientes:

Email/ Telefone: 


\section{APÊNDICE VII -PROTOCOLO DE PESQUISA (ESTUDO RETROSPECTIVO E PROSPECTIVO)}

TÍTULO DA PESQUISA: ESCORPIONISMO NO INTERIOR DA AMAZÔNIA: GEOESPACIALIZAÇÃO, ASPECTOS CLÍNICO-EPIDEMIOLÓGICOS

\section{DADOS EPIDEMIOLÓGICOS}

1. Iniciais do Paciente:

2. Idade:

3. Sexo: ( ) Masculino ( ) Feminino ( )Ignorado/sem informação

4. Data e Hora da Admissão na Unidade de Saúde:

5. Data e Hora do Acidente:

6. Ocupação:

7. Escolaridade ( $\mathbf{n}^{0}$ de anos de estudo):

8. Local (endereço) e Município da Ocorrência do Acidente:

9. O acidente ocorreu em:

( ) Zona Urbana $\quad$ ( )Zona Rural $\rightarrow$ Qual comunidade?

( )Ignorado/sem informação

10. Situação em que ocorreu o acidente:( ) lazer （ )trabalho （ ) trabalho doméstico ( ) outras. Especificar:

11. Nome do animal: 12. Cor do animal:

13.Trouxe o animal: （ ）Sim （ ） Não （ ） Ignorado/sem informação

14. Espécie do Animal:

\section{DADOS CLÍNICOS}

15. Manifestações Locais: 1- sim 2- não( ) dor ( ) edema ( ) eritema ( ) calor local ( ) piloereção ( ) sudorese ( ) parestesia ( ) sensação de choque elétrico ( )outros Especificar:

16. Se dor, quanto tempo após a picada apareceu e desapareceu, respectivamente?

17. Em que parte do corpo sentiu dor? 1- sim 2- não

( ) somente no local da picada ( ) No membro afetado ( ) no lado do corpo afetado ( ) em todo corpo

18. Se dor no corpo, como foi a evolução? Crescente ou imediata?

19. Qual score você atribui ao início da dor? 


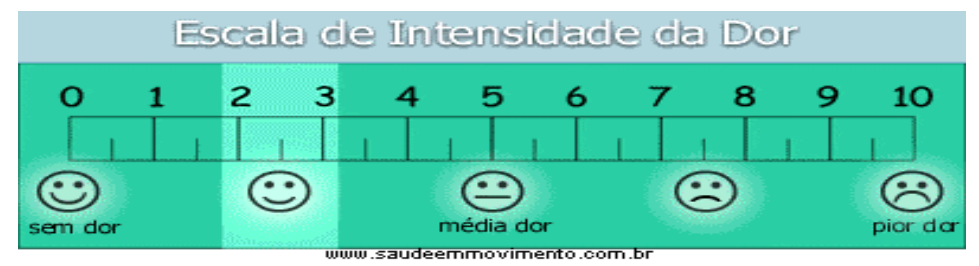

20. Se houve formigamento, quanto tempo após a picada ela apareceu e desapareceu, respectivamente?

21. Em que partes do corpo você sentiu formigamento? 1- sim 2- não

( ) somente no local da picada ( ) no membro afetado ( ) no lado do corpo afetado ( ) Em todo o corpo

22. Se houve formigamento, como foi a evolução? Crescente ou imediata?

23. Manifestações Sistêmicas: 1- sim2- não( ) Hipertensão ( ) Hipotensão

( ) sudorese ( ) náuseas ( ) vômitos ( ) sialorréia ( ) diarreia

( ) priaprismo ( ) oligúria ( ) anúria ( ) Taquicardia ( ) Arritmia Cardíaca ( )

Bradicardia ( ) Astenia ( ) Disfagia ( ) Tremores ( ) Hipertemia.

24. Apresenta sensação de choque elétrico pelo corpo:

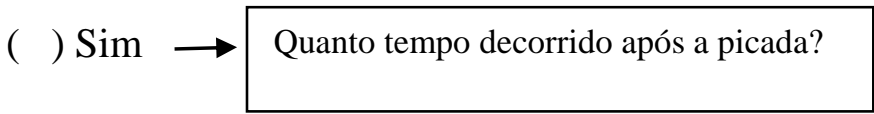

( ) Não ( ) Ignorado/Sem informação

25. Quanto tempo após a picada a sensação de choque elétrico desapareceu?

26. Em que partes do corpo você sentiu esse choque? 1- sim 2- não

( ) somente no local da picada ( ) No membro afetado ( ) No lado do corpo afetado ( ) Em todo corpo

27. Se em corpo todo, como foi a evolução do choque? Foi crescente ou imediata?

28. Teve mioclonia? ( ) Sim $\rightarrow$ Quanto tempo decorrido após a picada?

( ) Não ( ) Ignorado/ Sem informação

29. Em que partes do corpo você sentiu mioclonia? 1- sim 2- não

( ) somente no local da picada ( ) No membro afetado ( ) No lado do corpo afetado ( ) Em todo corpo

30. Se em corpo todo, como foi a evolução da mioclonia? Foi crescente ou imediata?

31. Se apresentoudisartria, dismetria e ataxia de marcha, quanto tempo após a picada esses sintomas iniciaram ou foram registrados?

32. Quanto tempo após a picada as manifestações acima citadas desapareceram? 
33. Teve espasmo?( ) Sim $\rightarrow$ Quanto tempo durou?

( ) Não ( ) Ignorado/Sem informação

34.Teve Hipertonia?( ) Sim

Quanto tempo durou?

( ) Não ( ) Ignorado / Sem informação

35. Teve Fasciculação?( ) Sim

( ) Não （ ） Ignorado/ Sem informação

36. Teve Alteração da fala ?( ) Sim

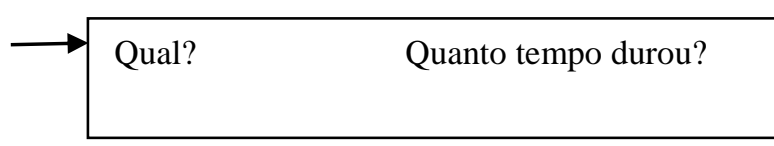

( ) Não ( ) Ignorado/ Sem informação

37. Teve dificuldade para andar?

( ) $\operatorname{Sim} \longrightarrow$ Qual? Quanto tempo durou?

( ) Não ( ) Ignorado/Sem informação

38. Teve falta de coordenação motora?( ) Sim

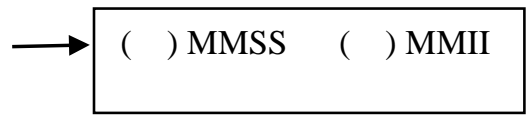

39. Se alterações urinárias, quanto tempo iniciaram após a picada?

40. Quais sintomas foram encontrados?

41. Quanto tempo depois da picada estes sintomas desapareceram?

42. Classificação do caso:( ) leve ( ) moderado ( )grave ( ) Sem informação/Ignorado

43. Soroterapia Específica: ( ) Sim

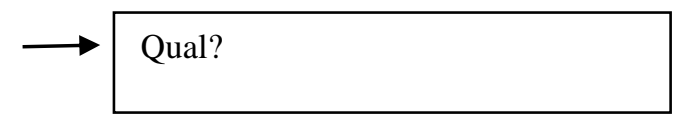

( ) Não ( ) Ignorado/ Sem informação

44. Condições da alta hospitalar:( ) Cura ( ) óbito

Causa Mortis: 
45. Outros dados clínicos de interesse: 


\section{EE DESPE USP - ESCOLA DE

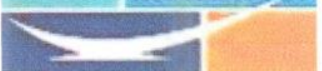 \\ ENFERMAGEM DA UNIVERSIDADE DE SÃO \\ Q Ploteforma 8rasil}

\section{PARECER CONSUBSTANCIADO DO CEP}

\section{DADOS DA EMENDA}

Título da Pesquisa: Escorpionismo no interior da Amazônia: Geoespacialização, Aspectos ClínicoEpidemiológicos

Pesquisador: Sheyla Mara Silva de Oliveira

Área Temática:

Versão: 3

CAAE: 57934116.9 .0000 .5392

Instituição Proponente: Escola de Enfermagem da Universidade de São Paulo - EEUSP

Patrocinador Principal: Financiamento Próprio

\section{DADOS DO PARECER}

Número do Parecer: 2.490.681

\section{Apresentação do Projeto:}

Trata-se de uma emenda referente a projeto de Doutorado vinculado à Escola de Enfermagem da Universidade de São Paulo (EEUSP) na área de concentração "Cuidado em Saúde", aprovado pelo CEP da EEUSP em 13/09/2016.

- O projeto pretende conhecer a amplitude e a diversidade dos acidentes escorpiônicos na mesoregião do Baixo Amazonas e Sudoeste do Pará. Trata-se de um estudo observacional, descritivo, retrospectivo e prospectivo de abordagem quantitativa. Na etapa retrospectiva serão analisadas as Fichas de Notificação de Acidentes por Animais Peçonhentos (SINAN) dos 29 municipios pertencentes ao $9^{\circ}$ e $10^{\circ}$ Centro Regional de Saúde, no periodo de 2011 a 2015, e os prontuários de 70 pacientes vítimas de escorpionismo, atendidos no Hospital Municipal de Santarém entre 2014 e 2015. Na etapa prospectiva, será realizado um estudo exploratório ancorado em metodologias mistas. Será aplicado um questionário dirigido aos profissionais de saúde; realizada a capacitação de 30 profissionais de enfermagem dos 20 municípios envolvidos na coleta de dados dos pacientes durante seis meses; e o georreferenciamento dos acidentes escorpiônicos. Os instrumentos de coleta dos dados constam dos anexos do protocolo da pesquisa. A proposta apresenta cronograma de execução com término previsto para dezembro de 2018.

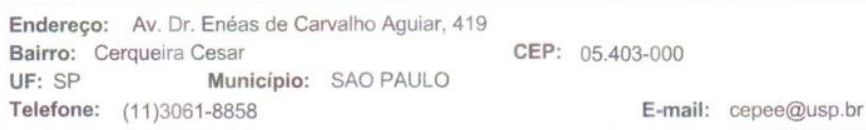




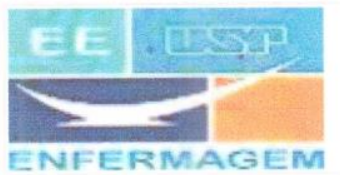

Continuação do Parecer: 2.490 .681

\section{USP - ESCOLA DE ENFERMAGEM DA UNIVERSIDADE DE SÃO}

Platoforma grosi

\section{Objetivo da Pesquisa:}

\section{Objetivo geral:}

Analisar a distribuição espacial e os aspectos clínico-epidemiológicos dos acidentes escorpiônicos no $9^{\circ} \mathrm{e}$ $10^{\circ}$ Centro Regional de Saúde do Estado do Pará.

Objetivos específicos:

1- Determinar a incidência dos acidentes escorpiônicos na mesoregião do Baixo Amazonas e Sudoeste do Pará.

2- Caracterizar a distribuição espacial dos acidentes que apresentam manifestações clínicas compativeis com comprometimento cerebelar e/ou muscular nessa Região.

3- Verificar as manifestaçōes clínicas que os pacientes acometidos apresentam.

4 - Identificar como são classificados tais agravos, em termos de gravidade e como se realiza o seu manejo clínico.

5 - Propor medidas de intervenção no âmbito da vigilância à saúde e da informação em saúde.

\section{Avaliação dos Riscos e Benefícios:}

A pesquisadora informa que para assegurar o sigilo da identidade dos pacientes serão utilizados códigos numéricos. Informa ainda que caso o participante sinta-se constrangido, insatisfeito ou incomodado durante a aplicação do questionário ou demais procedimentos do protocolo de pesquisa, o mesmo poderá desistir a qualquer momento, sem qualquer prejuizo.

Quanto aos benefícios poderá contribuir para a produção de conhecimento científico, bem como para o aprimoramento das ações de detecção, manejo clínico dos acidentes e prevenção primária baseada na informação em saúde.

\section{Comentários e Considerações sobre a Pesquisa:}

A pesquisadora informou que no projeto aprovado seriam analisados os prontuários de 70 pacientes vítimas de escorpionismo atendidos no Hospital Municipal de Santarém entre 2014 e 2015. Contudo, constatou que, os prontuários não estavam devidamente organizados, readequando o período de coleta dos dados de 2014 a 2015 para 2016. Quanto ao estudo prospectivo com coleta prevista para outubro de 2016 a abril de 2017. em função das mudanças ocorridas no quadro funcional dos 20 municípios foi necessário reprogramar o período para março a setembro de 2017

Foi anexada a autorização com o período atualizado para a coleta dos dados dos prontuários.

Endereço: Av. Dr. Enéas de Carvalho Aguiar, 419

Bairro: Cerqueira Cesar
UF: SP Municipio: SAO PAULO

Telefone: (11)3061-8858
CEP: $05.403-000$

E-mail: cepee@usp.br 
$\approx E=\sin ^{2}$

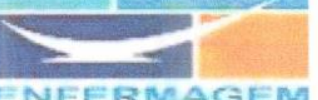

ENFERMAGEMI

Continuaçăo do Parecer 2.490 .681

\section{USP - ESCOLA DE \\ ENFERMAGEM DA UNIVERSIDADE DE SÃO}

Plotoforma Prasil

Considerações sobre os Termos de apresentação obrigatória:

Constam do protocolo de pesquisa os três Termos de Consentimento Livre e Esclarecido (TCLE) destinados aos profissionais de saúde, aos usuários vítimas de acidentes escorpiônicos e aos pais, além do Termo de Assentimento para os menores de idade. Os TCLEs e o Termo de Assentimento estão adequados à resolução 466/2012 - CNS/Conep.

Recomendações:

Não há recomendações.

Conclusões ou Pendências e Lista de Inadequações:

A emenda ao projeto não apresenta óbices éticos que impeçam a continuidade do estudo.

Considerações Finais a critério do CEP:

- Este CEP informa a necessidade de registro dos resultados parciais e finais na Plataforma Brasil;

- Esta aprovação não substitui a autorização da instituição coparticipante, antes do início da coleta de dados.

Este parecer foi elaborado baseado nos documentos abaixo relacionados:

\begin{tabular}{|c|c|c|c|c|}
\hline Tipo Documento & Arquivo & Postagem & Autor & Situação \\
\hline $\begin{array}{l}\text { Informaçōes Básicas } \\
\text { do Projeto }\end{array}$ & $\begin{array}{l}\text { PB_INFORMAÇŌES_BÁSICAS_106554 } \\
8 \text { Ė1.pdf }\end{array}$ & $\begin{array}{c}19 / 01 / 2018 \\
18: 06: 58 \\
\end{array}$ & & Aceito \\
\hline $\begin{array}{l}\text { Projeto Detalhado / } \\
\text { Brochura } \\
\text { Investigador }\end{array}$ & Projeto_revisto.docx & $\begin{array}{c}19 / 01 / 2018 \\
18: 05: 47\end{array}$ & $\begin{array}{l}\text { Sheyla Mara Silva de } \\
\text { Oliveira }\end{array}$ & Aceito \\
\hline $\begin{array}{l}\text { TCLE / Termos de } \\
\text { Assentimento / } \\
\text { Justificativa de } \\
\text { Ausência }\end{array}$ & $\begin{array}{l}\text { Apendice_termodeassentimento_Revist } \\
\text { o.docx }\end{array}$ & $\begin{array}{c}12 / 08 / 2016 \\
22: 56: 57\end{array}$ & $\begin{array}{l}\text { Sheyla Mara Silva de } \\
\text { Oliveira }\end{array}$ & Aceito \\
\hline $\begin{array}{l}\text { TCLE / Termos de } \\
\text { Assentimento / } \\
\text { Justificativa de } \\
\text { Ausência }\end{array}$ & $\begin{array}{l}\text { Apendice_tcle_profissionais_Revisto.doo } \\
x\end{array}$ & $\begin{array}{c}12 / 08 / 2016 \\
22: 56: 41\end{array}$ & $\begin{array}{l}\text { Sheyla Mara Silva de } \\
\text { Oliveira }\end{array}$ & Aceito \\
\hline $\begin{array}{l}\text { TCLE / Termos de } \\
\text { Assentimento / } \\
\text { Justificativa de } \\
\text { Ausência }\end{array}$ & Apendice_tcle_pais_Revisto.docx & $\begin{array}{c}12 / 08 / 2016 \\
22: 56: 22\end{array}$ & $\begin{array}{l}\text { Sheyla Mara Silva de } \\
\text { Oliveira }\end{array}$ & Aceito \\
\hline $\begin{array}{l}\text { TCLE / Termos de } \\
\text { Assentimento / }\end{array}$ & Apendice_tcle_pacientes_Revisto.docx & $\begin{array}{c}12 / 08 / 2016 \\
22: 55: 58 \\
\end{array}$ & $\begin{array}{l}\text { Sheyla Mara Silva de } \\
\text { Oliveira }\end{array}$ & Aceito \\
\hline
\end{tabular}

Endereço: Av. Dr. Enéas de Carvalho Aguiar, 419

Bairro: Cerqueira Cesar

CEP: $\quad 05.403-000$

UF: SP Município: SAOPAULO

Telefone: (11)3061-8858

E-mail: cepee@usp.br 

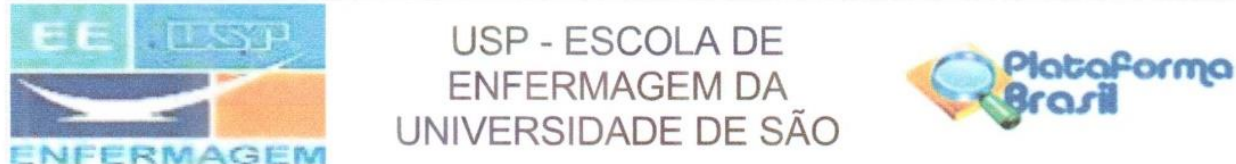

Continuaçăo do Parecer: 2.490.681

\begin{tabular}{|l|l|c|l|c|}
\hline $\begin{array}{l}\text { Justificativa de } \\
\text { Ausência }\end{array}$ & Apendice_tcle_pacientes_Revisto.docx & $\begin{array}{c}12 / 08 / 2016 \\
22: 55: 58\end{array}$ & $\begin{array}{l}\text { Sheyla Mara Silva de } \\
\text { Oliveira }\end{array}$ & Aceito \\
\hline $\begin{array}{l}\text { Declaração de } \\
\text { Instituição e } \\
\text { Infraestrutura }\end{array}$ & CartadeAceite_HMS.pdf & $\begin{array}{c}16 / 07 / 2016 \\
18: 43: 04\end{array}$ & $\begin{array}{l}\text { Sheyla Mara Silva de } \\
\text { Oliveira }\end{array}$ & Aceito \\
\hline $\begin{array}{l}\text { Declaração de } \\
\text { Instituição e } \\
\text { Infraestrutura }\end{array}$ & Cartadeaceite_SEMSA.pdf & $\begin{array}{c}16 / 07 / 2016 \\
18: 42: 31\end{array}$ & $\begin{array}{l}\text { Sheyla Mara Silva de } \\
\text { Oliveira }\end{array}$ & Aceito \\
\hline $\begin{array}{l}\text { Declaração de } \\
\text { Instituição e } \\
\text { Infraestrutura }\end{array}$ & CartadeAceite_SESPA.pdf & $\begin{array}{c}16 / 07 / 2016 \\
18: 41: 54\end{array}$ & $\begin{array}{l}\text { Sheyla Mara Silva de } \\
\text { Oliveira }\end{array}$ & Aceito \\
\hline Outros & & $16 / 07 / 2016$ & $\begin{array}{l}\text { Sheyla Mara Silva de } \\
\text { Oliveira }\end{array}$ & Aceito \\
\hline Folha de Rosto & Apendice_tcud.docx & $15 / 07 / 2016$ \\
$23: 28: 49$ & $\begin{array}{l}\text { Sheyla Mara Silva de } \\
\text { Oliveira }\end{array}$ & Aceito \\
\hline
\end{tabular}

Situação do Parecer:

Aprovado

Necessita Apreciação da CONEP:

Não

SAO PAULO, 07 de Fevereiro de 2018

Assinado por:

Marcelo José dos Santos

(Coordenador)

Endereço: Av. Dr. Enéas de Carvalho Aguiar, 419

Bairro: Cerqueira Cesar

CEP: $\quad 05.403-000$

UF: SP

Municipio: SAO PAULO

Telefone: (11)3061-8858

E-mail: cepee@usp.br 